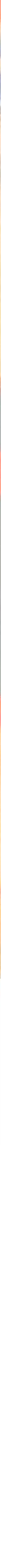



Border Crossing 
This book is dedicated to our children:

Elliott, Jacob, and Leopold Burry

\&

Ruth Beatrice "Ruby" White 


\section{Border Crossing}

Russian Literature into Film

Edited by Alexander Burry and Frederick H. White 
Edinburgh University Press is one of the leading university presses in the UK. We publish academic books and journals in our selected subject areas across the humanities and social sciences, combining cuttingedge scholarship with high editorial and production values to produce academic works of lasting importance. For more information visit our website: www.edinburghuniversitypress.com

(C) editorial matter and organization Alexander Burry and Frederick H. White, 2016

(C) the chapters their several authors, 2016

Edinburgh University Press Ltd

The Tun-Holyrood Road

I 2 (2f) Jackson's Entry

Edinburgh EH8 8PJ

Typeset in I I I zpt Ehrhardt MT Pro by

Servis Filmsetting Ltd, Stockport, Cheshire, and printed and bound in Great Britain by CPI Group (UK) Ltd, Croydon CRo 4 YY

A CIP record for this book is available from the British Library

ISBN 978 I 4744 I I 424 (hardback)

ISBN 978 I 4744 I I 43 I (webready PDF)

ISBN 978 I 4744 I I 448 (epub)

The right of the contributors to be identified as authors of this work has been asserted in accordance with the Copyright, Designs and Patents Act I988 and the Copyright and Related Rights Regulations 2003 (SI No. 2498)

\section{Acknowledgments}

Grateful acknowledgment is made to the following sources for permission to reproduce material previously published elsewhere. Every effort has been made to trace the copyright holders, but if any have been inadvertently overlooked, the publisher will be pleased to make the necessary arrangements at the first opportunity.

Alastair Renfrew's chapter in this volume is reproduced with the permission of the Modern Humanities Research Association. The original appeared in 2007 in Modern Language Reviem I02(1): г 57-76.

Yuri Leving's chapter in this collection is a variation on a Russian language version originally published in the Nem Literary Observer. This version can be found as "Ideologiia travmirovannogo glaza, ili kak ubit' Annu Kareninu nezhno.” Novoe literaturnoe obozrenie, I25(I) (20I4): 75-I02. 


\section{Contents}

List of Figures

Notes on the Contributors

vii

ix

Introduction: Filming Russian Classics—Challenges and

Opportunities

I

Alexander Burry

I Across the Russian Border

Thomas Leitch

2 Dostoevskii's "White Nights": The Dreamer Goes Abroad

40 Ronald Meyer

3 On Not Showing Dostoevskii's Work: Robert Bresson's Pickpocket 64 Olga Peters Hasty

4 Stealing the Scene: Crime as Confession in Robert Bresson's

Pickpocket

S. Ceilidh Orr

5 The Eye-deology of Trauma: Killing Anna Karenina Softly

IO2 Yuri Leving

6 "A Vicious Circle": Karen Shakhnazarov's Ward no. 6 Alexander Burry

7 A Slap in the Face of American Taste: Transporting He Who Gets Slapped to American Audiences

140 Frederick H. White

8 Against Adaptation? The Strange Case of (Pod) Poruchik Kizhe Alastair Renfrem 
9 Chasing the Wealth: The Americanization of Il'f and Petrov's The Twelve Chairs

Robert Mulcahy

Io Fassbinder's Nabokov-From Text to Action: Repressed

Homosexuality, Provocative Jewishness, and Anti-German

Sentiment

Dennis Ioffe

I I "The Soviet Abroad (That We Lost)": The Fate of Vasilii

Aksenov's Cult Novel A Starry Ticket on Paper and on Screen

Otto Boele

Conclusion: Passport Control—Departing on a Cinematic Journey Frederick H. White

Bibliography

Filmography

Index 


\section{Figures}

I. I A movie poster for Robert Bresson's Pickpocket

I.2 A movie poster for Luchino Visconti's 1957 film based on Fedor Dostoevskii's hypotext

2.I The neon illumination in Le notti bianche

2.2 The neon signs in Saamariya

2.3 Reflections in windows and mirrors comment on the Dreamer's vision throughout En la ciudad de Sylvia

5.I Anna Karenina (I9I4), production still

5.2 Frame from Dziga Vertov's Man with a Movie Camera juxtaposed with a screenshot from Anna Karenina (1997)

5.3 Frame from Luis Buñuel's An Andalusian Dog

5.4 and 5.5 The cutting motif from Buñuel's An Andalusian Dog is juxtaposed with corresponding images from Anna Karenina (2012) I I 3

5.6 In Wright's version Anna almost touches her own face with the paper knife's edge

6. I Vladimir Kozlov, an actual patient interviewed in Ward no. 6

6.2 The real and fictional patients of the ward at the New Year's party

7.I Postcard of the Art Theater's I9I 5 production of He Who Gets Slapped

7.2 Postcard of Illarion Pevtsov as He

7.3 Production still of Lon Chaney as He in Sjöström's He Who Gets Slapped (1924)

7.4 Production still of Consuelo (Norma Shearer), Bezano (John Gilbert), and He (Lon Chaney)

Io. I Hermann parts sexual ways with Lydia

I0.2 Hermann and the naked Felix, taking a bath

I0.3 Hieronymus Bosch, a Fragment from The Garden of Earthly Delights 
I0.4 Hermann and Felix

I0.5 The scene of the murder. Hermann kills Felix, his imaginary

C.I Movie poster for Iakov Protazanov's The Forty-First

C.2 Movie poster for The Eagle

C.3 American movie poster for the Dino De Laurentiis production of La tempesta 


\section{Notes on the Contributors}

Otto Boele is an Associate Professor of Russian literature at the University of Leiden (Netherlands). He is the author of The North in Russian Romantic Literature (1996) and Erotic Nihilism in Late Imperial Russia. The Case of Mikhail Artsybashev's Sanin (2009). Currently he is working on the reception of Thaw literature and film, as well as on the cultural memory of the I99os in contemporary poetry and prose.

Alexander Burry is an Associate Professor of Slavic and East European Languages and Cultures at The Ohio State University. He is the author of Multi-Mediated Dostoevsky (20II), and the co-translator, with Tatiana Tulchinsky, of Anna Politkovskaya's A Small Corner of Hell: Dispatches from Chechnya $(2003,2007)$. He has published articles on Dostoevskii, Tolstoi, Chekhov, Erofeev, Prokofiev, Meierkhol'd, and other writers and artists in the Slavic and East European Journal, The Russian Reviem, Literature/Film Quarterly, and other journals and collections.

Olga Peters Hasty is a Professor in the Department of Slavic Languages and Literatures at Princeton University, where she teaches courses on Russian poetry, drama, film theory, and ornamentalist prose. She is the co-author of America Through Russian Eyes (I988) and author of Tseveteva's Orphic Fourneys in the Worlds of the Word (1996), Pushkin's Tatiana (1999), as well as numerous articles devoted to Russian poetry, women's writing, film adaptation, and Vladimir Nabokov.

Dennis Ioffe is an Assistant Professor in the Department of Languages and Cultures at Ghent University (Belgium). Ioffe has held teaching and research appointments at the University of Edinburgh (United Kingdom), Memorial University (Canada), University of Amsterdam (Netherlands), 
and the University of Haifa (Israel). He has authored more than eighty scholarly articles and edited/co-edited a number of academic collections. His publications have appeared in Studies in Slavic Cultures, Neohelicon, The Fournal of European Studies, Russian Literature, Slavic E East European Journal, Acta Semiotica Fennica, Kritika i Semiotika, Nem Zealand Slavonic Fournal, Cultura. International Fournal of Philosophy of Culture and Axiology, Philologica, Tijdschrift voor Slavische Literatuur, Slavica Occitania, and others.

Thomas Leitch is Professor of English at the University of Delaware. His most recent books are $A$ Companion to Hitchcock Studies (co-edited with Leland Poague; 20 I I), Wikipedia U: Knomledge, Authority, and Liberal Education in the Digital Age (2014), and The Oxford Handbook of Adaptation Studies (forthcoming). He is currently working on The History of American Literature on Film.

Yuri Leving is Professor of Russian Literature and Film in the Department of Russian Studies, Dalhousie University, Canada. In 20I3-I4, he was an Alexander von Humboldt Senior Research Fellow at Heidelberg University, Germany, and a Visiting Professor at the American Academy in Rome (20 I5). Leving is the author of four monographs: Marketing Literature and Posthumous Legacies: The Symbolic Capital of Leonid Andreev and Vladimir Nabokov (coauthored with Frederick H. White; 20I3); Keys to The Gift. A Guide to V. Nabokov's Novel (20I I); Upbringing by Optics: Book Illustration, Animation, and Text (2010); and Train Station-Garage-Hangar. Vladimir Nabokov and the Poetics of Russian Urbanism (2004; short-listed for Andrey Bely Prize). He has also edited and co-edited six volumes of articles, most recently: Shades of Laura. Vladimir Nabokov's Last Novel The Original of Laura (2013); Lolita: The Story of a Cover Girl-Vladimir Nabokov's Novel in Art and Design (20I3; reviews in The New Yorker, The Los Angeles Times, The New York Times, and The Huffington Post); and Anatomy of a Short Story (2012, with an afterword by John Banville). Leving has published over a hundred scholarly articles on various aspects of Russian and comparative literature. He served as a commentator on the first authorized Russian edition of The Collected Works of Vladimir Nabokov in five volumes (I999-200I), and was the curator for the exhibition "Nabokov's Lolita: 1955-2005" in Washington, DC, which celebrated the fiftieth anniversary of the publication of Lolita. Leving is the founding editor of the Nabokov Online Fournal (since 2007). He is currently finishing a booklength project, The Artist Foseph Brodsky.

Ronald Meyer teaches the seminar in Russian literary translation at Columbia University. He is the translator of Anna Akhmatova, My Half-Century. Selected Prose (3rd edn, 2013); Fyodor Dostoyevsky, The Gambler and Other Stories (2010); and three stories in the new Norton Critical Edition of 
Chekhov's Selected Stories, edited by Cathy Popkin (2014). Recent articles include "Chekhov's 'House with the Mezzanine' and the History of Russian Literature in English Translation," in The History of Translation in the CrossCultural Perspective, ed. Natalya Reinhold (2012); and "The Cherry Orchard in the Twenty-first Century: New Adaptations and Versions," in Chekhov for the 2 Ist Century, ed. Carol Apollonio and Angela Brintlinger (2012).

Robert Mulcahy is a Lecturer in Slavic at The Ohio State University. He is currently researching Boris Akunin's Erast Fandorin series and the film adaptations of the popular author's works.

S. Ceilidh Orr is Lecturer at The Ohio State University. Her research interests include nineteenth-century Russian fiction and the image of the copyist in world literature.

Alastair Renfrew is Professor of English and Comparative Literature at Durham University. His main area of research specialization is literary and critical theory, particularly Mikhail Bakhtin and the so-called Russian Formalists; he has also taught and published on Russian and Soviet Cinema and on Russian and Scottish Literature. He is author of Tomards a Nem Material Aesthetics (2006) and Mikhail Bakhtin (2014); co-editor of the collection Critical Theory in Russia and the West (2010); and is currently working on a project on "Dialectics and Dialogics."

Frederick H. White is Associate Vice President, Academic Affairs, Engaged Learning at Utah Valley University. He is also Professor in the Department of Languages and Cultures. He has published a co-edited selection of essays with Dennis Ioffe (20I2) on the Russian avant-garde for a series on Russian cultural movements. He is also the author of Memoirs and Madness: Leonid Andreev through the Prism of the Literary Portrait (2006) and Degeneration, decadence and disease in the Russian fin de siècle. Neurasthenia in the Life and Work of Leonid Andreev (20I4); and co-author of Marketing Literature and Posthumous Legacies: The Symbolic Capital of Leonid Andreev and Vladimir Nabokov (2013) with Yuri Leving. White is the author of twenty-five scholarly articles on Russian Modernism; psychology, literature and science in the Russian fin de siecle; the economics of culture; and post-Soviet cinema. 



\section{Introduction: \\ Filming Russian Classics- Challenges and Opportunities}

Alexander Burry

Russian literature has occupied a special position as an object of cinematic Radaptation in the hundred-year-plus history of film. The invention and development of the medium closely followed a period of robust literary and cultural achievements rare for any nation. Early in the I8oos, Aleksandr Pushkin, Nikolai Gogol, and Mikhail Lermontov launched the so-called Golden Age of poetry and prose. In the latter part of the century, Ivan Turgenev, Fedor Dostoevskii, and Lev Tolstoi established the international dominance of the Russian novel through compulsively readable narratives that featured bold generic experimentation and a nearly obsessive focus on what the critic Mikhail Mikhailov called the "accursed questions": the meaning of life, the existence or non-existence of God, and the potential impact of revolutionary transformation of society, among others. Anton Chekhov, toward the end of the century, adapted these concerns to the short story and the play. By the modernist period, beginning after the assassination of Tsar Aleksandr II in I88I, Russian literature was recognized as ascendant in the West and elsewhere, with Turgenev (the most popular Russian writer in Europe, with ties to Gustave Flaubert and the Goncourt Brothers), Dostoevskii, Tolstoi, Chekhov, and other writers translated into all European languages and, in the case of Dostoevskii in particular, attaining cult-like status throughout the continent. The early interest in Russian literature beyond its borders established it as a leading world literature. This international recognition grew in the course of the twentieth century and continues to the present day, as writers such as Mikhail Bulgakov, Boris Pasternak, Vladimir Nabokov, and Viktor Pelevin produced narratives that achieved massive appeal far beyond Russia.

At the same time, nineteenth-century Russian writers brought an unusual degree of contemporaneity to problems of modernity that followed decades after their publication. The I 860 s radical movement, both created and praised by writers such as Nikolai Chernyshevskii and critiqued by such figures as 
Dostoevskii, a half-century later would eventually help inspire the Russian Revolutions of 1905 and I9I 7 that transformed twentieth-century history and politics. Tolstoyanism, as a philosophical and religious expression of the universal brotherhood, love of one's enemies, and passive resistance to evil that in some way shape all of his greatest fictional works, was enormously influential on Mahatma Gandhi's non-violent rebellion against British colonial rule of India, and through him, on Martin Luther King, Jr.'s peaceful marches for civil rights in the United States. Chekhov's drama helped contribute to the establishment of a school of acting, developed by Konstantin Stanislavskii and the Moscow Art Theater, that continues to impact the training of some of the most prominent actors worldwide. Vsevolod Meierkhol'd and Michael Chekhov (nephew of the writer), disciples who departed from Stanislavskii's brand of theater and whose careers were shaped by adaptations of classic Russian literature, also left their mark on American and European theater and film. In other ways, too many to be listed here, Russian literature and culture have influenced world culture, and this universality suggests one of the reasons for the recurring migration of Russian literary narratives into world cinema.

The broad range of social, political, and religious questions posed by Russian writers, combined with their ongoing contemporary relevance, accounts in part for the wide variety of directors - many of them discussed in this book-who produced films based on Russian literary works. These filmmakers include such luminaries as Sergei Eisenstein, Akira Kurosawa, Robert Bresson, Louis Malle, Luchino Visconti, Bernardo Bertolucci, Nikita Mikhalkov, Sergei Bondarchuk, and many others. In some of these cases, Russian literature has so influenced the careers of directors as to affect permanently their style and thematic emphasis. Thus film adaptation of Russian literature has played a central role in extending the latter's influence on world culture, as well as the continuing development of Russia's own culture and politics in the twentieth and twenty-first centuries. This is particularly the case in the era of Vladimir Putin, which has seen a renewed call for filmed versions of the classics, usually in the form of televised serials. Directors such as Vladimir Bortko, who produced highly popular serials of Dostoevskii's The Idiot (2003) and Bulgakov's The Master and Margarita (2005), followed by a feature film of Gogol's Taras $B u l ' b a$ (2009), have attempted to enhance Russia's national prestige through maximally "faithful" settings of its classic works. As the last of these films shows, adaptation can have political consequences far beyond reminding Russians of their literary heritage and rallying their national pride: Bortko's decision to have the Ukrainian Cossacks speak Russian, the anti-Polish elements of the story, and the director's own vociferous support of Putin have led to accusations that the film is mere pro-regime propaganda.

Particularly for Russian writers and filmmakers, then, adaptation should be seen in part as a political act, never simply an insulated aesthetic exercise, 
since these artists have so often striven to make their works politically relevant; at different times in their history, they have felt a greater imperative to do so than artists in other nations, who worked under less strict censorship laws. As an autocratic nation, Imperial Russia notably lacked opportunities for political participation even by the highest stratum of society, in contrast to the constitutional monarchies of the time in Britain, France, and other West European nations. In the absence of outlets for political participation, writers sensed an urgent need to convey political ideas through literature, even if great skill and tact were required to circumnavigate the onerous, ever-present demands of imperial censorship, and to avoid arrest and exile. In the Soviet period, particularly at its darkest point under Stalin, a different politicization of literature took place, as writers and filmmakers (as well as all other artists) were required to support and promote both the larger goal-the path to a Communist society - and the particular means of achieving this goal at any given time, from agricultural collectivization to five-year plans to victory over the Nazis in World War II. As several essays in this volume show, adaptation has often been dictated by such political necessities, especially during the Soviet period.

Despite the far-reaching reverberations of these literary works and the films based on them, scholarship on the transposition of Russian texts into film is relatively meager. The major exception is the publications stemming from a May 2002 conference at the University of Surrey, organized by Stephen Hutchings and Anat Vernitski. Ten papers from this conference became articles in the spring and summer 2004 special issues of Russian Studies in Literature, introduced by John Givens. Others were published in Hutchings and Vernitski's 2005 volume, which covers Russian-language films ranging from reworkings of Soviet-era fiction such as Dmitrii Furmanov's Chapaev and Vasilii Grossman's "In the Town of Berdichev" to adaptations of classic novels such as The Idiot and Ivan Goncharov's Oblomov. Other than these collections, however, most studies of filmed Russian literary texts have been confined to separate, individual articles.

The present volume attempts to address this lacuna as well as extend the scholarly conversation through essays on a broad selection of film adaptations of Russian texts. Moreover, in contrast to the aforementioned Hutchings/ Vernitski collection and Russian Studies in Literature issues, our contributors analyze films by non-Russian as well as Russian directors, in order to explore the worldwide impact of Russian literature. In taking this approach, the study also seeks new directions in understanding the phenomenon of adaptation itself, particularly in light of the criticism flourishing in this field during the past two decades. Border Crossing: Russian Literature into Film derives from a conference titled Adaptation: Russian Text into Film, which took place at The Ohio State University in May 2013. This event explored a variety of the multiple possible interactions between Russian writers and filmmakers within and outside of 
Russia; all of the present contributions first appeared as papers at this conference, with the exceptions of Yuri Leving's and Alastair Renfrew's republished articles, respectively, on Anna Karenina and Lieutenant Kizhe. The conference aimed not at an exhaustive survey of film adaptation of Russian literature, but a discussion of films organized around the theme of border crossing, on which more later in this introduction. For that reason, the present collection of essays derived from the conference papers presents what may seem to be a curious cross-section of adaptations. The oddities include both the actual chapters (three on films of Bresson, for example, and two on Pickpocket) and seeming omissions of key texts and authors (there is no extended discussion of adaptations of Tolstoi's War and Peace and Dostoevskii's The Brothers Karamazov, for example, or the many films based on Chekhov's plays). The collection coheres, we hope, as a sample of the many ways Russian literary texts have been transported to different nations, time periods, and social and historical contexts, and in the process of doing so acquired radically new semantic values as they entered new cultural sign systems.

Maybe this goes without saying, but scholarly opinion is not at a point in the academic exploration of how culture influences film adaptations that we can establish hierarchies or even make definitive claims until more research has been done, especially on the impact of Russian literature in world cinema. It is for this reason that we have made these chapters accessible to the widest range of scholars and students in more than one field. We believe that Slavic and film scholars, graduate students, and undergraduates will find different purposes for the chapters in this book, but, most importantly, that they all will be spurred to further exploration. In particular, the concluding chapter is not your typical summary of theory and the preceding arguments, providing a final summation. In an attempt to overcome the fact that this or that text and/or movie was not included in the preceding chapters; to give a nod to the fact that the essays only cover literature from I 844 to I96I (although the real focus is the various cinematic adaptations up to the present day), the conclusion attempts to expand the conversation and to invite students and scholars to explore all of the other research possibilities.

\section{ADAPTATION STUDIES TODAY}

Although adaptation studies is by now firmly entrenched as a subgenre of film studies, its path toward scholarly respectability has been rocky, and in many ways remains a work in progress. Indeed, criticism of films based on literature has lagged far behind other artistic and intellectual areas that have considered multiple versions of the same narrative or theme. In literary studies, for instance, deconstructionist critics, beginning nearly half a century 
ago, undermined the very notion of an "original" text that should be given priority over subsequent versions. Although deconstruction as a philosophy and approach to literary interpretation, of course, experienced a strong backlash, our sense of the stability of forms, rhetoric, and language has been permanently affected. This has direct consequences for our understanding of adaptations, which by nature involve at least two instantiations of the same basic narrative. Jacques Derrida, Gilles Deleuze, and other poststructuralists, in their undermining of the idea of a stable original of which copies are made, at the very least force us to view the idea of an "original" work skeptically, and to question hierarchical relations of authority between such a work and its successors.

As Robert Stam and other critics have pointed out, such theories should have challenged the tendency to view adaptations negatively in relation to their source texts; however, until relatively recently, they have not done so. The binary opposition of "original" and "adaptation," and the illusion of a hierarchical order between a source text and films (or operas, or other literary works) based on it, has been notoriously slow to recede. Perhaps because of the very fact that-despite their obvious medium-based differences-film can "tell a story" in a way recognizably similar to a novel on a superficial level, reviewers and audiences, if not academic writers, continue to some degree to measure the success of the film by its success in capturing the letter or spirit (whatever that may entail) of the source text. ${ }^{1}$

In the past two or three decades, however, critics in this field have made tremendous strides in undoing the persistent but limited approach known as "fidelity criticism." These attempts to substitute more productive ways of looking at such films have included various approaches. In different ways, such theorists as Geoffrey Wagner, Michael Klein and Gillian Parker, and Dudley Andrew each proposed categories that could be used to distinguish different relations between a source text (what the French structuralist Gérard Genette called the "hypotext") and its cinematic reworking (the "hypertext"). These categories can be very useful in measuring the distance filmmakers travel from their source text in adapting it for the screen. However, in their very focus on this distance, these critics reinforce-albeit in opposition to their stated aims - the basic premise of fidelity criticism: that films should be evaluated in terms of how closely they hew to their literary sources. Moreover, the very premise that films can be expected to replicate their hypotexts in any complete way is faulty, as George Bluestone pointed out in his seminal I957 study of adaptation. In his 1996 volume on British films of novels, Brian McFarlane revisits this question, proposing that adaptation be viewed as convergence and intertextuality, and borrowing Roland Barthes's distinction between narrative functions proper and indices to differentiate between transferrable and nontransferrable elements of a source text. 
This notion of adaptation as intertextuality proved especially fruitful for critics of the following decade. Robert Stam, using Bakhtinian dialogue and deconstructionist theory, argues against the rigid, seemingly automatic favoring of hypotext over hypertext. "In a Derridean perspective," he notes, "the auratic prestige of the original does not run counter to the copy; rather, the prestige of the original is created by the copies, without which the very idea of originality has no meaning." ${ }^{3}$ Instead, Stam analyzes adaptation as "dialogic intertextuality." He also emphasizes that such adaptations trigger a plethora of associations, rather than being restricted to the ostensible source text indicated by the title or basic narrative. As David Kranz points out, the idea of infinite intertextual connections, taken to an extreme, can obscure the central role of the source text. According to Kranz, "we need to find a satisfactory mean or range between the essentialistic extreme of fidelity criticism as depicted by its detractors and the relativistic extremes of poststructuralist theory." 4 Nevertheless, Stam's proposal to view adaptation as a dialogue of numerous intertexts - not simply an original/adaptation relationship that almost invariably asserts the source text's primacy-proves crucial to understanding such films, as demonstrated in all the essays in the present volume.

Another recent critic, Linda Hutcheon, similarly seeks to define adaptations in terms of their intertextual engagement. She defines such a work as "an extended, deliberate, announced revisitation of a particular work of art." ${ }^{5}$ By including a variety of types of adaptation in her study in addition to film-opera, visual art, book covers, comic books, etc.—and noting the sheer numbers of these works, she is able to inquire into the undeniable appeal of adaptations, despite the frequent harsh judgments against them. Claiming that the omnipresence of adaptation reveals a pleasure based on "the comfort of ritual combined with the piquancy of surprise," Hutcheon affirms that such works need to be evaluated in terms of the adapter's skill and creativity, rather than his or her fidelity to the given source text. ${ }^{6}$

Other critics similarly call upon adaptation studies to address broader cultural questions. Thomas Leitch argues that the study of adaptation is an ideal approach to literacy in the sense of active engagement with literature and film, or "illustrations of the incessant process of rewriting as critical reading." investigates the process of adaptation and the various economic, political, technological, and cultural questions it raises, rather than evaluating their fidelity to source texts. And in a 2012 study of Italian films based on American novels, Cristina Della Coletta defines adaptation as encounters across not only media, but also cultures and traditions. Applying Hans Georg Gadamer's hermeneutics, she views adaptation as an act of estrangement that tests our prejudices and challenges our habitual interpretations. Adaptations, she remarks, involve "a conjuncture of production and consumption that can be defined only by 
the plurality of its voices, the expandability of its borders, and the complex interplay of cultural forces and ideological constructs that operate within its changing boundaries." ${ }^{\prime 8} \mathrm{We}$ take such critics' attention to these processes as a starting point for our volume.

\section{ADAPTATION AS CROSS-CULTURAL COMMUNICATION}

Our approach in this volume differs in two major ways from those of most other film adaptation scholars. First, rather than focusing on the inevitable loss and gain that takes place when works are transposed from one medium into another, which almost inevitably leads to fruitless discussions of "fidelity," we take a culturological approach, using the films to describe how cultural texts become adaptable through semantic shifts as they enter different temporal, spatial, social, and historical contexts. More specifically, the focus of this collection of essays is the transportation of Russian texts across borders into new cinematic territories. As mentioned, the literary theorist Gérard Genette first suggested the term "hypertextuality" for when a text B (hypertext) originates from a text A (hypotext). Genette refers to this process as a "transformation." Stam builds on Genette's theoretical language by suggesting that film adaptations of literary texts are involved in this dialogical process in which the hypotext (the original text) generates hypertexts (elaborations of the original). ${ }^{10}$ This assertion frees one from a line-by-line comparison of text and film, emphasizing each presentation as only a reading of the hypotext, not as a successful or unsuccessful copy. Both hypotexts and their cinematic hypertexts, in this sense, "participate in an ever-renewed and estranging dialogue across temporal distances, signifying systems, and cultural domains." 11

This approach allows for the fact that when a Russian literary text, with all of its embedded cultural meanings, is transported to another country or time or both, these meanings are foreign and must be redefined to correspond with the new spatial and temporal territories. In this process of redefinition, new cultural realities will transform those original semantic meanings. Significantly, in order to get from the hypotext to the final cinematic version, there might be several hypertexts building upon each other, each hypertext making subtle cultural distinctions. For example, the hypotext is translated into French or English. Will the French and English translations be exactly the same? Obviously not, as the cultures are very different and the way of perceiving the world is not exactly the same. In this instance, the translation is the first hypertext - when Constance Garnett refused to translate Dostoevskii's vulgarities, already cultural and social norms were forced upon the original. From possibly two different translations of the hypotext, the scriptwriter will create a new, third hypertext. Tom Stoppard is a well-known playwright and 
has written many successful movie scripts including, most recently, Anna Karenina (2012). What does a British playwright bring to Tolstoi's novel that explored Russia's "woman question" at the end of the nineteenth century? The rights of women have evolved significantly between Tolstoi's hypotext of the I 870 os and Joe Wright's cinematic hypertext (derived from Stoppard's script) of 20I2. Audiences probably did not go to the theater to watch how Tolstoi wished to punish Anna for her indiscretions as much as to see an epic romance about a woman trapped by her social and aristocratic status. In this instance, Tolstoi's hypotext generated many hypertexts (translations, scripts, and nearly a dozen cinematic versions), all of these hypertexts struggling with elements of the original in order to say something unique about British, American, or Soviet society; their own taboos; their own cultural understandings of fidelity, love, and passion in 1935, 1948, I967, I997, and 2012.

Moreover, we do not confine ourselves to one national tradition, or even a straightforward comparison of Russian texts with films in another culture. Rather, each of our contributors examines the multiple cross-cultural connections inherent in all of these literature/film dialogues. A discussion of Russian-French or Russian-American "collaborations," for instance, may also involve attention to other influential literary or cinematic traditions (the influence of Albert Camus on Bresson in his reworking of Crime and Punishment, for instance, or the impact of Nazism and even the paintings of Hieronymus Bosch on Rainer Werner Fassbinder's adaptation of Nabokov's Despair). Cinematic transpositions of Russian literature, in this light, can be analyzed not just as a two-way border crossing between two nations (or two periods of Russian history), but also as a kind of crossroads in which multiple semantic fields intersect, exchanging and shifting meanings in the process.

The study of culture often concentrates on the semiotics or sign systems of a particular culture's understanding of itself. Each country has its own concept of freedom, for example. Is the concept of freedom the same in France as it is in the United States? What about the concept of democracy? Russian democracy is not the same as American democracy, for historical, political, and social reasons. In Putin's Russia, democracy has the remaining stain from the transition from a one-party political system to a free-wheeling democracy of the I990s that also included a lurch toward a free-market economy, banditry, corruption, and the rise of the oligarchs. Russian democracy has been transformed into an autocratic authoritarianism under Putin who brought law and order to the nation in the twenty-first century. Although most Russians would argue that Putin was democratically elected, they would not say that this was the same system of political representation as that found in the United States. Therefore, is an American scriptwriter or filmmaker presenting concepts of 
freedom and democracy, with his or her own semantic understandings of these concepts, able to depict the Russian version accurately? Will the American filmmaker portray it in the same way that a Russian filmmaker might? In fact, there is no right way to depict democracy just as there is no right way to depict the contents of a novel by Tolstoi. All filmmakers reflect their own semantic understandings of freedom, love, betrayal, democracy, and a whole host of other concepts in a way that makes sense to their own sign systems. The scholarly discussion in this collection begins to untangle some of these issues and asserts that whereas the fidelity question is unproductive, the question of cultural semantics offers fruitful avenues for exploration.

By shifting approaches from a mechanistic evaluation of the film director's degree of fidelity in transferring literary texts to the screen to a broader exploration of the cross-cultural complexity this process entails, we aim to point to broader implications of the genre. As scholars of adaptation, we view our essential task as clarifying the complex cultural semantic language that takes place in the intersection between Russian and world cultures. We use the term "border crossing" in this introduction and throughout the volume to refer to these points of intersection. In focusing on what happens to Russian literary works when they enter new national, temporal, and cultural contexts, we investigate how they are "policed," that is, regulated (sometimes forcibly) by the ideological demands of their new environment. We emphasize the role of ideological, political, and other cultural pressures in the process of recreating literary narratives in another medium. These pressures, we would argue, always take place, whether a Russian literary work is adapted within its own society (such as the films based on works of Chekhov, Iurii Tynianov, and Vasilii Aksenov that will be examined) or in a radically different cultural context, such as the "Hollywoodizations" of Anna Karenina, The Brothers Karamazov, and other classic Russian novels. We hope to illuminate some of the many ways in which Russian literature has found new homes in cinema, and in the process, regenerated itself through fresh meanings that were unforeseen at its conception.

\section{BORDER CROSSINGS}

Thomas Leitch's discussion of Hollywood's appropriation of Russia sets the tone for this exploration of border crossing in film adaptation. Citing Della Coletta's discussion of this phenomenon, he examines different ways in which Hollywood films treating not only Russian literature but also the political entity of the Soviet Union involve various patterns of border crossing. As US-Soviet relations changed from the I940s through the end of the Soviet Union, Hollywood adaptations of both classic Russian literature and Russian 
characters and themes reflected these ideological adjustments in various ways. By putting adaptations of literature in the same category as films that make use of US-Soviet political conflicts, cultural imports, etc., Leitch demonstrates that the term does not even have to apply only to straightforward adaptations of literary texts. Indeed, several of the other chapters - especially the two on Bresson's Pickpocket - demonstrate that the concept of adaptation can apply to a variety of works, including highly unorthodox films, source texts, and relationships between them.

The chapters that follow Leitch's broad-based discussion concentrate more on particular settings of literary texts, although the contributors address anywhere from one film to many based on a given hypotext. In the chapters by Frederick H. White and Robert Mulcahy, other border crossings from Russia into Hollywood are explored. White analyzes Leonid Andreev's He Who Gets Slapped, a I9I 5 "panpsyche" drama about a failed intellectual who joins the circus; the dramatic action in this particular genre was focused on internal experiences rather than external events. This play turned out to be astonishingly generative for American audiences in different periods, starting in I924, when filmmaker Victor Sjöström emphasized the play's revenge motif in dramatic fashion, as the hero's betrayers are devoured by a lion at the end of the film. As White points out, the circus served as a particularly apt vehicle for a border crossing, since it offered a great deal of semantic material for exploring the destabilization of social norms. In the 1970 film The Twelve Chairs, as Mulcahy shows, a different type of border crossing takes place. Mel Brooks, a Jewish-American director with ancestry from the Pale of Settlement, personalizes the plot of Il'ia Il'f and Evgenii Petrov's picaresque novel by adding Jewish motifs and in a sense recreating the imagined Russia of his own heritage. Brooks's combination of "Borscht Belt" humor with numerous Russian and Soviet stereotypes and cultural references attempts, with mixed success, to transport Il'f and Petrov's New Economic Policy-era satire, with its critique of greed and pettiness, to an American audience.

The term "border crossing," however, is hardly restricted to the traversing of geographical boundaries. As the chapters on the films of Aleksandr Faintsimmer, Aleksandr Zarkhi, and Karen Shakhnazarov show, the concept can apply just as easily to Russian settings of Russian works. Border crossings can be temporal as well as geographical. Karen Shakhnazarov's 2009 Ward no. 6, in Alexander Burry's analysis, reinterprets Chekhov's story as an exploration not only of the problems of mental illness and imprisonment, but also of degeneration, questioning whether - in the course of over a centurypatterns of devolution from generation to generation have ever really ceased. Does Putin's Russia still suffer from the same or a similar hereditary (and national) taint that plagued Chekhov's understanding of his country on the eve of the twentieth century? Significantly, in the Soviet period, even a few 


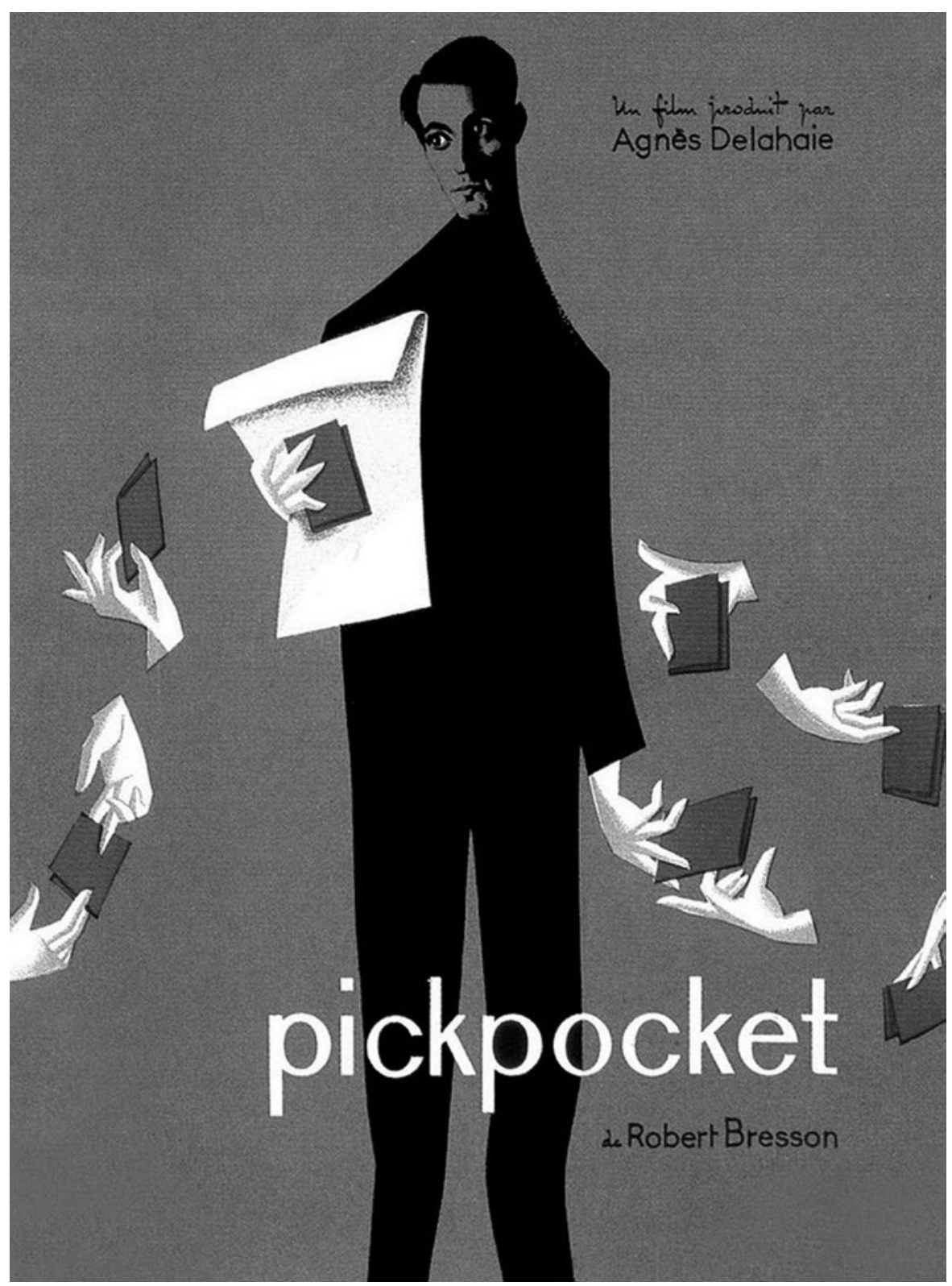

Figure I. I A movie poster for Robert Bresson's Pickpocket (I959).

years could necessitate an ideological overhaul of a hypotext. Otto Boele, in his chapter on Zarkhi's My Younger Brother (i962), shows that significant changes were required to allow Aksenov's A Starry Ticket, a youth novel written the previous year, to attain an ideologically successful transportation to the screen. 
Alastair Renfrew explores an even more unusual non-geographical border crossing in his chapter on Tynianov's screenplay of his own novella Lieutenant Kizhe in Faintsimmer's I934 film. As Renfrew points out, the usual chronology of film adaptation is reversed, as Tynianov's screenplay preceded his novella, which then underwent considerable changes on the road to becoming a film in I934. Unfortunately, he argues, Faintsimmer failed to find successful devices for meeting the challenges proffered by Tynianov's novella of a hero whose existence is confined solely to official documents, with its challenge to literary realism through the presentation of different planes of reality.

If the term "adaptation" can encompass a variety of source texts and films, then surely the genre is especially challenged by Robert Bresson's I959 film Pickpocket. Although many films that clearly function as adaptations do not share a title with their hypotext (for instance, the aforementioned film based on A Starry Ticket), the difficulty of categorizing Bresson's film far exceeds its title. Despite the obvious parallels between Bresson's narrative and Dostoevskii's Crime and Punishment, the director took great pains to discourage the viewer from interpreting this novel as a straightforward hypotext, in the process achieving a kind of "anti-adaptation" that has long mystified critics. As Olga Peters Hasty argues, this process involves a dissolution of the borders between Dostoevskii's Russia and Bresson's France, and a suppression of Dostoevskii's plot and psychological realism in order to recuperate the particular possibilities of the cinematic medium to depict interiority. However, in doing so, Hasty shows, Bresson finds a way to draw closer to Dostoevskii's essential moral and philosophical statement on the dangers of alienation from others. S. Ceilidh Orr, in her chapter on the same film, claims that Bresson, rather than adapting Dostoevskii, is actually taking part in a common generic tradition: the confession (along with Albert Camus, the influence of whose The Stranger also can also be felt in Pickpocket). By disrupting expectations of cause and effect, Bresson turns the very act of pickpocketing that he substitutes for Raskolnikov's murder into an act of confession. In focusing on Bresson's use of cinematic devices to disrupt both narrative expectations and viewers' anticipation of how a cinematic reworking of Dostoevskii's novel should look, both Hasty and Orr demonstrate the estrangement of the viewer that Della Coletta discusses, thus illustrating the degree to which adaptation involves a hermeneutic border crossing.

In the case of the émigré writer and translator Vladimir Nabokov, whose life and career consisted of several border crossings, the theme acquires numerous nuances. As Dennis Ioffe discusses, Fassbinder's i 978 film of Nabokov's I936 novel Despair focuses specifically on the writer's own Russian-German border crossing, as the director draws out the implications of the novel's German setting. By focusing on the homosexual and Jewish themes in light 
of Fassbinder's own homosexuality and experience as a citizen of a nation that had carried out the Holocaust just before his birth in I945, the director creates a highly complex cultural exchange.

The chapters by Yuri Leving and Ronald Meyer, respectively, demonstrate the extensive intertextual history of transporting Tolstoi's Anna Karenina and Dostoevskii's "White Nights" into film in a variety of languages, cultures, and time periods. Leving traces the development of the scene of Anna's suicide in several film adaptations, showing that the semantic language of Anna Karenina changes substantially under the influence of Dziga Vertov's Man with a Movie Camera (I929), and its linking of woman, film camera, and train as a traumatic image. Analyzing adaptations by Bernard Rose, Sergei Solov'ev, Joe Wright, and other directors, Leving points to symbols such as the eye, the color red, and the image of Anna's dead body as evidence of a new visual language, images not found in the hypotext, that is used by directors to interpret the novel's depiction of violence and self-destruction. Similarly in the case of cinematic versions of "White Nights," as Meyer shows, the film adaptations become influential cinematic hypertexts, along with Dostoevskii's original hypotext, in the course of its adaptation. The films of Luchino Visconti (I957) and Robert Bresson (I97I) threaten to supplant Dostoevskii's hypotext in subsequent adaptations in 2007 by Sanjay Leela Bhansali and José Luis Guerín, as the directors include episodes, motifs, setting, and characters, respectively, from Visconti and Bresson as they transport Dostoevskii's basic story across the borders of India and Strasbourg.

Importantly, both Leving's and Meyer's chapters also engage gender readings of film, and in doing so point out their potential application to adaptation studies. Laura Mulvey's ground-breaking I975 essay, drawing on feminist and psychoanalytic theory, argues that cinema offers distinct pleasures to the male viewer that reinforce stereotypical gender roles: It allows him to satisfy voyeuristic drives by objectifying on-screen women, and by projecting his gaze onto the male actor with whom he identifies, in order to possess the heroine indirectly and thus create a more powerful ego ideal. ${ }^{12}$ As Meyer notes, directors of White Nights often reverse this voyeurism by putting the male body on display, and thus creating a female gaze. Depending on the director's choice, then, Dostoevskii's hypotext can yield gender associations that go far beyond what the novelist envisioned. Leving, citing Mulvey's essay in his discussion of how Anna Karenina's suicide is filmed, notes Gayle Studlar's observation that spectators can derive not only sadistic but also masochistic pleasure from the voyeurism involved in viewing a heroine's death. In the case of Anna in particular, directors often play with the simultaneous fear and thrill the viewer receives from observing such gestures as her suicide, and the famous scene on the train in which she brushes the knife she uses for cutting pages in her book against her face. 


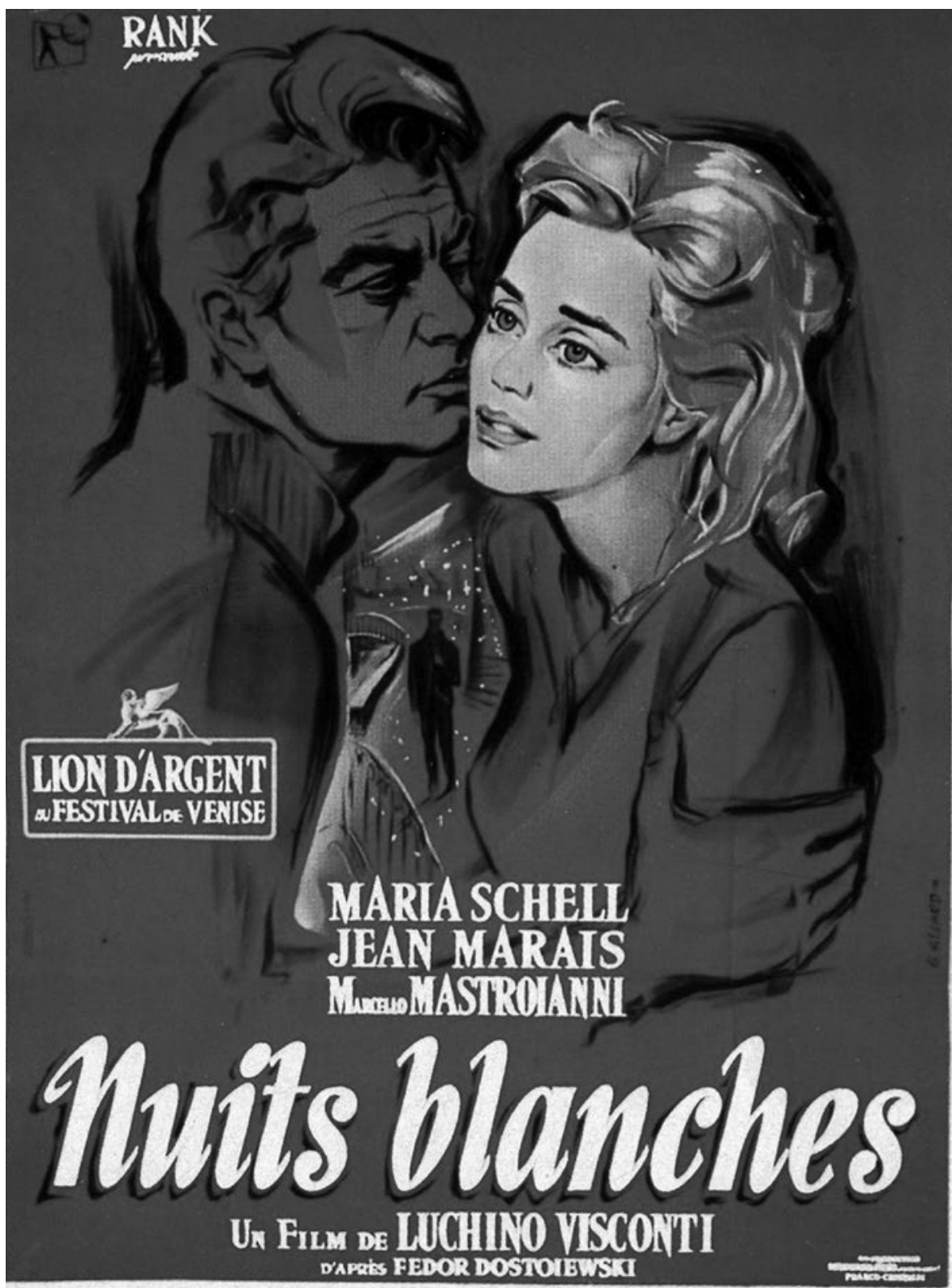

Figure I.2 A movie poster for Luchino Visconti's 1957 film based on a Fedor Dostoevskii's hypotext.

Thus, all of the studies in this volume, in one way or another, emphasize the notion that adaptation has a great deal to tell us about the unexpected cultural journeys that take place when Russian literature interacts with film. As the various contributors show, adaptation involves a series of complex cultural, 
economic, political, and technical processes that go far beyond simply comparing literary text with film. As such, we hope that this volume can introduce new territories to explore for the field of adaptation studies, adding new insights not only into the specific writers and directors discussed, but also the possibilities for envisioning the very process of adaptation.

米米

In conclusion, a brief note on terminology may be useful. Although the term "adaptation" is most commonly used to describe the phenomenon of films derived from literary works, it is far from universally agreed upon as ideal. For many theorists, the term "adaptation" has highly desirable connotations. Stam makes a biological comparison, describing such films as "mutations" that ensure the survival of the source text. ${ }^{13}$ Hutcheon, continuing the metaphor, cites Richard Dawkins's analogy between cultural and genetic transmission to suggest that stories "adapt to new environments by virtue of mutation-in their 'offspring' or their adaptations." 14 Persuasive though this argument may be, other critics find the term less satisfactory, because "adaptation" also has hierarchical connotations that can hinder a fair-minded comparison of literary and cinematic works that bear an intertextual relation to each other, regardless of which text (or medium) came first. The term "adapt," for some, implies an act of adjustment, an effort to suit the literary work to another medium: This has the danger of working against the type of dialogic, lateral relationship that would allow both works to be appreciated on their own terms. Perhaps this is why, although Hutcheon points out that "the word ['adaptation'] has stuck for a reason," 15 it causes a great deal of dissatisfaction among theorists who use different terms.

Our contributors reflect this lack of unanimity, as part of an ongoing search for new ways of describing this process. While some are content to use the term "adaptation," others prefer to characterize the source text and film via Genette's aforementioned concepts of "hypotext" and "hypertext," respectively. These terms, as we suggest above, offer the advantage of covering additional literary intertexts as well as the primary source text. Still other contributors employ terms such as "transportation" and "transposition," demonstrating the diverse language that can be applied to the process this volume describes. ${ }^{16}$ Ultimately, we hope that our use of the term "border crossing" is flexible enough not only to encompass all of these variations, but also to open up the discussion to broader ways of thinking about the impact of filmed literature, and its interconnections with crucial social, political, and historical issues of Russia and other nations that continually rework its literature.

The metaphor of crossing from one temporal or spatial territory into another in which language, customs, cultural identity, social attitudes, and political systems are often different captures this exploration into new 
cinematic environments. Arguably, each time a border is crossed there are cultural, political, and social issues to be considered. Border Crossing: Russian Literature into Film examines how political and economic circumstances play a crucial role in dictating how filmmakers transport their cinematic hypertext into this new cultural environment. A shifting Soviet political landscape or the perceived demands of the European and American commercial markets must be accounted for as the Russian literary text is relocated into a different space and time. Film adaptations of literature are involved in a dialogical process in which the original hypotext generates hypertexts; this collection explores the role of ideological, political, and other cultural pressures in the task of transforming literary narratives into cinematic offerings.

\section{NOTES}

I. Dudley Andrew, noting the natural propensity for audiences to make these comparisons, calls it "the umbilical cord that nourishes the judgments of ordinary viewers." MacCabe, True to the Spirit, 27.

2. Not all critics, by any means, have abandoned this approach. Colin MacCabe introduces his 2013 co-edited volume on film adaptation by arguing that complete disregard for the question of fidelity is symptomatic of an academic tendency in recent years to dismiss important questions of value in relation to both the traditional canon and the newer field of cultural studies. He argues that the phrase "true to the spirit" restores this emphasis, as it "avoids in its very formulation any notion of a literal fidelity and demonstrates a much greater sophistication in the general culture than adaptation studies allow." MacCabe, True to the Spirit, 7.

3. Stam, Literature through Film, 8.

4. Kranz, "Trying Harder," 98.

5. Hutcheon with O'Flynn, $A$ Theory of Adaptation, I7o.

6. Ibid., 4, 20.

7. Leitch, Film Adaptation and its Discontents, I6.

8. Della Coletta, When Stories Travel, 2.

9. Genette, Palimpsests, 4-6.

Io. Stam, Literature through Film, 5 .

I I. Della Coletta, When Stories Travel, 2 I (original italics).

I2. Mulvey, "Visual Pleasure and Narrative Cinema."

13. Stam and Raengo, Literature and Film, 2-3.

I4. Hutcheon with O'Flynn, $A$ Theory of Adaptation, 32.

I5. Ibid., I 5 (original italics).

I6. It should be noted that the Russian language does not have a term for "adaptation" in the sense that Anglo-American critics use it. Russians typically use the word ekranizatsiia (most accurately translated as "screening") to describe films that recast literary works. 


\title{
Across the Russian Border
}

\author{
Thomas Leitch
}

\begin{abstract}
A daptation, the process by which texts are transformed to suit them to new media (novels made into films) or historical periods (updated theatrical versions of The Seagull) or languages (translations from Russian to English or English to Russian), is essentially a metaphorical concept that is defined and understood, though often without acknowledgment, with reference to the biological processes whereby organisms and species survive by adapting to new environments. The metaphorical valence of the term has only been intensified by the range of synonyms commentators have offered to help understand it. Robert Stam has suggested that we can think about "adaptation as reading, rewriting, critique, translation, transmutation, metamorphosis, recreation, transvocalization, resuscitation, transfiguration, actualization, transmodalization, signifying, performance, dialogization, cannibalization, reinvisioning, incarnation, or reaccentuation."1 Julie Sanders's list of ways of thinking about adaptation, published the following year, overlaps with Stam's remarkably little: "version, variation, interpretation, continuation, transformation, imitation, pastiche, parody, forgery, travesty, transposition, revaluation, revision, rewriting, echo."

Hollywood adaptations of Russian literature suggest still another metaphor that is especially pregnant: border crossing. Some film adaptations, like Joe Wright's 2012 version of Anna Karenina, cross national borders; others cross intermedial borders between literary and cinematic modes of presentation; and all of them cross what might be called ideational borders, as adapters wrestle the actions, characters, and thematic motifs associated with one author, culture, historical period, and audience into new frames in order to suit them for a new market. "Market" may seem a crass word to drop into a discussion of adapting what are often classic novels, but a medium as capital-intensive as cinema demands consideration of the implications of this kind of border crossing as well: the crossover from the relatively personal, low-risk medium
\end{abstract}


of fiction or drama to the high-stakes medium of film, where millions of rubles are routinely gambled on a single adaptation.

Basing her analysis on Hans-Georg Gadamer's account of the horizon of expectations that frames all human understanding, Cristina Della Coletta has compared the ways that audience members cross national and cultural borders when they travel geographically to the ways they cross hermeneutical borders whenever they encounter an adaptation of any sort:

Understanding a different horizon does not involve crossing over into alien worlds unconnected in any way with our own but, rather, achieving that fusion of horizons that allows us to see the world from a larger perspective. A knowing audience enters the adaptive process with a varied set of experiences, memories, competencies, biases, emotional as well as conceptual presuppositions, namely with a "horizon of expectations." By entering into play with the adapting work, all these expectations undergo transformative changes while interpreting (and thus modifying) both the adapting and the adapted work - thus the horizon evolves and challenges fixed notions of priority, originality, univocity, and stability of meaning. ${ }^{3}$

Reading or hearing or viewing adaptations can be just as broadening as geographical travel, and in much the same ways, because crossing borders encourages travelers both to explore new horizons and to consider their accustomed horizons more critically.

A significant benefit of Della Coletta's metaphor is that it provides a way of theorizing a broader range of adaptations than any of the metaphors on the expansive lists of Stam or Sanders. Recent work in adaptation studies has attempted to broaden the field of adaptations to a wider range of intertextual relations than films based on novels or plays or stories. Led by Deborah Cartmell, Imelda Whelehan, Robert Stam, and Linda Hutcheon, adaptation scholars have turned their attention away from cinema to consider dramatizations of novels, novelizations of films, films based on video games, franchises, mashups, wikis, and fan fiction as adaptations.

The distinctive power of Della Coletta's metaphorical focus on the hermeneutics of intertextual border crossing depends on its literal referent, the considerably more fraught phenomenon of crossing political borders. In the first instance, Della Coletta calls the travels characters undertake within their fictional worlds "the objective correlative of narrativity itself"4 as they cue, invite, and model the metaphorical travels of audience members. In addition, adaptations and their readers or viewers or listeners inevitably cross metaphorical borders in the course of expressing, communicating, understanding, and interpreting their views on the worlds they present. The borders that citizens, visitors, tourists, and refugees cross from one country to another may be 
equally virtual, but the often stark political differences they mark make them far less metaphorical. The process of border crossing means different things to different travelers, from the nuisance tourists may feel in obtaining the appropriate immunizations and visas to political refugees' fight for survival as they struggle to escape persecution in their native lands.

Most intertextual border crossings, of course, are far less challenging. Like all border crossings, they have significant consequences, but these are likely to be limited in their scope, impact, and exigency. Thousands of books cross national, linguistic, intermedial, and ideational borders without any incident except the presumed edification of new audiences on the other side of the borders they cross. From time to time, however, intertextual border crossings become just as problematic as political border crossings. A particularly notorious case is Salman Rushdie's novel The Satanic Verses, whose allegedly blasphemous portrayal of the prophet Mohammed led to demands that the book be banned from publication, paperback reprinting, or translation, and bans on its importation into India, Pakistan, and South Africa even before Ayatollah Ruhollah Khomeini issued a fatwa calling for Rushdie's death, which the Iranian government publicly supported for ten years.

As its title suggests, this chapter focuses on a series of films that seek to cross a virtual border that is barely less fraught: the border between the United States, or more generally the Western world represented by Hollywood or internationally co-produced movies, and the Soviet Union. Like Della Coletta's book, it is interested in cinematic adaptations of literature as a special case of border crossing within the larger context of political and cultural border crossing, an activity that often plays out in films that are cross-cultural explorations rather than literary adaptations. So it will approach American adaptations (and one British adaptation) of Russian novels only gradually, through a consideration of other, broader kinds of border crossing.

The traffic across the US-USSR border-the legal and ideological border between the two nations and their cultures rather than the geographical border between Big Diomede Island in the Chukotka Autonomous Okrug and Little Diomede Island two miles away in Alaska - is two-way, and a great deal has been written about Soviet adaptations of Western literature. ${ }^{5}$ Crossing the border in the opposite direction, from Soviet Russia to the West, is if anything even more difficult. The obvious test case is Doctor Zhivago, the portrait of post-revolutionary Russia on which the poet Boris Pasternak toiled for twenty years. Pasternak's novel examined the personal costs of revolution in insuring the progress of social collectivism. Not surprisingly, it was refused publication in the USSR, and Pasternak agreed to have the manuscript smuggled to Milan, where it was published in Italian translation in I957. The following year, the author was awarded the Nobel Prize for Literature, enraging his country's Communist Party, which forced him to decline the prize. In the meantime, his 
novel, translated into English in $195^{8}$, spent twenty-six weeks atop the Nem York Times bestseller list. It was a remarkable success story for a novel whose border crossing amounted to a defection that had been universally condemned in its native land, which had in effect annulled its citizenship.

Doctor Zhivago's defection to the West represents an extreme case of illegal border crossing, a crossing that was not legally sanctioned by both nations involved and went legally unrecognized in one of them. The circumstances of its publication helped make the novel a literary cause célèbre. It was not only Pasternak's criticism of the Soviet Revolution that made his novel appealing to Western readers but also its negative imprimatur as a strenuously unauthorized importation of Russia itself to the West. Like so many of Della Coletta's examples, Pasternak's novel crossed a border not by adapting a foreign text but by appropriating a quasi-text, post-revolutionary Russia itself, that was never explicitly identified as a text. The drama of its publication history and its resourcefulness in surviving by crossing a border suggest not only new ways of considering Hollywood adaptations of Russian novels but also a wider range of ways to think about exactly what the Soviet authorities at the time feared: the West's appropriation or colonization of Russia, which Hollywood filmmakers in particular approach as a variously tantalizing, alluring, and obscure master text to be grasped, interpreted, and marketed to American audiences.

The conflict between Russia and the West is rarely as sharp as Pasternak's example would indicate. From time to time it has been presented in terms of sportive conquest, as when the nations' teams have competed against each other in the Olympic Games, or when Oprah Winfrey announced Anna Karenina as the summer 2004 selection of Oprah's Book Club. "I've never, ever chosen a novel that I had not personally read," Oprah told her television audience. "It's been on my list for years but I didn't do it because I was scared. Now I'm going to team up with all of you and read it together." A newsreel charting Tolstoi's subsequent rise on bestseller lists included a shot of Book Club members in matching T-shirts labeled "I'm not scared," rebranding Anna Karenina as an Everest Oprah and her fellow readers would climb together. ${ }^{6}$ Perhaps the clearest examples of adaptations that grow out of this sportive attitude are Stanley Kubrick's Lolita, marketed under the tagline, "How did they ever make a movie of Lolita?," and Woody Allen's Everything You Always Wanted to Know about Sex *But Were Afraid to Ask ("If you want to know how this man made a movie out of this book, you'll have to see the movie!"). But even if they are not as white-hot as the relations between Downing Street and Tehran at the height of the Rushdie affair, the relations between Hollywood and Russia are always fraught, especially during the twenty-year period of the Cold War following World War II.

In the years before the war, the approach American films most often adopt in relation to Russia is to regard it as the Other, sometimes quaint, sometimes 
barbaric, but always exotic. Rasputin and the Empress and The Scarlet Empress delve into recent or distant history to present Russia as the ultimate Gothic tourist destination, a place riven by picturesque, wildly overheated conflicts between poverty and material splendor, religion and sin, suffocating protocol and the kind of heroic passions that can only lead to chaos, all of it whipped up, most recently, by the Russian Revolution. Tovarich and Ninotchka present a comic version of this exoticism, as Russians abroad struggle to come to terms with the demands of life in the West. In Tovarich, two impoverished members of the royal family (Claudette Colbert and Charles Boyer), exiled by the Bolshevik Revolution, make their living as a housemaid and butler to a Parisian couple (Anita Louise and Melville Cooper) until their recognition leads to new problems. Rasputin and the Empress and The Scarlet Empress both invite their audiences to cross the Russian border using tourist visas that allow them access to a studio-built Mother Russia whose spectacular and menacing strangeness draws shivers and gasps from them before the closing credits return them safely to their homeland. In Tovarich and Ninotchka, by contrast, it is the lead characters themselves who cross the border from Russia to the West, allowing audiences to savor the familiar pleasures of Hollywood's Paris, from opulent dining to stock shots of the Eiffel Tower, while marveling at the novelty these pleasures hold for the innocents abroad.

The case of Ninotchka is notable because Nina Ivanovna Yakushova (Greta Garbo) - the Envoy Extraordinary sent from Moscow to take control of negotiations over the sale of the jewels the Bolsheviks confiscated from the Grand Duchess Swana (Ina Claire) after Buljanoff (Felix Bressart), Iranoff (Sig Rumann), and Kopalski (Alexander Granach), the three trade delegates originally tasked with the sale, are bamboozled into a stalemate by the Grand Duchess's lover, Count Leon d'Algout (Melvyn Douglas) — at first finds Paris and the Western values it represents anything but attractive. The film's programmatic defense of Western values requires Leon to awaken Ninotchka's appetite for the pleasures that mark Paris's advantage over Moscow: beauty, glamour, freedom, license, fashion, romance, laughter, love, and conspicuous consumption. Ninotchka initially resists every one of these blandishments, from the saucy hat she sees on display in a window to the jokes Leon tells her at a proletarian café; it is not until, angry and impatient, he falls off his chair that Garbo laughs. This pivotal scene, which allows both leads to surrender to each other without either losing face, poses a new model for border crossing. If historical epics like Rasputin and the Empress and The Scarlet Empress adopt a tourist's viewpoint toward a Russia figured as impossibly exotic and foreign and Tovarich shows its leading couple crossing the border as refugees and succeeding professionally as the world's best domestics, Ninotchka figures border crossing as seduction. Leon seduces everyone who crosses the border from Moscow to Paris, first the three trade delegates who are only too ready to give 
up their reservation in the bare-bones Hotel Terminus to hole up in the Royal Suite of the opulent Hotel Clarence and use their telephone to summon a parade of cigarette girls while Leon tangles their attempt to sell their country's jewels in the Grand Duchess's lawsuit, then Nina Ivanovna, who, sent to grab the reins from them, falls for Paris even harder than they have done. Unlike the Grand Duchess herself, these Russian visitors have come to Paris in a professional capacity but are swiftly seduced into remaining in quite a different capacity. They learn to live on Western terms by surrendering their national principles and personal scruples, Ninotchka to Leon's charm, the envoys to the high-end consumer lifestyle he represents.

The film, released shortly after the outbreak of World War II but set, as an opening title announces, during the period when "if a Frenchman turned out the light it was not on account of an air raid!," consistently satirizes pre-war Russia as a place of iron control and material deprivation. On first meeting her, Leon tells Ninotchka, "I love Russians. Comrade, I've been fascinated by your Five-Year Plan for the past fifteen years." Ninotchka herself, asked how things are back in Moscow, replies, "The last mass trials were a great success. There are going to be fewer but better Russians." Back in her flat in Moscow, Ninotchka's friend Anna (Tamara Shayne) worries about their silently menacing neighbor Gurganov (Harry Semels): "You never know whether he's on his way to the washroom or the Secret Police." For her part, Ninotchka, on learning that Leon does not work and does nothing for mankind, tells him, "You are something we do not have in Russia ... That's why I believe in the future of my country." In general, however, Paris gets much the better in this exchange of satiric thrusts. Watching the swallows outside her hotel window, Ninotchka ruefully reflects, "We have the high ideals, but they have the climate." When she asks of the offensive hat, "How can such a civilization survive which permits their women to put things like that on their heads?" or admits, "I do not deny [Paris's] beauty, but it's a waste of electricity," the film's target audience groans sympathetically at her limited appetite for the pleasures of Parisian life and waits for her to open her mind, fall in love with the City of Lights, and purchase that hat.

After the Grand Duchess blackmails Ninotchka into returning to Moscow, the film takes pains to distinguish the Stalinist regime it satirizes as harsh, categorically rule-bound, and impoverished, and traditional Russian values represented by sharing food and clothing, singing, and playing the balalaika. It is this Russia - "The Russia of borscht, the Russia of boeuf stroganoff, the Russia of blinis and sour cream"- that the three envoys plan to keep alive in the expatriate restaurant they end up opening in Constantinople, an evocation of a Russian exotica safely removed from the Russia of 1939 . The final joke that ends the film, a shot of one of the envoys picketing the restaurant with the sign "BULJANOFF AND IRANOFF UNFAIR TO KOPALSKI" as a snatch of 
the "Song of the Volga Boatmen" plays, implies still another model of border crossing: complete assimilation from the old ideology to the new, as Kopalski, for all his identification with a Russian restaurant, has grown Western enough to call a one-man labor strike. Like Ninotchka herself, Kopalski has been repoliticized but not deracinated.

Ninotchka is in many ways a textbook case of Della Coletta's Gadamerian border crosser. In crossing the border from Moscow to Paris, she opens herself to new experiences and perspectives that remain with her when she returns home, opening more critical new perspectives on the experiences she had formerly taken for granted back in Moscow. What is crucial in Ninotchka, however, is that the heroine is a reactive border crosser; she does not choose to cross any borders on her own. She is dispatched to Paris by her superiors, opened to the magic of Paris by Leon, and forced to return home by the Grand Duchess. Even her final trip to Constantinople is undertaken unwillingly and unaware that Leon has connived with Buljanoff, Iranoff, and Kopalski to arrange her escape from Soviet Russia. Ninotchka is repeatedly manipulated by other people to cross borders and persuaded by Leon into choosing Western over Soviet values. Her film complicates Della Coletta's model by presenting at least three alternatives to the freely undertaken journey that model assumes and the smuggling operation Pasternak represents. Characters in Ninotchka cross national and cultural borders through satiric critique from outside (the film ridicules the Soviet Union from a safe position in the West), political assimilation that preserves ethnic identity (Kopalski calls a strike against his fellow Russian restaurateurs), and their own enthusiastic responses to seduction (the three envoys open the film by succumbing to the blandishments of a grand Parisian hotel, and Ninotchka ends it by adopting Western values under Leon's example, tutelage, and sexual charisma).

The alliance between Russia and the US during World War II presents Hollywood with the occasion for quite a different kind of border crossing, with humanist universalism replacing both exotic tourism and seduction by the other side. Instead of presenting Russia as a strange foreign land where anything could happen and Russians as gargoyles like Lionel Barrymore's Rasputin or Sam Jaffe's Grand Duke Peter or vulnerable innocents abroad like Ninotchka, films like Mission to Moscom, The North Star, and Song of Russia announce to American filmgoers the comforting news that crossing the Russian border involves no fundamental realignment or re-examination of one's world view because Russians are just like them. It is hardly surprising that these films would have shared such a universalist attitude. The Soviet Union was an important war ally, and public opinion polls consistently showed that Americans trusted it significantly less than the UK or France. The variously fictionalized propaganda films Samuel Goldwyn, MGM, and Warner Bros. contributed to the war effort follow different paths to the same goal: 
indicating that Soviet leaders, when they are represented or mentioned at all, are motivated by exactly the same sentiments as American leaders and that Russian citizens are indistinguishable from Americans, only with more picturesque costumes and music.

The North Star shows how readily exoticism and universalism can be combined. Unlike the relatively realistic Washington social scene disrupted by the war in the contemporaneous Watch on the Rhine, the everyday life of the villagers in The North Star seems to consist entirely of singing and dancing to pastoral quasi-Russian tunes actually written by Ira Gershwin and Aaron Copland and falling in love with other young Russians played by American performers. When the village of North Star is shadowed by war, the approach of the Germans is signaled by villagers on horseback riding to warn their friends, "The Germans are coming!," presenting Russian civil defense in I94I as indistinguishable from Paul Revere's ride in I775. The cast includes rising all-Americans like Dana Andrews, Farley Granger, and Anne Baxter supported by equally non-ethnic veterans Walter Huston and Walter Brennan in heavy makeup. Only Austrian-born Erich von Stroheim, as the German physician and military officer Dr. von Harden, is cast according to his customary ethnic stereotype.

Such casting suggests another attitude Hollywood adopts toward Russia: the impulse to colonize it with recognizably American types. This colonization never amounts to conquest, not only because the United States never conquered the Soviet Union, but also because American movies never show the nation conquering anyone; the closest it comes is in the successful defensive operations many years later of Red Damn. Instead, just as Ninotchka had shown the most dedicated Russian civil servant imaginable falling prey to the seductive wiles of a Parisian boulevardier, The North Star presents a Mother Russia colonized by American performers: Evidently no one of Russian extraction lives there anymore. The result is to present the village as quaintly exotic until the moment it is threatened by the German army, at which point it becomes deracinated and universalized, if not downright American. By staying on a local level, the film can ignore the ideological specifics of Soviet politics in favor of a universalized Russian culture.

Song of Russia develops still more stylized versions of these universalizing tropes. The film's opening sequence, in which a shot of John Meredith (Robert Taylor), a conductor leading a concert performance of "The StarSpangled Banner" in America for Soviet war relief, dissolves into a shot of a responsive Russian crowd with a Soviet flag displayed prominently above their heads, wastes no time in establishing the equivalence and interchangeability of Americans and Russians. The main theme from Tchaikovsky's First Piano Concerto, already transformed into the American hit song "Tonight We Love," unites the two nations on a global level but foreshadows Meredith's 
blooming romance with Nadya Stepanova (Susan Peters). When Meredith accepts Nadya's invitation to come to her Russian village and lead concerts there, he finds that both urban life in Moscow and rural life in her village strikingly resemble their counterparts in America. On Meredith's tour of a peasant farm, his host, whose cottage is equipped with a radio and a telephone, proudly displays his modern tractor but neglects to mention that it belongs to the collective, not to him. When war breaks out, Meredith, who has now married Nadya in a church wedding, urges her to return to America with him, but she insists that she must stay: "I have a great responsibility to my family, to my village, and to the way I have lived," carefully substituting in that last phrase a statement about lifestyle for one about nation, party, or ideology. Meredith's manager Hank Higgins (Robert Benchley) tells her, "You are a fool, but a lot of fools like you died on the village green at Lexington," explicitly equating the Soviet response to Hitler's violation of the Non-Aggression Pact he had signed with Stalin to the American Revolution. Small wonder, then, that in I947 the House Un-American Affairs Committee explicitly held up the film as evidence of the Communist infiltration of Hollywood, prompting Robert Taylor's appearance before HUAC as a friendly witness.

Mission to Moscom, which was clearly undertaken at Franklin Delano Roosevelt's "agreeing — or urging — that a pro-Soviet feature film be made,"7 addresses Soviet politics more directly by suggesting still another approach to border crossing: the affirmation of a strong political alliance that seeks to reduce the severity of the borders in question. In filming Ambassador Joseph E. Davies's memoir of his service in Russia during 1936-8, Warner Bros. could hardly have avoided dealing with Joseph Stalin's conduct of the Moscow Trials that condemned so many former revolutionaries as conspirators plotting to restore Russian capitalism. In view of the script control Davies's contract with Warner Bros. gave him, it is hardly surprising that the film uncritically presents what Davies's spoken prologue describes as "the integrity and the honesty of the Soviet leaders," whose people were "devoted to world peace." John Dewey, who had headed an independent commission that had denounced the Moscow Trials as a wholesale party purge, wrote an outraged letter to the New York Times describing the film as "the first instance in our country of totalitarian propaganda for mass consumption-a propaganda which falsifies history through distortion, omission or pure invention of facts." "An open letter signed by Edmund Wilson, Dwight Macdonald, James T. Farrell, and a dozen other activists and intellectuals, accused the film of rewriting past history to produce "a deliberate confusion of Soviet and American policy, so that critics of the one at any time in the past few years are presented as necessarily opposing the other." ${ }^{10}$ These charges could well be dismissed as highly partisan if a response urging public defense of the film had not tacitly conceded them by describing the film as presenting "a close-up of 
Russia's fight for industrialization and a modern and mechanized agriculture" that included "authentic newsreel shots" that helped make it "an instrument for understanding and friendship between the Allies," "a picture of truth" that is being "attacked by some whose hatred of the Soviet Union is greater than their desire to win the war." 11 The market and history took swift revenge on the film, which lost an estimated $\$ 500$, 000 before, reading the writing on HUAC's walls, "the company ordered all existing prints destroyed in a notice sent to every exchange in October I947."12

All these approaches to border crossing-tourist exoticism, universalism, seduction, defection-persisted after the war. But the coming of the Cold War gave them a new edge. The foreign publication of Doctor Zhivago, the awarding of the Nobel Prize to its author, and his refusal of the prize under pressure from Soviet authorities amounted to a public relations coup for the West, which feted his defecting novel as a refugee that had escaped certain destruction and oblivion (condemned in the Soviet Union to an unofficial existence in samizdat - underground self-publishing) only by crossing the Russian border. Ten years earlier, State Department official George Kennan's anonymously published essay "The Sources of Soviet Conflict" had outlined a strategy of containing the Soviet Union that amounted to prolonged seduction of the Russian Other from a position of military and diplomatic strength, "recommend[ing] that American foreign policy imitate the proverbial boss trying to extract sexual favors from his proverbial secretary by exploiting the advantages that accrue to his physical, financial, and educational superiority, in order to thwart or reward her material desires." 13 The process by which Leon had so effortlessly seduced Ninotchka became more tangled and two-way in Fet Pilot, in which Colonel Jim Shannon (John Wayne), tasked with interviewing Lieutenant Anna Marladovna (Janet Leigh), a Soviet military pilot apparently defecting to the United States, falls in love with her, marries her, and follows her back to her homeland, where she has schemed to lead him all along. Only Shannon's success in outwitting his bride at her own game vindicates American national and military honor. Josef von Sternberg, directing his final film, was a past master of the game of mutual seduction. But now, with the geopolitical stakes raised far beyond the playfully exotic games of seduction in Morocco, Blonde Venus, Shanghai Express, or even The Scarlet Empress, on which the only empires at stake had long since passed from the scene, the film, completed in I949, languished in RKO's vaults for eight years before it was finally released in I957. In the meantime, Never Let Me Go had resolved the dilemma of its hero, American correspondent Philip Sutherland (Clark Gable), who had married Russian ballerina Marya Lamarkina (Gene Tierney) while stationed in Moscow, when Soviet officials forbade her from emigrating to the United States with him, in even more simplified terms: Sutherland kidnapped his bride and spirited her over the border illegally. 
As these cross-cultural defections, seductions, and abductions indicate, Hollywood's Cold War appropriation of Russia proceeded apace, but political tensions with the enemy state were displaced by more familiar narratives of crime, romance, and domestic melodrama. As Irina Sandomirskaia has pointed out in her analysis of The Third Man and North by Northmest, the most distinctive feature of Russia in American movies of the period is its absence: "[T] here was no Russia to be found, but instead Russia's non-being, a shadow, a ghost, a negative presence." ${ }^{14}$ The systematic non-representation of Russia comports oddly with the anti-Communist fervor sweeping the nation, a rabidly Red-baiting tendency that landed especially hard in Hollywood. The McCarthy hearings, the jailing of the Hollywood Ten, and the blacklist that ended the careers of hundreds of Communists, ex-Communists, suspected Communists, and fellow-travelers were complemented by a spate of rabidly anti-Communist movies released between 1948 and I953: The Iron Curtain, The Sickle or the Cross, The Red Danube, The Red Menace, I Married a Communist (aka The Woman on Pier I3), I Was a Communist for the FBI, Big Fim McLain, My Son Fohn, Invasion USA, and Pickup on South Street. To their number might be added roughly contemporaneous anti-Communist (or perhaps anti-McCarthyite) allegories like Invasion of the Body Snatchers; movies like Strangers on a Train that feature "hysteria over the possibility that the federal government had been infiltrated by Communists, homosexuals, and lesbians" and identify "individual conformity to the political and sexual norms sanctioned by the state as an act of supreme patriotism"; 15 and finally spy films like From Russia with Love that designate James Bond to defend not only queen and country but also the world as we know it from an escalating series of threats to global security.

Just because Hollywood studios churned out anti-Communist potboilers like The Red Menace and A-list embarrassments like My Son Fohn, however, did not mean they had become anti-Russian. Indeed, the single most consistent and remarkable feature of these films is their apparent determination to avoid adopting any attitude toward Russia, even to the point of acknowledging its existence. Whether it was to comply with government directives that forbade anti-Russian propaganda, to avoid embarrassing ethnically Russian stars or executives, to protect European markets for these and other films, or simply to allow the studios room to deny accusations of anti-Russian xenophobia, these films take extraordinary pains to avoid mentioning Russia at all.

Beginning with its very title, displayed over the background of a globebestriding octopus, The Red Menace is typical in combining Red-baiting with an extreme reluctance to identify the insidious menace it is warning against. Borrowing a durable narrative trope from contemporaneous film noir, the film frames its story as a series of flashbacks that make the missteps of ex-GI Bill Jones (Robert Rockwell) as he drifts toward involvement with Communism 
far more obvious to the audience than they are to him from the beginning. Although an aggressive journalist's voiceover narration refers to "the worldwide Marxist racket," the film sedulously avoids mentioning Russia. When Bill falls victim to the federal government's bureaucratic injustices against veterans, an apparently sympathetic recruiter tells him, "Somebody's doing something about it." "Who?" asks Bill. "Oh, some friends of mine," says his new acquaintance. It is only reasonable, of course, that Communists seeking to recruit Americans to their cause would be more eager to show them sympathy than reveal their own true colors. But the film declines to identify its enemy even once its hero has fallen into its clutches. Even when Bill realizes from perusing the titles on her library shelves that his new friend Mollie O'Flaherty (Barbra Fuller) is a Communist, she speaks only of "the Party," though he obviously knows which party she means. As the film frames a poster at a Party meeting that reads, "STALIN says-Dictatorship means unlimited power, resting solely on violence, and not on law," a voiceover identifies him as "the world's foremost Marxist," though not as Russian, or even by his first name.

Big Fim McLain, intent on rescuing HUAC members and agents from unfair attacks, more forthrightly mentions Communism and Moscow several times in its opening sequence, a Congressional hearing that ignores the fact that membership of the Party is legal. From that point on, however, it adopts a don't-ask-don't-tell attitude toward its targets, even among the Communists. Sturak (Alan Napier), one of the leaders of the Hawaiian cell Jim McLain (John Wayne) and Mal Baxter (James Arness) have been sent to investigate, testily tells one of his underlings, "For security reasons, don't call me Comrade," even though the two of them are alone. The film has its cake and eats it too by identifying both men as Reds but insisting that it will not consistently name them as such. Instead of confronting Reds in the American heartland, McLain and Baxter travel to Hawaii, an exotic American colony that just happens to confirm the traditional American values of beauty, romance, marriage, and religion, while presenting a landscape that could scarcely be more different from the Soviet Union's. And the fist fight that provides the film's climax is provoked by an imprudently incendiary remark by one of the Communists"No, I'm from the country club set. Chopping cotton is for white trash and niggers" - that indicates fissures within the United States, not global conflicts. The film turns out to be a celebration and anatomy of America, with no room for Russia except as an unspecified Other.

The disavowal of the Soviet Union as America's enemy reaches a climax in the ultra-low-budget Invasion USA, which unfolds a nightmare scenario of America invaded by a foreign power. When Hollywood gossip columnist Hedda Hopper announced after a preview screening, "It will scare the pants off you!," American Pictures promptly adopted her description as the tag line for the film's publicity. Yet the film never identifies the invading nation. 
When military flights arrive over the Pacific and attack Washington State, it is obvious where they have come from, but they carry no identifying insignia, presumably because so many of the film's aerial shots are stock footage, and close-ups inside the planes show the fliers' faces mostly obscured by radio gear. In these scenes and elsewhere, the invaders speak only briefly, though with obvious foreign accents, and they dress as American military personnel for the purposes of the invasion. Even the American president, going on TV and radio to promise nuclear retaliation, speaks only of taking the battle to "the enemy's homeland." He assures his listeners that England and France have declared war on "our enemy" and that all members of "the Atlantic alliance" support the United States. When the invaders finally do get around to delivering complete sentences, they sound at least as much German as Russian, for example when one officer smirks that from now on, an industrial plant will be building tanks for "the People's Army." As in The Red Menace, the feature most of these periphrases share is not ambiguity or obfuscation but deniability, since their referents are so easily recognized that they could not possibly be misunderstood. In acting consistently as if they are reminding rather than informing audiences of what they already know about a mortal enemy, both films, like Big Fim McLain, present themselves as arguing an anti-Communist position they already take for granted.

The determination to indict Soviet Russia as an enemy without identifying it gives the domestic melodrama My Son fohn a hushed tone whose systematic periphrases, like the strategies Hollywood had developed for telegraphing sexual information under the Production Code, fetishizes Russia by presenting it as the ultimate taboo, the country that dare not speak its name. Once he returns home from a foreign trip, the film presents the behavior of John Jefferson (Robert Walker) as suspicious not because of what he is doing but because of what he is not. He no longer accompanies his parents to church; he seems to have grown more distant from his brothers Chuck (Richard Jaeckel) and Ben (James Young), who serve in the military; and his mother Lucy (Helen Hayes) senses that his exaggerated, intermittent expressions of affection for her have been assumed to lull her suspicions. John's father Dan (Dean Jagger), a member of the American Legion who preaches "alertness," is worried that John is "one of the guys we have to be alert about." Telling Lucy that his father thinks that their shared belief in the brotherhood of man makes them "leftists-Communists - subversives," John duly swears on his mother's Bible: "I have never been a member of the Communist Party." But Dan rejects this ritual: "If you were a-if you were a-then this wouldn't mean anything." After speaking to Chuck and Ben on the phone, John expresses hope for "a lasting peace," another Communist code phrase. Even when Dan shows Lucy a headline-"RUTH CARLIN SENTENCED"- that refers to a woman the Jeffersons believe has been involved in the mysterious meetings 
that have stolen their son from them, the accompanying news story makes no visible mention of the USSR.

The film complements its reluctance to identify the Soviet Union as the enemy by an even stranger omission: the government agency that employs John. When Stedman (Van Heflin), the Communist-chasing federal agent whose persistent interest in John has taken him into the heart of the Jefferson household, hears that Lucy, who has never before been on an airplane, has taken flight to Washington, DC, he tells a fellow agent: "She's either coming to see me, or going to- that other place." When John receives a telegram announcing that he has been awarded an honorary doctorate of laws, only the word "BUILDING" appears in the internal address; the preceding word is obscured by his hand. The film declines to identify not only Mother Russia but the State Department, where John presumably works, because it must disavow the possibility that the State Department could be infiltrated by a Communist.

After John is killed in a police chase, his posthumous taped commencement address does finally mention Russia by name- "Even now the eyes of Soviet agents are upon some of you. They have observed your abilities and seen qualities that I once possessed"-but concludes with a more oblique confession: "I am a traitor. I am a native American Communist spy" working for "a foreign power." What is most salient is not that John is a Communist, but that he is not a true-blue American. The result of the film's persistently negative characterization of John's perfidy is an overarching and unintentional irony. Like Henry James's novel The Princess Casamassima, My Son Fohn works by not saying things about taboo subjects. Yet the overpointed dialogue and performances make its import as shriekingly obvious as the sexual references in many another film produced under the Code.

Even though Red-baiting movies rarely mention Russia by name, there are any number of other Cold War films that are less inhibited. One of the most surprising examples is Sam Fuller's Pickup on South Street, which uses the conventions of film noir rather than action or family drama to frame its political parable. Like anti-Communist films from The Red Menace to My Son Fohn, it avoids mentioning Russia in its tale of Skip McCoy (Richard Widmark), a pickpocket who dips his hand into the purse of Candy (Jean Peters), a prostitute turned courier, and inadvertently winds up with a roll of microfilm full of government secrets. Federal agent Zara (Willis Bouchey) tells NYPD Capt. Dan Tiger (Murvyn Vye) that Mr. Big, to whom Candy was delivering the microfilm, is connected to some "foreign power"; as soon as he gets the secret design, it will go instantly "across the ocean," without further specifying its destination.

All these elisions are straight out of Hollywood's playbook: Point a finger at Russia without naming names in order to maintain deniability. For all its 
obvious anti-Communist fervor, however, Pickup on South Street turns out to be more interested in a critique of capitalism. Joey (Richard Kiley), the exboyfriend who gave Candy the microfilm to pass on before it was stolen, insists that he is involved in nothing more than the sort of industrial espionage that is as American as apple pie: "How many times do I have to tell you we're not criminals? This is big business. Cutthroat business." Moe Williams (Thelma Ritter), the small-time informant who fingers Skip to Tiger, provides a sad parody of capitalism as she haggles over the cost of her information: "When the price of living goes up, my prices go up. When the price of living goes down ..." When Tiger refuses to pay her off, Moe makes a new offer concerning the pickpocket: "I'll bet you $\$ 38.50$ your cannon is on that list [of eight names]." The big investment for which Moe is feeding her kitty is a burial plot and stone on Long Island so that she will not have to be buried in Potter's Field. As Skip and Tiger cross swords, their conversation turns on political and economic threats. Tiger announces that he is going to put Skip away for life; Skip schemes to get Tiger suspended from the force for a full year, not just six months. Adding his latest acquisition to the stash of stolen items he keeps in a chest sunk beneath the waters that lap the sides of his shack at the tip of South Street, Skip looks like nothing so much as a parody of a banker with his safe deposit box photographed against the background of the skyline of New York, the financial capital of the world.

Although the film attacks Communism at every turn, its strictures against Communism are as vague as Invasion USA's identification of the invaders' nationality or My Son Fohn's references to the Soviet Union and the State Department. When Zara talks about "a top Red" who's going to get "classified military information," Skip retorts: "Are you wavin' the flag at me? I'm just tryin' to keep my hands in my own pockets." When Zara asks furiously, "Do you know what treason is?," Skip responds, "Who cares?" Candy, who believes Joey's protestations that he is engaged in nothing worse than industrial espionage, is outraged when Skip accuses her of being "a Commie" and adds, "I'll do business with a Red, but I don't have to trust one." Warned by Candy not to give up Skip to Joey, Moe tells her, "What do you think I am, an informer?," even though that is exactly what she is. Moe finds it hard to forgive Skip for being "mixed up with Reds"; as she tells Candy, "Even in our crummy line of work, you have to draw the line somewhere." And when Joey, about to kill Moe because she knows his true colors, tells her, "You just talked yourself into an early grave. What else do you know?," she famously replies: "About Commies? Nothing. I just know I don't like them."

What is most surprising about Pickup on South Street, then, is that in addition to its impassioned but characteristically unspecific denunciation of Communism, it is equally skeptical about capitalism, which it frames in a much more specific series of metaphors. The film's relentless focus on the 
seamy side of New York prevents its audience from ever seeing capitalism operating normally in the nation's financial capital. Instead, it is figured through a series of parodic metaphors. For Joey, capitalism is a cutthroat business. For Tiger and Zara, it is a horse trade of leniency for the information they want to extract from Skip. For Moe and Candy, it is a series of gambles, from Moe's disingenuous bet with Tiger over whether she has placed Skip's picture in the photo array she has assembled to Candy's breezy closing response to Tiger's prediction, "I'll give you thirty days before I pick you up with your hand in somebody else's pocket": "You wanna bet?" For Skip, it is a prospector's search for resources, as when he tells Candy after she comes to his shack looking for the microfilm and he crushes her mouth in a brutal kiss: "Sometimes you look for oil, you hit a gusher." Capitalism is linked to the dead end of the grave for Moe, who is selling neckties and information in order to avoid Potter's Field, and for Skip, who holes up in a picturesque but dangerously located shack at the very end of South Street. The film's leading metaphor for capitalism, however, is pickpocketing, which involves an endless series of generally criminal seizures of items whose intrinsic value is less than their exchange value. The microfilm Skip illicitly lifts from Candy was Joey's, not hers to begin with. But it was not really Joey's either, and he has not stolen the information for the reason he gives Candy, nor is it the same information he tells her it is. So the film, framed as a denunciation of Communism, is equally and much more specifically a critique of capitalism as well.

By the I96os, the time of The Ugly American, From Russia with Love, Dr. Strangelove, Fail-Safe, and The Russians Are Coming the Russians Are Coming, Russia is freely named and stigmatized by the characters, but not nearly so much by the movies themselves. As in Pickup on South Street, Americans and Americanism come in for as searching criticism as Russians in all these films. The leading critique of Americans in The Ugly American, in which Harrison Carter MacWhite (Marlon Brando) allows his old friendship with local agitator Deong (Eiji Okada) to cloud the political judgment he must display as the unpopular new ambassador to the Southeast Asian country of Sarkan, and Fail-Safe, in which a well-meaning American president (Henry Fonda) struggles in vain to recall Colonel Grady (Edward Binns), an Air Force pilot who has mistakenly been ordered to drop a nuclear bomb on Moscow, is that they are idealistically categorical and paranoid, unable to see the world in any terms but those of a black-and-white arena of American good and foreign evil. The same criticism is echoed in variously comic registers in Dr. Strangelove, which reworks the apocalyptic plot of Fail-Safe as pitch-black farce, and The Russians Are Coming the Russians Are Coming, an altogether gentler film showing the comical panic that sweeps across an island of Connecticut summer vacationers when a Soviet submarine staffed by an unthreatening captain (Theodore Bikel) and a crew headed by the adorable Lieutenant Rozanov (Alan Arkin) makes a 
forced landing offshore. Americans in these films are satirized for their persistence in seeing Russian plots everywhere, even when, as in The Ugly American and Dr. Strangelove, they happen to be correct.

The early installments in the James Bond franchise reveal the perils of crossing the Russian border even as they downplay the stark economic and ideological differences that have made that border so fraught. From Russia with Love, the second of the Bond films and the one most explicitly concerned with border crossing, revolves around the uneasy partnership between Bond (Sean Connery) and Tanya Romanova (Daniela Bianchi), a Russian clerk who has offered to steal a Lektor decoding machine from her Istanbul mission if Bond will arrange to receive it personally. What is surprising here is the identity of the dark powers who have manipulated the principals in the hope of profiting financially and diplomatically from their theft. In Ian Fleming's I957 novel, this power is the explicitly Soviet organization SMERSH, which takes its name from the Russian "smiert shpionam" (death to spies). But although the film mentions SMERSH in passing, it has been replaced as the chief villain, as it is in all the Bond films except Goldfinger through I97I, by SPECTRE, a freelance cabal whose name, an acronym for Special Executive for Counterintelligence, Terrorism, Revenge, and Extortion, accurately indicates its non-aligned brief and its intent of equally victimizing the spies from the US and the USSR. Predictably, Tanya and Bond, each determined to seduce the other, fall in love, outwit the powers who have manipulated them into their roles, and survive in a curious update of Ninotchka.

The most extended and revealing echo of Ninotchka, however, is Silk Stockings. Despite its Cold War setting, the film, the last feature director Rouben Mamoulian completed, and the one based on Cole Porter's final musical, has a curiously retrospective tone, and not simply because it is a musical remake of Ninotchka. The film, following Porter's musical, departs from Ninotchka in any number of ways, dropping the Grand Duchess Swana, changing its hero from a kept man to a Hollywood filmmaker and the prize over which both sides are fighting from a jewelry collection to a Russian-born composer, and eliminating all financial pressures on its Russian characters. Perhaps its single most strikingly updated feature, however, is its constant references to the Soviet Union. Even more than Ninotchka, Silk Stockings mentions Russia early and often, making constant jokes about political suppression there. Seeking information about one Comrade Yoschenko, incoming Commissioner of Arts Vassili Markovitch (George Tobias, who had been cast as a passport clerk in Ninotchka), asks a subordinate, "Does this office have a copy of Who's Still Who?" Hollywood producer Steve Canfield (Fred Astaire), pressing the three Soviet commissars Brankov (Peter Lorre), Bibinski (Jules Munshin), and Ivanov (Joseph Buloff) to allow "French citizen [Peter Ilyitch] Boroff" (Wim Sonnefeld) to stay in Paris and write the score to his new 
musical, urges them: "The Iron Curtain dissolved by music! What a goodwill gesture - and what propaganda." They respond by wondering whether they will receive the Order of Lenin and singing "Too bad we can't go back to Moscow."

In general, the film seems much less interested in Khrushchev or Stalin than in Lenin, whose portrait hangs in Markovitch's Moscow office, most of its head quietly cut off by the upper frame line. The scene in Markovitch's office echoes a similar moment in Ninotchka in which Ninotchka pleads so earnestly with Lenin's photo for understanding that it smiles at her. Both films' determination to identify the Soviet Union with its pioneering revolutionary rather than its contemporaneous leader suggest that both of them, especially Silk Stockings, identify the West with modernity and the USSR with an earlier period, the I920s or I930s.

Silk Stockings uses musical numbers to stage rapprochements of East and West. As Steve reprises "Paris Loves Lovers," Nina Yoschenko, the commissar who has been dispatched to retrieve Boroff after her three junior colleagues have failed, interpolates a dour but rhythmically precise counterpoint, pronouncing his encomiums "capitalistic," "characteristic," "sensualistic," "imperialistic," and "anti-Communistic," and adding that the lovers who find the city "heaven above," as Steve has claimed, "should be atheistic." Two minutes after Yoschenko says of Astaire's dancing, "Go, go, go, but you don't get anywhere," he has her dancing to "I Love the Look of You," then kissing. Since the film is based on a well-known musical comedy and Yoschenko is played by Cyd Charisse, the audience confidently awaits her metamorphosis into a musical star. The film Steve plans to make is War and Peace ("we'll have to change that title," he muses). The film satirizes Russia for producing the stodgy masterpieces of state-sanctioned culture and Hollywood for its shallow obsession with glitz. "Glorious Technicolor, Breathtaking CinemaScope, and Stereophonic Sound," the song in which his star Peggy Dayton (Janis Paige) describes contemporary films, paves the way for accord between Russia and Hollywood even as it ridicules Hollywood excess. And of course Silk Stockings is itself presented in glorious Metrocolor, breathtaking CinemaScope, and four-track stereo.

The film's central conflict is more accurately described as "Russia versus Paris" or "Russia versus Hollywood" than "Russia versus the United States" because it localizes the two Western cities but generalizes the Eastern power it constantly invokes. Since the only Russian locations the film ever shows are in Moscow, the city becomes a synecdoche for the Russian government rather than a place with its own individual identity. By contrast, Hollywood and Paris, the two locations with which Silk Stockings is most concerned, are synecdoches for Western culture. By localizing Hollywood and Paris but not Russia, the film pits Paris and Hollywood against all of Russia. 
Like Ninotchka, the film generally frames the debate between Paris and Russia as if it were non-ideological. In a line recycled from the earlier film, Yoschenko reflects, "We have the high ideals, but they have the climate." Ideological debates are repeatedly raised only to be defused, as when Boroff tells Yoschenko at a fashion atelier, "You can utter dissenting ideas in a very loud voice. The views here are different. Very different," as a nightgown-clad model emerges in a run-up to Peggy's "Satin and Silk" seduction number. Brankov chides Bibinski, “"Maybe, maybe, maybe.' Don't sound so Russian.” By writing the Grand Duchess Swana out of the story, Silk Stockings internalizes Yoschenko's conflict and makes the climactic plot complications less sharp, ideological, and materialistic, and more ritualistic. Yoschenko is no longer forced to leave Paris but chooses to leave on her own after recoiling from Peggy's War and Peace number as Josephine, which she calls "the most insulting travesty on Russian culture that ever existed," and turning on Steve as its producer. The conflict between East and West turns this time on cultural values, not the Depression-era hunger for rubles that motivated the commissars in Ninotchka or the ideological differences audiences might have expected from a Cold War adaptation. And different cultural mores represent a far more permeable border to cross.

As Steve's ludicrous attempt to adapt War and Peace to the conventions of musical comedy shows, adapting Russian literary masterpieces to Hollywood can be just as challenging for Cold War producers as adapting the Soviet Union itself. How can American movies trade on the prestige of Russian classics without presenting themselves as soft on Russia? The obvious answer is to stick to nineteenth-century classics that can be celebrated as examples of a glorious heritage that has withered under the Soviets. But different adaptations spin this strategy in surprisingly different ways. The Inspector General, whose credits identify it as "inspired by the play by Nikolai Gogol," represents the simplest solution: evacuate all Russian content from the adaptation. In Philip Rapp and Harry Kurnitz's screenplay, Gogol's farce, which is Russian to its core, no longer seems to take place in Russia. Brodny, the town in which is it set, is never located in a particular country. The military costumes look more French than Russian. The ultimate authority for all civic power, duly attested by numerous documents, is "the great Napoleon." And the real Inspector General (Rhys Williams), when he finally arrives, pronounces the imposter Georgi (Danny Kaye) "the first honest man I've met since I left Budapest." The result is to uproot the story from Russia, placing it in an underspecified middle-European Ruritania - an especially ironic development for its star, who was born David Daniel Kaminski to Ukrainian immigrants who had settled in Brooklyn.

Russia is engaged in more strategic terms in London Films' I948 Anna Karenina. This British film partly follows the lead of MGM's betterknown I935 adaptation in treating Russia as a site of exotic tourism but 
partly complicates it by suggesting through its musical score, which mingles nineteenth-century Russian and European classics, Russia's own cultural acquisitiveness. Julien Duvivier's film makes no attempt to suggest that its star, Vivien Leigh, is Russian, but it gives both her husband Karenin (Ralph Richardson) and her lover Vronskii (Kieron Moore) distinctively Russian tropisms. Dry, pinched Karenin is identified with the Russian political bureaucracy, Vronskii with the Russian military and the Russian people, who, as in Hollywood's wartime films, are sharply distinguished from the government. The film clearly presents Karenin as neglecting Anna in favor of a more active engagement in statecraft but cuts away from the speech he makes on the legislative floor before he can identify the important new measure he is proposing. Politics is hypostasized here as an anti-emotional, anti-human force irrespective of any specific ideology. By making Karenin more sympathetic than Basil Rathbone's coldly monstrous villain in the MGM adaptation, Richardson seems to plead with the politically unaligned Anna for a truce beyond her power to offer. Instead of depoliticizing Russia, the film splits its Russia into variously sympathetic parties already at war with each other.

The most Russian of all Hollywood Cold War adaptations of canonical Russian novels is The Brothers Karamazov, which meticulously labels each shift in place (e.g., "Ryevsk, a small town in Tsarist Russia, I87o") even when it is departing from Dostoevskii, whose novel is set in I 866. Richard Brooks's Russia, which seeks to out-Russia the real thing, brings on gypsies, who after all are not native to Russia, and calls on an original score by house composer Bronislau Kaper whenever it wants to turn up the Russian-seeming heat. Katia (Claire Bloom) pointedly tells Dmitrii Karamazov (Yul Brynner): "You're like Russia herself. Too strong, too excitable, too unpredictable." When Dmitrii is arrested for the murder of his father (Lee J. Cobb), however, the case is labeled "Russia vs. Karamazov," suggesting, like the I948 Anna Karenina, another split within the country and its culture. The film follows Dostoevskii's novel in making the three Karamazov brothers three images of Russia. Dmitrii, his impulsive and sensual father's son who frequently calls for folk music, represents Tsarist Russia. Alesha (William Shatner), pious and withdrawn, represents Orthodox Russia. Ivan (Richard Basehart), the analytical atheist, represents Communist Russia. Not surprisingly, this last identification is the most understated of the three, making Ivan apparently the least prominent agent of the three brothers until the film reveals that his ideas have inflamed his bastard half-brother Smerdiakov (Albert Salmi), the actual killer of their father. Audiences wondering what sort of Russia Salmi's Smerdiakov represents need only listen to his voice, for of all the Karamazovs, he alone speaks with anything like a Russian accent, one that recalls countless Hollywood portrayals of KGB thugs. Out of all Hollywood Cold War adaptations, this Karamazov provides the most complex and nuanced view of Russia through a divide-and-conquer 
strategy that allows it to present multiple Russias without deciding which is most authentic, or even weighing them against each other.

The Brothers Karamazov, based on a comfortably pre-Soviet novel, sharpens the approach of typical Cold War Hollywood adaptations of Russian literature - celebrate traditional Russian culture, ignore the political realities of the present-day Soviet Union-by valorizing the old Russia of Dmitrii Karamazov while criticizing the new Russia of Ivan and especially Smerdiakov. The situation is much trickier for David Lean's 1965 adaptation of Doctor Zhivago because it is based on a celebrated contemporary novel, one whose subject is announced by General Evgraf Zhivago (Alec Guinness), the eponymous hero's half-brother, in the film's opening scene: "We've come very far, very fast. But do you know at what cost?" This line, which could serve as a motto for the entire film, goes far to explain its banning in the USSR until 1994. An equally pervasive motto is iconographic: the prominence of the color red, which first appears in a star in this opening scene. In a film that runs well over three hours, red, associated with both the revolution and the balalaika Iurii Zhivago (Omar Sharif) inherits from his mother, is the only saturated color for long stretches, especially in nighttime scenes. The persistence of red is relieved in the film's long middle section by the green of the countryside, representing a politically unaligned retreat.

The film's expansive production design, emphasizing striking long shots of scenes filmed in Portugal, Finland, Canada, and (mostly) Spain, presents a sweepingly scenic view of Russia's post-revolutionary history. In Pasternak's novel, this history, which Pasha (Tom Courtenay) experiences as an ideological struggle and General Zhivago as material for mordant reflection, is filtered through Iurii's consciousness as raw material, not just for the poetry he writes, but for the poetic sensibility that dominates Pasternak's narrative, which subordinates sharply delineated characters, clear psychological and political motivations, and linear sequence to the exploration of that sensibility. In Lean's international co-production, by contrast, Iurii experiences history as a purely exteriorized pageant, a backdrop for a romantic triangle involving Iurii, his wife Tonia (Geraldine Chaplin), and Pasha's wife Lara (Julie Christie), the lover who bears Iurii's daughter. The film, whose original advertising posters feature a dominating double portrait of the lovers and a smaller image of Tonia against a much smaller background showing the minarets of Moscow on one side and a cavalry charge on the other, recalls the poster for Gone with the Wind. So does the emphasis of Doctor Zhivago's publicity tagline: "A love caught in the fire of revolution." The deepest insult the film offers the Soviet Union is not its view of individual characters but its view of history as either an external spectacle whose decisive events happen off-camera or raw material whose interpretation depends on the way it is filtered through a sensitive individual consciousness in the manner of Henry James. 
The possibility of meaningful border crossings within the film is precluded by the fact that there are no meaningful borders to cross. A number of key scenes in the film involve traveling. Iurii first spots Lara on a tram whose sparks represent the kindling of his love. Tonia is introduced, like Anna Karenina, arriving home on a train. Most notably, the film's long central sequence brings Zhivago, Tonia, and her father Alexander (Ralph Richardson) from Moscow to the far-off countryside on a harrowing ride aboard a freight train. Yet no one, certainly not Iurii, ever acts in a way that constitutes a true border crossing because the characters' journeys from red worlds to green never take them anywhere except to different scenery. In the film's most decisive elision of history, Iurii, who has departed to war service from a Tsarist culture, returns years later to a post-revolutionary culture that has taken root in his absence. Instead of crossing borders, he finds that revolutionary borders have changed profoundly without his moving or doing anything except remaining always himself.

Pasha's dismissive description of Zhivago's poetry as too personal- "The personal life is dead in Russia; the Revolution killed it"-reveals the film's central conflict between personal and political values. Yet this pronouncement does nothing to change the situation. Pasha dismisses "lucky" Zhivago as no collaborator with counterrevolutionary Whites, and their confrontation leads to nothing except more thematic conflict, not any particular action. In reviewing the film, Pauline Kael observed that "neither the contemplative Zhivago nor the flux of events is intelligible, and what is worse, they seem unrelated to each other." ${ }^{16}$ Robert Bolt's screenplay follows what Michael A. Anderegg has called Pasternak's "highbrow potboiler" 17 in presenting Iurii as a passive register of history rather than an active participant in it but, following the long-established model of Hollywood films about writers, keeps his poetic sensibility at such a distance that he seems to have nothing to do in the film except take in the pageantry and commit swooning adultery. For the hero of an epic historical film, Iurii has remarkably little dialogue. Instead, the film develops his character almost exclusively by reaction shots to social and historical spectacles more interesting than he is. By projecting static images of different Russias onto different characters and relegating history to a backdrop, the film consistently emphasizes not how the characters act in decisive historical moments but how they react intellectually and emotionally to "an excess of simplified history"18 in which they have no part, a history whose only connection to them is that of a malign and irrational power. Even Zhivago's opposite number, the amoral Komarovskii (Rod Steiger), survives the Revolution not because he has the right political sympathies but because he has none at all; as Zhivago's medical professor (Geoffrey Keen) says, he is "in with the government, in with the liberals, in with everybody," and he is willing to do whatever it takes to survive. 
If Cold War propaganda features like The Red Menace and Invasion USA show the paramount importance of disavowal in naming the enemy the movies are engaging, Cold War adaptations of Russian literary works like The Inspector General, The Brothers Karamazov, and Doctor Zhivago show an equally cagey desire either to disavow or to multiply the Russias that are being depicted, dividing them into the good, the bad, and the ugly. The primary strategies these adaptations use to cross the Russian border are to dilute the Russia in which their literary progenitors were set to the point of non-existence, to emphasize pre-revolutionary historical settings, to colonize the Soviet Union by presenting Russians in universalistic terms, to detach contemporary characters from the historical agency and necessity that would serve a Marxist, materialist view of history, and to suggest that because the characters do not cross national or ideological borders - those borders, in Iurii Zhivago's case, have crossed them while their attention was directed elsewhere- the audience does not need to cross them either.

This refusal to engage the Soviet Union in ideological or material terms is Cold War Hollywood's most distinctive attitude toward Russian literature. A Soviet analyst might assert that it marks Hollywood's failure ever to cross the Russian border. But it seems more judicious to conclude that it illustrates the many ways texts can cross borders, cross them partially, cross them while not crossing them, and not cross them at all.

\section{NOTES}

I. Stam, "Introduction," 25.

2. Sanders, Adaptation and Appropriation, I8.

3. Della Coletta, When Stories Travel, I4.

4. Ibid., 22.

5. See for instance Woll, Real Images; Gillespie, "Adapting Foreign Classics"; and Nepomnyashchy, “'Imperially'."

6. Collins, Bring on the Books, 90, 92.

7. Culbert, Mission to Moscom, I7.

8. Ibid., 226.

9. Ibid., 3 I.

Io. Ibid., 259.

I I. Ibid., 260.

I2. Ibid., 34 .

I3. Nadel, Containment Culture, 3 I.

I4. Sandomirskaia, "Cinema," I30.

I5. Corber, In the Name, 3, 69.

I6. Kael, 500 I Nights, I95.

I7. Anderegg, David Lean, I22.

I8. Silver and Ursini, David Lean, I70. 


\section{Dostoevskii's "White Nights": The Dreamer Goes Abroad}

Ronald Meyer

Ahista Ahista is [...] yet another adaptation of Fyodor Dostoyevsky's short story "White Nights" - and honestly, I've read and reread this story and [...] I wonder what it inspires in filmmakers, that so many of them want to explore it. ${ }^{1}$

Cedor Dostoevskii's short story "White Nights" (I 848 ), subtitled a "senfor the screen more than any other of his short works. A staggering twelve feature films have been mounted on the basis of this early short story, though only two Russian entries and Luchino Visconti's Le notti bianche (I957) carry Dostoevskii's title. ${ }^{2}$ Perhaps even more surprising than the sheer number of adaptations, half of which were released in the twenty-first century, is the language distribution: Russian and Hindi tie for the most with three each, followed by two in English and French, and one in Iranian and Italian. ${ }^{3}$ Like the reviewer of Ahista Ahista in my epigraph, one wonders why this simple story of the eternal triangle has inspired so many filmmakers.

None of the non-Russian adaptations strives to recreate the time and place of Dostoevskii's story, that is, St. Petersburg of the $1840{ }^{4}{ }^{4}$ How, then, are these films framed? What happens to Dostoevskii's narrator when he goes abroad and settles down in twentieth- or twenty-first-century Livorno, Paris, Mumbai, or Strasbourg? Or, to use Lawrence Venuti's terminology, how does a film adaptation decontextualize the source text and recontextualize that same text in a different setting and time? ${ }^{5}$ One might also begin to think about how Dostoevskii's hypotext was translated into French and Italian hypertexts. This complex process of translation into a foreign language encodes cultural meaning into the hypertext, even before the translation is used in making a film script. What happens when the Romantic idealist of Dostoevskii's fiction is transformed into a character plucked from the cinema of the French New 
Wave or Bollywood? Finally, how does the canon of film transpositions of "White Nights" influence subsequent versions? Visconti's film, for example, serves as an intertext, equal in significance to Dostoevskii's hypotext, not only for subsequent adaptations in the West (e.g., Two Lovers, 2009), but also in the East (e.g., Saamariya, 2007).

To answer these questions, I propose, first, to examine the two best-known cinematic hypertexts, namely, Luchino Visconti's Le notti bianche (I957) and Robert Bresson's Quatre nuits d'un rêveur (I97I), focusing on how these two hypertexts interpret the identical hypotext (most likely through two different translations) so very differently, not only in terms of the details these directors choose to accent, but also how they manipulate the medium of film to convey their interpretations. I want to explore how these directors make use of what Alexander Burry refers to as "transpositional openings," that is, "transposable material-biographical, literary, religious, or journalistic intertexts - that had already been reworked by Dostoevsky in his creation of the source text, and because of the resulting instability is especially inviting of further transposition." "I will demonstrate that Le notti bianche and Quatre nuits d'un rêveur, even though they are often regarded as minor films in these two directors' oeuvres, hold a special place among "White Nights" hypertexts, in that subsequent films might almost be regarded as remakes, although conceived in a completely different genre, for example Bollywood or twenty-first-century Catalan film. In other words, the cinematic language of Visconti and Bresson has become an integral component of what we might call the "White Nights Text." My consideration of Sanjay Leela Bhansali's Saamariya and José Luis Guerín's En la ciudad de Sylvia, both released in 2007 , will establish the "continuing life,"7 to use Walter Benjamin's term, of "White Nights" in the twenty-first century, and the continuing importance of Visconti and Bresson in that life.

Before turning to the films themselves, I want to say a few words about Dostoevskii's "charming" story (not necessarily an adjective that one associates with Dostoevskii's work), highlighting some of the features that have lent this film to such varied transpositional interpretations. The Dreamer in "White Nights" is the first in a series of nameless monologists in Dostoevskii's works - the most famous of whom is the spiteful narrator of Notes from Underground (I 864) — who tell their own stories, often self-consciously foregrounding the act of narration itself. These dreamers all live their lives through books rather than experiencing real life, and their stories all involve an encounter with a young girl in distress. Virtually friendless, without family, seemingly without occupation, the dreamers in these tales live in almost permanent isolation. In the case of "White Nights," we learn in the extended monologue that opens the work that the Dreamer has been a resident in St. Petersburg for eight years. He roams the city and observes, but does not speak to anyone. He is the flaneur transported from Dostoevskii's "Petersburg Chronicle" of the 
preceding year. He befriends not people but certain houses he passes on his wanderings, and it is with them that he converses. The reader assumes that he is one of the hordes of clerks that people St. Petersburg and so much of Russian literature of the I840s, for example Nikolai Gogol's "Overcoat" and Dostoevskii's own earlier "Poor Folk," but no mention is made of his occupation, except near the end when he remarks that he is behind in his rent, but will take care of that when his salary is paid.

"White Nights" takes place over four nights and one morning during the magical period from late May through late July when the skies never completely darken, making the already ethereal St. Petersburg landscape even more magical, dreamlike, and unearthly. The days are marked by section titles in the text. On the first night, after returning to the city from a day in the countryside, the Dreamer chances to observe a young girl leaning against the railing of a canal and believes that he hears a muffled sigh. The Dreamer's actions and speech take their cue from books - everything he sees and experiences is filtered through literature and his imagination. He first imagines how he might act, as if he were a character in a novel: "I turned around, took a step in her direction and would certainly have uttered the word 'Madam,' but for the fact that I knew that this exclamation had already been uttered a thousand times in all our Russian society novels." ${ }^{9}$ It is not until a reeling gentleman begins to pursue the girl that the Dreamer finally does spring into action and save her from the man's unwanted attentions. Conversation ensues, during which the traditional gender roles are reversed: It is the Dreamer who admits to being "frightened" and Nastenka who tries to calm him. On the second night the Dreamer, aged twenty-six, the same age as Dostoevskii when writing this story, and seventeen-year-old Nastenka exchange their life stories. The Dreamer begins his "ridiculous story ... as though [he] were reading something that had been written down," 10 embellishing it with rhetorical flourishes and a profusion of literary and cultural allusions, which begins, significantly, with E. T. A. Hoffmann and ends with Aleksandr Pushkin (with multiple references to the novels of Walter Scott and many others in between). The allusion to Hoffmann is not by chance, as the narrator's philosophy and his escape from mundane reality by means of the imagination all point to his ties with German Romanticism. We must assume, however, that this dizzying display of erudition is beyond the understanding of Nastenka, whose story is as simple and straightforward as the Dreamer's was florid and grand. She lives a quiet life with her blind grandmother, who pins Nastenka to her dress so that she knows where she is. Everything changes with the arrival of a young lodger, who invites them to the opera to see Gioachino Rossini's Barber of Seville and loans them books (Pushkin and Scott). Nastenka, of course, falls in love with him and when he is about to leave for a year, she packs up her belongings and goes to his room. It is now a year since the Lodger has left, and Nastenka waits for him nightly on 
the embankment. The second night ends with a "letter scene," borrowed from Rossini's Barber. The Dreamer suggests to Nastenka that she write the Lodger a letter. After discussing how it should be written, the Dreamer suggests that he return tomorrow to pick up the letter and deliver it. To which Nastenka, blushing, hands the Dreamer her letter, already composed. On the third night, Nastenka, full of expectation, is disappointed that her lover has not come. On the fourth night, the Dreamer declares his love for Nastenka. At first she rejects the proposal, but she gradually reconciles herself to the idea, even going so far as to plan their future life and where they will live. The Lodger then suddenly appears, Nastenka rushes to him, and the Dreamer is left behind, alone, as the two walk off together. On the next morning, the Dreamer receives a letter from Nastenka in which she begs the Dreamer to forgive her and to remain her friend. The Dreamer never sees Nastenka again. The story ends with a postscript from the Dreamer, delivered fifteen years after the events of the story:

May your sky be clear, may your sweet smile be bright and serene, may you be blessed for that moment of bliss and happiness that you gave to another lonely, grateful heart! My God! A whole minute of bliss! Is that really so little for the whole of a man's life? ${ }^{11}$

This concluding rhetorical benediction highlights a few of the issues facing the director, namely, the self-conscious mode of narration, the dual time structure of the story proper framed by the narrator in the present, fifteen years later, and finally, how the Dreamer's abstractness can be translated into concrete visual detail, given the absence of physical description of both characters and place. Foremost, however, is the opportunity provided by the text's reflexivity and the way in which the director, who in all the films I will discuss is the author of the screenplay, chooses to transpose Dostoevskii's narrative voice.

\section{VISCONTI'S LE NOTTI BIANCHE: THE DREAMER'S FIRST STOP ABROAD}

In their screenplay for Le notti bianche, certainly the best-known film adaptation of "White Nights," co-authors Suso Cecchi d'Amico and Luchino Visconti make no attempt to transpose the reflexive nature of Dostoevskii's narrative, erasing all traces of the rhetorical first-person narrator as well as the story's bookishness: murder mysteries replace Scott and Pushkin. The film marked a departure for Visconti, one of the major directors of Italian neorealism, which among other things was noted for its depictions of the lives of ordinary characters from the lower classes viewed from a Marxist aesthetic, promoted the use of non-professional actors, and eschewed the sound stage 
for filming on location out of doors. Le notti bianche, much to the dismay of many, featured a love story absolutely devoid of politics, was shot entirely on a set deliberately made to look artificial, and cast experienced actors in the leading roles. Indeed, Visconti embraced the dream-like atmosphere of the source text, as the director describes in a 1959 interview:

We wanted to make a film, nothing very big or extravagant, which could tell its story in a comparatively short space of time, preferably realistic, yet which at the same time moves on the fringe of a dream. [...] For my own part, I must say I'm attached to this little story — very big the way Dostoevsky wrote it, little in the way I filmed it-attached because it offers this possible escape from reality. ${ }^{12}$

Visconti transposes Dostoevskii's tale to mid-century Livorno. Mario (the Dreamer, played by Marcello Mastroianni), like many men in post-war Italy, has traveled in search of a job. Mario disembarks from a bus with an older couple and their two children after spending a day in the country. $\mathrm{He}$ walks to his lodgings alone, stopping in a bar not so much for a drink as for company, but is hurried out, as the bartender wants to close up. He observes a young girl, Natalia (Maria Schell), sobbing on the canal bridge. Two men on a motorcycle with a roaring engine harass Natalia, whom Mario then claims as his girl in order to get rid of the motorcyclists, and then offers to walk home. They agree to meet the following evening. On the second night she confesses that she is in love with her grandmother's former lodger (Jean Marais) who went away a year ago and promised to return in a year's time. It is for him that she waits on the canal bridge. The "letter scene" ensues, resulting in Mario's reluctant agreement to deliver Natalia's letter to his rival, which he ends up shredding to bits in a rage as a prostitute looks on. On the third night, the pair meets once more, and this time they go to a small café and dance to Bill Haley and the Comets. Mario confesses his love, but she runs away to the bridge to stand watch for the lodger. Affronted, Mario walks off with the prostitute (Clara Calamai), who has been stalking him the past few nights, but he suddenly changes his mind, prompting a brawl with her pimp, which coincidentally involves the Lodger, whom of course he does not recognize. The entire episode with the prostitute is Visconti's invention and will be incorporated by Bhansali a half-century later. On his way home Mario sees Natalia standing alone. They commandeer a boat moored at the canal's edge and Mario rows them away in the still night. All of a sudden it begins to snow and the two become enraptured, feeling themselves to be chosen, for only they are awake to enjoy the fluffy white snow, falling in the black night. As they walk home they see the dark figure of the Lodger. Natalia rushes to him, leaving Mario all alone, save the dog that followed him in the opening 
scenes of the film, thus turning the narrative full circle with Mario once again alone.

Visconti's film, shot on a set that emphasizes its man-made quality, is set amidst the ruins of bombed-out buildings. The small-scale set with its simple geography of two halves of the city center divided by the canal, but joined by the bridge where they meet, sets in stark contrast the lives of Mario and Natalia: The side where Mario lives hums with vibrant life, lights, bars, and cafés. What catches the viewer's eye in the opening scenes are the almost German Expressionist stage-set and the play of the neon illumination of Esso, Ristorante, Tabacchi, and Farmacia that pierces the dark inky blackness. This play of light and dark dominates the entire film right through to the end when it begins to snow. On the other side lives Natalia with her grandmother, amongst barely illuminated ruins and empty streets. Despite the visible ravages of war, Natalia's side of the canal has a fairy-tale quality about it, which engulfs Mario, too, when he is drawn there, but he never wholly becomes part of that dream world. ${ }^{13}$ The morning after the second night he says to his landlady: “These past nights ... I don't know myself what I was doing. I was dreaming. That's what I was doing. I was dreaming." ${ }^{14}$ Dreaming here takes on a negative connotation-Mario chastises himself for being made a fool.

The oneiric landscape, however, does not prepare the viewer for the startling noises that resound in the opening scene, as outlined in Visconti's screenplay: "the muffled sound of cars and buses" and "the strident screech of the brakes of a bus stopping at the end of the line and the voices of the few people who are getting off." 15 A few minutes later, "preceded by an ear-shattering noise, a motorcycle with two boys riding on it now sweeps into the scene from a nearby street." 16 This automotive noise finds its counterpoint in the dance scene and Bill Haley's "Thirteen Women," which opens with the lines: "Last night I

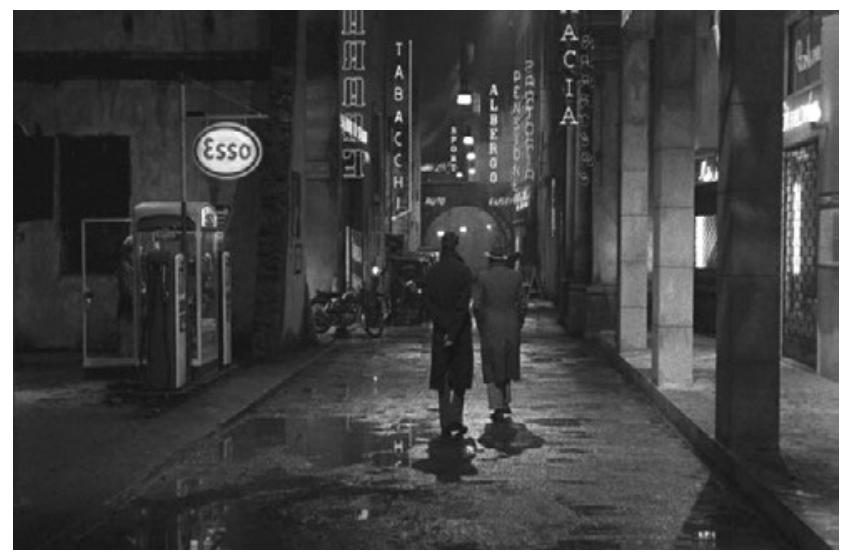

Figure 2.I The neon illumination in Le notti bianche (I957) plays an important role in the interplay of light and dark, a neo-Realist intrusion in Visconti's dreamscape. 
was dreamin' / Dreamed about the H-bomb." That the song opens with a dream cannot be coincidence, but the reference to the $\mathrm{H}$-bomb squarely places the song in the 1950s. At moments when the couple is alone, particularly on that final snowy night, only Nino Rota's haunting musical score breaks the unearthly silence.

Several critics have commented on the film's "theatricality," pointing out that in addition to his film work, Visconti had a distinguished career in the dramatic theater and opera stage. ${ }^{17}$ Visconti himself responded in an interview that Le notti bianche is

theatrical in the sense that it was a story about two people shot entirely in a studio set. That gave a sort of depth or resonance to the backgrounds. [...] I know what people say about me every now and then: that my films are a bit on the theatrical side and my stage productions a bit filmic. I don't see anything very wrong in that. ${ }^{18}$

The studio set, grainy film stock, and lighting all contribute to the film's fairy-tale atmosphere and sense of theater. At certain points realism and fairy tale are superimposed: for example, Visconti sets Natalia's fairy-tale story of parting with the Lodger firmly in a "realist" setting, namely, the window ledge of a bombed-out building. The narrative shifts in point of view are handled deftly. For example, Mario and Natalia, sitting in the window, face each other as Natalia begins telling her story; her first-person account of the past seamlessly shifts to a flashback of events in the past, ending with the Lodger speaking in the present tense as he bids his farewell. We hear sobbing and then the camera closes in on Natalia's tear-stained face and she resumes her first-person narrative, which she finishes speaking to Mario once again-Marais has dissolved into Mastroianni.

In keeping with Italian neo-realism, the characters all come from humble circumstances, but the international cast provides an unusual counterpoint. Casting Schell to play a blond Slavic immigrant with a foreign accent in her Italian, instead of Dostoevskii's brunette, contributes to the dream-like quality of her appearance in the film, which is further enhanced by casting the swashbuckling French actor Marais, whose maturity provides a vivid contrast to Mastroianni's boyishness. In fact, Marais's massive physical presence seems almost menacing in his few scenes with Schell. Schell's foreignness, by contrast, serves to highlight the Italianness of Calamai as the prostitute, whose neo-realist roots place her outside the dreamscape. ${ }^{19}$

Mario is a man in love with a flesh-and-blood woman, not an ideal. He does not deliver Natalia's letter. He suffers for love, catching cold from standing in the rain with Natalia, and in one of the great comic scenes in the movie his boarding house landlady nurses him to health the next morning. As he 
confesses to Natalia on that first night, he is "terribly timid. I mean with girls. I'm not used to them." 20 In the dance scene, after accepting the challenge of the rival dancer, a "thin young fellow who looks insistently at Natalia," Mario "with the courage of the timid ... begins to attempt to show off: he removes his hand from Natalia's waist and begins to jump about rather awkwardly, staring back defiantly at the other dancer." ${ }^{21}$ Natalia is delighted with Mario's performance and her first dance, and the couple settles down at a table in the café. Mario is lulled into hoping that she has forgotten her lover, but when she hears that it is past ten, she runs to her post on the bridge.

The film ends in a snowstorm-Natalia and the Lodger are reunited on the bridge as Mario looks on. No moral is drawn that Mario's fate has been sealed and he will never find happiness, though he does offer Natalia this parting benediction: "Go to him. Don't be sorry. I ... I was wrong ... to try to make you doubt. Go to him. And God bless you for the moment of happiness you've given me. (Natalia kisses Mario.) It's not a little thing." ${ }^{22}$ He happens upon the same stray dog as in the opening of the film, which follows him into the distance, not another soul to be seen.

The dream vs. reality dichotomy spelled out by the geography of the set fundamentally structures the film. Natalia and the Lodger inhabit the dream world; indeed, the Lodger is such a nebulous character that the viewer, like Mario, almost does not believe in his existence. Mario is a real-life character who happens to intrude in a fairy tale, but never becomes part of that realm. Although Visconti clearly cultivates the atmosphere of Dostoevskii's "White Nights," the forays into the real world, as epitomized by the dance episode and the scenes set in Mario's lodgings, mark some of the film's real strengths. More importantly, Visconti's film establishes a visual hypertext, one which asserts its own cinematic vocabulary (Italian neo-realism), that will be a starting point for future filmmakers working within their own national cinema genresFrench New Wave, Bollywood, Hollywood, post-Soviet cinema, etc.

\section{ROBERT BRESSON'S QUATRE NUITS D'UN RÊVEUR:}

\section{THE DREAMER AS ARTIST}

Bresson's Quatre nuits d'un rêveur came fourteen years after Visconti's hypertext of "White Nights," but Bresson's opinion of his predecessor's work is not on record, unless one takes his own screenplay and film to be a response to the Italian. Where Visconti erased almost all traces of Dostoevskii's reflexivity, filmed his work on a sound stage, embraced theatricality, and used professional actors, Bresson did the exact opposite through his careful transposition of the Dreamer's first-person narrative, making Paris almost a character in the film, eliminating any traces of the theater, and employing non-professional actors. 
In an interview published after the release of Quatre nuits d'un rêveur, Bresson comments on his use of Dostoevskii's stories: "I try to avoid a simple rendering. Although the films keep to the plots of Dostoevskii, I try to communicate impressions that are mine and part of my experience." ${ }^{23}$ Curiously, Bresson, like Visconti, states that he turned to the Dostoevskii short stories "partly because of lack of time." In that same interview he explicitly draws a distinction between Dostoevskii's short narratives and the novels, thus excluding his film Pickpocket, which clearly makes use of Crime and Punishment, from his Dostoevskii-inspired works ${ }^{24}$ saying that

[he] would never dare to adapt the novels (The Idiot, The Brothers Karamazov, Crime and Punishment, etc.), which are formally perfect and complete in themselves. The two [Dostoevskii] stories from which I made my films are rather skimped, but perfect for my purpose. ${ }^{25}$

That Bresson, the director of Fournal d'un curé de campagne (I95I), which ushered in his engagement with first-person narrative in film, should be drawn to Dostoevskii's confessors seems only natural. In that film the priest witnesses every event that we observe on screen, which Bresson emphasizes with brief scenes of the priest writing in his journal, accompanied by his voice speaking the words he is writing. These scenes may introduce the event or come afterwards, but in all cases they create a tension between the written text and the cinematic transposition. ${ }^{26}$

In interviews Bresson would often lament that he found it difficult to finance his films on account of his practice of using "models," that is, non-professional actors. What interested him, above all, was the quality of the voice; therefore, the ideal audition situation took place over the telephone. Physical presence supposedly came second, though one should note that both Dominque Sanda and Isabelle Weingarten, the leads in Une femme douce and Quatre nuits d'un rêveur, were professional fashion models before their appearance in Bresson's films, and one cannot help but notice the passing resemblance between Guillaume des Forêts, who plays Jacques in Quatre nuits d'un rêveur, and Jean-Pierre Leaud, one of the most famous faces in the French New Wave (about which more later). Bresson's Notes on the Cinematographer has a great deal to say about the use of models: "No actors. (No directing of actors). No parts"; or, "Models. Letting themselves be led not by you, but by the words and gestures you make them say and do." 27 There are numerous of accounts of Bresson putting his models through their paces, which included endless repetitions of gestures, lines, looks, all of which accounts for the reserved or flat delivery of lines and his characters' blank expressions. ${ }^{28}$ One need only compare Mastroianni's winning performance with the strangely disconnected portrayal by des Forêts. 
Hand in hand with his use of models is Bresson's absolute disdain for theatricality in the cinema. As he writes in Notes on the Cinematographer: "Two types of film: those that employ the resources of the theatre (actors, direction, etc.) and use the camera in order to reproduce; those that employ the resources of cinematography and use the camera to create"; or, "Nothing rings more false in a film than that natural tone of the theatre copying life and traced over studied sentiments." ${ }^{29}$ Bresson's scorn for theatricality and big-name actors to support or even carry a movie could not be further removed from Visconti's Le notti bianche.

Bresson translates the Dostoevskii story to a very specific time and place: post-I968 Paris. Or to be more exact, a very small section of Paris, namely, the Pont Neuf, the oldest bridge in Paris, and the surrounding embankment, including the statue of Henri IV, and Boulevard St. Germain where they part on the fourth night. The river is a much more palpable presence in Bresson than in Dostoevskii's hypotext, where descriptions of the city, the river, and the embankment are dropped after the Dreamer's introductory stroll and his first meeting with Nastenka. When Jacques first sees Marthe she is contemplating suicide on the Pont Neuf - with the emphasis on contemplation: The studied removal of her shoes and her careful climb onto the parapet signal that she is waiting for someone to come to her aid. Curiously, at least one writer on Bresson has credited Dostoevskii with the suicide motif, thus ostensibly granting equal authority to the texts of Bresson and Dostoevskii. ${ }^{30} \mathrm{It}$ is as if Bresson had sensed the suicides that one encounters in Dostoevskii's mature works from the $\mathrm{I} 86$ os on from the vantage point of $\mathrm{I} 848$, for example the woman who throws herself off a bridge in Crime and Punishment.

Jacques and Marthe meet on the bridge and walk along the riverfront on the following three nights, once walking past a group of hippies, singing; at other points excursion boats cruise down the river both in daylight and at night, and a small band plays Brazilian bossa nova music. The traffic on the river is complemented by the sound of vehicular traffic: honking horns, motorcycles revving, automobile motors running, more often than actual shots of trafficthe major exception being the humorous opening scene where Jacques is hitchhiking out of town, and the camera eventually pulls back so that we see three other hitchhikers, and are let in on the joke. Typically, when a car does stop and he is asked where he is going he literally throws his hands up in the air, but does not give a verbal answer. Throughout the film dialogue, indeed human speech, plays a minimal role - it is the world around the characters that contributes the soundtrack to this film.

In the narrative of his story, Jacques recounts an unexpected visit by a fellow student from art school, an episode from Dostoevskii's text not usually transposed to the screen. At the sound of the doorbell, Jacques clears away the dishes and ashtray, and turns all his paintings toward the wall, so that not 
one is on view. But the colleague has not come to view Jacques's art, but to lecture him that "craftsmanship is dead"; painting is a "meeting of the painter and the concept": "what's crucial is not the object but the painter ... the gesture." The post-I 968 rhetoric does not engage Jacques, whose apartness from the student is emphasized by the fact that throughout the entire episode there is not a single shot of the two together. We watch the visitor speak, followed by a reaction shot of Jacques that consists of a non-verbal response: a word mouthed, a shrug of the shoulders. The visitor's long hair, moustache, and sweatshirt set into high contrast Jacques's unwavering uniform of Oxford cloth shirt and brown corduroy jacket, which he wears even to the country, where he performs an awkward somersault.

As the title indicates, Bresson retains Dostoevskii's structure of four nights, each of which is introduced by an intertitle, as are the life stories of Jacques and Marthe, which are exchanged on the second night. Marthe and Jacques settle down on the embankment, and she asks him to tell his life story, to which Jacques replies:

"My story? I have no story. I see no one. I speak to no one."

The camera cuts to the intertitle "Histoire de Jacques" which appears above the street sign Rue Antoine Dubois. The camera then cuts to a shot of Jacques walking down this street, accompanied by the voice-over:

"I live at 6 Rue Antoine Dubois ... in a loft on the third floor."

The voice-over ends, and the next several scenes take place in silence, that is, in the absence of dialogue, though we hear the sounds of traffic, and shoes clacking on the street. We watch as he enters his building from the street, and in the next frame we see him enter his apartment, carrying a basket of produce. The scene then shifts to Jacques exiting the metro and walking down the street following women. He looks in the shop window and a woman notices him. He follows her once she is outside. Then he is taken by another woman, and follows her until she boards a bus, while he stands near a placard advertising the Opéra Comique-a telling commentary on Jacques's activities. The camera then cuts back to Marthe and Jacques sitting on the embankment, and Jacques admitting that he has fallen in love innumerable times, but "with no one, an ideal, the woman in my dream." Eventually, after following a couple as they leave their Rolls-Royce, Jacques does return to his loft and proceeds to record his dream on a tape recorder. Once he finishes taping this segment, he turns to painting. Bresson's solution of the tape recorder allows Jacques to tell his dreams only to the viewer. ${ }^{31}$ The events are not transferred to the screen, since he does not confide these dreams to Marthe. The dream itself is a variation on the rather long dream in Dostoevskii's story: "where they so often would walk together, where they 
hoped, grieved, loved, loved each other for such a long time ... How innocent and pure was their love ..."32 Jacques will continue to record sounds and stories into his tape recorder to the film's very end. He records pigeons cooing, the incessant repetition of Marthe's name, and then listens to his recordings on the bus and in the park. The film's final scene shows Jacques alone in his loft, recording yet another fantasy: "I have suffered a thousand deaths, but it's you I love ... What strength makes your eyes shine ... ?" Once the recording is finished, he turns to his painting.

Dostoevskii's Dreamer is a loner of unspecified occupation, more than likely a government clerk in St. Petersburg's overgrown officialdom. He has been in the city for eight years but knows no one. His only "creations" are his ephemeral dreams, which even he realizes will fade. Even though he is a decade older than Nastenka, he is terribly bashful. Bresson's Jacques, on the other hand, is a painter. It surely is no coincidence that Bresson moved to Paris as a young man to study painting. In answer to Jean-Luc Godard's statement that Bresson seems to be "someone who loves painting very much," Bresson replies,

I am a painter. And perhaps it is there, precisely, that you find your idea. [...] I write as I put color: I put a little on the left, a little on the right, a little in the middle, I stop, I start again ... ${ }^{33}$

Bresson here is describing in precise detail the manner in which Jacques paints. None of his several painting sessions lasts more than a few minutes. He works on several canvases simultaneously, but in each instance he fills in a bit of color here, draws part of a line there. And it is worth noting that the canvases are large, and the fields of color he paints are correspondingly large. Compare Jacques's painting with the tiny black spots the fellow student shows him during his visit.

Painting complements the act of recording, perhaps a metaphor for the sound and picture that go together to make a film. After delivering Marthe's letter to the Lodger's friends, he returns to his room. In a characteristic shot we see only a fragment of Jacques from the knees down as he enters the room. According to Bresson, "fragmentation ... is indispensable if one does not want to fall into representation. See beings and things in their separate parts. Render them in order to give them a new independence." 34 Jacques then proceeds to paint, and then lies down on his bed, where he listens to his recording of repetitions of the name Marthe over and over again, all the while holding his erect paintbrush at waist level. The viewer literally awaits his climax as the masturbatory chant of Marthe's name speeds up and reaches a crescendo.

Bresson's Jacques is straight out of the French New Wave and bears a strong resemblance to Jean-Pierre Leaud, French New Wave actor par excellence 
and the hero of François Truffaut's series of films about Antoine Doinel. In Bresson's universe, it would be difficult to choose someone more appropriate to represent the anti-“model.” In the I 968 Truffaut film Baisers volés, the bumbling Doinel loses a succession of jobs, but does, ultimately, end up in bed with his girlfriend. Bresson, not a director of romantic comedies, follows Dostoevskii's lead and withholds a happy ending for Jacques. Nevertheless, Bresson unmistakably alludes to this Truffaut film, which had come out three years earlier. ${ }^{35}$ Jacques's intoning of the name Marthe, which he records and plays back in his room, on the bus, and in the park, is a direct quotation from Baisers volés, where Doinel looks into the bathroom mirror and repeats over and over again the names of three women. The repetition of the name Marthe is complemented by visual repetition: Jacques passes a store named Marthe, and the barge cruising down the Seine, which cannot help but remind the filmgoer of Jean Vigo's L'Atalante (another intertextual quotation), bears her name. Jacques is clearly following in Doinel's footsteps, though he is not rewarded with the girl in the end. Nonetheless, he is not Dostoevskii's "sexless" Dreamer. He may be comical and may not end up with the girl, but not for lack of trying on his part. He flirts, he stares, he follows unknown women on the street.

Marthe's physical longings complement those of Jacques. She, too, is inexperienced sexually, but so anxious to leave behind her virginity and her mother's apartment that she falls in love with the homely Lodger, sight unseen. Marthe learns about the Lodger through the books he loans her mother, a selection that includes Louis Aragon's erotic novel Irène. Later he presents her mother with tickets to a film premiere (the twentieth-century equivalent of the opera), but does not accompany them. The film, tellingly titled The Bonds of Love, is an awful gangster movie that ends with a drawnout death scene where the man who has been shot pulls out a photo of his girlfriend and kisses it. It would be difficult to picture a more un-Bressonian scene. And, indeed, Bresson admits to having fun with the interpolated movie:

In Four Nights I profited from the chance to poke fun at a certain kind of movie; it's just a mockery of passion and romanticism, of blood and violence. I also thought that all that exaggeration would contrast with the restraint of my character, which is not really restraint but simply a refusal to indulge in theatrics. ${ }^{36}$

The romance of Marthe and the Lodger, a too serious, long-haired young man who is about to leave for Yale University, consists of tapping on the wall that separates their two rooms until the night she goes to him and they make love-all the while with her mother pacing about the apartment, calling her 
name repeatedly (an analogue to Jacques's recording of her name on the tape recorder). Bresson employs parallel montage of the mother's calls and the unfolding scene of lovemaking in the Lodger's room to emphasize the thin membrane of walls and door that separate them. ${ }^{37}$ We watch as he unhooks her bra, but we see only his hands and her torso, and then the bra lands on the bed, after which he places his glasses next to it-a metaphor of their two selves. When she does go to his room, she gives boredom and wanting to leave her mother's apartment as reasons for coming - quite prosaic when compared with Nastenka's Romantic longings. This is preceded, however, by the extended nude scene, in which Marthe examines herself in the mirror. Marthe's body is viewed in fragments - there is only a quick glimpse of her entire body - the camera does not pull back to linger on her body from head to toe. ${ }^{38}$ The nude scene told in fragments is certainly one of the loveliest episodes in Bresson's entire oeuvre. The long shots - so atypical of Bresson — of river life, couples in the park, life on the streets of Paris, particularly on that final night when he asks Marthe to look at the moon, point to the film's special place in Bresson's oeuvre.

Quatre nuits d'un rêveur received the British Film Institute Award for 197I, although many viewed the award as one given for Bresson's work as a whole and not this particular film. Like Dostoevskii's text it represents something of an anomaly in the director's work. Where his previous film, Une femme douce, based on Dostoevskii's "The Meek One," opens with the title character's suicide (death and suicide haunt most of Bresson's oeuvre), Quatre nuits d'un rêveur begins with suicide averted. Bresson's story of Jacques's endearing longing and innocence is as charming as Dostoevskii's text. Until recently the film never achieved the recognition of Visconti's Le notti bianche, but with the passing of time the two films are now viewed as minor masterpieces in the work of the two directors. More importantly for my purposes, the two films continue to resonate today, not merely as works of art in their own right, but as important hypertexts in the history of adaptations of "White Nights." So important, in fact, that they almost supplant the hypotext in subsequent transpositions. Visconti and Bresson, each in his own way, brilliantly decontextualize Dostoevskii's reflexive mid-nineteenth-century tale of the eternal triangle and recontextualize the work in contemporary Europe and European cinematic culture (Italian neo-realism and French New Wave), thus paving the way for future recontextualizations and permutations of the Dreamer.

THE DREAMER IN THE TWENTY-FIRST CENTURY:

SAAWARIYA AND EN LA CIUDAD DE SYLVIA

Two film adaptations of Dostoevskii's "White Nights" were released in 2007: Sanjay Bhansali's Hindi-language Saawariya, a flamboyant song-and-dance 
spectacle, and En la ciudad de Sylvia, a French-language art film almost without dialogue, shot in the old part of central Strasbourg by the Spanish director José Luis Guerín. Despite the very different sensibilities of the two works, both films grapple with similar problems, for example transferring the action out of Russia and into the twenty-first century, utilizing the legacy of Visconti and Bresson and yet situating the film in their respective traditions (Bollywood and Catalan cinema). Both films present love stories, but the telling of their stories could not be more different. Gulab, the "princess of the streets," is charged with the narration of the story of Raj, the would-be rock star, while En la ciudad de Sylvia opens wordlessly.

The plot of Saamariya, to a large extent, follows Dostoevskii by way of Visconti. The story opens in the red-light district of an unnamed town, a "dreamland," presumably in India, but with attributes borrowed from the US and Italy, and perhaps St. Petersburg via Venice. Raj (Ranbir Kapoor), a musician newly arrived to town looking for work, meets the prostitute Gulab (Rani Mukherjee) in the RK Bar and sings for her his signature song "Saawariya" ("My Love"). She is taken by the handsome singer, but he just wants to be friends. On a rainy night he falls in love with Sakina (Sonam Kapoor), who, he learns the following night, when they exchange their stories, awaits her lover Imaan (Salman Khan) on the bridge. Sakina lives with her grandmother, a carpet weaver, who also takes in lodgers. Imaan, the lodger, invites them to the cinema, where he embraces her. He leaves the following day, but has promised to return on the night of the festival of Eid, which is fast approaching. Raj nevertheless continues his wooing, confiding in both Gulab and Lillian, his landlady who is allotted the role of the Bollywood mother figure. There is a letter scene, after which Raj, like Mario in Le Notti bianche, destroys the letter. But Lillian persuades him to go to the address and deliver the message in person. Raj reprises "Saawariya" for Sakina in his bar and becomes convinced that she loves him, which he announces to Lillian over the phone. Sakina, however, runs back to the bridge, where she finds Imaan, and the two walk off, leaving Raj alone.

Even this brief capsule of the plot shows ties to Visconti: for example, Raj is a recent arrival to the town; the grandmother's carpet business; they take shelter by a building when caught in the rain and as in Visconti a man asks when the rain will stop; the prostitute witnesses Raj burning the letter; Raj sings and dances for Sakina at a bar in front of an audience and she briefly dances with him (her first dance), which reminds the viewer of the dance scene set in the café in Le notti bianche; it snows on the last night, and Raj scampers about. The general contours of the lavish set (bridge, canal, neon lights) clearly allude to Visconti's more modest scenery, but whereas the Italian film is a study in chiaroscuro, Bhansali's over-the-top production is awash in purples and royal blue, so much so that the viewer is blinded when a chorus dressed 


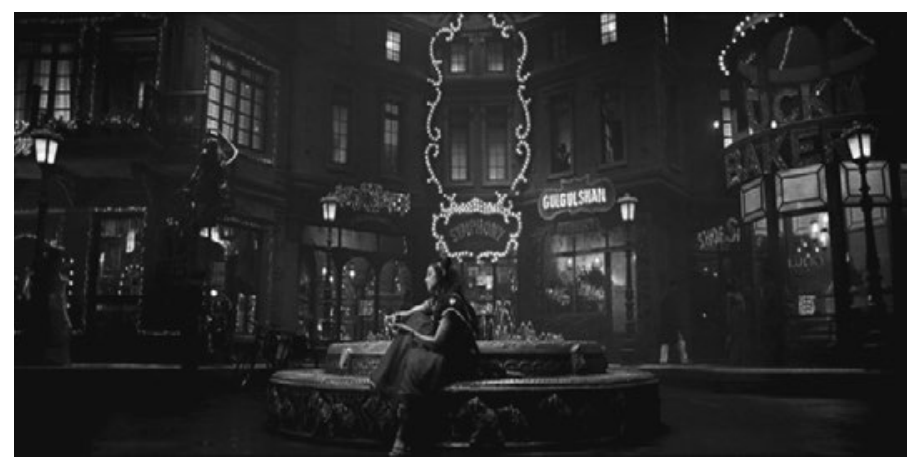

Figure 2.2 The neon signs in Saamariya might be read as homage to Le notti bianche.

in white takes the stage. The English-language neon signs - and indeed all the signs are in Roman letters (Windermere, Lilianji, Ace, Capitol, Clifton Hotel, and most importantly, RK) — clearly represent a homage to Visconti, though they have more in common with twenty-first-century Las Vegas than Visconti's haunting neon illumination. The combination of closed set and the lavish song-and-dance numbers creates a theatrical atmosphere that verges on musical theater. ${ }^{39}$

While recognizing the major influence of Visconti's film in shaping the plot and set design, however, the viewer is ever mindful that this is a Bollywood production; moreover, a production that makes frequent reference to its native roots. As Naman Ramachandran writes,

Saamariya introduces a pair of actors with film lineage into the Bollywood pantheon: Ranbir Kapoor (as Raj, the singer who falls for the mysterious Sakina on the bridge) is the fourth generation of the legendary Kapoor family, while female lead Sonam Kapoor (no relation) is the daughter of actor Anil Kapoor. Bhansali ignores Soman's lineage, but litters his film with references to Ranbir's family: Saamariya features a bar called RK after Ranbir's grandfather Raj Kapoor's well-known RK studios; there is imagery from the RK film Shree 420 (I955); and Ranbir is made to ape his grandfather's mannerisms and mouth lines from his father Rishi Kapoor's iconic Karz (I980). ${ }^{40}$

Bhansali's allusions to the Hindi cinema tradition, like Bresson's intertextual reference to New Wave cinema, both comment on the present and situate his film not only in the history of adaptations of "White Nights," but also in the history of Indian film. For example, the entire episode with the umbrella that first night (first she is on the bridge under an umbrella, later they alternately walk under the umbrella, and finally they share it) alludes to 
Kapoor's Shree 420, as Vijay Mishra points out in his discussion of Bhansali and Dostoevskii. ${ }^{41}$ The recognition of these intertextual references both complicates the film's reception and at the same time indigenizes the foreign story. The umbrella motif reappears in the film's final scene. As in Le notti bianche, snow falls on the final night, rendering the cityscape even more dreamlike. Raj scampers about, a snowball fight ensues, and he drapes his coat over Sakina's shoulders. Bhansali here follows Visconti to the letter-not Dostoevskii. In these few details, all scripted by Visconti, Bhansali clearly acknowledges his Italian predecessor. Visconti transposes Dostoevskii's midnineteenth-century reflexive narrative to war-ravaged, post-war Italy, and yet he manages to retain the story's dreamlike, fairy-tale aspect. The Lodger suddenly appears on the bridge, and she runs to meet him. In Bhansail's hypertext, Raj, left alone, discovers in the snow the anklet Sakina lost on their first meeting - and then the umbrella from their first meeting opens, a maneuver that allows Bhansali to bring to a close the "umbrella motif" and its allusions to the Bollywood cinematic tradition. The Dreamer does indeed speak Hindi, but the journey is by way of Italy.

José Luis Guerín's En la ciudad de Sylvia, on the other hand, subtly points to Bresson's film as its formative hypertext. The Dostoevskii story is all but gone, save the intertitles that announce the three nights-and not Bresson's four-even though most of the film takes place during the day. The film is set in the old city of central Strasbourg, which seems to be populated almost exclusively by handsome young people, women comprising an overwhelming majority, whom the protagonist studies, much as Jacques in Quatre nuits d'un rêveur follows women on the streets of Paris and observes them through shop windows. The importance of the urban setting is announced in the title, though it is Sylvia that defines this particular city. The film's single extended scene with dialogue takes place more than halfway through the film and is only ten minutes long. We hear the hum of human speech, voices in the hotel hallway, a few stray words, but nothing that helps the viewer build a narrative. Instead we hear the noises of the city: traffic, birdsong, church bells, the clack of shoes on cobblestone, wheeling suitcases, rolling bottles, music (e.g., female buskers at an outside café play a traditional Macedonian tune)—all of which puts Guerín firmly in the Bresson branch of "White Nights" versions.

The protagonist's occupation might be rendered as flaneur, a term that has been used to describe the roving Dreamer in the introductory pages of Dostoevskii's "White Nights." ${ }^{22}$ Charles Baudelaire's disquisition in "The Painter of Modern Life" on the flâneur, whose element is the crowd, a spectator of the highest order who is both away from home and yet feels at home, perfectly describes Guerín's Dreamer. ${ }^{43}$ Baudelaire sums up not only the Dreamer's character but also the film's "plot": the observation of 
beautiful women by a foreigner, which takes place amidst crowds, framed in part through mirrors, reflections, and kaleidoscopes. ${ }^{44}$

The film opens with the camera panning a dark hotel room, curtains billowing in the breeze from the open windows. A handsome young man, the Dreamer, played by the French actor Xavier Lafitte, is asleep, his torso bared to the camera. On the bedside table lie a hotel key (Room 307), a color map of Barcelona, and a coaster from a bar named Les Aviateurs, on which another map has been drawn by hand. The next morning he sits on his bed, absolutely still, clutching a pencil. He is clothed, with tousled long dark hair, barefoot, a white loose shirt open at the neck exposing his chest. He writes in his notebook and then erases.

Later he exits the Hotel Patricia holding a map, saunters down the cobblestone street and eventually walks off camera, while the camera follows other pedestrians. The shot had been set up by the camera recording other pedestrians on the street: A man wheeling a suitcase, for example, walks down the street and takes a right turn, out of our view. Again, one is reminded of Bresson's tendency to record where the character has been rather than where he is going. The viewer is left to piece together these clues to the puzzle as the film progresses.

The Dreamer, an artist and writer, is in search of Sylvia, a woman he met in the Strasbourg bar Les Aviateurs six years ago. In a scene that lasts some twenty minutes, the Dreamer sits alone in the outside café at the Conservatory of Dramatic Arts and sketches the heads of the beautiful women (and they are all handsome) in a notebook titled "En la ciudad de Sylvia / Dans la ville de Sylvie." It is important that, as was the case in Bresson, we witness the Dreamer in the act of creation and see his works, even though he ruthlessly erases and scribbles over them. As David Bordwell writes,

The sequence is a pleasure to watch, partly because of the constant refreshing of the image with faces, nearly all of them gorgeous, most of them female. [...] Yet the scene builds curiosity and suspense too, thanks to Guerín's sustained and varied use of optical POV [point of view]. He gives us an almost dialogue-free exploration of a cinematic space through one character's viewpoint. ${ }^{45}$

Bordwell further describes how the Dreamer is revealed in this scene only after a succession of six shots, slightly out of focus. Guerín then manipulates the point of view by obstructing the viewed object and playing with the reaction shots to create suspense and a narrative from a situation that can be succinctly summed up as: young man sits at table and sketches beautiful women around him.

Unsurprisingly, La Ciudad de Sylvia came in for sharp criticism at the 2007 
Venice Film Festival for its objectification of women. ${ }^{46}$ Rob Stone, however, counters this critique by asserting that this assumes that the film is exclusively shot from the Dreamer's perspective, which is clearly not the case. Be that as it may, one certainly senses a male gaze obsessively following the shapely non-Sylvia through the half-deserted streets of Strasbourg, very much in line with Bresson's Jacques who follows women through the streets of a much busier Paris. And yet it is not insignificant that the male body is the one that is disrobed and bared to the camera in the opening sequence and the final scene in the hotel room, where we dimly see the Dreamer's naked body alongside a woman wrapped in the sheets. In Saamariya, too, it is the male body that is displayed to the audience-I have in mind the song and dance sequence after Raj's meeting with Sakina when he dances in his lodgings, covered only by a towel. Charu Gupta, for one, is of the opinion that the "masculinity on display is almost 'feminine,' especially his shapely waxed legs ... His lean body, draped in a scanty towel, actively invited the viewer to linger over it." ${ }^{\prime 77} \mathrm{By}$ contrast, we do not see more than Sakina's ankle. The female or homoerotic gaze is also at work in the dance scene in Visconti's Le Notti bianche, with the male dancer seizing the spotlight in his tight pants and seductive moves on the dance floor-we barely notice his female partner. Tied to this phenomenon is the figure of the Lodger in Visconti, Bresson, and Bhansali, who in all cases is older, more mature and "more masculine"- the dreamers in these three instances are mere boys. Dostoevskii offers only the information that the Dreamer is "timid" with women, whereas the Lodger actively courts Nastenka and then promises to come back for her.

At long last, Guerín's Dreamer espies a woman through the café window (in a stunning bit of camera work, the window both mirrors the outside and refracts the images on the inside) whom he believes to be Sylvia (Pilar López de Ayala). He follows her closely for ten minutes in silence through the labyrinthine cobblestone streets of the old city, losing her at one point, but picking up her trail, eventually boarding the same tram as she, where he finally speaks to her, addressing her as Sylvie. The sequence on the tram is a tour de force: the windows on the tram and their reflection of the landscape and passengers while the tram is in motion continue the mirror effects at the conservatory café. She replies that she is not Sylvia, and that he is mistaken, to which he profusely apologizes. She prepares to leave the tram, warning him not to follow. When she alights, she turns around, blows him a kiss and then walks away. That night he goes to Les Aviateurs, where we first glimpse him in a mirror as he watches the barmaid. The combination of her looks and the physical set combine to achieve the impression that she has just stepped out of Edouard Manet's last painting, "A Bar at the Folies-Bergère" (I882); she then places a flower in her cleavage, thus emphasizing the resemblance even more, to the accompaniment of Blondie's seventies hit "Heart of Glass." The Dreamer 
watches the women dance (women far outnumber men at Les Aviateurs, as is the case everywhere in this film) to "That Woman" (2007) a song by the Madrid-based group Migala, bringing the music into the twenty-first century. Later that same night the camera pans the dark hotel room, lit only by light from the street and traffic, just as in the film's opening scene, but now there are two naked bodies in bed: the Dreamer and a woman. Guerín's Dreamer is not the "sexless" being of Dostoevskii's creation. The next day finds the Dreamer once again visiting sites from earlier in the film, continuing his search for Sylvia. The film is as much about the city as it is about Sylvia, his muse, and in this respect Guerín is certainly following in the footsteps of his predecessor Bresson.

The Dreamer's quest for Sylvia belongs to the time-honored tradition of the artist and his muse. ${ }^{48}$ The graffiti "LAURE JE T'AIME" that the Dreamer encounters so frequently in central Strasbourg alludes to Petrarch and his Sonnets to Laura, while the shots of Johann Wolfgang von Goethe's statue-Goethe spent time in Strasbourg as a young writer-lead one to the novel The Sorrows of Young Werther ( I 774), a pre-Romantic epistolary novel in which the eponymous hero visits a village and falls in love with Lotte, who is already engaged to be married, much as Nastenka is betrothed. Like Werther, the Dreamer in Guerín's film is a stranger-a panhandler at the Conservatory café even calls Guerín's Dreamer a "dumb hick," thus branding him as an outsider. In fact, like Dostoevskii's Dreamer, the male protagonists in these four films are all strangers to the city where they live. ${ }^{49}$ Guerín reinterprets and transposes the allusions to German Romanticism in Dostoevskii's text, which

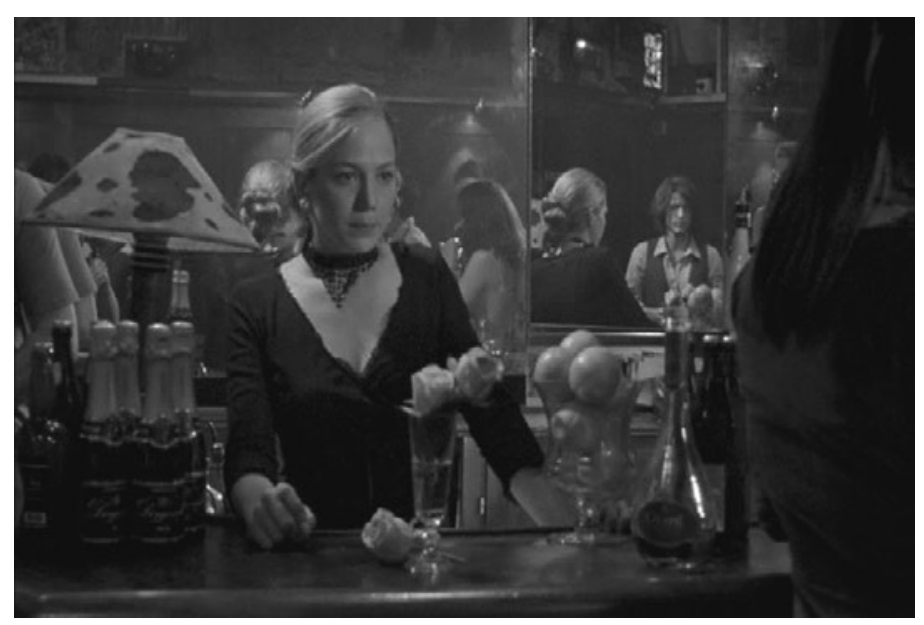

Figure 2.3 Reflections in windows and mirrors comment on the Dreamer's vision throughout En la ciudad de Sylvia. Here the barmaid at Les Aviateurs and the Dreamer's reflection in the mirror behind her. 
are used to justify and explain the Dreamer's fantasy dream life, along with references to other early nineteenth-century writers and artists, such as Scott, Pushkin, and Rossini. By replacing them with literary allusions that suit his interpretation and incorporation of the theme of artist and muse he actualizes a latent potential in Dostoevskii's text. In the other films under discussion, the Dreamer is left alone as he watches his "beloved" walk away with the Lodger. The Dreamer/Artist in En la ciudad de Sylvia, on the other hand, continues his quest for Sylvia, his muse. He cannot abandon his quest for inspiration if he is to remain an artist.

The combination of the familiar and the new, what Linda Hutcheon refers to as the pleasure that one derives from "repetition and surprise" is what drives transpositions. ${ }^{50}$ It is surely this amalgam of fidelity and change that Visconti, Bresson, Bhansali, and Guerín each in his own way exploits in their transpositions of Dostoevskii's story. In so doing, they contribute not only to the story's "continuing life," but also to the lives of its transpositions. One need only look to James Gray's Two Lovers, released in 2008, the year after the films by Bhansali and Guerín, and interviews in which Gray credits Dostoevskii's "White Nights" as one of the inspirations for the film, along with "Vertigo and lots of Fellini from the I950s." ${ }^{11}$ While the references to $V e r t i g o$ and Fellini might startle on first glance, it is only natural that cinematic texts comprise the vocabulary of cinematic transpositions. The blogger on Not Just Movies more fully acknowledges Gray's indebtedness to Visconti, when he writes that Two Lovers is "based on a Visconti film in turn based on Dostoevsky's short story." 52 In other words, "White Nights" is no longer merely a verbal text, but rather is one component of the "White Nights Text," which includes visual texts as well, the films under discussion here, but also, for example, Mstislav Dobuzhinskii's modernist black-and-white illustrations first published in I922, which have firmly become a visual component to the Dostoevskii text in the Russian context.

Visconti and Bresson have forever altered the way we view "White Nights." The migration from a purely literary text into new visual territory, crossing the border from short story to the cinema with Visconti and Bresson as guides, has been accomplished. The twenty-first-century audience can no longer see "White Nights" without their films. Their works, together with those by Bhansali, Guerín, and Gray, among others, have created a new language for the "White Nights Text" that incorporates elements of Italian neo-realism, the French New Wave, Bollywood, and the contemporary flâneur. 


\section{NOTES}

I. <http://www.totallyfilmi.com/20 I I/o3/ahista-ahista-dir-shivam-nair-2006.html> (last accessed January I I, 20I4). The blog is subtitled "West meets East-the musings of a Canadian fan of Hindi cinema."

2. The twelve films, in chronological order, are: I934: Peterburgskaia noch' (Petersburg Night), dir. G. Roshal' and Vera Stroeva, USSR; i957: Le notti bianche (White Nights), dir. L. Visconti, Italy; I959: Belye nochi (White Nights), dir. I. Pyr'ev, USSR; I96o: Chhalia, dir. Manmohan Desai, India; I97I: Quatre nuits d'un rêveur (Four Nights of a Dreamer), dir. Robert Bresson, France; 1991: Belye nochi (White Nights), dir. Leonid Kvinikhidze, Russia; 2002: White Nights, dir. Farzad Motamen, Iran; 2006: Shades of Day, dir. Vitaly Sumin, USA; 2006: Ahista Ahista (Slowly Slowly), dir. Shivam Nair, India; 2007: Saamariya (My Love), dir. Sanjay Leela Bhansali, India; 2007: En la ciudad de Sylvia (In the City of Sylvia), dir. José Luis Guerín, Spain; 2009: Two Lovers, dir. James Gray, USA. This group does not take into consideration the animated version by Sulaiman Khan ("starring Johnny Depp as Jacques") and Belye nochi: Film-Ballet (as opposed to a film of a ballet) with Bolshoi Ballet dancers Nina Timofeeva and Mikhail Lavrovskii (I972). Both of these works are available on YouTube at <http://www.youtube.com/watch? $\mathrm{v}=\mathrm{NQnFIYutlXA}>$ and <http://www.youtube.com/watch? $\mathrm{v}=$ SETSNsbVwAk\&list=PL $\mathrm{A}_{5} 8_{2} \mathrm{~B}_{4} \mathrm{E}_{0} 8 \mathrm{~B}_{32} \mathrm{C}_{95}>$ (last accessed January 29, 20 I4). I am grateful to Alexandra Smith for bringing the "film-ballet" to my attention. Even though these two works lay outside of my inquiry in this chapter, it is worth noting that the credit "starring Johnny Depp as Jacques” references Robert Bresson's Quatre nuits d'un rêveur, where Dostoevskii's nameless Dreamer is christened Jacques. For now, I want to draw attention to the fact that the animation short is an adaptation of Dostoevskii by way of Bresson.

3. The very small amount of dialogue in En la ciudad de Sylvia, by the Spanish director José Luis Guerín, is in French, as the movie is set in Strasbourg.

4. Only Pyr'ev's Belye nochi is set in I 840 St. Petersburg. Petersburg Night opens with a scene of snow-swept countryside, while Kvinikhidze's I99 I film is set in contemporary Leningrad.

5. Venuti, “Adaptation, Translation, Critique," 30.

6. Burry, Multi-Mediated Dostoevsky, 34.

7. Benjamin, "The Translator's Task," 76 . Readers may be more familiar with the earlier translation of this term as "afterlife."

8. The adjective belongs to Joseph Frank, Dostoevsky: The Seeds of Revolt, 343 .

9. Dostoevsky, "White Nights," 8.

Io. Ibid., I7.

I I. Ibid., 57 .

I2. Doniol-Valcroze and Domarchi, "Visconti," I46.

I3. Nowell-Smith, among others, discusses the "central spatial metaphor" and its thematic implications, 98 .

I4. Visconti, "White Nights," 56.

I 5. Ibid., 3 .

I6. Ibid., I2.

I7. Visconti staged Crime and Punishment in I946; his productions of Verdi's La Traviata and Bellini's La Sonnambula were both staged to tremendous acclaim at La Scala in I 955 with Maria Callas in the leading roles.

I8. Doniol-Valcroze and Domarchi, "Visconti," I45.

I9. See Hennessey, “Theatrical Space," I68-74. 
20. Visconti, "White Nights," I 7.

21. Ibid., 65 .

22. Ibid., 89-90.

23. Clarens, “Four Nights of a Dreamer," 4.

24. See Chapter 3 by Olga Peters Hasty and Chapter 4 by S. Ceilidh Orr on Bresson and Pickpocket in this volume; see also Frazier, "Sun-bathed Steppes in French Prisons."

25. Clarens, "Four Nights of a Dreamer," 4.

26. See Sitney, "The Rhetoric of Robert Bresson," esp. I28-9.

27. Bresson, Notes on the Cinematographer, I4, 66.

28. See, for example, Jonathan Rosenbaum's account of working on Bresson's Four Nights of a Dreamer: "Two Nights of an Extra." See also Hanlon, Fragments, I I 5-24, for a discussion of Bresson's use of models and the effects he achieves.

29. Bresson, Notes on the Cinematographer, I $5,18$.

30. See Stadler, "Bresson, Dostoevsky, Bakhtin": "Dostoevsky's dreamer ... meets a girl of seventeen, desperate and apparently ready to commit suicide," I7. The motif, displaced from girl to Dreamer, opens James Gray's Two Lovers, where the male protagonist throws himself into the freezing waters off Brighton Beach.

3I. Bresson's strategy of the tape recorder as a means to convey Jacques's dreams looks forward to Gary Walkow's 1995 film Notes from Underground, where the Underground Man tells his story cum confession to a video camera. As Robert Stam writes, "The fact that we as an audience become Underground Man's interlocutors-by looking at the camera he is also looking at us - cinematizes the implied verbal interlocution of the written text. The camera (and therefore the spectator) takes the place of Underground Man's imaginary interlocutors." Stam, Literature Through Film, 204.

32. Dostoevskii, "White Nights," 24.

33. Godard and Delahaye, "The Question," 46o.

34. Bresson, Notes on the Cinematographer, 93.

35. Keith Reader confirmed my surmise regarding the connection to Baisers Volés. Reader, Robert Bresson, 107.

36. Clarens, "“Four Nights of a Dreamer," 3.

37. In general, there is an emphasis in Quatre nuits d'un rêveur similar to certain Dostoevskii works, Crime and Punishment being a good example, on liminal spaces. Many interior scenes in the film are introduced by the opening and shutting of doors and the accompanying rattle of the handle, buzz of the doorbell, and slamming of the door. This is particularly pronounced in this lovemaking scene, and earlier when Jacques goes to deliver Marthe's letter to the Lodger's friends, and visits them later to see if there has been a response. He enters the building, closing the door behind him, he ascends the stairs-and the camera remains stationary so that we see where he has been as opposed to where he has gone - and he then remains outside the apartment on the threshold as he speaks to the Lodger's friends.

38. See Hanlon, Fragments, I34, and Clarens, "Four Nights of a Dreamer," 3, for an analysis of the choreography of the nude scene.

39. More than one reviewer has noted the influence of Baz Luhrmann's Moulin Rouge. See, for example, Mishra, "News from the Crypt," 325; and Ramachandran, "Saawariya," 83.

40. Ramachandran, "Saawariya," 83. See Mishra, "Spectres of Sentimentality," for an extensive analysis of the Kapoor intertext in Saamariya.

4I. Mishra, "Spectres of Sentimentality," 454.

42. See, for example, Fanger, Dostoevsky and Romantic Realism, i68.

43. According to Stone, the protagonist is named the Dreamer in the credits; this is not the 
case in my Cinema Guild DVD, but it does nicely tie the character to the other Dreamers in this chapter. See Stone, "En la ciudad de Sylvia," I 76.

44. Baudelaire, The Painter of Modern Life, 9.

45. Bordwell and Thompson, "Three Nights of a Dreamer."

46. Stone, "En la ciudad de Sylvia," I $77 \mathrm{ff}$.

47. Gupta, "Visual Pleasures for the Female Gaze," I9.

48. This is clearly spelled out in Guerín's Unas fotos ... en la ciudad de Sylvia (Some Photos ... In the City of Sylvia), which some have called a preparatory work for the feature film, but which is probably better described as a companion film.

49. This is not made explicit in Bresson, though there is certainly no indication that Jacques has family in Paris. It is more likely that he moved to Paris from the provinces, like Bresson, to study art.

50. Hutcheon with O'Flynn, A Theory of Adaptation, 4.

5. "Relying on His Own Tastes."

52. Not Just Movies, available at <http://armchairc.blogspot.com/2009/I2/two-lovers.html> (last accessed April I, 20I4). 


\title{
On Not Showing Dostoevskii's Work: Robert Bresson's Pickpocket
}

\author{
Olga Peters Hasty
}

Hide the ideas, but so that people find them. The most important will be the most hidden. ${ }^{1}$

$\mathrm{H}$ ow does French filmmaker Robert Bresson, who minimizes affect and expressivity on the screen and rejects psychological realism in filmmaking, connect with the Russian novelist Fedor Dostoevskii, a master of psychology whose works burst with emotional turmoil and scandal? The question is an important one because underlying these obvious stylistic differences are ideational ties with Dostoevskii that are vital to Bresson's films. Allen Thiher observes that "[i]n nearly all his works, [...] Bresson's narrative turns in one way or another on isolation and humiliation, on estrangement and the impossibility of a desired community." It is precisely these quintessentially Dostoevskian concerns, and not the intense, complex narratives in which they are embedded, that draw the French filmmaker to engage with the Russian novelist in his films. Significantly, Bresson is determined not to reproduce the stories that Dostoevskii tells in his own quest for understanding. Nor does the filmmaker wish to create innovative cultural recontextualizations of these stories by moving them out of nineteenth-century Russia to situate them in his own time. Rather, he engages with Dostoevskii in an ideational sphere, positioning the existential questions that famously preoccupy the Russian novelist at the core of the newly created worlds of his films.

The way in which Bresson connects with Dostoevskii's thinking emerges directly from his emphatically articulated desire to distinguish his own art form from literature to which, as he felt, film had subjugated itself. Bresson's resolve to revitalize cinema works hand in hand with his concentration on Dostoevskii's thinking, which he privileges over the action habitually featured in film. As he connects with Dostoevskii, Bresson is intent on doing so in uniquely cinematic terms and at a level considerably deeper than that of 
conventional film adaptations. The cultural borders between Dostoevskii's nineteenth-century Russia and Bresson's mid-twentieth-century France fall away before the two artists' shared concerns about the human condition. How Bresson negotiates the boundaries between their media, respecting their unique, distinguishing features as he activates the cohesion of his own thinking with Dostoevskii's, is the subject of this chapter.

To prepare the subsequent examination of how Bresson relates to Dostoevskii, I will begin by providing brief overviews (I) of how the filmmaker relates to literature in the context of the cinematography he develops and (2) of how Dostoevskii's place in Bresson's oeuvre has been described. I will then focus my attention on Pickpocket, a black-and-white film that Bresson shot in seven weeks in the summer of I959, and whose release Louis Malle called "one of the four or five great dates in the history of cinema." ${ }^{3}$ My overarching purpose is to study how ideas that are conveyed by the psychological realism of Dostoevskii's action- and character-packed works are carried over into Bresson's ascetic, uniquely cinematic vision. How Bresson accomplishes the intermedial crossing from literature to cinematography, as we will see, shapes the lived experience of his film. Remarkably, it also takes us deeper into Dostoevskii's thinking. The complexity of Bresson's project dictates a multi-faceted approach that attends closely to how his film is made and how this making connects him with the Russian novelist. The brief outline below of how this approach will unfold over the course of this chapter will help us navigate the multifarious but closely interrelated issues that claim our attention.

To begin with, the importance Bresson assigns to suppressing plot and psychological realism and to achieving interiority on the screen demands that we give serious attention to how he uses the form and style of his film to advance these challenging goals. This will prepare us to consider Pickpocket's points of contact with Dostoevskii's Crime and Punishment specifically in light of radical departures from it. As we will see, these departures are merely apparent and ultimately bring his film closer to the issues Dostoevskii addresses in his novel. At the same time, they work to draw yet another of the author's novels into the orbit of the film-The Gambler, whose important role in Pickpocket has thus far remained without notice. Finally, Pickpocket prompts us to reflect on the hands that it so prominently features and that are instrumental in accomplishing an impressive range of border crossings, drawing the viewer beyond the surface of the screen to a deeper domain where Bresson connects with Dostoevskii.

类米

As Jonathan Griffin notes, the "cinematography" in terms of which Bresson defines his work "has the special meaning of creative film making which thoroughly exploits the nature of film as such." ${ }^{4}$ This guiding principle, which manifests itself in all of Bresson's work, informs how he relates to literature in 
general and to Dostoevskii in particular. Bresson works consciously to recuperate the particularity of his medium, pulling away from literary and theatrical conventions to which, as he felt, this particularity had succumbed. In an interview with Paul Schrader, he explains:

I want to be as far from literature as possible, as far from every existing art. [...] Until now, I have found only two writers with whom I could agree: Georges Bernanos, a little, not too much, and, of course, Dostoevsky. I would like the source of my films to be in me, apart from literature. Even if I make a film from Dostoevsky, I try always to take out all the literary parts. I try to go directly to the sentiments of the author and only what can pass through me. I don't want to make a film showing the work of Dostoevsky. ${ }^{5}$

This far-reaching statement draws attention both to the level at which Bresson engages with the literary text and to the terms of this engagement. Bresson's cinematographic project takes him beyond that well-trodden space where film and literature most effortlessly overlap: "I try more and more in my films to suppress what people call plot. Plot is a novelist's trick," he maintains. ${ }^{6}$ Predicated on his attention to the uniqueness of his own medium, Bresson's suppression of plot reflects also his understanding that in great fiction plot is not an end in itself but a vehicle that conveys its author's ideational and philosophical concerns. Works of literature, too, have much to lose from being recast as visual plot summaries that amount to little more than filmic equivalents of CliffsNotes. When working with Dostoevskii, Bresson affiliates his films with questions that impel Dostoevskii's writings - moral, ethical, social, and philosophical issues that the author grappled with over the course of his entire literary career.

Attendant on the question of how films might best connect with literary texts as rich as Dostoevskii's is also the question of whether the filmmaker offers viewers an experience that is commensurate with what the novelist affords his readers. To translate demanding reading into passive spectatorship is to deny the viewer entry into the complex issues that Dostoevskii's densely interwoven, action-packed novels interrogate. Bresson's focus on deeper levels of signification compels his viewer to attend more closely both to his films and to the literary works with which they engage. As he pushes against the degeneration of his medium into a storytelling venue, Bresson works also against the passivity of desensitized viewers for whom the wonder of cinema had been eroded by habituation and by films that did not go beyond repeating stories in moving pictures. "CINEMA, radio, television, magazines are a school of inattention: people look without seeing, listen in without hearing," 7 Bresson protests in an entry in Notes on Cinematography. The recuperation of 
acute, mindful seeing and hearing that is crucial to the reception and continued development of his cinematography demands the successful subversion of mindless habit and convention. For Bresson this means refusing to replicate not only novels but any existing reality-whether of the actual world or an artifact in it- to insist instead on the created world of the film itself.

Bresson's idiosyncratic views on how literature might find its way into film make it difficult to define or even to discern connections between his films and literary texts, something that has led him to be widely acknowledged as a director who has "revolutionized our ideas [...] of literary adaptation in the cinema." 8 The inapplicability of the term "adaptation" to describe Bresson's working method has led scholars to speak of his recognizably Dostoevskian films as "refractions," "paraphrases," "allusions," or "travesties" of the Russian novelist's works. The overall significance of Dostoevskii in Bresson's oeuvre is variously described or even discounted altogether. Indeed, even the question of which films to consider Dostoevskian remains in dispute. Thus, for example, Mireille Latil le Dantec sees the Russian novelist's presence in virtually every one of the twelve films Bresson made over the course of his thirty-five-year career. ${ }^{9}$ Sergei Iutkevich, on the other hand, acknowledges this presence only in the two films that Bresson links explicitly with the Russian novelist's works: Une femme douce (1969), which, as the title suggests, is based on "The Meek One" and the I97 I film Quatre nuits d'un rêveur, which Iutkevich labels a "free improvisation" on White Nights. ${ }^{10}$ Although its less apparent ties with Dostoevskii have, on occasion, been overlooked, Pickpocket (I959), as scholars recognize, must necessarily join the two films that Iutkevich singles out as having demonstrable connections to Dostoevskii-specifically to his novel Crime and Punishment. ${ }^{11}$

Dostoevskii presents the suspenseful plot and sensational axe murders of Crime and Punishment in a world dense with pathos, scandal, and psychologically unstable, emotionally demonstrative characters. Its main storyline features an impoverished student whose axe murder of an old, disagreeable pawnbroker is ostensibly motivated by the desire to use the money he plans to steal from her for the swift betterment of his own life and that of his mother and sister. Yet Raskolnikov commits murder also to test himself. The theoretical underpinning of the crime is the exceptional man theory that he describes in an article advancing his claim that some individuals are above moral and ethical constraints and are entitled by their very exceptionality to transgress them freely at will. Raskolnikov's meticulously laid murder plans are quickly derailed when the pawnbroker's sister suddenly appears at the scene of the crime and he kills her too. Sensational as they are, it is not these two axe murders themselves but what leads up to them and especially Raskolnikov's condition in their aftermath that are of primary concern for Dostoevskii. This central narrative is imbedded in densely populated interlacing storylines that 
permit their author to offer a variety of perspectives from which to assess the situation in which Raskolnikov finds himself and the attempts he makes to grapple with it. A police detective is hot on the criminal's trail, while a self-sacrificing prostitute with a story of her own offers him unconditional Christian love, urging him to surrender to the authorities and confess to his crimes. Raskolnikov finds himself torn between the desire to evade arrest and the desire to be apprehended. Transposed into film, the suspenseful, hyperactive narrative makes for gripping viewing but, by the same token, threatens to overwhelm the ideational dimension that commands Bresson's attention.

Bresson's sparsely populated, pared-down hypertext appears far removed from the dense complexity of Crime and Punishment, especially given the gulf that separates the crime announced in the film's title and the axe murders perpetrated by Dostoevskii's Raskolnikov. The film is set in Paris in the I95os, and its lean seventy-five minutes do not evoke the voluminous hypotext that runs to over four hundred pages. In place of the novel's multiple, densely interwoven storylines the film offers only a series of disconnected scenes that show the lead character developing his pickpocketing skills, plying his transgressive art, and, until the very end, evading capture. Its sparse cast of characters - seven in all and only three with given names - can hardly bear comparison with the bounteous dramatis personae (all with multiple names) of Crime and Punishment. Yet though Pickpocket does not immediately bring Dostoevskii to mind, those familiar with Crime and Punishment can recognize three clear points of intersection between that novel and Bresson's hypertext. These are: (I) the notion of the exceptional man that is espoused by the protagonist and that provides the theoretical underpinning and justification for his transgressive behavior, (2) the catand-mouse game between him and the police inspector who is on his trail, and (3) an ending whose carefully crafted openness indicates possibility for the protagonist's regeneration thanks to the unconditional love extended to him by a selfless woman. ${ }^{12}$ Upon recognizing these similarities with Crime and Punishment, the viewer can discern Raskolnikov in the poverty-stricken garret dweller Michel, Razumikhin in his sensible friend Jacques, and a hybrid of Raskolnikov's sister Dunia and the prostitute Sonia in Jeanne, the woman who offers Michel salvific love.

Yet because these underlying similarities appear in a film so unlike Dostoevskii's novel, they are attenuated and thus easy to overlook. This helps explain why assessments of the role that Crime and Punishment plays (or does not play) in Pickpocket differ and why the film is not always recognized as one in which Dostoevskii figures at all. ${ }^{13}$ Bresson himself contributed to this lack of clarity with his inconsistent claims that he had never read the novel (an assertion belied by the "well-thumbed copy" of the book in his library noted by James Quandt ${ }^{14}$ ), or that any ties between his film and Crime and Punishment 
were purely coincidental or wrought unconsciously. The filmmaker's reticence on this score is not difficult to understand. Beyond his efforts to realize the cinematographic precepts he developed to distinguish film from literature was the danger that his contemplative film could be swallowed up by the tumultuous hypotext it referenced. Well known in and of itself, Crime and Punishment was perhaps even more widely familiar through its film versions, some twelve of which already existed at the time of Pickpocket's release in I959. (Georges Lampin's Crime et châtiment had come out in France only three years earlier.) Bresson treads lightly in indicating Pickpocket's ties to Crime and Punishment lest it distract his viewers from the deeper reaches of both the novel and his film. It is plausible to suggest, too, that he did not want exclusive focus on Pickpocket's ties to Crime and Punishment to obscure the film's important links to Dostoevskii's less well-known novel The Gambler to which we will turn after considering Crime and Punishment.

Determined to push away from what he calls the "contagion of literature"15 and to create a uniquely filmic experience, Bresson evades the psychological realism of which Dostoevskii was a master and for which film is eminently well suited. Instead he sets his sights on attaining an interiority that lies beyond the camera's reach and to which the very surface of the screen is an impediment. To avoid making "a film shoming the work of Dostoevsky," and yet also to connect with that writer's thinking, Bresson works purposefully against the grain of his visual medium in an effort to convey the inner world of his protagonist. In order to draw the viewer beyond the screen's surface, he minimizes what appears on it, prompting Russian filmmaker Andrei Tarkovskii to observe in admiration that "nobody has ever reached such a degree of asceticism." ${ }^{16}$ Resorting to parametric narration which privileges style over plot, Bresson uses style also to impart a psychological dimension to his character. ${ }^{17}$ In other words, Bresson relies on style to accomplish what Dostoevskii does by means of plot and character development. What has remained unnoticed thus far is that the distinctive style that carries this weighty dual function of standing in for plot and bringing psychology into Pickpocket is motivated by the literary form on which Bresson chooses to structure his film. Even as he resists novelistic plot, Bresson draws on another literary genre to create the framework for his film. This is the genre of the journal that he used also in his earlier film Fournal d'un curé de campagne (I95I) and that is ideally suited for his project to pull away from plot and to achieve interiority on the screen.

Pickpocket begins with a shot of Michel's hand writing in a spiral notebook. This entry, whose text we will consider shortly, is the point of departure for the action seen in the film. A dissolve leads directly to Longchamp racetracksite of Michel's first attempt at pickpocketing that is ostensibly being recorded in that same notebook. There are only three other shots of Michel's hand making entries in it, but, as Tony Pipolo trenchantly observes, the journal 
is continuously evoked by the voice-overs that persist over the course of the entire film. ${ }^{18}$ It is given to understand that this is a diary in progress and that the film is not simply punctuated by flashbacks that interpolate past events into its unfolding present, but is comprised entirely of the visualization of journal entries as Michel writes them. Though viewers may lose sight of the fact that the film presents not the events themselves but Michel's recollections and the records he makes of them, the journal form on which the film is built is essential to its created world. Pipolo writes that the journal "reiterates Michel's loneliness and the anxiety that prevents him from doing anything about it." 19 That Michel is lonely and anxious is certainly true, but it is also the case that in the act of keeping the journal he is, in fact, doing something very important about it, for keeping the journal ultimately brings him to the insight at which he arrives at the end of the film. Crucial to the protagonist, the journal form is crucial also to Bresson's making of the film, for much of what goes on in itincluding the connections it forges with Dostoevskii-hinges specifically on the distinctive features of this genre. By considering these characteristics, we can better appreciate the complex functions they assume in Pickpocket.

Seen as private disclosures of the self, the journal is characterized by the narrative and temporal discontinuities of its individual entries and by the dual temporality arising from the non-coincidence of the time of the action and the time in which it is recollected. Journal entries record events not as they transpire, but only after they have already taken place. Whatever the elapse of time between the event and when it is set down (and this elapse is fluid and need not be consistent), the journal is predicated on a recollecting writer confronting a recollected self and on the reconnection of these two selves that is effected on its pages. Although, as the conceit of the genre would have it, this is a private venture, it remains the case that the journal entries bring a reader into being, even if it is only the writer himself who peruses the text. As the author of the journal entry becomes the reader of his own disclosures, he spans the first person of the entry and the third-person vantage point on the recollected "he" whom he observes in the written text, thus gaining an outside perspective on himself. In his quest for selfhood, Michel, like Dostoevskii's obsessively self-analytical Raskolnikov (whose very name derives from raskol, the Russian word for "split" or "schism"), must find a way to reintegrate his divided selves and to reconnect with the surrounding world from which his transgressive actions sever him. The entries in the journal provide a means to accomplish this. Enabling the film's inward turn and adding depth to the theme of alienation that Pickpocket shares with Crime and Punishment, the journal ultimately carries a restorative function that the ending of the hypertext makes manifest.

The significance that the journal carries for Michel and the ideational content with which Bresson invests it are augmented by the way this particular genre informs Pickpocket's distinctive style. Like the defining characteristics 
of the journal form, the stylistic peculiarities of the film insist on recollection in process and work to distinguish the action on the screen from a first-hand record of the unfolding events themselves. Michel's individual journal entries translate into the discrete scenes of the hypertext and account for its discontinuity, its ellipses, and the disproportionate attention it accords to some events and details, while leaving others virtually without notice. Not only novelistic plot, but psychology, too, is implicit in what the character reveals of himself in entries that isolate and privilege particular incidents from his past. Michel's perspective — what commands his attention and how he sees it—offers insights into his personality, his emotional states, and what preoccupies him. Bresson, who demands complete impassivity from his cast, has these self-revelatory recollections rather than the actor's artifice create his character. ${ }^{20}$ Steeped in Michel's subjectivity, his journal entries are apertures into his inner world that provide not plot, but vestiges of a story that the viewer must piece together. The content of the journal, which is also the content of the film, is determined not by the contingencies of plot development, but by the meaningfulness of the events for the character who writes it.

Michel's self-revelation dictates the film's distinctive style whose purpose is best appreciated in light of the journal form. In the film's four shots of Michel's hand making entries in his notebook, the text appears legibly on the screen and is also heard being read aloud in narrative voice-off before dissolving into action that is thus doubly introduced. Given the exceptional economy that is a defining feature of Bresson's work, this redundancy, which has been duly noted but not explained, must surely signify and thus demands attention. Inasmuch as the writing hand and the speaking voice belong to Michel, it stands to reason that the visual images that repeat (at times imperfectly) what he records and reads aloud are also his, that these are his recollections as they flash on his inward eye as he remembers them and sets them down in his journal. This may seem like a small point, but its ramifications are hugely significant, for it is here that the uniquely filmic sets in as the camera eye merges with Michel's mind's eye to bring his inner vision to the screen. Rather than show Michel engaging with his surrounding world, the film shows how Michel himself envisions these engagements, thus allowing Bresson to accomplish a seemingly impossible interiority on the surface of the screen. If in literature the journal form is predicated on conjoining the first- and third-person perspectives of the recollecting and the recollected selves, in film the journal form resolves the awkward incongruity of conveying first-person narration through the third-person perspective of the camera. ${ }^{21}$

The mind's-eye-view that Bresson's well-conceived redundancy urges his viewer to recognize helps to explain the stylistic peculiarities of the film with persuasive consistency. Just as Michel's journal entries account for the discrete scenes that comprise the film, so too does his subjective take on his own past 
account for the content, the idiosyncratic perspectives, and what he attends to as he tries to make sense of his life and where it has taken him. The centrality of money, the impassivity of his victims who command no sympathy, the starkness of the settings, the dearth of emotional content all point to Michel's preoccupation with his transgressive behavior-the need for money that prompted it, the theory that authorized it, and the alienation that both precipitated and exacerbated it. The meticulous attention to detail that combines strangely with lapses of attention and with the perspectival and temporal distortions of the film is indicative of Michel's mental rearrangements of his past.

Louis Malle astutely observes that in Pickpocket "the characters are compelled by the camera, pulled, pushed, held back by it." 22 This is so because the dictatorial "camera" is Michel's mind's eye in action, documenting the control that his memory exerts on events from his past. Recollected events are not subject to the laws of the actual world in which they transpired, and memory is lax in distinguishing fact from invention. The creative imagination and the psychology of the individual play a notable part in reconstituting the past. Beyond innate cognitive flaws that make it impossible for human memory to retain and replicate what has transpired with exactitude, are various distortions to which memory falls prey. Wishful thinking, repression, denial, a need to justify or redefine the course of events or to impart meaning to them from the vantage point of what subsequently transpires - these are only a few of the forces that take part in setting the mental stage and directing the mind's eye of the reminiscing individual. The peculiar style of Bresson's film captures these distortions, and in so doing, conveys information about Michel's psychological and emotional states both at the time of the events he records and at the time in which he remembers them.

Unsurprisingly, Michel's thefts figure with especial prominence in his perforce selective recollections. While these are replete with great specificity of detail, the point is that Michel's mental replays of his pickpocketing provide the viewer with a realistic presentation not of the events themselves, but of how Michel remembers them. The ruminations that appear on the screen reflect the extent to which Michel is concentrated on his crime. His victims are dehumanized, and it is only his extractions of money from their persons and not the individuals themselves that command Michel's attention. Not only do the rehearsals for and repeated enactments of pickpocketing receive the greatest share of his attention, but they are presented with far greater vivacity than anything else that he recollects.

Bresson sees to this with the care he lavishes on the thefts. Engaging Henri Kassagi, a pickpocket by trade, to serve as his crime consultant and to play the role of the master thief who instructs Michel in his art, ${ }^{23}$ he makes sure to get every detail right. The thefts are showcased in close-ups, while stopaction editing accords them extra time. This prompts $\mathrm{T}$. Jefferson Kline to 
comment on "stop-action editing on certain hand movements that, were they conducted so slowly, would surely have been detected by the victim." Kline goes on to observe that " $t]$ he impression given by this 'co-operative' camera work and editing is that the image maker enjoys a very Gidean complicity with the thieves in their most intimate activities." 24 The precision of specific detail in combination with an uneven distribution of attention and with temporal distortions are hallmarks of memory and of the journal genre that records it. Though there is no question that Bresson looks on, the "image maker" in question is most immediately the recollecting Michel who is shown in these scenes to be the accomplice of his recollected self.

The degree of the recollected Michel's obsession with pickpocketing and the extent to which it had blotted out all human relations and concerns emerge clearly as he reconstructs his past. At the same time, in the process of recording these memories, the recollecting Michel reveals the extent to which he is still captivated by the crime he describes in his journal. The seductive appeal that pickpocketing continues to hold for him is exquisitely delivered in the renowned Gare de Lyon sequence in which the camera comes suddenly to life to track fantastic feats of legerdemain in which crime aspires to art. Thoughts of monetary gain are superseded by the flowing choreography of the sequence, which showcases Michel working in concert with two thieves as they move swiftly through the station and onto a train, relieving travelers of cash and wristwatches with remarkable elegance and creative flourishes that include replacing an emptied wallet into the breast pocket of its unsuspecting owner. There is every reason to question the verity of this highly aestheticized vision of pickpocketing, and we are reminded that what is at stake in the film is not how it actually was (or even whether it was at all), but rather how Michel envisions his thieving in the course of his retrospective ruminations. The "hyperreal quality" that Pipolo speaks of in connection with this sequence and his description of it as "beyond any character's point of view" 25 can be explained as sure signs of memory at work - hallmarks of the mind's eye in action.

Writing about the camera work and editing of thefts shown in the film, Sandra L. Beck notes that

[a]t the moment of transference, i.e., when the money of the object ceases being owned by the "victim," the shot of this precarious exchange is held for a few "long" seconds. The distention of this moment denies verisimilitude to the representation of the theft and serves to call it to our attention on a symbolic level. ${ }^{26}$

Michel's pickpocketing is indeed possessed of a capacity to indicate something beyond itself, but, more immediately, the departure from verisimilitude in its iterations draws attention to the subjectivity attendant on Michel's 
reconstruction of the thefts. The camera work reminds us that it is this subjectivity that is at stake. Detailed though they are, Michel's recollections cannot be expected to possess either the scope or the documentary accuracy of which the camera eye is usually possessed. Nor is it reasonable to expect any consistency in the degree to which Michel departs from objective reality in the various entries of the journal he keeps. Human memory, as we have noted, is fallible and subject moreover to alteration by subsequent experience as well as various needs and desires. It is also an individuating and creative force that aligns itself closely with the creative imagination. Michel's recollections are not confined to the temporal and spatial constraints of the actual world any more than film is.

The journal form and the mind's eye view that it enables provide Bresson with a productive way to dissociate his camera from the here and now in which it operates. In the essay quoted above, Malle commends the success with which Bresson avoided the mere replication of the surrounding world: "He starts by strangling realism by the throat, that touchstone of cinema which, quite often, is still only an instrument of reproduction." ${ }^{27}$ Marveling at what Bresson is able to achieve, Malle goes on to say:

How much talent must one not have, let it be said in passing, to "reorganize" reality to such a degree in a film, two-thirds of which takes place outside the studio, in the streets, cafés, subway-those places where filmmakers are usually condemned to documentarism. ${ }^{28}$

It is on the strength of the journal he has Michel keep that Bresson successfully evades such documentarism. Presenting with exactitude events not as they happened, but as Michel subsequently remembers and envisions them, Bresson replaces realism with a reality of a different order. The viewer of the film does not watch Michel. The viewer sees with him.

At the end of Pickpocket Michel is seen behind bars, and viewers understand that he has been keeping the journal while in prison, presumably working through the events that landed him there. This naturally explains Michel's focus on the crime. At the same time, Bresson uses it to foreground one of the film's most prominent points of contact with Crime and Punishment, namely the exceptional man theory that their respective characters author. Reference to this theory features prominently both in Pickpocket and in Crime and Punishment. Michel echoes Dostoevskii's Raskolnikov in claiming that there are exceptional men who need not remain within commonly accepted moral and legal bounds, but can overstep them in the name of a greater cause. The very ability to defy conventional social and ethical norms with impunity authorizes the transgression. Though the crimes that become their testing ground could scarcely be more different, Michel's extended series of petty thefts and the two murders Raskolnikov commits in the process of robbing the old pawnbroker 
stem from a common cause: their impoverished perpetrators' pride-fueled need for self-assertion - both in their own eyes and in the eyes of society at large. Beyond authorizing their transgressive behavior, the theory they develop suggests a means to ennoble the base thefts that the conjunction of pride and impoverishment drives them to commit. The swift monetary gain they foresee is framed as an opportunity to set things right, opening a new path into the future, while the risk that they are prepared to incur valorizes the enterprise and its authors. It is not difficult to see that the theory stems from a very human weakness - the susceptibility to construing selfhood in terms of exceptionality that pulls away from rather than toward humanity at large. The theory, as Michel and Raskolnikov conceive it, is predicated on a self-sufficiency that casts off ties with others and that sets them above the rest of humanity. Crime and Punishment and Pickpocket demonstrate repeatedly that the "freedoms" that were to have derived from this notion are in fact sources of alienation and of metaphysical constriction within a radically diminished self. Dostoevskii and Bresson firmly believe that the theory is misguided, but their characters must learn this on their own over the course of the novel and the film.

Bresson's film goes immediately to the heart of this matter. Pickpocket begins with Michel's first journal entry, which states: "I know that those who have done these things remain silent and those who speak have not done them. Yet I have done them." 29 Whether or not Michel is fully cognizant of this, his opening statement offers a cogent summary of one of the many flaws inherent in his (and Raskolnikov's) exceptional man theory. The problem is that he can define himself as exceptional only against others who are not and that he must rely on these others to acknowledge his exceptionality, a situation that leaves him dependent on those very people over whom he claims ascendency. This is the source of the impasse that Michel's opening statement encapsulates: To advertise the transgression that validates his ascendency is to land in prison, but to remain silent is to consign his exceptionality to obscurity. In both film and novel the characters are torn between the conflicting desires to be recognized and to remain undetected. Thus, for example, Raskolnikov's and Michel's returns to the scenes of their crimes - the former to the apartment where he killed the old woman and her sister, the latter to Longchamp racetrack, where he first succeeded at pickpocketing — can be seen as manifestations of a guilt-driven need for punishment, but also as the desire to break out of anonymity and to claim authorship of their crimes. The insuperable tension that develops between the fear of apprehension and the desire for it similarly derives from the impasse to which their efforts to put the exceptional man theory into practice brings Raskolnikov and Michel.

Yet even as it offers a concise formulation of this impasse, the opening statement of Michel's journal announces also that he has broken free from it: with his arrest, the tensions are resolved, and he can now speak of his crimes in the 
prison journal that he keeps. In the process of doing so, Michel escapes from what Bresson speaks of as "the terrible solitude that is a thief's prison," ${ }^{30}$ as the punishment he endures is commuted, like Raskolnikov's, from metaphysical constriction to physical confinement. How Raskolnikov and Michel position themselves vis-à-vis others is problematized in their respective worlds as potentially enriching ties with those around them are replaced by alienation that erodes selfhood. In place of the transgressions that can only intensify isolation, Bresson, like Dostoevskii, advocates boundary crossings that enhance communion with others, enlarging the self and the possibilities open to it. In Pickpocket the writing hand that accomplishes curative ties between self and others is a positive counterexample to the thieving hand that crosses surreptitiously into the private space of others. Michel's confrontations with his recollected self in his journal accomplish the reintegration of his divided self and thus prepare the way for connecting with others. Like Crime and Punishment, Pickpocket ends with the protagonist's alienation giving way before the possibility of meaningful human ties as Michel, again like Raskolnikov, shows signs of awakening to the unconditional love that is offered him.

The profound connections between Pickpocket and Crime and Punishment that we have been examining thus far are embedded in salient differences, which must also be considered, for they, too, enlarge Bresson's relations with Dostoevskii in this film. As we noted earlier in passing, what is perhaps Bresson's most conspicuous departure from Dostoevskii's Crime and Punishment is his astonishing replacement of Raskolnikov's axe murders with Michel's petty thefts. The difference in register between these crimes is instrumental in preventing immediate recognition of the film's ties to the novel, but at a deeper level serves additionally to strengthen ties to Dostoevskii. I have written elsewhere on the significance of the scene in Crime and Punishment that references pickpocketing, observing that it repeats on a smaller scale the broader concern of the novel which explores how "the boundaries between self and others might best be negotiated to attain selfhood and a fullness of life." ${ }^{31}$ In that context I described Michel's pickpocketing as both a cause and a consequence of his extreme alienation and as a manifestation of an underlying need to connect with others. The quandary is that the very pickpocketing that brings Michel into close physical proximity with others also forces him to flee from them. Michel's repeated reaching out in a gesture that intensifies alienation, as I discuss, encapsulates Raskolnikov's competing urges to connect with others and to cut himself off from them. ${ }^{32}$ Here I will go on to pursue the connection between Pickpocket and another of Dostoevskii's works that is enabled by the pickpocketing that Bresson features in his film to the bafflement of many, including his own cameraman. ${ }^{33}$ This is The Gambler, a shorter novel that Dostoevskii wrote in I866, immediately upon completing Crime and Punishment. 
Dostoevskii had initially planned to write Crime and Punishment in the first person so as to draw his readers into Raskolnikov's inner world. The vast array of characters and storylines, the breadth and depth of the psychologizing, and the spiritual questing that were ultimately absorbed into this voluminous novel, however, called for omniscience, making first person impracticable and leading Dostoevskii to resort instead to third-person narration. In The Gambler, which was significantly narrower in scope, he was able to use the first person-specifically in the form of notes kept by his character. Dostoevskii wrote The Gambler while in desperate need of money and in the throes of the very compulsion the novel describes.$^{34}$ Recognizable in it are variations on themes that are central also to Crime and Punishment, including the dehumanizing desire for money and overweening pride that generate a sense of exceptionality and promote risk-taking. In The Gambler Dostoevskii has Aleksei Ivanovich write accounts of his tumultuous experiences, thus allowing the character to create himself, much as Bresson has Michel do in his film. Beyond their generic correspondence, both The Gambler and Pickpocket have a thematic kinship with Crime and Punishment - one that helps us appreciate Bresson's choice of crime and what it brings to the film.

The notes that Aleksei Ivanovich keeps abound with descriptions of behaviors impelled by the novel's various characters' desperate need for money, to which they ascribe transformative power over their lives. As presaged in the title, the principal and most dramatic of these behaviors is the compulsive gambling, which Dostoevskii knew-disastrously_at first hand. In The Gambler the games of chance are situated in a society characterized by obsessive preoccupation with monetary gain. Aleksei Ivanovich insists on the similarity between the unbridled greed exhibited in the casino and the materialism rampant in society at large: "And why should gambling be worse than any other means of making money-for instance commerce?" he asks, and later goes on to say, "and as for profits and winnings, why, people, not only at the roulette wheel, but everywhere do nothing but try to gain or squeeze something out of one another." His conclusion draws attention to the social malaise and spiritual bankruptcy that thread their way through Bresson's film as well: "Money is everything!" 35 Distinguishing his own desire for money, as Aleksei Ivanovich would have it, is the risk that he is prepared to incur in going after it. It is this risk, as he claims, in muted echo of Raskolnikov, that elevates his gaming above the diligence and parsimoniousness that characterizes those who stay away from the roulette wheel, but still share the gambler's dream of amassing a fortune. In a clear parallel to Dostoevskii's gambler, the pickpocket Bresson creates tests himself repeatedly, as the filmmaker follows the Russian novelist in splintering the singular, tragic ordeal through which Raskolnikov puts himself, into debased iterations of risk-taking that, far from establishing exceptionality, erode selfhood. 
Aleksei Ivanovich describes the avarice, toadyism, and shamelessness that he observes in the crowd that surrounds the roulette wheel in the seedy casino he frequents. Yet the gaming to which his own need for money drives him is ennobled in his accounts into contests with fate itself. As Dostoevskii's gambler describes it, his very need for money generates in him a sense of exceptionality that manifests itself in the conviction that he must surely come out the winner. This delusional conviction exacts a high cost: Winning affirms this erroneous notion and only whets Aleksei Ivanovich's appetite for more gaming, while losing sharpens the need to prove himself and fuels his insatiable urge to continue playing. Gradually the desire to secure the money that would free him from service to his employer recedes before the obsessive need to persist in the exhilarating risk-taking that ultimately enslaves him and swallows up all aspects of his humanity. Like Raskolnikov before him and Michel after him, the gambler fails to use the money he gets to improve his condition and fixates instead on the means by which he procures it. The gambler's notes record an extended conversation with Mr. Astley, an insightful Englishman whose friendship he abandoned for the gaming tables. In it Mr. Astley recapitulates Aleksei Ivanovich's unhappy trajectory and assesses the extent of his losses:

"You have grown wooden," he observed, "you have not only given up life, all your interests, private and public, your duties as a man and a citizen, your friends (and you really had friends) - you have not only given up all your goals except winning-you have even given up your memories. [...] I am sure that you have forgotten all the best feelings you had then; your dreams, your present, most genuine desires now do not rise above pair and impair, rouge, noir, the twelve middle numbers, and so forth, and so on, I am certain!"36

The only thing worse than how very much the gambler loses is the degree to which he is enslaved by his obsession: Aleksei Ivanovich comes to perceive the very gambling that devours his life as the only possible means for his salvation. He replies to Astley,

let me tell you, I've forgotten absolutely nothing; but I've only for a time put everything out of my mind, even my memories, until I can make a radical improvement in my circumstances; then ... you will see, I shall rise again from the dead ${ }^{37}$

By the end of his notes Aleksei Ivanovich is hopelessly far from resurrection. Indifferent to all but the roulette wheel, he remains unmoved by the news Mr. Astley brings that the woman he once loved is still in love with him. The gambler records Mr. Astley's diagnosis: "Yes, you have destroyed yourself," 
and offers no response to Astley's prophetic warning: "So far," he tells the inveterate gambler, "you've been honest and preferred serving as a lackey to stealing ... But I dread to think what may come in the future." 38 There can be no doubt that the money Mr. Astley gives the gambler in parting is destined for the casino, and the odds are slim indeed that it can forefend indefinitely the thieving that would mark the next step in the process of the gambler's degeneration. The novel ends with this bleak outlook.

Even this brief sketch of The Gambler alerts us to underlying similarities both with its own author's Crime and Punishment and with Bresson's Pickpocket. As we have noted, Michel closely resembles Raskolnikov in important particulars, but he is best understood as a hybrid of that character and Aleksei Ivanovich of The Gambler. It is clear from Bresson's hypertext that he discerned in The Gambler a variation on Raskolnikov's need to test himself and to assert a selfhood in the face of his impoverishment and low social standing. Although the self-aggrandizing exceptional man theory to which Michel resorts corresponds with Raskolnikov's thinking, his increasingly risk-laden iterations of pickpocketing accord with the gambler's escalating contests with chance. Bresson links pickpocketing with gambling by situating Michel's first and last thefts in the midst of the betting at Longchamp racetrack. Other references to gambling in the film subtly support this connection as the accomplices divide their spoils under the cover of wagering at cards and Michel speaks of money he lost at gambling during his sojourn in London. The risk that is entailed in both gambling and pickpocketing contributes to that sense of exceptionality that ultimately intensifies both Aleksei Ivanovich's and Michel's alienation. Like Aleksei Ivanovich's gambling, Michel's thieving sends his heart racing, in a signal that his compulsion has replaced love. Unlike Raskolnikov's tragically high stake and devastating loss - the taking of human life - the gaming and pickpocketing are repeated over the course of the novel and the film in which they are featured. Their iteration draws particular attention to the steady erosion of selfhood that results from Aleksei Ivanovich's and Michel's misguided attempts at self-affirmation, making them slaves to the very means by which they seek to assert themselves. At the end of The Gambler Aleksei Ivanovich is left trapped in an obsession that promises a future of further degradation.

By making his character the thief that the gambler is likely to become, Bresson has Michel begin where Mr. Astley predicts Aleksei Ivanovich is heading. Echoing the gambler's contention that his exertions at the gaming table are no worse than the money-seeking behaviors of those around him, Michel situates his pickpocketing on a continuum with the abiding preoccupation with money in his materialistic society. The recollections that Pickpocket brings to the screen abound with images of money exchanging hands as racetrack bookies, bank tellers, and ticket sellers attend to their customers, allowing 
Michel to narrow the distinction between this perpetual exchange of money and his own extractions of cash from his victims. As for Dostoevskii, so too for Bresson, the replacement of meaningful human relations with monetary transactions is indicative of the spiritual bankruptcy of the worlds in which their characters seek to define themselves. Crucially, however, this social ill does not absolve them from individual responsibility, but only implicates them all the more: Raskolnikov, Aleksei Ivanovich, and Michel are not simply victims of a dehumanizing society, but themselves perpetrators of dehumanization.

Michel provides only a perfunctory record of the two years he spends in London after fleeing Paris in the aftermath of his accomplices' arrest at the Gare de Lyon: "During the two years I lived in London, I made some handsome strikes, but I lost the greater part of my gains on gambling or wasted it on women. I found myself in Paris again aimless and penniless." ${ }^{39}$ Like Dostoevskii's gambler, Michel ends up squandering the fruits of his risktaking. The transformative power ascribed to money by Raskolnikov, Aleksei Ivanovich, and Michel is illusory. ${ }^{40}$

The dismissive brevity of the entry that spans Michel's two years in London indicates the lesser importance he ascribes to this stretch of time in the confrontation with his past that he undertakes in his journal. The diarist Michel is eager to go back to the scene of his crimes. The entries pick up with his return to Paris where he goes to see Jeanne. Finding her abandoned both by her own father and the father of the child she now has, Michel is moved to find gainful employment so as to support them with money that he has honestly earned. The possibility of a new life opens before him, but the urge to pick pockets is not so easily tamed. Like the gambler, Michel is irresistibly drawn to the risktaking that, as he construes it, supersedes his degrading need for money. The inordinately daring theft at Longchamp racetrack from someone who, as he rightly believes, is a police agent speaks of audaciously high stakes, but also of a desire for the arrest that would put an end both to his compulsive pickpocketing and to the uncertainty of whether his criminal behavior is known to the police inspector who is on his trail. ${ }^{41}$ In the act of removing a thick wad of bills from the breast pocket of the police detective who stands directly behind him, Michel's thieving hand is manacled and he is taken into custody.

At the end of The Gambler Aleksei Ivanovich is left a slave to his gambling compulsion-doomed to repeat the very gesture that was to have transformed his life, but that ultimately destroys it. At the end of Pickpocket, Michel's compulsion similarly continues to exercise a hold on him. He, however, is rescued from it by his arrest. Here Pickpocket rejoins Crime and Punishment, and, like Raskolnikov, Michel finds himself "in prison, and free." ${ }^{42}$ Whether or not this is something Dostoevskii envisioned when he had Mr. Astley foresee thievery in Aleksei Ivanovich's inevitable decline, Bresson discerns in the very hopelessness of that character's entrapment the possibility for an 
oxymoronically liberating imprisonment. In light of Crime and Punishment and Pickpocket the thievery that is projected as the next step in Aleksei Ivanovich's decline suggests the possibility for his regeneration.

The notes Aleksei Ivanovich keeps cannot dispel his compulsion to gamble, and he is left impervious to the potentially salvific love of which Mr. Astley apprises him. Michel's thieving hand becomes a writing hand only after his last wager has been lost and he is behind bars. The film, which is to say, Michel's prison journal, brings him to a conclusion that imparts meaning to the events that he has recorded in it: "O Jeanne, what a strange path I have had to take to reach you." ${ }^{43}$ Michel's words are heard in a narrative voice-off. The hand that was seen recording his pickpocketing career is now seen clutching the prison bars and receiving Jeanne's kiss. The accelerated heartbeat previously triggered by stealing is now that of a heart beating with love. Having fulfilled its function, the journal is now complete, and Michel can move beyond his past to embrace the present and, like Dostoevskii's Raskolnikov, step into a future possessed of the openness carefully crafted for him by his creator.

****

Pickpocket, as Lindley Hanlon observes, "made famous Bresson's focus on hands as expressive, skilled objects." ${ }^{44}$ In Pickpocket it is indeed the hands that take center stage. Repeated hand gestures create an underlying rhythmic continuity for the discrete episodes recorded in the diary entries, and it is in his hands that Michel's selfhood is concentrated. ${ }^{45}$ There is good reason to center attention on hands in a film that has much to say about types of human exchange and does so with exceptional economy. ${ }^{46}$ Money repeatedly changing hands over the course of the film speaks of dehumanizing materialism. Michel's finger-limbering exercises draw attention to the beauty and gestural potential of hands, which can extend into the surrounding world to touch others. Unlike so much of the body, hands are visible both to the self and to others. In Bresson's hypertext hands are repeatedly shown in close-ups performing gestures that negotiate in various ways the boundaries between self and others-Michel's hooking and unhooking of the door of his garret, the pickpocketing episodes, pervasive exchanges of money, and the writing. The thieving hands that cross into the private space of their victims can only intensify and not heal the alienation that prompts the reaching out. Yet hands also demonstrate another sort of reaching out: The writing hand, as we have seen, has restorative powers. It is also possessed of creative vitality. Pickpocket was the first film for which Bresson wrote the screenplay himself, and Michel's writing hand is also his own. Engaging with quintessentially Dostoevskian questions that revolve around issues relating to selfhood and meaningful human exchange, Bresson uses hands to deliver his message. In so doing, he does not replicate the work of the novelist. Rather, he charts his own "drôle de 
chemin": The conclusion at which Michel arrives at the end of Pickpocket is one that Bresson establishes at the very start - even before Michel begins to write in his journal. A prière d'insérer, "a technique belonging to a long literary tradition of confessional literature [...] of orienting the reader's attention in a particular way, ${ }^{47}$ appears on the screen immediately after the film's title. It reads:

The style of this film is not a thriller. The author attempts to explain in pictures and sounds the nightmare of a young man forced by his weakness into an adventure in theft for which he was not made. Yet this adventure, by strange paths, brings together two souls which might otherwise never have been united. ${ }^{48}$

As Michel's creator, Bresson directs the circuitous route that leads his character not only to Jeanne, but to an understanding of what his maker knows from the outset: Michel's transgressive behavior is a sign of weakness and not of exceptionality, and it is love and not money that is possessed of transformative power. Daniel Millar speaks insightfully of "Michel who spends the whole film discovering his true self, who therefore exists only after the end of the film." ${ }^{49}$ Like Dostoevskii in Crime and Punishment, so, too, Bresson in Pickpocket lets his character go free in the end.

This freedom manifests itself specifically in Michel's recognition of the "strange path," that is to say, the providential erring that brings him to Jeanne. Relinquishing his petty contests with chance, he embraces the unknown and the unforeseeable that lie beyond human understanding and control. The point of arrival is the merging of two souls, for, together with Dostoevskii, Bresson centers on the regenerative power of love, but also-and at greater length - on the forces that obstruct the capacity to experience it and respond to it. Pickpocket's idiosyncratic engagement with Dostoevskii's Crime and Punishment and The Gambler is a direct manifestation of both Bresson's cinematography and his embrace of Dostoevskii's thinking. Countering what he saw as cinema's subservience to narrative and the desensitization of viewers that this subservience promoted, Bresson transcends medial and stylistic boundaries to delve deeply into Dostoevskii's ideational sphere, enlarging on it within his own creative domain, which is thereby itself enlarged.

\section{NOTES}

I. Bresson, Notes on Cinematography, I8.

2. Thiher, "Bresson's Un condamné à mort," 292.

3. Malle, "With Pickpocket Bresson Has Found," 73I.

4. Bresson, Notes on Cinematography, 2. 
5. Schrader, "Robert Bresson, Possibly," 696.

6. Cited in Arnes, "Robert Bresson," 9.

7. Bresson, Notes on Cinematography, 55.

8. Taylor, "Robert Bresson," I37.

9. Le Dantec, "Bresson, Dostoevsky," 4I3-25.

Io. Iutkevich, “'Sinematograf' Robera Bressona," 2: I5 I, I 52.

I I. Bresson authored the screen plays for all three of these films, with Pickpocket being the first one in his career that he wrote himself.

I2. The most detailed discussion to date of these points of intersection is provided by Kline in "Picking Dostoevsky's Pocket."

I3. Iutkevich does not include it in his list of Bresson's Dostoevskian films, while Taylor maintains that Pickpocket has "no literary original, no pre-existent story even." Taylor, "Robert Bresson," I35.

I4. Quandt, "Audio Commentary to Pickpocket."

I 5. Bresson, Notes on Cinematography, 27.

I6. Tarkovsky, Interviems, 45.

I7. Film scholar Tony Pipolo writes that "the conflicted nature of the protagonist in Pickpocket was an acid test of whether Bresson's style was strong enough to minimize psychology." Pipolo, Robert Bresson, I25.

I8. Ibid., I30. Here I take a different approach, arguing that the style is instrumental to the psychology in the film.

I9. Ibid.

20. At the time he made Pickpocket Bresson called his cast members "interpreters," while in later films he called them "models" as part of his effort to instill the idea that his cast members were expected not to act, but to $b e$ in front of the camera. His penchant for inexperienced individuals rather than professional actors in his films is part of this project.

2I. Here I part company with Kline's assessment of the genre as he describes it in his superb article "Picking Dostoevsky's Pocket," 30 I.

22. Malle, "With Pickpocket Bresson Has Found," 733.

23. As the film was being made Kassagi amused himself and amazed others by stealing watches and billfolds from policemen present at shoots and returning them later at a bar.

24. Kline, "Picking Dostoevsky's Pocket," 326.

25. Pipolo, Robert Bresson, I3I.

26. Beck, "Pickpocket."

27. Malle, "With Pickpocket Bresson Has Found," 732.

28. Ibid., 734, n. 3 .

29. "Je sais que d'habitude ceux qui ont fait ces choses se taisent au que ceux qui en parlent ne les ont pas faites. Et pourtant je les ai faites." Pickpocket, DVD (my translation).

30. Bresson, "Interview with Bresson from Cinépanorama."

31. Hasty, "Bresson and Dostoevskii," 324.

32. Ibid., 325 .

33. Bresson's cameraman Léonce-Henry Burel, for example, frankly admitted his bewilderment: "I didn't understand what he was trying to say. As a matter of fact I don't think anybody has ever understood, really. Who is this pickpocket, why does he steal and so on?" Kline, "Picking Dostoevsky's Pocket," 300.

34. For Dostoevskii the years I 863-7I were punctuated by fits of compulsive gambling. Among the disastrous consequences of this obsession was an ill-advised contract Dostoevskii entered into with one F. T. Stellovskii, an opportunistic editor who demanded a new novel by November I, I 866. According to the contract, failure to meet this deadline 
would give Stellovskii publishing rights to all of Dostoevskii's works for nine years with no compensation to the author. In danger of losing his livelihood, Dostoevskii was hard pressed to deliver the promised manuscript. He succeeded in doing so thanks only to Anna Grigorevna Snitkina, a stenographer he engaged on October 4, I866, who first set down the text of The Gambler from Dostoevskii's dictation and then made a fair copy of it for Stellovskii. The grateful author proposed to Snitkina in November of that year, and they were married in February of 1867.

35. Dostoevsky, The Gambler, 390, 391, 407.

36. Ibid., 5 $5^{\mathrm{I}}{ }^{-\mathrm{I}} 4$.

37. Ibid., 5 I4.

38. Ibid., 5I 7 .

39. Here I rely on T. Jefferson Kline's translation. "Picking Dostoevsky's Pocket," 320. The French in the film is: "De Milan je descende à Rome et peu de temps après je passai en Angleterre. Pendent les deux années que je vécus à Londres je fis de très beaux coups, mais je perdis aux jeux ou gaspillai avec des femmes la plus grande partie de mes gains. Je me retrouvai à Paris sans but et n'ayant presque plus rien en poche.”

40. Kline refers to this entry as "wildly out of character for Michel" and notes parenthetically that "gambling does not occupy his time in Paris." Kline, "Picking Dostoevsky's Pocket," 320. Inasmuch as journal entries provide only fragmentary glimpses into their putative author's life, this is not something that can be claimed with any degree of certainty. The very nature of the genre precludes continuity and completeness, presenting only those isolated episodes that the writing character considers important enough to inscribe in what consequently becomes a self-revelatory text. In any event, the proximity of gambling and pickpocketing is clearly indicated in the film, establishing its ties to The Gambler.

4I. Bresson originally intended to call his film Incertitude (Uncertainty).

42. Dostoevsky, Crime and Punishment, 459.

43. Here I rely on T. Jefferson Kline's translation. "Picking Dostoevsky's Pocket," 3 I6. The French in the film is: "O Jeanne, pour arriver jusqu'à toi, quel drôle de chemin j'ai dû prendre."

44. Hanlon, Fragments, I20.

45. In a documentary made some thirty years after the film, Martin Lassalle says that he is convinced that it was for his eyes and especially for his hands that Bresson chose him for the part of Michel. Mangolte, "The Models of Pickpocket."

46. "The things one can express with the hand, with the head, with the shoulders! ... How many useless and encumbering words then disappear. What economy!" Bresson observes. Notes on Cinematography, 64 .

47. Kline, "Picking Dostoevsky's Pocket," 300.

48. Ibid., 300.

49. Millar, "Pickpocket," 88. 


\section{Stealing the Scene: Crime as Confession in Robert Bresson's Pickpocket}

S. Ceilidh Orr

Robert Bresson's I959 film Pickpocket, ostensibly based on Crime and 1 Punishment, begins with the declaration, "This is not a detective story."1 And it is not. The titular thief, Michel (Martin LaSalle), confesses in the opening scene, so that viewers learn "whodunnit" before ever witnessing a crime. The only mystery left is motive: What drives Michel to steal, and to pick pockets, in particular? And how does it become so compulsive that he will drop everything, even romance, when a stranger with a handsome watch walks by? Studies of Bresson and Pickpocket are full of references to the inscrutability of the protagonist. T. Jefferson Kline quotes Bresson's cameraman, LéonceHenry Burel, as saying, "I didn't understand what [Bresson] was trying to say. As I matter of fact I don't think anybody has ever understood, really. Who is this pickpocket, why does he steal, and so on?"2 Keith Reader notes that it is hard to read the film as "a confessional autobiography," as the frame narration would suggest, due to the "extraordinary lack of psychological detail." Susan Sontag thinks Michel's "psychological implausibility" is a "flaw" of the film, elaborating that she believes Bresson "does not intend his characters to be implausible, I'm sure; but he does, I think, intend them to be opaque."4 As these evaluations suggest, Michel's own discussion of his behavior is far from coherent or insightful. In fact, his narration adds nothing to our understanding of the events unfolding on screen. Pickpocket is not a detective story, because the plot is not driven by the investigation of the crime, but by Michel's attempts to confess. What baffles us is not how Michel picks pockets - the technique is shown in minute detail-but why he cannot explain the impetus behind his acts.

Pickpocket belongs to the subset of confessional narratives reserved for criminals whose motives elude them, works like Fedor Dostoevskii's Crime and Punishment and Albert Camus's The Stranger, which serve as important intertexts for Bresson's film. This chapter explores the relationship of Pickpocket 
with these earlier texts and elucidates Bresson's engagement with the problems of confession, particularly of confession in the context of modernism, with its rejection of determinism and accompanying breakdown in causality. I will approach the film as a study of confession taking place at the nexus of religion and existentialism, the lineage Bresson claims by placing Pickpocket in dialogue with Dostoevskii and Camus. I will show how Bresson addresses both the disruption of causal connections and the problems of confession without God by suggesting a new mode of confessing, in which the crime of picking pockets itself becomes a confessional act. Bresson's engagement with confession in turn elucidates his approach to adaptation in Pickpocket, as he draws the film's intertexts into a multi-authored confessional project composed of numerous interdependent iterations and multiple voices.

Pickpocket, Bresson's fifth feature-length film, in many ways typifies the director's distinctive style and ideology. The spare sets, minimal dialogue, and rare (though significant) use of non-diegetic music are characteristic of Bresson's asceticism. As usual in his films, the major roles are played by nonprofessional actors who have been meticulously drilled on their smallest gestures and expressions. ${ }^{5}$ Pickpocket's relationship to The Stranger and Crime and Punishment reflects an interest in adaptation and intertextuality that spans the director's career. Bresson frequently experiments with the boundary between adaptation and allusion, and eleven of his thirteen features are based to some extent on a hypotext composed by someone else. The films reveal varying approaches to adaptation, from a very literal treatment of the hypotext in Fournal d'un curé de campagne (Diary of a Country Priest, 195I), which preserves the setting and events of the novel by Georges Bernanos on which it is based, to his much looser updating of Lev Tolstoi's 1904 short story "The Forged Coupon," the first part of which, transposed from tsarist Russia to I980s France, provides the basis for Bresson's final film, L'Argent (Money, I983).

The relationship between Pickpocket and its most obvious source text, Dostoevskii's Crime and Punishment, is much more complex than it appears at first glance and serves both as part of the mechanism of confession in the film and as an element of Bresson's metacommentary on confession. Bresson borrows extensively from Dostoevskii in Pickpocket, so that viewers familiar with Crime and Punishment will recognize it as the source of numerous plot elements, characters, and motifs. Despite this, Pickpocket cannot be treated as a straightforward "retelling" or a transposition of Dostoevskii's novel. Instead, Bresson's flaunting of the Dostoevskian connection serves as a red herring, inviting the literate viewer to take the novel as a key to the film, when in fact its role is quite different. Crime and Punishment exists within Pickpocket as a notquite-assimilated hypotext, acting, as we will see below, as a non-explanation for Michel's puzzling behavior by suggesting a comparison with Raskolnikov, Dostoevskii's protagonist, that ultimately falls flat. The relationship between 
novel and cinematic hypertext thus establishes a central concern of Pickpocket, namely, the state of knowing what has transpired without understanding why, which for Michel is realized as a confession of deeds that does not comprehend a motive. Furthermore, Crime and Punishment, in conjunction with Camus's The Stranger, connects Pickpocket to a lineage of literary works that engage the problems of confession, contextualizing the film as a new response to an established aesthetic and philosophical problem.

Bresson's references to Crime and Punishment and The Stranger, the former concerned with the possibility of redemption and the latter with freedom from conventional morality, locate the director's own engagement with confession at the border between religion and existentialism. In doing so, Bresson connects himself with a tradition that simultaneously acknowledges the Christian view of confession as a means of reconciliation with God and man and moves past it. Such a context is consistent with the investigation of faith and doubt that characterizes all of Bresson's films, a tension captured in Pickpocket in the relationship between the amoral Michel and Jeanne (Marika Green), the Christian woman who loves him. Though much has been written about Bresson's interest in Catholicism, and specifically in the Jansenist theology of predestination, his religious views remain ambiguous. Recent scholarship has been increasingly hesitant to accept his religious affiliations without question. Jonathan Rosenbaum describes Bresson's Jansenism as "alleged and at times avowed," preferring to call him a materialist. ${ }^{6}$ Raymond Durgnat reminds us of Bresson's alleged statement in 1974 that he was "a Christian atheist." ${ }^{7}$ René Prédal points to the ultimate ambiguity of the films: There may be a God, and there may be fate, but "the Bressonian hero can scarcely hope to find in the sky precise signs of destiny." 8 In other words, Bresson continuously makes films on Christian themes, about characters who should be paragons of virtueJoan of Arc, Lancelot du Lac, the priest of Ambricourt, a saintly and suffering donkey-yet with no final affirmation that their faith was justified. Like Dostoevskii, he poses questions of faith but allows no supernatural proof. This lack of absolute assertions and allowance for doubt are what bring Bresson's films closest to the vision of the existentialists. Christian and atheistic philosophies converge in Bresson's work without contradiction or superficial resolutions. In Pickpocket, this means that he works out his aesthetics of confession without a guarantee either of redemption or of a knowable, cause-effect chain of motivation within the human psyche.

\section{PICKPOCKET AND ITS INTERTEXTS}

A central difficulty of Pickpocket is discovering how Michel understands and communicates the motives behind his crime, if in fact he does. The recipients 
of a confession expect to hear more than a simple list of actions. Confession has historically been both a religious genre and a literary one. While modern confession has not preserved all of the redemptive and didactic functions of works like St. Augustine's Confessions, the audience (or readership) still expects a modicum of self-examination or self-justification. To put it into terms more suited to Pickpocket, a satisfactory confession must address both the criminal act and the underlying motivation, whether those are theological (original sin) or psychological. Michel manages to tell what he has done, but he cannot give a convincing explanation as to why.

Both of the film's two major intertexts, Dostoevskii's Crime and Punishment and Camus's The Stranger, set up this problem, as they depict crimes with unclear motivations. In Crime and Punishment, the protagonist, Raskolnikov, murders a moneylender and robs her. Though he has rationalized the crime by arguing that one should be allowed to kill a useless, spiteful old woman if her wealth is then used to benefit others, Raskolnikov never actually uses any of the money that he steals. This crime is further complicated when Raskolnikov is unexpectedly forced to kill the pawnbroker's innocent sister. As a result of his failed experiment, he spends the rest of the novel wrestling with his conscience and trying to discern his true motives, and in the end he turns himself in to the police. In The Stranger, the typically placid Meursault is condemned to death for killing an Arab on the beach almost without provocation. (In fact, he does so shortly after talking his friend Raymond out of shooting the same man.) In court, he can explain only that it was "because of the sun." ${ }^{9}$ In prison, he mulls over the judgment against him and his own detachment and alienation, at last making peace with the "gentle indifference" of the world ${ }^{10}$ His epiphany has little to do with the motive behind his crime, other than to render the notion of motive meaningless.

Pickpocket contains clear references to both works, though it draws far more material from Crime and Punishment. In fact, the basic plot follows Dostoevskii's quite closely, though the murder has been replaced by a series of thefts. Michel and Raskolnikov both engage in games of cat and mouse with tenacious police inspectors. Both have aging mothers whom they are arguably exploiting, Raskolnikov because his family makes huge sacrifices to support him, and Michel because he has actually stolen from his. They are aided by friends, Razumikhin and Jacques, who help them find work (and whose help they refuse), and they fall in love with virtuous (though fallen) women who inspire them to reform. Sonia, a prostitute who is the sole support for her alcoholic father and step-siblings, convinces Raskolnikov to confess and goes with him to Siberia. Jeanne, who works to support her sister and their alcoholic father, also takes care of Michel's mother, her neighbor. When she is seduced by Jacques, who abandons her with their illegitimate child, Michel is inspired to seek honest work so that she will accept his support. Though she does not 
urge him to turn himself in, she does visit him in prison, just as Sonia visits Raskolnikov. ${ }^{11}$

Bresson also includes many smaller details from Crime and Punishment. Michel's cramped room looks just like Raskolnikov's, down to the dust on the books and their secret hiding place near the floorboards. Some lines of dialogue are almost exactly preserved, especially in interviews with the police. Bresson repeats the stair motif from Crime and Punishment, frequently framing his protagonist in a stairwell, as in the scene of his first conversation with Jeanne. Dostoevskii's novel opens with Raskolnikov hesitating on a staircase, and stairs become so associated with his crime and the police that he even has dreams set in his stairwell. ${ }^{12}$

Allusions to The Stranger are less overt, but they are present. (If nothing else, it would be difficult to make so many references to Crime and Punishment in post-war France without reminding viewers of the novel, one of Camus's wellknown responses to Dostoevskii.) The scene of Michel at his mother's funeral, which has no analogue in Crime and Punishment, is the most direct reference: interestingly, Michel weeps, while Meursault cannot. The Stranger also shares a number of elements with both Pickpocket and Crime and Punishment, since the latter serves as a common source for both of the French works. Meursault has moved his mother into a nursing home, so he shares Raskolnikov's and Michel's uneasy family obligations. His girlfriend, Marie, visits him in prison, though she is less saintly than Sonia and Jeanne and eventually stops coming to see him. (While not especially moral from a Christian standpoint, she is neither an unwed mother nor a prostitute - though her name alludes to both.) Like the other two works, the novel ends with a "conversion" scene in prison, though in Meursault's case it is not a religious conversion but a triumph over religion. Unlike Raskolnikov and Michel, he experiences his revelation when he is alone.

The philosophical struggles of Raskolnikov and Meursault, which visibly impact the clarity of their confessions, provide some insight into Michel's difficulties with motive and causality. The two works frame the development of existentialism over almost a century. They also capture the transition from confession before God and man to confession without God, and with only a tenuous connection to the rest of humanity. Dostoevskii's focus on themes like self-determination and freedom, which are central to the French existentialists, strongly influenced the movement's development. Jean-Paul Sartre and André Gide both acknowledge a debt to him, and Camus, in his I955 article "Pour Dostoïevski," writes that, "without Dostoevsky, twentieth-century French literature would not be what it is." ${ }^{13}$ In Camus: The Challenge of Dostoevsky, Ray Davidson argues that "Camus's work appears to be conceived in a profound spirit of debate and dialogue with the Russian writer," with whom he engages extensively in his essays, especially The Rebel and The Myth 
of Sisyphus. ${ }^{14}$ The crux of the debate, according to Davidson, is that Camus rejects the notion that stable social structures, human relationships, and enjoyment of life require faith in God. He believes that, in reality, "faith ... is the true obstacle to passionate experience of the world." 15 The same disagreement over the necessity of faith for a meaningful existence is illustrated in the opposing trajectories of confession in Crime and Punishment and The Stranger. Raskolnikov confesses in order to reconcile with mankind, after he tries to win freedom by denying moral absolutes. Meursault begins free from rules, is rejected by society, and writes himself into an epiphany about his total freedom, including freedom from God. Even without its religious force, confession remains a valuable tool, guiding Meursault to self-knowledge along a path Michel cannot quite follow. ${ }^{16}$

For Raskolnikov, the crisis in confession accompanies a trial of his freedom from moral law. His crime, and his theory, test the idea more famously formulated by the character Ivan in The Brothers Karamazov: "If there is no God, then everything is permitted." 17 In other words, if social justice and the advancement of mankind are the only standards for what is good, then one hundred people could be sacrificed for the prosperity of millions, provided the person sacrificing them had a discerning vision of the future. For Raskolnikov to prove he had the right to kill, he must demonstrate two things. First, he has to show that his theory is correct. Second, he has to in fact be a person of vision, the so-called extraordinary man.

Doubts on both fronts complicate his attempts to confess. He flirts with the idea of admitting everything to the police almost from the moment the crime is committed. In fact, within a few days he has confessed all of the details to a police clerk, but he plays it off by saying that it was all a joke and laughing at the clerk for believing him. At the same time, even after his trial, when he is in Siberia, he is not positive that he was wrong. At worst, he thinks, he made "a simple blunder that could have happened to anyone." 18 The very fact that he does not mention the extraordinary man theory at his trial, giving poverty as his only motive, suggests that his feelings toward it are unresolved. On the one hand, it is a gesture of humility not to claim a grand justification for his crime. At the same time, he avoids publicly denouncing the theory and subjecting it to scorn.

Even more problematic, though, is his assessment of his own application of the theory. Raskolnikov suffers from an overabundance of possible motivations, and cannot be sure why he killed the old woman: To help his family? To escape poverty? To better society? Or just to see if he could? It is the last option that he dreads the most, and it is the last one that he brings up when he confesses his crime to Sonia in Part Five: "I wanted to find out $[\ldots]$ whether I was a louse like all the rest, or a man? [...] Am I a trembling creature, or do I have the right ... ${ }^{19}$ Shocking in its arrogance, this particular reason is also 
horrible because it means that he has failed a priori: while an extraordinary man pursues his cause without thinking twice about the cost, Raskolnikov concocts elaborate and fatal games merely to test his own status. Obsession with extraordinariness is a mark of the ordinary, and Raskolnikov's own theory would thus condemn him to suffer like a typical criminal.

Aside from his fevers and obsessions, another element adds to Raskolnikov's difficulty in pinpointing the reason why he kills. The extraordinary man theory is about erasing boundaries, or shattering them. "Would I be able to step over, or not!" Raskolnikov wonders. ${ }^{20}$ The Russian word prestuplenie ("crime") in the novel's title refers etymologically to the act of stepping over a line. In essence, Raskolnikov wants to escape all the normal boundaries and restrictions on human behavior. In abandoning traditional rules, though, he destroys the standards by which he would have judged himself. Behavior does not map to character as it once would have: The philanthropist and the murderer become one, and he is left outside of every system of evaluation until he confesses and submits to punishment. The same sense of being alienated by one's own transgressions may apply to Michel, who, tellingly, can connect with Jeanne emotionally and physically only as they kiss through prison bars, which both literally and figuratively close him back into a defined role within society.

In The Stranger, the central question is not "What is permitted?" but "What is determined?" The novel challenges the idea that it is relevant to talk about motivation at all. Certainly Meursault displays no interest in $w h y$ he kills (or why he does not cry at his mother's funeral, or why he might love one particular woman instead of another). Similarly, he does not form expectations of others based on what the "normal" reaction to a situation might be. For example, after getting into a fight with a police officer, Meursault's neighbor "asked me if I'd expected him to hit the cop back. I said I masn't expecting anything, and besides I didn't like cops." ${ }^{21}$ Fittingly, Meursault's crime is the only one of the three not committed with any expectation of financial gain. Camus chooses not to offer money even as a red herring.

Meursault's narrative thus departs from the traditional confession not only by not elucidating his motive but by dismissing the very ideas of motivation and causality. He has completed the rejection of determinism that the other two works explore as well, though from more stable ground. For example, Razumikhin in Crime and Punishment flies into a rage at the socialist idea that "crime is a protest against the abnormality of the social set up" and that, in a well-ordered society, "all crimes will at once disappear." 22 The viewer of Pickpocket will recognize this as Jacques's idea about crime: that some acts are justified, depending on the environment. (Jacques in Pickpocket is a mere foil for Michel, far less sophisticated than his Dostoevskian counterpart.) Razumikhin argues that you must leave room for the "living soul" 23 
when talking about human behavior. In other words, people do not react in accordance with unbreakable laws. To borrow an image from Notes from Underground, one cannot look up a few factors in a scientific table and predict what a person will do.

Meursault has embraced the fact that a total rejection of determinism means you cannot scrutinize your own motives or predict your own behavior. With this acceptance, which he accomplishes on the eve of his death, comes a freedom both absurd and powerful. It is absurd, because the world is such that you can go for a walk on the beach and come home a murderer, with no greater impetus than the heat of the sun. Powerful, because it puts him outside of all constraints, allowing him to see the artificiality of traditional customs and beliefs. Of course, it is the same freedom that hopelessly alienates him from society, causing him to be labeled an "Antichrist" and to be condemned to death, but only in the face of that condemnation does he discover that he is truly alive. Comparing himself to the priest who tries to convert him at the last moment, Meursault says, "He wasn't even sure he was alive, because he was living like a dead man." ${ }^{24}$ His confession does not lead toward a moral epiphany but away from morality altogether. In addition, rather than reconciling him with humanity, as Sonia believes Raskolnikov's confession will, Meursault's epiphany concerns freedom in alienation and liberation from social—and causal—constraints.

It is worth noting that Bresson rejects this approach to the problem of causality and confession. He does not allow Michel to embrace incoherence and absolute freedom, either because Bresson himself finds the idea untenable, or because Michel would simply not be capable of moving beyond the confusion and paralysis such a revelation would cause. Perhaps Michel's confusion comes from currents of existential angst that he only partially understands, enough to be disoriented, but not enough to take responsibility for himself as a new, free man. Michel thus inherits the difficulties of Raskolnikov and Meursault, but the solution that he comes to is neither Christian reconciliation nor existential freedom. Instead, he communicates his own disorientation and confusion about his motives through the act of picking pockets, an intimate and immediate approach to confession that remains both psychologically and philosophically ambiguous, more impenetrable than Raskolnikov's and Meursault's confessions.

\section{PICKPOCKET AND THE BREAKDOWN OF CONFESSION}

Pickpocket follows Michel's attempt to narrate a coherent confession and exposes the limits of the traditional first-person confessional narrative. The film is structured around shots of his hand recording the confession in a 
notebook interspersed with dramatizations of the events that he is narrating. Though it is unclear how much time has elapsed between the events portrayed in the film and Michel's decision to write his confession, by the end of the film the viewer knows that Michel has already been arrested for picking pockets and has admitted his guilt to the police, and that Jeanne, the woman he loves, is aware of his crimes. Presumably, Michel is not risking much by composing a full account of his crimes, and yet his confession is utterly unsatisfactory. It comes off as flat, even insincere, and strangely incomplete.

Michel's narration begins with an acknowledgment of the unlikeliness of his confession. "I know that those who have done these things usually keep quiet," he writes, "and that those who talk haven't done them. And yet I have done them." This preface raises immediate questions about the confession to follow. In the first place, what has happened to make him break the silence his fellow thieves preserve? Is there something unusual about him, or are we to understand that he has abandoned his former life? Perhaps religious conversion prompts him to confess and renounce his crimes. At the same time, our awareness that Michel's confession is (according to him) largely unprecedented suggests that he may face narrative difficulties. To confess he must break taboos and find the words to explain a secret world to viewers on the outside. Complicating matters is the fact that he is a criminal whose life's work has been illusion and stealth. Speaking openly and honestly requires a total break with the past, a recounting of old actions in an entirely new, antithetical spirit. Michel's project is imperiled in its very conception..$^{25}$

It is not surprising, in light of these difficulties, that Michel fails to make a satisfying confession. Though he provides a full account of the thefts, including details about his failures of nerve, near misses, and run-ins with the police, his motives both for becoming a pickpocket and for writing a confession remain obscure. In fact, his narration displays a complete lack of interest in motivation and causality. He begins with the moment of his first theft and provides no back story, other than the fact that he "had made [his] decision some days before." As he identifies, stalks, and finally robs his victim, the voice-over continues to be so terse that it provides almost no information. Michel's entire commentary on the three-minute scene consists of the following five lines: "I had made my decision some days before ... Would I have the nerve? ... I should have left ... I was walking on air with the world at my feet ... But I was caught right away." As will be the case for the rest of the film, Michel provides minimal information about the state of his nerves but none at all about what compels him to steal or how he himself evaluates the morality of the act.

This scene, which takes place during a horse race, also establishes a tension between image and text that will continue through the entire film. Bresson often employs extensive voice-over narration juxtaposed with on-screen actions nearly devoid of dialogue. Diary of a Country Priest,${ }^{26}$ released in I95 I, 
relies heavily on this technique, to the point that image and text begin to render one another superfluous. This lends the otherwise straightforward narrative a charge of irony. In Pickpocket, Michel's narration is laconic enough to avoid redundancy with the on-screen action. Instead, the juxtaposition of image and text reveals the inadequacy of the latter, exposing deep flaws in Michel's written confession. As mentioned above, the voice-over fails to supply significant insight into Michel's psyche, and one feels that it has little role in the film other than to remind us that Michel is attempting to confess. Worse, what little information we do glean from it is not always supported by the visual component of the film. This is especially the case when narration of Michel's thoughts or state of mind plays against an image of Martin LaSalle's mild, expressionless face. (Susan Sontag describes his performance as "convey[ing] something wooden, at times evasive." ${ }^{27}$ ) For example, at the racetrack, Michel (as cited above) asks, "But would I have the nerve?" Nothing in his face demonstrates a crisis of courage, though his downcast eyes are perhaps slightly preoccupied. We do feel his hesitation, but it is broadcast through his stillness, in contrast with the crowd that swarms around him. Later, when he says he is "walking on air," it is with almost the same expression, only he is looking straight ahead, and his mouth is slightly open: He can breathe freely for the first time in the scene. It is a very slight alteration for the exhilaration "walking on air" implies, and this is precisely the problem with Michel's gestures and expressions. It is not that they are implausible-after all, a thief cannot wear his intentions and emotions on his face. It is that his reactions are so muted, so interior, that viewers cannot bridge the gap and feel any connection with him. Even if, at moments, we worry for him, we can never identify with him. Unable to draw us into Michel's experience, his narrated confession falls flat. He may be telling the truth, but it is a truth to which we have no access, a confession devoid of revelation or cogency. We listen with reservations to an account that cannot be verified.

The same problems - an inability to describe his motives, and a general lack of conviction-underlie his reluctance to confess during the course of the events recounted in the film. Unlike Raskolnikov, Bresson's protagonist never chooses to turn himself in to the police. ${ }^{28} \mathrm{He}$ confesses to them only when caught red-handed. Even then, the narrator tells us, he plans to retract the confession. Before his arrest, Michel does give two partial explanations for his crime, one to the police inspector investigating his case and one to Jeanne. He tells the police inspector about a theory that he claims to have developed, though it is borrowed almost verbatim from Crime and Punishment. (He himself says, "It's nothing new.") He believes in a category of people who are above the law. "Can we not admit," he asks, "that certain skilled men, gifted with intelligence, talent, or even genius, and thus indispensable to society, rather than stagnate, should be free to disobey laws in certain cases?" When 
the inspector asks who or what will distinguish these "supermen," Michel replies, "Themselves, their conscience."

Any viewer familiar with Dostoevskii will immediately recognize this as a reiteration of Raskolnikov's "extraordinary man" theory: the notion that certain figures, inspired by a "new idea" that will benefit humanity, should not be restricted by laws and customs enforced by and for people of lesser vision. Such "extraordinary men," akin to Hegel's concept of the world historical figure, tend to be rejected by their contemporaries but acknowledged retrospectively for their daring and brilliance. (Raskolnikov gives Napoleon and Mohammed as examples.) Like Michel, he uses the theory to justify certain categories of crime, asserting in an article, '[A]n 'extraordinary' man has the right ... that is, not an official right, but his own right, to allow his conscience to ... step over certain obstacles." 29

The difference between them is that, when we hear Raskolnikov's theory, we penetrate to the core of the novel and his psyche; when we hear Michel's, we doubt that he himself believes it. Raskolnikov is utterly obsessed with the idea of the extraordinary man and has staked his soul on it. The viewer of Pickpocket never sees such doubt and torment in Michel. At times he is nervous, at others mildly puzzled, and little more. Despite his ominous voiceover during the café scene ("Stupidly, I greeted him"), he presents his theory to the chief inspector dispassionately. ${ }^{30}$ Perhaps he has come up with the idea solely out of propriety, having the vague idea that a student turned criminal needs a clever, socially conscious defense. Lacking a concrete understanding of his own motives, he has pilfered one from Raskolnikov, picking the pocket of his predecessor. The stolen goods are worth less in their new context: Michel's theory of the superman could be omitted from the film with little effect, while reading Crime and Punishment inevitably entails entering the debate about the extraordinary man.

When Jeanne asks Michel why he steals, he gives a simpler response. "To get ahead," he explains. "I was frustrated getting nowhere." This is plausible, but it does not explain the way his behavior escalates, until he appears to be addicted to the act of picking pockets. Merely wanting to escape poverty would not, for example, explain what happens the day Michel goes out with Jacques (his friend, who resembles Razumikhin from Crime and Punishment) and Jeanne. When he spots a passerby with an expensive watch, Michel is overcome with such a strong urge to steal that he abandons the other two on a carnival ride to pursue his mark. They find him later in his room, bleeding because he fell while being pursued. Michel is a successful enough thief at this point that there is no need for him to go after watches at random to get by. Similarly, during the two years he spends in London, he claims to have made a great deal of money but squandered it on women and gambling. (This statement recalls the moment when Michel explains to the police inspector 
that the "supermen" would stop stealing once they had acquired the resources they needed. The inspector replies, "They don't stop.") It is clear that the compulsion to steal comes from something more complex than a mere desire to be financially solvent. Neither during his career as a criminal, nor later as he reflects upon it, is Michel able to elucidate this complexity.

\section{CONFESSION THROUGH CRIME: BRESSON'S SLEIGHT OF HAND}

Having established the problems of narrating a satisfactory confession, Bresson presents a solution that is embedded in Michel's criminal acts. By picking his victims' pockets, Michel forces them to experience the same breakdown in causality that makes it impossible for him to explain his motives. For example, in one scene Michel steals from a woman who is standing in line with her purse tucked under her elbow. He eases the purse out from under her arm and replaces it with a rolled-up newspaper of approximately the same size. The woman feels nothing. The audience does not witness her eventual discovery of the crime, but she surely perceives it as the work of a magician: The purse, which she has held firmly this whole time, has been transformed into a worthless scrap of paper. It is an effect without any possible cause. Confronted with the breakdown of causality, she must experience a disorientation very close to Michel's confusion about his own actions.

The merging of crime and confession suggests that Michel's choice of crime is motivated in part by his need to confess, and that his desire to confess is not a straightforward result of having committed a crime. ${ }^{31}$ Picking pockets enables Michel to express something about his existential state that he cannot put into words. This explains why Bresson's film is focused on a comparatively petty crime, though its major intertexts deal with murder. Neither Raskolnikov's nor Meursault's murder accomplishes the same disruption of causality, as they confront their victims face to face. It is specifically the element of sleight of hand inherent in picking pockets (along with the fact that the victims survive to be puzzled by the crime) that makes it effective. Fittingly, the film fixates on pickpocketing techniques. Michel practices unhooking a watch from a table leg and plays pinball to improve his dexterity, and his accomplice, played by professional sleight-of-hand artist Henri Kassagi, demonstrates numerous tricks of his trade.

Bresson draws attention to Michel's odd confessional technique through some sleight of hand of his own. Effectively picking his viewers' pockets, he pushes his famously spare style to an extreme by eliminating connective material and would-be climactic scenes from Pickpocket. The scene of Michel's first theft at the racetrack, described above, is full of such instances. Consider, for 
example, the presentation of the horse race during which Michel steals from a woman's purse. During the race, the assembled crowd focuses intently on the track, but the film's viewers miss the spectacle. The camera stays on Michel as he inches his hand into the purse. We experience the race only through the crowd's reaction, as they turn their heads to follow it, and through the sound of cheers and hoof beats. In other words, we witness certain effects and are left to imagine their cause. The scene serves a dual purpose: the viewer, "robbed" of the thrill of the race, begins to understand how the pickpocket exploits the misdirected attention of the crowd. Simultaneously, we become aware of how much work we ourselves will have to do to put the pieces of Michel's confession together.

When Michel leaves the races followed by detectives, the audience must once again provide their own causal connections, this time between scenes. Here it happens because we are not allowed to see the moment of Michel's arrest, which in a typical detective film would be the climax of the racetrack adventure. Instead, just after the detectives appear, the voice-over narrator ruins the suspense of the moment by saying, "But I was caught right away." Bresson then cuts from a shot of the detectives reaching for Michel to an image of Michel seated in the back of a police car. Though it is not difficult to imagine what happened in between, skipping the arrest deflates the dramatic tension that has been building since Michel selected his mark. Significantly, we are not allowed to experience the interpersonal conflict of the arrest: Bresson carefully rations direct confrontations and genuine interactions in the film. This cut also "bares the device" of film editing, to use Viktor Shklovskii's term, by making the viewers realize how much they contribute to a film's coherence by inferring causal connections between scenes. The upshot of Bresson's trademark minimalism, in Pickpocket, is precisely this awareness that the viewer actively negotiates gaps in causality, and that narratives are, in general, fragile constructions.

By employing pickpocketing as a narrative device, Bresson legitimizes Michel's confessional technique, but he also provides a context that completes it. Even when picking pockets, Michel is still making only half a confession at a time. In writing, he is able, barely, to say what he has done. When he steals, he leaves a clue about why. His victims likely share his confusion; they do not know exactly what has happened to them, or who is to blame. The pieces of Michel's confession come together only when they are presented to the viewer, by Bresson. That is to say that the only successful confession in Pickpocket is the one completed when an audience watches the film. Michel cannot tell his whole story until it has been taken out of his hands. In this we see the cost of confession through picking pockets. The recipient of confession has access to the confessor's psychological, and existential, state in an unprecedentedly direct way, having been forced to share part of his or her experience. For 
this shared confusion to be meaningful, though, or even to be recognizable as a confession, it must be presented in a broader context, with additional information about the crime. As the confessor can no longer contextualize the information on his or her own, confession by picking pockets requires multiple confessors, and multiple, incomplete attempts to confess.

What emerges in Pickpocket is a view of confession as no longer a narrative in itself, but a moment of disorientation that must be given narrative and context. The film and its intertexts provide a framework for Michel's mute gestures of shared disorientation, knitting these repetitive, fragmentary acts into what the viewer can recognize as a story. The idea of a coherent, univocal confession, like Augustine's or Jean-Jacques Rousseau's — or even Meursault's—is a thing of the past. Michel's written confession is unsatisfactory because it is an attempt at exactly this kind of univocal, first-person confessional narrative, but a pickpocket confession requires third person and polyphony, a plurality of voices to surround the moments of silent confusion at its core. Michel's sleight of hand only becomes meaningful to the viewer when tied to his face, to his biography, and to a certain social and cultural milieu by the other elements of the film: images, music, sounds, the preface ("Ce film n'est pas du style policier"), and the puzzling voice-over narration.

In this respect, of course, Crime and Punishment is an especially significant intertext, as it is an early example of a work about confession moving into third person to resolve narrative problems. As Olga Peters Hasty points out in the previous chapter, Dostoevskii originally drafted the novel in first person, as a diary and then as a confession, but rewrote it in the third person. ${ }^{32}$ Though the impediment to Raskolnikov's confession is a number of competing narratives, rather than a lack of narrative, the novel anticipates Bresson's view of fragmentary confessional acts pieced together by a narrator and other elements. Already in the novel there is a sense that Raskolnikov's motives are too complex to be narrated satisfactorily, but his conception of the crime and subsequent moral and psychological torment still loosely fall into a cause-effect narrative in a way that Michel's experience does not.

Intertextuality and adaptation play a double role in this new aesthetics of confession. Robin Feuer Miller describes confession in Dostoevskii's works as an act of "indecent exposure," characters displaying their basest qualities as "a form of vanity [...] that depends upon the existence of an audience to outrage." 33 Confession in Pickpocket is given a similarly sexualized metaphor in the image of Michel's hand slipping stealthily into the purse of the woman at the race track, but this is a clandestine and furtive indecency, not one that invites the eyes and the outrage of the public. His fragmentary confessions involve too little exposure rather than too much, and the scene at the racetrack hinges on his misdirection of the public's attention, revealed by the camera's redirection of the viewer's eye toward this stealthy penetration. The film's 
intertexts, similarly, serve both to misdirect and redirect the audience. They act as red herrings, as described above, by suggesting ultimately unsatisfactory explanations for Michel's behavior and creating the illusion that his confession might, after all, be a coherent narrative. As that illusion crumbles, they fold Pickpocket into a broader context of confessional narratives, and even into a broader narrative about human beings trying to confess.

By working with these intertexts without fully assimilating them or settling into an easy relationship, Pickpocket creates clear borders that the viewer must actively negotiate, just as he or she negotiates the gaps left by missing connective material. Confession has been stripped of its most recognizable features, the overt statement of motive and deed, and then had them partially restored. The act of confessing is no longer identical with the narrative itself but a mute gesture inscribed within the narrative, so that the confessional genre now relies on what was once its antithesis: that which is not and cannot be articulated. Ultimately, the viewer still gets some information about motive and causality, but we can no longer have them without recognizable borders. We examine those boundary lines, the meeting points of film and literature.

In conclusion, Bresson uses his intertexts to create a form of confession that is influenced by, and yet distinct from, those of Dostoevskii and Camus. Like his predecessors, Bresson does not deal with criminal motivation as a matter of simple, psychological cause and effect. Instead, he approaches confession as something that eludes straightforward narration, something around which a narrative must be built, but which acts exactly where the surrounding narrative is least forthcoming, and where causality gives way to bewilderment. Confession in Pickpocket is itself transgressive and illicit and works through acts of theft, through the stripping away of expected elements, so that the reader stumbles in the gaps. It is about realizing what we do not understand and cannot say, but it is also about the construction of narratives in spite of, or even as complements to, those aporias, so that confession becomes a chain of voices, perspectives, and texts simultaneously exposing and ordering the moments of wordless, stealthy contact at their core.

\section{NOTES}

I. "Ce film n'est pas du style policier."

2. Kline, "Picking Dostoevsky's Pocket," 300.

3. Reader, Robert Bresson, $29 \mathrm{I}$.

4. Sontag, "Spiritual Style," 65.

5. Bresson rejected the term "actor" and worked with "models," whom he instructed not to act or emote at all, in an attempt to keep the actor's interpretation of the role from obscuring his or her spirit and skewing the effect of a scene. Set out somewhat cryptically 
in Notes on Cinematography, Bresson's theory of models has been extensively analyzed. See, for example, T. Jefferson Kline's analysis in "Picking Dostoevsky's Pocket."

6. Rosenbaum, "The Last Filmmaker," 2 I.

7. Durgnat, "The Negative Vision," 4I I .

8. Prédal, "Robert Bresson," 89.

9. Camus, The Stranger, I03.

Io. Ibid., I22.

I I. The extensive parallels between the ending of Pickpocket and the epilogue of Crime and Punishment, both ostensibly conversion narratives, deserve to be the subject of their own, separate analysis. To give a brief picture of their similarity, both stories end with the protagonists being visited in jail by their love interests, who have been absent for some time due to illness. Each visit culminates in a moment of realization. As Michel kisses Jeanne through the cell bars, the narrator says, "Oh Jeanne, to reach you at last, what a path I had to take." Literally locked into a place in society, he appears to genuinely connect with and need another person for the first time. In a comparable gesture, Raskolnikov suddenly flings himself at Sonia's feet. She realizes "that he loved her, loved her infinitely, and that at last the moment had come ... In [their] pale, sick faces there already shone the dawn of a renewed future, of a complete resurrection into a new life." Dostoevsky, Crime and Punishment, 549 .

I2. Given the numerous allusions in the final version of the film, it is fascinating to recall that Bresson claims not to have had Dostoevskii in mind when he began working on Pickpocket. Despite this, he is clearly very familiar with the Russian writer's work, and returns to it twice more as a source for Une femme douce (i969), based on "The Meek One" ("Krotkaia"), and Quatre nuits d'un rêveur (I97I), analyzed in Chapter 2 of this volume, which follows the premise of "White Nights" ("Belye nochi").

I3. Davidson, Camus, 3 .

I4. Ibid., I.

I5. Ibid., 2.

I6. Peter Axthelm considers this a key characteristic of the modern confessional novel. $\mathrm{He}$ suggests that, without the hope of redemption or rebirth, the "intense self-examination" of confession is the only way for an existentialist protagonist to "seek meaning." Axthelm, The Modern Confessional Novel, 55 .

I 7. At least, this sentiment is twice attributed to Ivan. In Book Two, chapter six, Petr Aleksandrovich quotes Ivan as saying that "were mankind's belief in its immortality to be destroyed, not only love but also any living power to continue the life of the world would at once dry up in it. Not only that, but then nothing would be immoral any longer, everything would be permitted, even anthropophagy." Ivan does not deny it. In Book Eleven, chapter eight, Smerdiakov quotes "everything is permitted" back to Ivan. Dostoevsky, The Brothers Karamazov, 69, 625.

I8. Dostoevsky, Crime and Punishment, 543 (original italics).

I9. Ibid., 4I9.

20. Ibid.

21. Camus, The Stranger, 37 (my italics).

22. Dostoevsky, Crime and Punishment, 256. The idea is repellent to the Underground Man, and to Dostoevskii, as well.

23. Ibid., 256 (original italics).

24. Camus, The Stranger, I20.

25. The phrase "these things" already sounds vague and evasive, especially in contrast to the blunt label of the film's title. 
26. Diary of a Country Priest is also a study of confession, though in a more overtly religious context.

27. Sontag, "Spiritual Style," 63.

28. Readers never find out whether Meursault in The Stranger is captured or turns himself in, as the narrative jumps from the murder to events after his arrest.

29. Dostoevsky, Crime and Punishment, 259.

30. In contrast, Raskolnikov and his interlocutors boil over with emotion. The following descriptions from their conversation about Raskolnikov's article illustrate the passionate nature of the debate: "Raskolnikov did his best to look as abashed as possible"; "Raskolnikov could not help himself, and angrily flashed a glance at him, his black eyes burning with wrath"; "Raskolnikov grinned awkwardly"; "Razumikhin all but flew into a rage"; "Porfiry could not sit still." Nothing could be further from the inscrutable calm of Michel in the café, who betrays no emotional or intellectual engagement with his claims. Dostoevsky, Crime and Punishment, 250, 251, 252, 257, 264.

3I. Camus, The Stranger, I2 I. Here again we see a complication of the linear cause-effect relationship.

32. See the chapter "Dostoevsky" in Peter Axthelm's The Modern Confessional Novel for a discussion of the confessions in Notes from Underground and Crime and Punishment.

33. Miller, "Dostoevsky and Rousseau," 85. 


\section{The Eye-deology of Trauma: Killing Anna Karenina Softly}

Yuri Leving

Tow did it happen that world directors turned out to be so susceptible to
Anna Karenina? First of all, from the standpoint of early Russian producers, this particular novel by Lev Tolstoi was a perfect candidate for a film adaptation because it enjoyed the status of a bestseller immediately upon its publication - it was even more successful than War and Peace. ${ }^{1}$ Popularizing literary classics was done in Russia in conjunction with the very democratic spirit of cinema- "its popular appeal, its educational and cultural orientation"- the features that were emphasized by early Russian producers and later by film historians. ${ }^{2}$ Turning to the classics did not guarantee high-quality films since, as Neya Zorkaya notes, "even the best films merely borrowed the story line and the names of the main characters," but the fledgling genre aspired to explore the psychological and philosophical depths of a literary work, that "labyrinth of connections," which, according to Tolstoi, is the essence of a novel. ${ }^{3}$

James Griffith claims that in setting out to transform a novel into a movie, a filmmaker usually makes many choices along the same lines as those of the novelist. Having said this, Griffith admits that for all the changes people can cite in numerous adaptations,

a novel and its adaptation rarely share no more resemblance than the title-and one could argue such an "adaptation" exemplifies no more than a hastily purchased property. The average audience regards fidelity as a question of how much is left in: how much of the plot and how many of the characters survive the usual condensing of the novel's action. ${ }^{4}$

Griffith argues that for the common filmgoer's notion of fidelity, the main objection usually refers not to ideas but to the practical inability of most films 
to include all of the events presented in a novel. ${ }^{5}$ As in this case, the hypertexts of Anna Karenina cannot adequately address all of the plotlines in Tolstoi's hypotext in the standard two-hour film.

In the case of the transposition of Anna Karenina to the silver screen, the one consistent scene among all of the various cinematic hypertexts is the heroine's suicide. ${ }^{6}$ So emblematic is Anna's death at the end of Part VII of the novel that few could imagine an alternative ending. Yet, as Tolstoi's character passed through various countries over more than a century, her numerous suicides created a new set of semantic markers, like so many decals on a traveler's steamer trunk. As the decal Biarritz suggests sandy beaches and the blue ocean, and Chamonix elicits thoughts of alpine skiing and a roaring fire in a ski lodge, so too, the cinematic eye, the color red, and the candle become associated with Anna's filmic suicide. In what follows, I will concentrate on a specific scene in Anna Karenina, the one that, paradoxically, is meant to both thrill and traumatize, in order to suggest that during Anna's travels, a new set of semantic markers were established for this scene by the authors of the various hypertexts. In so doing, a new visual language for Anna's death has been created by filmmakers, one that does not necessarily correspond to Tolstoi's hypotext.

\section{LITERARY SUICIDE IN CULTURAL CONTEXT}

The early i 870 os in Russia witnessed a "suicide epidemic," and the pages of the Russian press discussed personal tragedies as a social fact at great length, publicizing society's ills, especially suicide and crime. Irina Paperno, who investigates suicide as a cultural institution in nineteenth-century Russia, notes that different themes converged in the image of suicide, and diverse ideological groups invested it with meaning. Paperno specifically dwells on the imagery pertaining to the depiction of the suicide in Russian public discourse: "The suicide's body, presented in graphic images of corporeal disorder, became an emblem of the disintegrating social body-Russian society after the Great Reforms."7 For positivists during the writer's lifetime, suicide was a test case for the issue of free will versus determinism, while those troubled by positivism and atheism saw suicide as the direct effect of these ideologies:

the fate of a suicide exemplified the fate of an atheistic society-willful reduction of the self to nothingness, a body deprived of a soul. The suicide's body was also the positivist's worst nightmare: the evidence of man's inability to determine what causes observable phenomena. ${ }^{8}$

As a result of changing societal norms, the body of the suicide assumed a second existence as a symbol in the Russian press of the i 860 os to I 880 os. 
Episodes in contemporary literary works, both Russian and European, have invited analogies with real-life incidents. Tolstoi's Anna Karenina holds a special place in the gallery of fictitious suicidal types. In comparison with the deaths of other literary heroines, Amy Mandelker suggests, Anna's suicide is "distinctive both in terms of its placement in her narrative- she is not, in fact, abandoned by her lover-and in terms of her chosen means." ${ }^{9}$ Indeed, as Mandelker reminds us, the literary antecedents for Tolstoi's heroine's lunge beneath the train are male protagonists driven by shame and ruin (such as Charles Dickens's Carker in Dombey and Son and Anthony Trollope's Lopez in The Prime Minister). In classical literature, heroines meet their death (whether it is murder, sacrifice, or suicide) "in the throat": either by hanging, decapitation, or the cutting of the throat. ${ }^{10}$ In Victorian literature, heroines commonly lose their heads before dying, but

[t]he action of severing the body from the head, the ornamental proclivities of a knotted rope or beading of blood, and, most important, the preservation of Anna's severed head from damage all suggest a form of framing - the heroine is transformed into a mute bust of immobile marble; she is ultimately seen as an inanimate objet d'art. ${ }^{11}$

Here we approach the very issue to be discussed in this chapter: depictions of Anna's death in cinematic hypertexts.

\section{A BRIEF HISTORY OF ANNA KARENINA IN CINEMA}

The moment film went from the animation of stills to telling a story, it was inevitable that "fiction would become the ore to be minted by story departments." 12 Tolstoi's Resurrection (igo9) happened to be one of D. W. Griffith's earliest screen adaptations, which came as no surprise to the Russian director Sergei Eisenstein. Discussing Griffith's films through the prose of Dickens, Eisenstein demonstrated that most of his major technical innovations, including the dissolve, the superimposed shot, the close-up, and the pan, were rooted in the Hollywood artist's interest in literary forms. ${ }^{13}$ Due to its numerous "cinema-ready" qualities, Tolstoi's Anna Karenina similarly offered fertile material to a creative mind willing to reinterpret the original. As a result, the book has inspired seven silent films, several ballet versions, TV miniseries, and big Hollywood productions with charismatic treatments of the main character by legendary actresses such as Vivien Leigh, Jacqueline Bisset, Sophie Marceau, and, most recently, Keira Knightley. Greta Garbo managed to perform the same role twice: first in the silent movie, Love (1927); then, eight years later, in Clarence Brown's Anna Karenina (1935). Russian 
auteurs have also treated their literary giant's work with great care-both in the early days of cinema, as well as in the Soviet and post-Soviet periods. Aleksandr Zarkhi's Anna Karenina (I967), with Tatiana Samoilova, is considered by many to be the best hypertext of Tolstoi's novel. The creative hybrid of I974, the film-ballet with Maiia Plisetskaia in the main role, was followed by Sergei Solov'ev's take (2009), peculiar for its unorthodox, digitally mastered visual style. A comparative study of narrative structures and devices in the novel and its various film adaptations has been the subject of several specialized studies. ${ }^{14}$ My study's aim is narrow in comparison: to examine how cinematic hypertexts have altered the way we view Anna's suicide; crossing the border from the novel to the cinema, within new temporal boundaries, has introduced unique visual elements that have forever changed our understanding of Tolstoi's hypotext. In so doing, a new language for Anna's death incorporates the cinematic decals of her many travels.

The history of Tolstoi's Anna Karenina screen adaptations begins with the I9I I version directed by Maurice Maitre, which has survived in a lone copy in the Amsterdam cinema archive. Yuri Tsivian provides its synopsis, of which the finale is of particular interest. In the closing moments of the film, Anna throws herself on the rail line from a hillside. The following shot shows the train passing by. In I9I4, Vladimir Gardin produced the second screen version of Anna Karenina under the Russian Golden Series brand. Maria Germanova of the Moscow Art Theater, a pupil of Konstantin Stanislavskii, appeared in the title role of Anna. Five years later the critic Il'ia Ignatov, who had closely followed the progress of Russian cinema, "recalled with some bewilderment the reaction of the Russian press to Gardin's film."15 Reviewers singled out the psychological complexity of Anna's role in his visualization of Anna Karenina. Some labeled Germanova's impersonation of Anna as "sacrilege." 16 For the purposes of this study, it is significant that Gardin's treatment of Anna's suicide turned out to be notably different from its original form in Tolstoi's novel. This scene persuaded critics that the film had "some special quality that enabled it to bear comparison with the novel"; regrettably for scholars of early Russian cinema, only the first reel of Anna Karenina has survived. ${ }^{17}$ The suicide scene, however, can be reconstructed using production stills and intertitles. An article by a reporter who was present at the location shooting has also proved helpful ("The Suicide of Anna Karenina" appeared in a Moscow theater periodical in I9I4). ${ }^{18}$ The author described the special effects employed in the production (a dummy substitution, plus a reverse shooting technique) to make the suicide scene look real. Among the noted discrepancies between the film and the novel was the fact that Anna

threw herself from the platform under the second car, not under the approaching engine as she did in the film. The reporter did not really 
object to this: "that is the way they do it in cinema." Neither did any of the other reviewers find this, or the anachronistic locomotive, to be a problem. Gardin's ending must have been really effective to be able to justify the liberty that the director had taken with the source in treating the novel's crucial scene. ${ }^{19}$

After studying the production still published by the illustrated weekly Sparks in I9I4-I7, Tsivian concluded that the position of the train relative to the camera is indebted to the Lumières' The Arrival of a Train from I $895 .{ }^{20}$ As time passed, directors who adapted the novel to the screen have been able to depart from the Lumière train's powerful imagery and to reconstruct Tolstoi's crime scene based on the actual verbal account of the suicide. While the versions of Anna Karenina released in 1914, I918, I927, and 1947, respectively

employ the canonical cinematic image of a train advancing toward the audience, some versions either omit it completely (I935, I985) or combine a view of the approaching train with side shots of its carriages

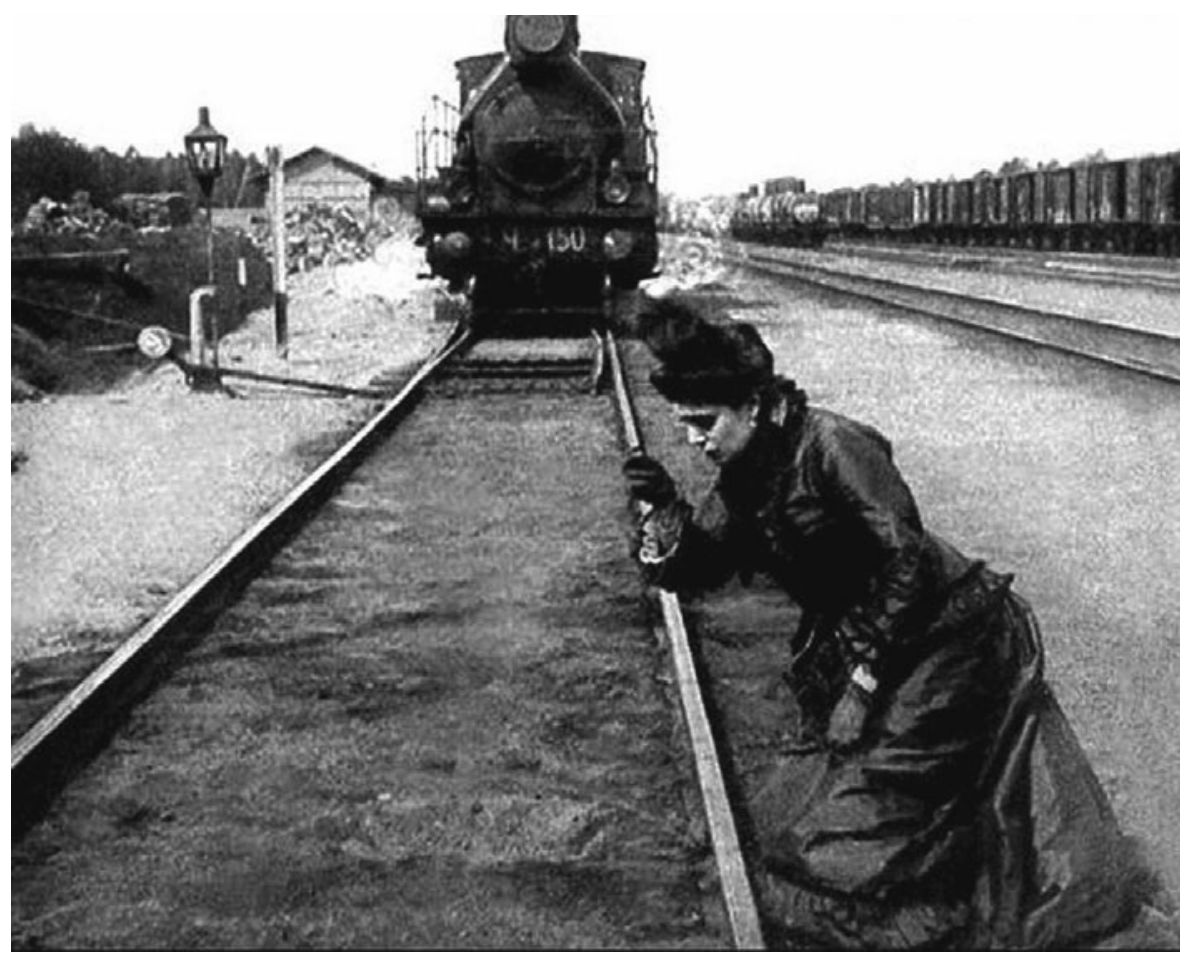

Figure 5.I Anna Karenina (Dir. Gardin, I9I4), production still. 
and wheels, which are intercut with Anna's face (1967, I997, 200I). [Bernard] Rose's film constitutes an eloquent farewell to the early cinema icon. ${ }^{21}$

Over time, other emphases have been given to Anna's death. Sergei Solov'ev's hypotext (2009) is the most gruesome cinematographic vivisection, featuring blood and dismembered limbs in a visually shocking scene that could rival Quentin Tarantino's signature style. Here Solov'ev approximates Tolstoi's hypotext: Stricken by the sight of Anna Karenina's dismembered body near the rails, Vronskii tries to remember its joyful wholeness during their first meeting, also at the train station. ${ }^{22}$ Much less shocking, but still quite powerful, is the depiction of Anna's suicide in Joe Wright's (2012) film, which subtly highlights the sadomasochistic desire of Anna's self-inflicted pain and evokes a clearly sexual origin. Anna's last gasp is highly suggestive, repeating the coital sequence in an earlier part of the film. "Vse koncheno" ("Everything is ended"), she says to Vronskii after they make love; used in the dubbed version of the film in its Russian official release, the phrase sounds extremely modernized due to its proximity to the idiomatic Russian, meaning "experiencing an orgasm" (konchat'). Compared with the same pose (head up; high angle) in the orgiastic mise-en-scène followed by the suggestively exploding fireworks, the last few seconds of Anna's earthly existence thus acquire a second, liberating meaning.

It is not accidental that several directors have attempted to inscribe onto this climactic scene the sound of a loud scream, which normally would be interpreted as a horrifying emotional outburst, as, for instance, in the Italian and English productions (Vronskii's yawning mouth in the 1985 American adaptation is eternalized with the help of a freeze-frame shot-hinting at a gap in the narrative or at a philosophical leap into a non-diegetic emptiness?). The Italian montage is remarkable because Anna's last scream is cut off, but appears to be metonymically redeployed in the immediate next sequence, showing a crying baby. The case is different in the latest (20I2) Oscarwinning visual rendering of the novel. ${ }^{23}$ Keira Knightley's sensuality and Wright's clever mirroring of the earlier shots allow one to connect the dots and to establish the commonality between all three types of sounds accompanying the human life cycle at its most meaningful moments: the noise of expressing pleasure during the act of impregnation; the primordial cry of a baby born; and the mourning of death.

What is clear is that this particular scene presents filmmakers with technical and filmic challenges that have resulted, over time, in a consensus in the visual language; a lexicon that is no longer reliant on Tolstoi's version of Anna's suicide. Tsivian's research suggests that the suicide scene has become the focus for most viewers when providing an evaluation of the entire film. 


\section{CINEMATIC REPRESENTATIONS OF KARENINA'S SUICIDE}

"There are few scenes in world literature as painful to read as Anna's last day on earth," Edward Wasiolek observes in his study of the novel. ${ }^{24}$ It was Tolstoi's heroine's ultimate decision to take her own life, but it is still the director who faces the uneasy task of reconstructing that terrible event on screen. Killing the unfortunate protagonist in a climactic sequence, replayed numerous times and performed by a score of talented actresses, raises broader issues of cultural identity, types and stereotypes, and interpretation through adaptation. To understand how closely the various plots correspond to one another and to the original text of the novel, let us take a closer look at the suicide sequence at the end of Tolstoi's novel:

"O God! where am I to go?" she thought, walking further and further along the platform. She stopped at the end of it. Some ladies and children, who had come to meet a spectacled gentleman and were laughing and talking noisily, became silent and gazed at her as she passed them. She walked faster away from them to the very end of the platform. A goods train was approaching. The platform shook, and it seemed to her as if she were again in the train.

Suddenly remembering the man who had been run over the day she first met Vronsky, she realized what she had to do. Quickly and lightly descending the steps that led from the water-tank to the rails, she stopped close to the passing train. She looked at the bottom of the trucks, at the bolts and chains and large iron wheels of the slowly-moving truck, and tried to estimate the middle point between the front and back wheels, and the moment when that point would be opposite her.

"There!" she said to herself, looking at the shadow of the car on the mingled sand and coal dust which covered the sleepers. "There, into the very middle, and I shall punish him and escape from everybody and from myself!"

She wanted to fall half-way between the wheels of the front car, which was drawing level with her, but the little red handbag which she began to take off her arm delayed her, and then it was too late. The middle had passed her. She was obliged to wait for the next truck. A feeling seized her like that she had experienced when preparing to enter the water in bathing, and she crossed herself. The familiar gesture of making the sign of the cross called up a whole series of girlish and childish memories, and suddenly the darkness, that obscured everything for her, broke, and life showed itself to her for an instant with all its bright past joys. But she did not take her eyes off the wheels of the approaching second car, and 
at the very moment when the midway point between the wheels drew level, she threw away her red bag, and drawing her head down between her shoulders threw herself forward on her hands under the car, and with a light movement as if preparing to rise again, immediately dropped on her knees. And at the same moment she was horror-struck at what she was doing. "Where am I? What am I doing? Why?" She wished to rise, to throw herself back, but something huge and relentless struck her on the head and dragged her down. "God forgive me everything!" she said, feeling the impossibility of struggling ... A little peasant muttering something was working at the rails. The candle, by the light of which she had been reading that book filled with anxieties, deceptions, grief, and evil, flared up with a brighter light than before, lit up for her all that had before been dark, flickered, began to grow dim, and went out for ever. ${ }^{25}$

To appreciate the role visualization plays in Tolstoi's narrative one should analyze Anna Karenina paying particular attention to how the author uses language to assist readers in picturing the plot, and how this mental image enhances their experience of the ethical issues portrayed in the novel. The literary techniques Tolstoi employs to facilitate the reader's imagination are surprisingly in tune with cinematographic art. The reader's mind creates images from verbal cues following (in Tolstoi's case, foreshadowing) the camera movement and common editing practices. For the sake of experiment I will try to simulate (based on many of the films under consideration) the simplified and straightforward transposition of the passage cited above into a kind of a verbal storyboard, a series of comic-strip-like sketches of the shots in this particular suicide scene, including notations about lighting, special effects and camera work:

Suddenly remembering [CLOSE-UP-ANNA'S FACE: MEDITATIVE] the man who had been run over [FLASHBACK: DEAD PEASANT] the day she first met Vronskii, she realized what she had to do. Quickly and lightly descending the steps [CUT: ANNA — FULL SHOT] that led from the water-tank to the rails [PANORAMIC VIEW OF THE PLATFORM], she stopped close to the passing train. She looked at the bottom of the trucks [CAMERA: HIGH-ANGLE SHOT], at the bolts and chains [EXTREME CLOSE-UP] and large iron wheels of the slowlymoving truck [SPECIAL EFFECT: SLOW MOTION], and tried to estimate the middle point between the front and back wheels [ANNA'S FACE AGAIN: EXPRESSION OF TORPOR], and the moment when that point would be opposite her. [CUT: WHEELS, NORMAL SPEED]

Style, like in a narrative film, functions in Tolstoi's formal system to advance the cause-effect chain - it creates parallels, manipulates story-plot relations, and sustains the narration's flow of information. Strategies of selecting and 
arranging events from Anna Karenina, as rightly asserted by Irina Makoveeva, "differ from writer to screenwriter, and from one film to another." ${ }^{\text {"6 }}$ Yet, over time, a visual language did emerge from Tolstoi's hypotext.

As Sydney Schultze notes, the train symbol does not stand alone but functions as the central member of a cluster of semantic meanings for Anna's suicide: "[1]inked with the train and death are other motifs: the peasant, dreams, telegrams, heat, light, the color red, and severe extremes of mood." 27 In his lectures on Anna Karenina, Vladimir Nabokov unequivocally praises Tolstoi's ability to create such clusters, or, rather, a web of interconnected symbols. "With an artistic force and subtlety unknown to Russian literature before this day," says Nabokov, "Tolstoy introduces the theme of violent death simultaneously with that of violent passion in Vronsky's and Anna's life: the fatal accident to a railway employee $[. .$.$] becomes a grim and mysterious$ link between them ... " 28 The similarity between the death of the peasantguard at the railroad station where Anna and Vronskii meet and the suicide of Anna herself at a railroad station is intentional; however, if in the first instance the peasant's death is probably an accident, Anna sees it as an evil prophecy. ${ }^{29}$ The Anna Karenina filmic hypertexts use this image differently: while some directors underscore with the figure of the muzhik the natural way of life that Anna is unable to share because of her misdeeds, others represent him as a terrifying warning akin to a mystical creature from typical Russian fairy tales. For example, Wright's 2012 version utilizes the peasant's accidental death as a necessary establishing element of Anna's own intended death.

\section{CUTTING ANNA'S EYES: MECHANICAL SHUTTERS AND DANGEROUS RAZORS}

The I997 hypertext, starring Sophie Marceau and directed by Bernard Rose, is faithful to Tolstoi's climactic scene in the sense that it attempts to consistently embrace all major symbols that had been incorporated into the visual language of the scene, including the dying out of a candle and the presence of a book that had been routinely dispersed throughout previous hypertexts. In addition, however, there is also a striking image, which is not explicitly present in Tolstoi's narrative- that is an image of an eye. If analyzed against the background of the classics of international and Russian cinema, this powerful image brings up numerous reverberations.

I am tempted to read this carefully inserted frame as an exquisite homage to the Russian cinematic tradition rooted in Dziga Vertov's Cine-Eyes (Kinoki) movement. His avant-garde masterpiece, Man with a Movie Camera (I929), establishes various associations between female sexuality and urban-based machines, especially the train and the camera. Lynne Kirby writes that the association of 
the camera lens and shutter with the woman's eye is the most frequently cited example of the self-reflexive operations of Vertov's film. ${ }^{30}$ Moreover, as Kirby insightfully remarks, the fact that this is first a woman's eye is often overlooked. Vertov's assimilation of the "movements of the human eye to the mechanical designs of the camera formally engages female vision in a manner much less shocking than in, for example, Luis Buñuel's An Andalusian Dog (Un chien andalou) of the same year." ${ }^{31}$ Both films, according to Kirby, ask us to

consider the female body as a surface of inscription for the filmic writing of a new vision and, in the case of Vertov, to look at the mechanical eye as forming part of a rhetoric that composes woman, cinema, the train, and the city in complex configurations. ${ }^{32}$

There is a firm connection between the conceptualization of the new Soviet art in the 1920 s and the very international perception of cinema as a new art form with revolutionary potential. Inspired by Freud, both Buñuel and Salvador Dalí embraced cinema as the ideal form to portray sexuality as a "primary, constant emotion" and "understood film as liberated from the impositions of language and culture." 33 As Ignacio López cautions, it is difficult to accept today

the authors' claim of radical objectivity, but it is this notion that accounts for the cruelty of the initial images [in Buñuel's film], including the horrible sight of a razor slashing an eye. This act, which so closely follows the ideal of provocation mandated by the Surrealists, is built upon a notion of art liberated from feelings of weakness. ${ }^{34}$

The new vision had to reflect and to adapt to the new world-the Cine-Eye group defined this transformative experience as a need to capture "film truth" (Vertov

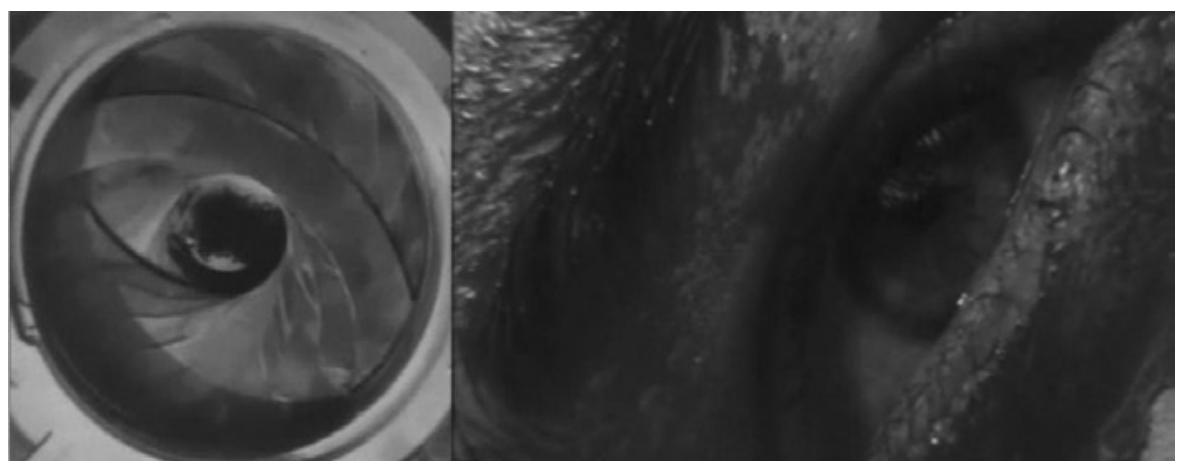

Figure 5.2 Frame from Dziga Vertov's Man with a Movie Camera (I929) juxtaposed with a screenshot from Anna Karenina (Dir. Rose, I997). 
believed that when organized together, fragments of actuality can lay bare a deeper truth unseen with the naked eye); the Surrealist circle of artists leaned toward Holy Objectivity (Santa Objetividad), which, they thought, could be achieved through the exhibition of unpleasant emotions such as fear and horror.

Wright's adaptation makes an explicit use of similarly sharp objects forming a rich motif based on the play of metal and the dangerous implications associated with its (mis)use. This motif is created through the images of a barber, who shaves Stiva while performing a dance of sorts, which exposes his client at his most vulnerable state; the scythe, both while grinding and cutting grass $; 3$ and Anna's paper knife with its sharp edge pointed directly at her left eye (discussed below). In Tolstoi's novel, the chorus of resounding metal greets Anna's sister-in-law Dolly when she arrives at Vronskii's estate. ${ }^{36}$ It is then that the "mechanics of cutting are underscored and joined to the metal motif": ${ }^{37}$ Dolly has just inspected a new reaping-machine and at the dinner table Vronskii, Anna, and other guests turn their conversation to the cutting ability of the reaper. Anna describes its working principle akin to "a lot of small scissors," and her guest Veslovskii explains: "like small penknives." 38

While Tolstoi the landowner is preoccupied in this episode with the virtues and potentially destructive forces of the iron-made machines, he foreshadows, in fact, an ideologically charged issue to be addressed numerous times in early Soviet cinema, from Aleksandr Dovzhenko's Earth (I930) to Vertov's Man

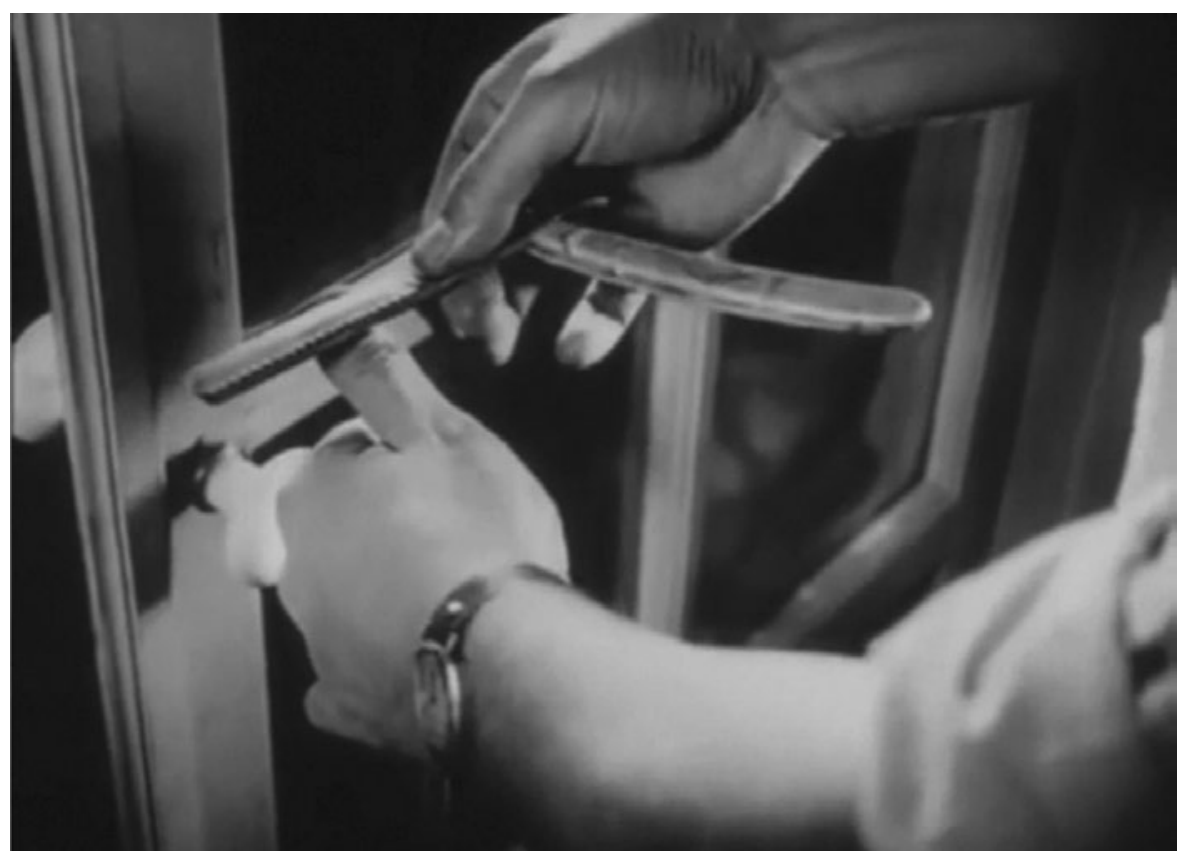

Figure 5.3 Frame from Luis Buñuel's An Andalusian Dog (I929). 

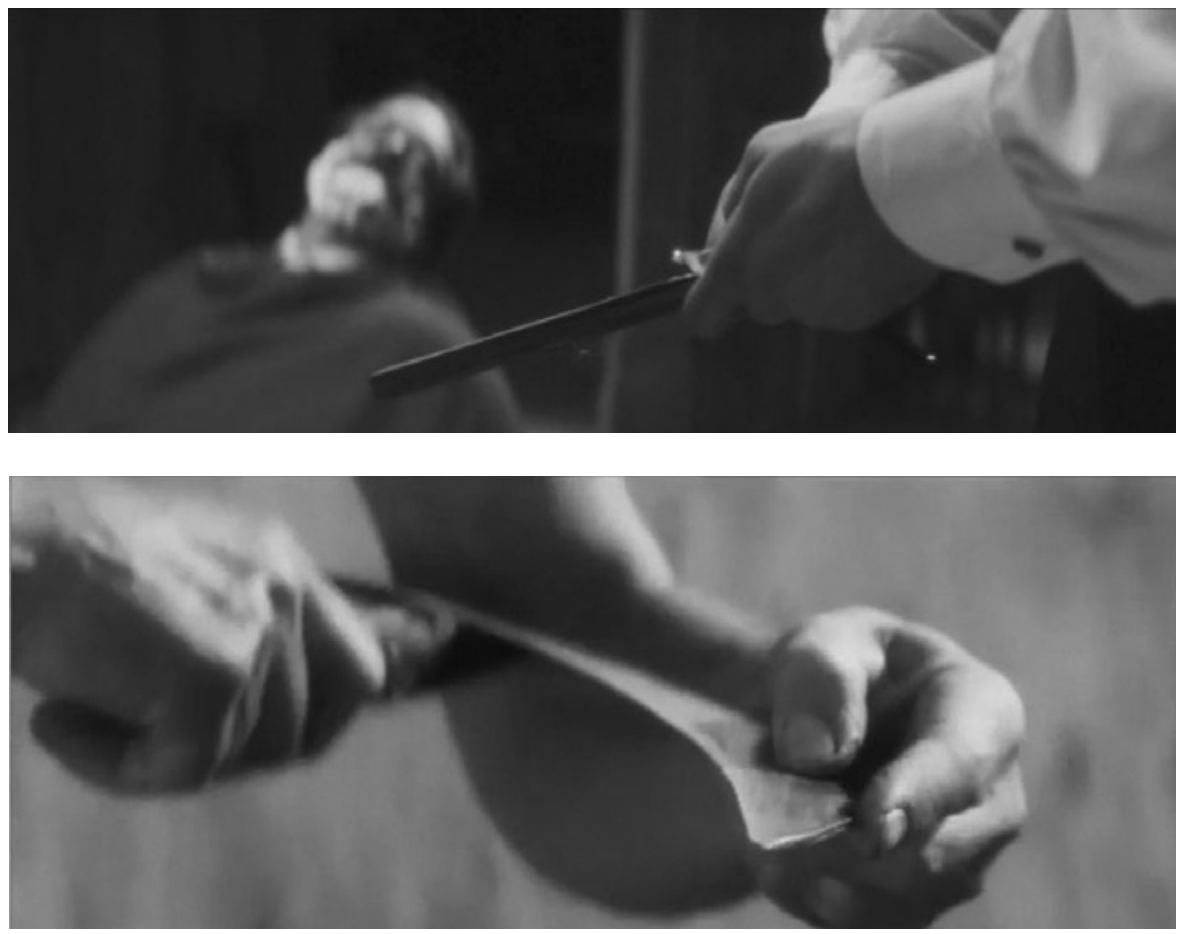

Figures 5.4 and 5.5 The cutting motif from Buñuel's An Andalusian Dog is juxtaposed with corresponding images from Anna Karenina (Dir. Wright, 2012).

with a Movie Camera. In the latter, not only a robotic eye and the metaphoric lines of communication and the modes of transportation of the modern cosmopolis are depicted triumphantly. Karl Marx's "locomotive of history"revolution-becomes a metaphor for cinema itself. An ideology of mechanized life (or "mechanical reproduction" in Walter Benjamin's terms) turns through this voyeuristic act into an Eye-deology. ${ }^{39}$ Vertov's cinematic conclusion, when the city asleep becomes completely transformed from a static into a dynamic organism, is striking because it represents "the combination of desire, vision, and aggression linked to the traumatic relation between a woman, a train, and the filmic apparatus." 40

How influential Vertov's cinematic tour de force proved to be for the subsequent hypertexts of Karenina is reinforced by the replication of a signature shot of a train made at a low angle from the pit dug between the railway track, allowing the audience to observe the belly of the passing locomotive and trucks: At least two cinematic versions use the very same technique, representing the dying Anna's point of view (Anna Karenina directed by Julien Duvivier in I948, starring Vivien Leigh, and Rudolph Cartier's British adaptation directed in 196r). 
Examining the suicide of Anna in several recent film adaptations reveals that a new cinematic hypertext has emerged with visual references to Vertov and Russian avant-garde cinema that make us reimagine the scene in Tolstoi's novel. Anna Karenina's eye is as vulnerable as ever, but it serves as a potent metaphor for the imminent danger of self-destruction through social inertia. The women of the Russian Revolution were able to harness the "locomotive of history." Vertov's "machine aesthetics rescues woman from adornment and aristocratic decorativeness," 41 and so Anna's revolt has taken on added meaning as it gains new temporal semantics over the years.

\section{RAILWAYS, SEX, AND THE MOVIES}

The love story of Anna and Vronskii began on the railway-the iron road (zheleznaia doroga in Russian) is "fatefully sealed by resounding metal."42 Many in Tolstoi's generation feared the changes in Russian life that trains would necessarily cause. Railway construction was costly and many of its builders perished because of the poor working conditions; the iron beasts on wheels "were considered evil, disruptive, and inhuman." 43

It has long been suggested that the train in Anna Karenina becomes a metaphor for the mechanical impulse of the sexual drive to which the heroine succumbs. ${ }^{44}$ A number of prominent Tolstoi scholars insist that "the imagery used to describe the suicide is sexual" and suggest the following as evidence:

the huge railway car throws Anna on her back; the peasant who appears at this point and who has appeared in her dreams is probably a symbol of the remorseless, impersonal power of sex. As he beats the iron, he pays no attention to her. ${ }^{45}$

Makoveeva maintains that "while some of the films visually focus on the sinister function of the Tolstoyan train, which transcends its commonplace task of delivering the characters to their geographical destinations, others foreground the interconnection between Anna's adultery and the railroad." 46 Tolstoi himself made this connection obvious when, in 1857 , he wrote of trains to Turgenev: "The railroad is to travel, as ---- is to love. It's just as comfortable, but just as inhumanly mechanical and fatally monotonous." ${ }^{47}$

In an early instance of the dream that Anna recounts to Vronskii, the bearded peasant runs into her bedroom; the last agonizing hours she spends on earth are also filled with sexual associations, maintains Edward Wasiolek. Anna sees the "world about her as dirty, and such dirt is associated with shame and with the self-hate resulting from the slavery of sex. [...] On the train she mentally undresses a stout woman dressed in a bustle and finds her hideous." 48 
The nature of physical passion gradually contributes to the eventual collapse of Anna and Vronskii's affair, and Tolstoi inserts a number of foreshadowing omens into the narrative to carefully orchestrate this imminent destruction. In her dream Anna sees a dreadful peasant with a disheveled beard, who mumbles in French ("il faut le batter, le fer: le broyer, le pétrir ... "). ${ }^{49}$ The French words of Anna's dream have the meaning: "you have to beat iron: grind it, knead it ..." Barbara Lönnqvist offers an insightful interpretation of this enigmatic operation: The man seems to be occupied with some creative process of forging or baking (the verb pétrir being used primarily in expressions like pétrir la pâte- “to knead dough”). Appearing as a blacksmith, by both working the iron and baking (bread), the man from a dream

joins a male activity to a female one. Both are symbol-laden in Russian culture: the blacksmith (kuznets) forges destinies, and especially marriages, which is reflected in the songs young women sing when telling their fortune at New Year's Eve. "Kneading," on the other hand, is related to childbearing in folk belief, according to which the child is "baked" in the womb. In folklore the symbolic transformation of the bride into wife is also celebrated by baking ritual "marital bread." Just like "forging," "kneading" is deeply rooted in rituals and beliefs connected with marriage and childbearing, i.e., the formation of a family. ${ }^{50}$

The feminist/Lacanian theory of cinema spectatorship was articulated first by Laura Mulvey in her influential essay "Visual Pleasure and Narrative Cinema" (I975). Judith Armstrong applies it to Anna Karenina and describes Anna in terms of a visual object. Following the cinematic codes, operating with the notions of a gaze and an object, "thereby producing an illusion cut to the measure of desire," ${ }^{51}$ Armstrong argues that Anna is "born in the first instance of the gaze of horror" that Tolstoi lets travel over the mutilated body of the real woman, Anna Pirogov, as it lay on a table in the railway station waitingroom near the Iasnaia Poliana estate; and "in the second, of Vronsky's gaze, when, after 'a single glance' (which registers Anna as belonging to the world of high society) he is 'compelled to have another look' at the lady about to enter the railway-carriage." 52 While Kitty's story is presented in a long series of sequential and consequential actions, Anna, by contrast, is viewed "in a series of vivid but still frames: Anna in the whirl of snow at the railway-station; Anna gazed down upon by the trembling Vronsky after their first sexual encounter," and so on. ${ }^{53}$ Indeed it is hard to disagree that Anna fits the female figure as described in psychoanalytic terms - "the woman as icon, displayed for the gaze and enjoyment of men, the active controllers of the look." ${ }^{54}$ What is more important for the filmic hypertexts of Tolstoi's book is that like any movie, by the act of visualization, it also becomes dependent on voyeuristic 
active/passive mechanisms. The more times that Anna commits suicide, the more opportunities there are for theory to become inscribed in the depiction. Temporal markers may include an ever harsher criticism of Anna's limited choices - criticism that may not have been embedded in Tolstoi's hypotext.

Gaylyn Studlar asserts that the masochistic narrative has a very specific story to tell and quotes Gilles Deleuze's famous definition that it is the story of how "the superego was destroyed and by whom, and what was the sequel to this destruction." ${ }^{55}$ Refuting Mulvey's seminal essay, Studlar has asserted that spectators often derive masochistic, rather than sadistic, pleasures. In an alternative paradigm of a masochistic aesthetic (Mulvey's phrase "sadism demands a story"), Studlar concurs with an inverted model ("a story demands sadism”) and expands sadism as force or aggression to include "the erotic nature of sadistic violence $[\ldots]$ and the formal expression of a desire that is always implicitly sadistic." ${ }^{56}$ To answer the ultimate question, why does Anna want to be hurt and to feel humiliated?, Edward Wasiolek also resorts to a psychoanalytic explanation of her motives behind the emotional abuse. The "trapped" nature of Anna's feelings has deep and powerful destructive drives that "can only come from early experiences"; Wasiolek believes that Anna

neurotically chooses someone who will hurt her, that she courts the feeling of being unloved, and chooses a situation in which she will feel shamed and corrupt. [...] On the night before her suicide, Anna waits in her room like a petulant child for Vronsky's return and for proof of his love by a visit to her before going to bed. ${ }^{57}$

But there is also a marked dynamic pattern in the behavior of Tolstoi's character, whereby her femininity undergoes a transformation and she assumes connotations associative with both genders. As has been noted, Anna's suicide "acquires a masculine, even a heroic character and no longer seems to belong to that register of pathetic, fallen women who die for love or its lack." ${ }^{58}$ Early in the novel, Tolstoi "allows Anna one supremely 'male' activity: he endows her with a pen, the instrument to which many theorists have appended an 'is', so great is its phallic power." 59 The ultimate fact that Anna kills herself leads Judith Armstrong to inquire: "Does this make her agent or victim? Actant or acted upon? The answer is of course that she is both." ${ }^{60}$ In Wright's version, this action is invested with both Tolstoi's description, but also, all of the scholarly criticism that has amassed over time to create an entirely new visual territory that can be explored.

Without engaging crude Freudian concepts and their subsequent interpretations by the many theorists of cinema (a woman's lack of a penis, implying the threat of castration and, hence, an inability to gain pleasure), I will cite one more instance of Anna's alleged transformation from an active to a passive 


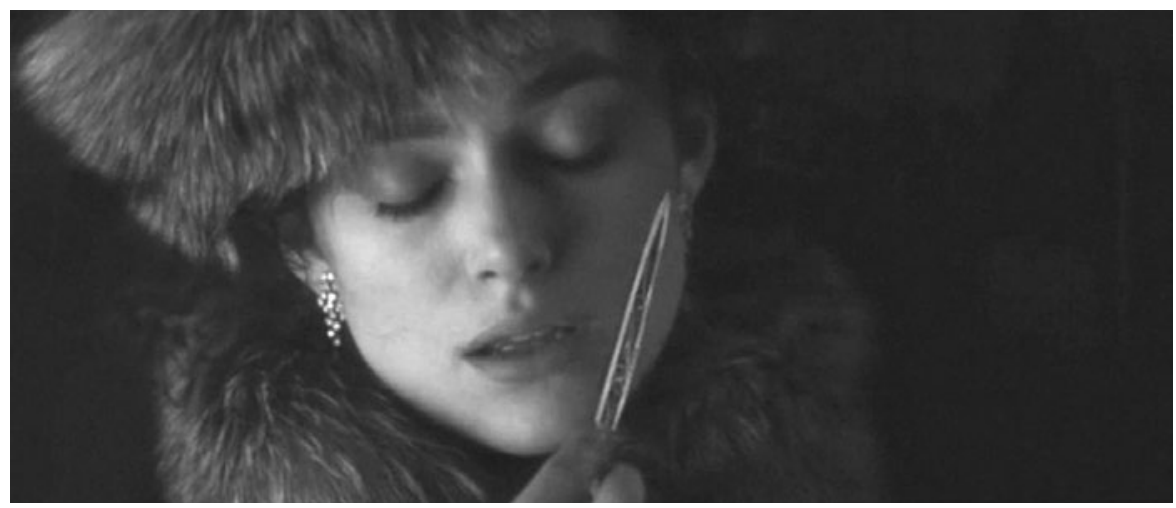

Figure 5.6 In Wright's version Anna almost touches her own face with the paper knife's edge.

participant in the text: Mandelker draws attention to Anna Karenina's play with the letter opener that accompanies her reading during the train ride:

The knife becomes a fetish, an enlarging, substitute phallus that Anna must wield or woo to gain entry into the world she decodes. The knife that cuts the pages operates as the cursor that indicates the breach between fiction and reality; thus Anna places the knife against the window glassthe membrane that separates the world from the vision of the world, the frame that imprisons experience. The knife directed against the text purchases Anna's only possible entry into the pictured world ... ${ }^{61}$

Directors must have been drawn to this embedded ambiguity of a sharp object with which Tolstoi indulges his heroine. In Wright's version, Anna almost touches her own face with the paper knife's edge (mirroring closely Tolstoi's hypotext) — which is more like a miniature double-edged sword — and this gesture is directed not only at her vulnerable eyeball, but turns the whole spectatorship process into a dual effect for the outside watchers: We are frightened and yet we do enjoy watching her inflict (possible) harm upon herself.

\section{MURDER BY LIGHT AND COLORS}

As our discussion of Anna's death has demonstrated, contemporary artists use the entire expressive palette available to them. A recurring image connected with Anna's death is the candle; however, the concepts of "light" and "dark," in general, form a special thematic thread in Tolstoi's hypotext. Tolstoi presents the burning candle as a symbol of life. The image of vital light, especially of her eyes and her smile, characterizes Anna's inner life in the first part of the novel. But when the light of Anna's passion turns into a conflagration, the course of her life literally veers off the tracks. ${ }^{62}$ 
The role of artificial light, which is attributed to machinery, is to further sharpen the contrasting dilemma of the heroine. The locomotive is reduced to a pair of burning beastly eyes in several hypertexts (filmic, ballet, and operatic). The battle of light and darkness is strengthened with flickering reflections on Anna's face as she is watching the cars passing by moments before committing suicide. The device was introduced first in Brown's film (I935), then has been applied onto "Anna's face" many times since (Garbo, I935; Bisset, I985; McCrory, 2000) and even then became a cliché. This visual effect creates a sense of insecurity and growing instability and functions as a destabilizing force.

The association of the red color with Anna's death, apparent already in Tolstoi's narrative (Anna's lips are often referred to as ruddy), became part of the visual discourse with the advent of color film. Modern directors exploit the blood color symbolism to its full potential, as is evident both from Karenina's accessories and the over-saturated red parts of the locomotive (for instance, especially vivid in Solov'ev's film). Red "has long been the color of violence, passion, and death." ${ }^{3}$ The red palette gains remarkable prominence in the suicide scene, where Anna clutches a red bag ("our old friend," as Nabokov jocularly puts it, drawing the reader's attention to this prominent detail of Anna's entourage $\left.{ }^{64}\right)$. Before hurling herself beneath the train, Anna flings aside her blood-colored bag and jumps, although in the 1977 BBC adaptation Anna's body is not shown-the red bag becomes its symbolic substitute. Conspicuously, the film's editor overlays her question ("Which way to go?") with an appropriate shot of the dual diverging tracks (as in Vertov's film), thus suggesting a metaphysical solution.

Readers' and spectators' minds are perceptible to the visualization of trauma both on page and screen, but it is the prerogative of the movie industry to impress and to shock. The violent imagery continues to dominate the Annainspired art in the past decades long after the revolutionary subtexts, both ideological (Vertov) and aesthetic (Buñuel), have been suppressed (though not entirely eliminated) by the public discourse. Since Tolstoi wrote his novel in I 876, and almost twenty years after the Lumière brothers introduced the cinematograph to the masses in 1895 , directors of various nationalities and different film schools have stubbornly continued to commit this act of violence against Anna Karenina. Each new act of violence strengthens a visual text that now reflects not only Tolstoi's hypotext, but the literary and film theory of over a century. In crossing spatial and temporal borders so many times throughout the years, a new visual vocabulary for Anna Karenina has accumulated like so many stamps in a passport or the colorful decals on the traveler's luggage. Vertov's eye, a candle, the color red, and more are now identifiable souvenirs of the suicide scene for moviegoers, not images that Tolstoi himself provided in his novel. In so many trips across the border, Anna has lost her 
distinctive Russian charm and is now an international figure, a woman known all over the world, even if the ending is always tragic.

\section{NOTES}

I. Tsivian, Early Cinema in Russia, I44.

2. Zorkaya, The Illustrated History of Soviet Cinema, 2 I.

3. Ibid., $2 \mathrm{I}$.

4. Griffith, Adaptations as Imitations, $4 \mathrm{I}$.

5. Ibid., 67 .

6. Love (I927), starring Greta Garbo, may be one of the only exceptions, in which Hollywood forces a "happy end" upon Tolstoi's novel.

7. Paperno, Suicide as a Cultural Institution, 94 (my italics).

8. Ibid., 94 .

9. Mandelker, Framing Anna Karenina, 93.

Io. Nicole Loraux's observation as quoted in ibid., 94.

I I. Ibid., 94 .

I2. Bluestone, Novels into Films, 2.

I3. In Eisenstein's essay, "Dickens, Griffith, and the Film Today"; Also see, Bluestone, Novels into Films, 2.

I4. See Lanoux, “Anna Karenina through Film,” I80; Makoveeva, Visualizing Anna Karenina.

I5. Tsivian, Early Cinema in Russia, I37.

I6. Maria Kallash, in her I9I4 letter to Chekhov's wife, the actress Olga Knipper-

Chekhov, waxed indignant: "I wasn't expecting very much, but all the same I didn't imagine that it would be such a mockery of Tolstoy." Quoted in Tsivian, Early Cinema in Russia, I37.

I7. Ibid., I37.

I8. Ibid., I I0.

I9. Ibid., I39.

20. Art critic Vladimir Stasov registered the cultural analogy prompted by the effect of Lumière's reel. Stasov referenced Tolstoi's novel in his 1896 letter after watching the now iconic short film: "All of a sudden a whole railway train comes rushing out of the picture towards you; it gets bigger and bigger, and you think it's going to run you over, just like in Anna Karenina-it's incredible." Tsivian, Early Cinema in Russia, I I I.

21. Makoveeva, "Anna Karenina on Page and Screen," I 54.

22. Helena Goscilo calls the cruel exposition of Anna's dead body "a moral autopsy," and ties it to Tolstoi's revulsion for women's libidinal urges, which compelled "him to sexualize Anna posthumously in a disturbing final image, mediated through Vronsky's pained recollections, of her sinful, lifeless body 'stretched out shamelessly [sic] before the eyes of strangers'." It is impossible, says Goscilo, to conceive "of an adulterous male body being subjected to such textual representation, which carries the weight of a moral autopsy." Goscilo, "Motif-Mesh as Matrix," 86.

23. The film won "Best Achievement in Costume Design" and was nominated for awards in three other categories: cinematography; music written for motion pictures; and production design.

24. Wasiolek, Tolstoy's Major Fiction, I49.

25. Tolstoy, Anna Karenina, 694-5.

26. Makoveeva, "Anna Karenina on Page and Screen," i I 5. 
27. Schultze, The Structure of Anna Karenina, 22.

28. Nabokov, Lectures on Russian Literature, I 89.

29. Schultze, The Structure of Anna Karenina, I I 8.

30. Kirby, Parallel Tracks, I 78 .

31. Ibid., I78.

32. Ibid.

33. López, "Film, Freud, and Paranoia," 38.

34. Ibid., 38 (my italics).

35. The activity of mowing is described as providing a physical (almost sexual) gratification, an "intense pleasure," in relation to Levin's physical sensations during the scene (Tolstoy, Anna Karenina, 228-9).

36. Ibid., 552. "The metallic sound of a scythe being hammered beside the cart ceased ..."

37. Lönnqvist, "Anna Karenina," 85.

38. Ibid., 85 .

39. Kirby, Parallel Tracks, I 78 .

40. Ibid., I79-8o.

4 I. Ibid., I83.

42. Lönnqvist, "Anna Karenina," 85.

43. Schultze, The Structure of Anna Karenina, I 8 . See also Leving, Vokzal-Garazh-Angar, I $5 \mathrm{I}-69$.

44. On the functional and symbolic significance of the four railroad episodes in the novel, see Stenbock-Fermor, The Architecture of Anna Karenina, 70-4.

45. Wasiolek, Tolstoy's Major Fiction, I 53.

46. Makoveeva, "Anna Karenina on Page and Screen," I 55.

47. Cited in Al'tman, Chitaia Tolstogo, I I8. The English translation is quoted in Schultze, The Structure of Anna Karenina, I 8.

48. Wasiolek, Tolstoy's Major Fiction, I 53.

49. Tolstoy, Anna Karenina, 329.

50. Lönnqvist, "Anna Karenina," 84-5.

5I. Mulvey, "Visual Pleasure and Narrative Cinema," I7.

52. Armstrong, The Unsaid Anna Karenina, I I 2.

53. Ibid., I I2. "[T] parallel stories of Anna and Kitty, the significance of which would be seen all the more clearly if some feature film version of Anna Karenina were to begin with a shot of Anna Pirogov's crushed body, hauled out from under the wheels of a train. If that film were made, its opening scene would predict with banal certainty not only that Anna Karenin was destined to die, but also the means of her destruction."

54. Mulvey, "Visual Pleasure and Narrative Cinema," I4.

55. Deleuze, Masochism, I I2. Quoted in Studlar, In the Realm of Pleasure, Io8.

56. Studlar, In the Realm of Pleasure, Io9.

57. Wasiolek, Tolstoy's Major Fiction, I 56-7.

58. Mandelker, Framing Anna Karenina, 94.

59. Armstrong, The Unsaid Anna Karenina, I 22.

6o. Ibid., I23.

6r. Mandelker, Framing Anna Karenina, I36.

62. For an interesting discussion of this motif, I refer to Schultze, The Structure of Anna Karenina, 127-30.

63. Ibid., I26.

64. Nabokov, Lectures on Russian Literature, I87. 


\title{
"A Vicious Circle": Karen Shakhnazarov's Ward no. 6
}

\author{
Alexander Burry
}

A nton Chekhov's "Ward no. 6" (I892) has inspired a large and varied body 1 of hypertexts in the twentieth and twenty-first centuries. The story's basic premise of a psychiatric doctor who is incarcerated in the same mental hospital he used to run proved extraordinarily generative for Russian writers in the following century, especially given the notorious Soviet practice of labeling political dissidents insane. Valerii Tarsis and Venedikt Erofeev, among others, reflect this aspect of the story in their works. ${ }^{1}$ Other major themes of "Ward no. 6," such as the unstable boundary between madness and sanity, psychological isolation from other people, and the elusive possibility of redemption - whether secular or otherworldly — have also proven important for Russian and Soviet writers. $^{2}$

Several film directors in Russia and abroad have also transported this hypotext to the silver screen, with equally diverse results. ${ }^{3}$ The most recent of these cinematic transpositions, Karen Shakhnazarov's 2009 Ward no. 6, represents a particularly innovative approach to Chekhov's story. If the dominant trend in the Russian ekranizatsiia (the term for screenings of literary works) of the early 2000 s has been lengthy televised serials that attempt to depict the literary text as "accurately" as possible through period settings, Shakhnazarov diverges radically from this approach. Ward no. 6 is set in a present-day mental hospital in the Moscow outskirts, formerly the Nikolo-Peshnoshskii monastery. Even more strikingly, the director intersperses Chekhov's fictional plot with interviews of actual patients, "mockumentary" interviews about the head psychiatric doctor Ragin, and amateur, home video-produced flashbacks of the fictional doctor's past. The actors and patients coexist on the same narrative plane, and the continual cutting back and forth between the documentary of the present-day patients, the mockumentary of Ragin, and the fictional plot has the deliberate effect of fragmenting Chekhov's narrative, and disorienting the viewer. ${ }^{4}$ Shakhnazarov's film thus presents an unusual type of 
border crossing, as he transforms Chekhov's story both temporally, with his early-twenty-first-century Russian setting, and generically, with his pastiche of cinematic genres. ${ }^{5}$

As I will argue, Shakhnazarov's mixture of genres and his contemporary setting of the plot, along with his selective rereading of the story, significantly shift Chekhov's thematic focus, developing the narrative in new directions. In particular, the director elaborates on Chekhov's references to child abuse and abandonment, emphasizing the cyclical effect of these problems on Russian society. In Chekhov's story, this theme is not as prominent as Ragin and Gromov's arguments about immortality, unjust imprisonment, and the choice of active resistance to evil vs. stoicism. Shakhnazarov further explores the theme of violence against children in his film by extending this material, recontextualizing it through real-life patient interviews, and highlighting the process of infantilization that takes place in the mental hospital. At the same time, he introduces two contrasting themes from nineteenth-century Russian culture in order to explore their significance for the present day: the possibility of Christian redemption, even in the face of the deepest suffering, and the less optimistic notion of degeneration theory, which proposes a hereditary "taint" (for both individuals and nations) that impedes progress from one generation to the next, or between eras of history, thus preventing the possibility of regeneration. Ultimately, the taint of the individual family reflects poorly on the health of the nation and, as a result, the easy transportation of Chekhov's story from the I 890 os to the early twenty-first century suggests a national pathology that has yet to be addressed in a meaningful way.

\section{CHEKHOV'S HYPOTEXT}

In "Ward no. 6," Chekhov tells the story of a disillusioned provincial doctor, Andrei Ragin, who has adopted an attitude of disengagement from the suffering around him. Despite the abominable conditions of his hospital, he makes no effort at reform and rarely even visits for rounds, preferring to devote as much time as possible to intellectual activities. However, his conversations with one of the patients, Ivan Gromov, force him to reevaluate his ideological views, and lead to his increasing rejection of the outside world. Confronting the angry Gromov during their first meeting, Ragin claims that there is no essential difference between confinement and freedom, arguing that one can be happy under any circumstances through indifference to feeling. Gromov undermines this philosophy, rooted in stoicism, by pointing out that Ragin has never actually suffered forced confinement, physical abuse, or poverty. Ragin, who has displayed signs of erratic behavior with his younger colleague Khobotov and his friend Mikhail Averianych, is eventually pushed out of 
his position and hospitalized in the very ward he had supervised. Faced with actual confinement, he suddenly realizes the flaws of his stoic philosophy (he immediately craves the physical comforts to which he is accustomed, such as tobacco and walks outside). Protesting the same conditions he had earlier minimized as unimportant, Ragin dies following a severe beating from the ward's brutal orderly, Nikita.

"Ward no. 6" occupies an unusual position in Chekhov's literary output. Having begun as a writer of humorous sketches (under the pseudonym of "Antosha Chekhonte") in order to support his family while he studied medicine in Moscow, Chekhov decided to devote himself full-time to writing in the late i 880 os. This decision resulted in more developed short stories and longer works such as The Steppe (i888); it also led to some regret for putting his original chosen profession, medicine, on the back burner. "Ward no. 6," written in I 892 , closely followed Chekhov's i 890 voyage to the penal colony of Sakhalin Island, a trip that the writer acknowledged taking in part to make up for what he perceived as a lack of usefulness to society after reducing his work as a doctor. ${ }^{6}$ This six-month commitment involved extensive interviews with prisoners, medical treatment, and the first census ever taken of the island. It culminated in the I 895 non-fiction work Sakhalin Island, a description of the colony's horrific conditions that is all the more shocking for its typically Chekhovian understated tone. The book serves as a description of social, economic, and medical conditions of Russian settlers, most of whom were convicts, as well as the native Ainu and Gilyak populations. Among the deathly, unsanitary conditions Chekhov describes are filthy toilets, poor nutrition, prostitution, flogging, executions, and other dehumanizing conditions of the island. Chekhov's description of this fringe of an empire implicitly compares Sakhalin to Russia itself, using it to imply the awful conditions of Russia much as Fedor Dostoevskii subversively described the Siberian prisons as preferable in some ways to life for the majority of peasants in Russia in his quasi-fictional prison memoir Notes from the House of the Dead (I86I-2). Chekhov, quoting Baron Korf, remarks: "I am convinced that the 'unfortunates' live better on Sakhalin than in any other place in Russia or even in Europe."

Along with this contribution to the all-too-extensive series of Russian prison narratives, Chekhov's trip left its mark on other works as well. Uncle Vania (I897), one of his four major plays, contains numerous references to prisons, mazes, and is occasionally punctuated by a watchman making rounds, underscoring the notion of the country estate as a prison. ${ }^{8}$ One of his best-known stories, "The Lady with a Little Dog" ( 1898 ) refers to its adulterous protagonists, Dmitrii Gurov and Anna Sergeevna, as "two migratory birds, a male and a female, who had been caught and made to live in separate cages." ${ }^{9}$ Such works metaphorically suggest the state of incarceration that Chekhov presents 
more literally in Sakhalin Island and "Ward no. 6." ${ }^{10}$ Chekhov deliberately describes the hospital in this story like a prison, suggesting uncomfortable parallels between the medical and penal institutions in late-nineteenth-century Russia. ${ }^{11}$ This focus distinguishes the story stylistically as well. The opening, with its description of the facility, is unusual for Chekhov's fiction in that it incorporates documentary features:

In the hospital yard there is a small outbuilding surrounded by a dense jungle of burdock, nettles and wild hemp. The roof is rusty, half of the chimney has collapsed, the steps to the door are rotten and overgrown with grass; only traces of plaster remain. The front faces the main hospital and the rear looks out on to open country, from which it is cut off by the grey hospital fence topped with nails. These nails, with their points sticking upwards, the fence and the outbuilding itself have that mournful, god-forsaken look that you find only in our hospitals and prisons. ${ }^{12}$

Because of this stylistic feature, Chekhov's story "invites" prospective filmmakers to envision his narrative as a generic mixture of fictional and documentary features.

\section{SHAKHNAZAROV'S HYPERTEXT}

Shakhnazarov highlights his provocative mixture of genres from the very beginning of the film. Although the title directs the viewer to think of Chekhov's story, the opening scene consists of interviews with actual psychiatric patients. An invisible cameraman, most likely Shakhnazarov himself, asks several patients in their twenties and thirties about their past, how they wound up in the institution, and their hopes for the future. Only after this scene, a voiceover recounting of the history of the hospital since medieval times, and an interview with Dr. Khobotov (Evgenii Stychkin) about mental illness (not included in Chekhov's story), does the director lead imperceptibly into the main plotline involving Ragin (Vladimir Il'in) and Gromov (Aleksei Vertkov).

As Yana Meerzon remarks, Shakhnazarov's juxtaposition of the fictional and the documentary evokes Chekhov's own mix of styles in his story, and in doing so calls into question the very notion of cinematic authenticity: "Shakhnazarov forces his audience to wonder whether what we see on-screen is real or fictional." 13 Meerzon argues that although Shakhnazarov clearly examines social ills and spiritual questions, the film is most interesting for its replication of Chekhov's generic complexity. Shakhnazarov's very mixing of genres encourages the viewer to question the ability of the camera accurately to 
record and communicate the human experience. As John McCarthy similarly notes in his Box Office Magazine review of the film,

The movie's documentary overlay suggests that for all our ability to record everyone on film with the [aid] of new technologies-i.e., without one authoritative camera - there still remains a level of human experience that can't be contained or communicated. Whether it's dismissed as absurd, avoided as disconcerting, or embraced as a source of solace, we find ourselves unable to escape religious and spiritual concerns. No matter how meticulously it is captured or relayed, a history is not a bulwark against uncertainty or madness. Then again, nor does it preclude knowledge and understanding. ${ }^{14}$

Shakhnazarov's setting of the story thus seems more interesting for its reordering and expression in various genres than for any development of the hypotext's actual content and themes. Indeed, for the most part, the director reproduces Chekhov's plot. With the important exception of a relatively "happy ending," in which Ragin survives his stroke and is able to celebrate the New Year, Shakhnazarov transfers Chekhov's content to his film. ${ }^{15}$ However, through his references to Christianity and degeneration theory, the director actually forces the audience to view Chekhov's hypotext through a unique intertextual prism.

\section{CHEKHOV AND DEGENERATION THEORY}

Transpositions of literature into film, by necessity, involve multiple intertexts, as the film incorporates not only its hypotext, but also many of that work's sources. In developing Chekhov's material, and in his intermingling of several film genres, Shakhnazarov also reveals the richness of the writer's own intertextuality. In both cases of the themes he emphasizes - the underscoring of cyclical violence and the notion of spiritual regeneration-Shakhnazarov implicitly refers to one of Chekhov's key sources, Dostoevskii's The Brothers Karamazov (I 880), with its concern for these same issues. In this manner, he adds new layers to a longstanding literary and cultural dialogue.

As explorations of the possibilities of redemption from cyclical evil, especially in the context of mental illness, Shakhnazarov's, Chekhov's, and Dostoevskii's respective narratives can be productively framed by the "degeneration theory" that dominated Russian and European thought on mental illness at the turn of the twentieth century. Frederick H. White, in a recent study on degeneration theory and turn-of-the-century writing, traces an evolving discourse on madness in works on the subject by Vsevolod Garshin, Chekhov, and Leonid Andreev. ${ }^{16}$ Chekhov's "Ward no. 6" replaces the romantic narrative of heroic 
madness employed by Garshin in his I 883 story "The Red Poppy" with a more scientifically oriented discourse, which reflects an implied distrust of psychiatry as a science, since the fate of Ragin suggests that anyone can be declared insane simply for exhibiting such "abnormal" behavior as enjoying the company of a patient. ${ }^{17}$ As White points out, The Brothers Karamazov seemed to exhibit for Russian writers, Chekhov included, what was being asserted as scientific fact by European medical theorists like Benedict Morel, Cesare Lombroso, and even Max Nordau, who wanted to demonstrate that moral and psychological degeneration was hereditary in nature. Russian readers only had to look at the Karamazov family to understand what these medical personages were asserting so assuredly. ${ }^{18}$ Based on Dostoevskii's own critique, especially in the Writer's Diary, of environment as an external explanation of crime that could substitute for personal guilt and repentance, and his fervent belief in the power of human freedom and choice in everyday and spiritual matters, it is likely that he would have rejected the hereditary explanations for human behavior that were in vogue in the decades after his death. Nevertheless, Dostoevskii's readers themselves were fully aware of these theories, and could read them into his works.

Chekhov's views on the theory of the hereditary taint, of which he was certainly cognizant, shifted from the late i 88 os through the i 890 os. His early enthusiasm for Darwinian evolution was tempered by his concerns about the popular Social Darwinist theories of his time. As Michael Finke shows, Chekhov feared his own possible degeneration (his tuberculosis was thought to be inherited), but also viewed his life as a battle to overcome this supposedly hereditary condition. ${ }^{19}$ His progressive doubts concerning hereditary degeneration can be seen not only in "Ward no. 6," but also in his story "The Duel" of the same year. In "The Duel," a dissipated romantic, Ivan Laevskii, drinks, gambles, and carries on an affair with a married woman, Nadezhda, with whom he has grown tired. His former friend Von Koren, a zoologist and proponent of Social Darwinism, challenges him to a duel, out of sheer animosity. The duel is stopped before either man dies, however. Afterwards, Laevskii, to Von Koren's surprise, reforms, recommitting himself to Nadezhda and working to improve his financial situation. Thus, Von Koren's explicitly stated conviction of his opponent's degenerative tendencies is proven decisively incorrect. ${ }^{20}$ As Finke argues, Chekhov also rejected these deterministic views in "Ward no. 6," and critiqued the notion of heredity as a cause of Gromov's and Ragin's incarceration. $^{21}$

Regardless of whether the characters' fates stem from heredity, parental upbringing, or the characters' own choices, however, Chekhov describes a distinctly cyclical effect from generation to generation, and raises the question of whether it can be overcome. Shakhnazarov, in turn, picks up on this theme, and attempts to resolve the question in his own way. He does so primarily by exploring the state of contemporary mental hospitals and contrasting them 
unfavorably to those of earlier eras, particularly in their lack of progress in treating patients with compassion. Perhaps the very fact that the same subject of abuse of mental patients turned out to be as apt in 2009 post-Soviet Russia as it was in I988 Soviet Russia, when he first conceived of the film (or in I 892 imperial Russia, for that matter), demonstrates the intractable nature of the problem.

\section{OPENING INTERVIEWS}

Although Shakhnazarov does not attempt to mute the continuing horrors of incarceration in a mental hospital through the twentieth century and beyond, his portrayal of them is noticeably different from Chekhov's. In the first pages of "Ward no. 6," Chekhov focuses on the physical conditions of the hospital, before moving on to its moral and psychological decrepitude. He refers to the hospital's "black as soot" ceiling, and "a stench that immediately makes you think you are entering a zoo." 22 In Shakhnazarov's film, by contrast, the mental ward itself is actually almost cheery, with fairly comfortable-looking cots, a clean appearance, food that resembles common Russian café fare,

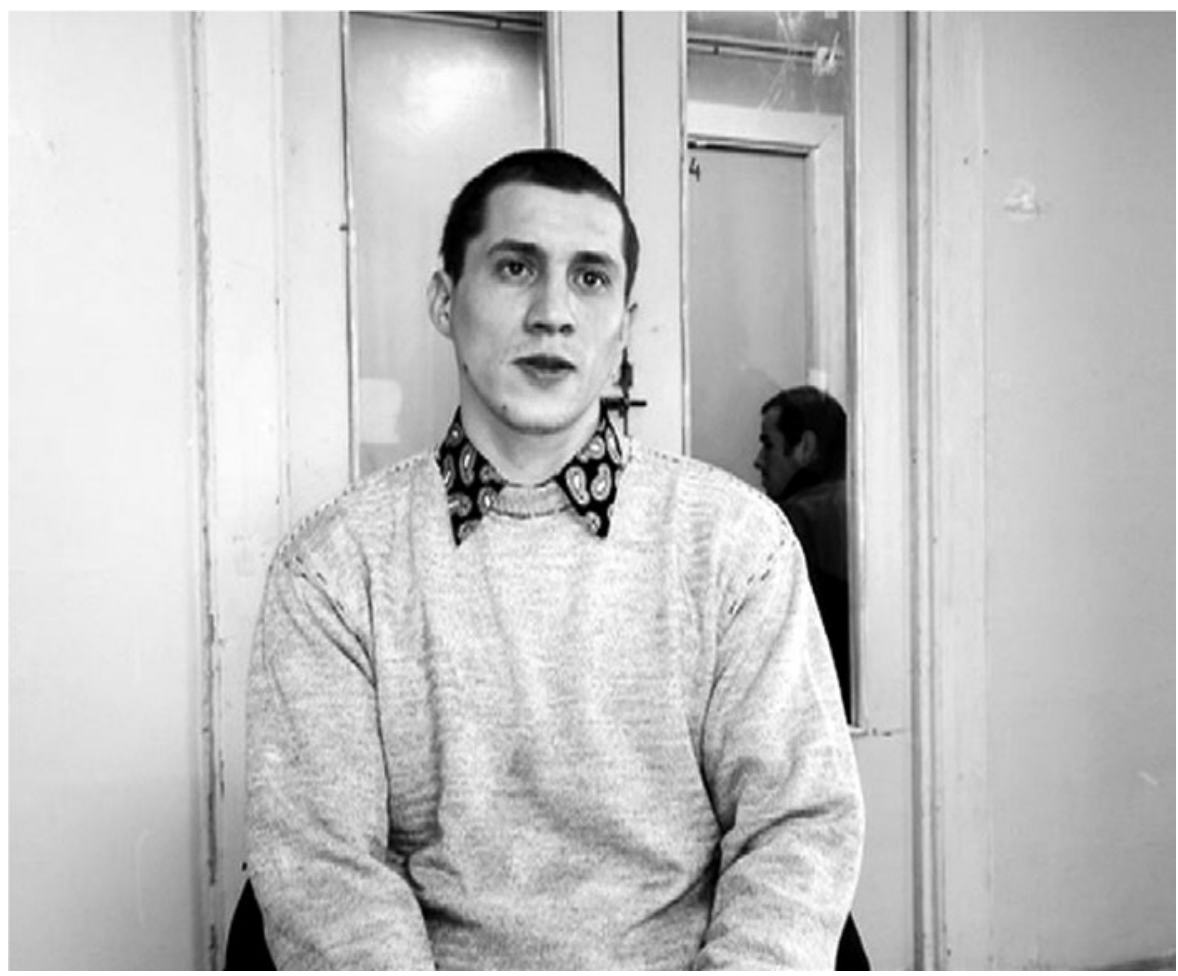

Figure 6.I Vladimir Kozlov, an actual patient interviewed in Ward no. 6. 
tapestries on the wall in the sleeping area, and encouragement of the patients' artistic and other talents. ${ }^{23}$ This does not mean that the hospital experience is any less harrowing; but the focus is shifted immediately from the rotten conditions observed early in the story to more philosophical questions of captivity and freedom. ${ }^{24}$

The interviews of present-day patients that open the film are a key to understanding Shakhnazarov's particular interest in Chekhov's story and its relevance for past and present Russian reality. They offer a concise summary of the story's major themes and recontextualize them in current Russian reality. Through them, Shakhnazarov "doubles" major parts of the conversations between Ragin and Gromov-particularly on childhood trauma, redemption, and immortality - that he reproduces later in the narrative. The following selection from the first patient's interview illustrates these concerns:

PATIENT: Kozlov, Vladimir Vladimirovich. Born Aug. I 5, I979.

INTERVIEWER: How long have you lived here?

PATIENT: It's my fifth year here.

INTERVIEWER: And before that?

PATIENT: Moscow Boarding Home 30. And before that it was the school for handicapped children. I got there after ... After my parents abandoned me at five. I mean, they didn't exactly abandon me. They were deprived of parental rights and I was given over to public custody. I had good teachers. They taught me a lot: cooking, sports. [...]

INTERVIEWER: Have you got a dream?

PATIENT: Yes.

INTERVIEWER: What is it?

PATIENT: I want to leave here, have a family, children, work ... Cause I'm fed up ... Twenty-five years of life at public expense because of my parents, those alkies deprived of parental rights ... They were gone before their time. They left me to the memory of fate.

The most striking part of this interview, perhaps, is the patient's focus on the roots of his mental illness and lot in life in his upbringing by alcoholic, incompetent parents. ${ }^{25}$ This becomes a refrain in the interviews. The patients do $n o t$, as we might expect given the Chekhovian narrative that follows, complain about hospital conditions: in some cases they even praise them. They trace their present-day fate to their parents' alcoholism, irresponsibility, and abandonment of them, rather than emphasizing the unfairness of an institution that treats patients like prisoners. The second (unnamed) patient similarly refers to his parents' abandoning him, blaming it for his growing up to be a "hooligan" in the orphanages. He remarks: "If they had taken care of me earlier, when I was little, I might have become a normal man." The third patient, after 
describing his mother and where she lives, admits that he has never seen her: "She disowned me right after I was born."

Given the attention the problem of Russian orphans has received in the last several years, which have witnessed Vladimir Putin's 2012 ban on American adoptions, this part of the film is even more topical now than when Shakhnazarov first conceived of the film in the last years of the Soviet Union. As of 2013 , approximately I20,000 children, many of whom-like these prisoners-are mentally and physically disabled, become orphaned each year. Out of the over 650,000 registered orphans in Russia, more than half grow up in orphanages, and move on to other government institutions as adults. ${ }^{26}$ Moreover, the over-diagnosis of orphans as mentally or physically disabled confirms that the notion of a hereditary taint exists today, just as it did in the I89os: "Even if abandoned infants do not display severe physical or mental disabilities, however, they often come from families with chronic social, financial and health problems - including alcoholism — and they cannot escape the stigma applied to that past." 27 The lack of proper diagnosis, and the resulting ill-treatment of children in orphanages and-later-in mental hospitals often leads to overcrowding of facilities, poor hygiene, and inadequate care that allows the initial misdiagnosis to come true.

Even in the best case, children who are closest to normal health at birth become retarded to some degree after these four years of collective living, deprived of individual nurture. An alarming number of less resilient infants seem to succumb to a self-fulfilling diagnosis of retarded. ${ }^{28}$

Thus, a vicious cycle is perpetuated, in which parents with alcoholism, poverty, and other social problems abandon infants; the orphans are ill-treated and stigmatized, and eventually fall into the same habits as their parents.

The interviewer also asks the patients to describe their hopes and dreams, which inspires varying responses. Significantly, in two cases, the patients express a desire to meet a girl, get married, and have children. The first patient (Kozlov) speaks of wanting to free himself from "twenty-five years of living at government expense." In conjunction with the description of their childhoods, these responses convey a desire to break the cycle of abandonment, abuse, and dependence by becoming independent people capable of having families, caring for others, and living normal lives. The second patient, by contrast, remarks with a pessimistic laugh that "only death can change me," and the fourth frankly answers: "You shouldn't believe in dreams. They never come true." The interviewer also solicits the patients' ideas on God and immortality. Kozlov answers that though he was baptized, he only has faith in himself and his own potential. The second patient, however, remarks that he believes in good overcoming evil. To the cameraman's approving remark ("It's good 
that you have faith" 29 ), he responds: "Of course I believe, and I will [continue to] believe." Thus the patients give contrasting responses, and the question of hope for the future is left ambiguous.

By placing these interviews at the beginning of the film, Shakhnazarov draws attention to aspects of Chekhov's hypotext that are of crucial importance, but may not necessarily strike the reader as such on first reading. The question of immortality, a crucial part of Ragin's discussions with Gromov, is easier to recall, and connect back to the story's themes. Less visible, perhaps, is the question of child abuse and abandonment, and the cycle of harm it creates. However, this turns out to be a very important part of the discussion as well: Gromov's attempt in Chekhov's story to prove that Ragin has not experienced true suffering, and therefore has no right to preach his "stoic" attitude toward it to those who are in the captivity of a mental ward, hinges on his childhood experience. Gromov tells Ragin in their first conversation that he (like Chekhov himself) was cruelly beaten as a child, and asks if Ragin too was beaten. The doctor responds that his parents "were averse to corporal punishment." 30 Gromov's father's conviction for embezzlement and subsequent death has destroyed the family, and most likely brought on the son's persecution mania. As Finke points out, however, Gromov is incorrect, as both patients, in fact, have experienced some type of parental abuse. ${ }^{31}$ The narrator reports that Ragin only became a doctor because his father had threatened him with disownment if he followed his chosen vocation of the priesthood; Ragin was thereby condemned to a profession in which he had no interest. In this sense, Ragin and Gromov have both in effect been stunted (physically and/or spiritually) by their fathers. The main themes of Shakhnazarov's interviews - the effect of destructive parents and the question of immortality - thus recall Ragin's and Gromov's own biographies and discussions.

\section{CHEKHOV, DOSTOEVSKII, AND THE HEREDITARY TAINT}

The opening interviews of the film, by extension, also bring to mind The Brothers Karamazov, which focuses even more overtly on abused children and religious belief. Andrew Durkin has noted many parallels between the two works, especially Chekhov's numerous allusions to Ivan Karamazov. Gromov shares this character's first name, background as an intellectual who devours books and ends up going mad, polemical style, and murderous expressions. ${ }^{32}$ As he puts it, "Gromov has assimilated several of Dostoevskii's crucial concerns (cruelty to children, immortality, the existence of God)." 33 Ragin also shares key traits with Ivan Karamazov, since he denies immortality, 
arrives at the truth only at the cost of his sanity, and-like Ivan with his Devil-is forced to confront the banality of his own ideas.

Chekhov's focus on the cyclicality of evil also recalls Dostoevskii's novel. In The Brothers Karamazov, absent or abusive parents create a chain of violence and abuse. Following the opening descriptions of the three Karamazov brothers, Dmitrii, Ivan, and Alesha, the narrator reports that their father simply "forgot" them. Dostoevskii implicitly ties Fedor Pavlovich Karamazov's negative act of forgetting his sons to his own fate. Crucially, when Alesha falls into a fit as his father speaks disrespectfully of his mother, Fedor Pavlovich inadvertently insults Ivan by forgetting his parentage; the furious Ivan will eventually play an important role in his father's murder. And as Vladimir Golstein argues, Fedor Pavlovich's putative illegitimate son Smerdiakov's violent actions — including the actual patricide — can be connected to his ill-treatment by three father figures: his presumptive biological father; his adoptive father, the abusive servant Grigorii; and his intellectual "father" Ivan, whose ideological principle that without God "all is permitted" sows the seeds of patricide. ${ }^{34}$ Dostoevskii proposes that only a breaking of this chain can remove-or at least mitigate - the sins of the father. He optimistically implies that surrogacy can accomplish this by countering the effects of an absent or abusive father. Alesha takes on Father Zosima, the revered spiritual leader of the local monastery, as a substitute for Fedor Pavlovich, and then fulfills a similar role in mentoring Kolia Krasotkin and his schoolmates. Similarly, Dostoevskii contrasts the Snegirevs with the Karamazovs, as Captain Snegirev's love for his dying son Il'iusha and Il'iusha's fierce loyalty toward his father offer an alternative model of father-son relations.

Chekhov draws darker conclusions than his predecessor in his portrayal of the impact of fathers on sons, and more importantly, the difficulty of breaking damaging patterns from generation to generation. "Ward no. 6" is filled with cruel repetition and cyclicality, as destructive and inhumane events repeat themselves in both immediate and more large-scale temporal contexts. Ragin becoming a patient in his own psychiatric ward is the most obvious such example. Gromov sadistically points out the irony of this turn of events: "Once you used to drink people's blood, now they'll be drinking yours." 35 Smaller examples of this repetition occur throughout the narrative. Gromov's violent language when he first sees Ragin ("Thief! Charlatan! Hangman!"36) is echoed later by Ragin himself, who yells at his replacement, Dr. Khobotov, and his meddling friend Mikhail Averianych and tells them to go to hell. The cyclicality embedded in Chekhov's plot creates a sense of deadly repetition and entrapment, which Ragin refers to three times in one of his conversations with Mikhail Averianych: "I've fallen into a vicious circle. Everything-even the genuine concern of my friend-points the same way-to my eventual destruction." 37 
On a larger scale, this cyclicality underscores possible patterns of hereditary degeneration. According to the medical science of Chekhov's day, the law of progressivity suggested that destructive biological material (immoral behavior as well) could be transmitted within a family. Over the course of several generations, early signs of degeneration (neurasthenia being one possibility), might progress within the family to alcoholism and, eventually, to idiocy. The belief was that criminal and immoral behaviors were not socially constructed, but indications of a hereditary taint, an outward sign of a person (and, ultimately, a nation) in the process of devolution. ${ }^{38}$ Gromov's incarceration in a hospital essentially repeats the fate of his father, who has died in a prison hospital following his arrest for embezzlement. A combination of parental abuse and absence triggers his break from sanity, and leads him down the same path as his father. Ragin similarly reacts adversely to his own father's violence (discouragement of his spiritual development) by retreating into the world of books, and refusing to engage others. Chekhov seems to doubt the possibility of recovery from this cycle. The hospital offers surrogate parents, to be sure, but they are even more abusive. The individual, Chekhov implies, can only achieve transformation on his own. Tragically, Ragin's realization that his stoical philosophy was bankrupt in the face of actual suffering comes too late for him to gain more than a moment of redemption, as he dies shortly after his stroke. ${ }^{39}$

In an interview for the film, Shakhnazarov compares Dostoevskii and Chekhov as "religious writers," so he may very well have had The Brothers Karamazov and its impact on "Ward no. 6" in mind when working on this film. ${ }^{40}$ By prefacing Chekhov's plot with these real-life interviews on the same themes, he extends this dialogue, encouraging us to re-examine this feature of the story and its predecessor. The opening interviews seem to leave the issue unresolved. Two of the patients hope to break the pattern of abuse by marrying and having families, and by freeing themselves from a journey from parent figure to parent figure. The comments by the other two that only death can change them, and that it is useless to hope, on the other hand, imply the impossibility of interrupting the law of progressivity. Moreover, unlike his predecessors, Shakhnazarov also emphasizes the role of mothers in this social crisis; he thus suggests that the crisis is more pervasive even than in previous eras.

PARENT-CHILD RELATIONS IN WARD NO. 6

Like Chekhov and Dostoevskii before him, Shakhnazarov explores metaphorical parent-child relations. The mental hospitals in both versions of "Ward no. 6" demonstrate this quite dramatically through the relations between 
abusive father figures - those in charge of the ward - and the patients, who are placed in subservient, child-like positions. Chekhov portrays the role of the ward officials in relation to the patients much as Michel Foucault describes the state taking on the role of a father figure for the mentally ill, treating them as children and giving them minority status. Foucault argues that medical professionals exercised moral and social authority over the minority status of the mentally ill, relying on the parental techniques of authority, judgment, punishment, and love. ${ }^{41}$

If anything, however, the ward's relatively civilized appearance in the film underscores a problem that is present but understated in Chekhov. The hospital becomes not just a prison, in which one has little hope of being cured, but also a return to a bleak childhood. Shakhnazarov uses the film's various genres to emphasize a kind of infantilization of the prisoners by "father figures" Khobotov and Nikita (Viktor Solov'ev), in which patients are condescended to, punished for rebellion, and rewarded for good behavior.

Several of the interpolated scenes in the film-particularly those involving actual patients-develop this theme of infantilization. The "mockumentary" interview of Ragin's replacement, Khobotov, early in the film demonstrates it. Following his discussion of the borderline between the "normal" and the mentally ill, the doctor proceeds to treat an artistic patient with condescending friendliness, referring to him as an avant-garde artist despite the patient's insistence that he's a realist. He also brushes aside the patient's complaint of "too many injections," clearly viewing him and the other patients as nothing more than case studies. Ragin, by contrast, is shown to have a more egalitarian attitude toward patients, as he sits on the bed with Gromov during their conversations (as in Chekhov's story) and takes him seriously as an equal from the beginning. Thus, by adding this "mockumentary" interview, Shakhnazarov seems to contrast two modes of doctor-patient relations. These contrasting relations are already present in Chekhov's story, but Shakhnazarov reinforces them by interpolating parallel interviews with real patients.

The conclusion of the film's narrative, which alters Chekhov's considerably, similarly focuses on the theme of parenting in relation to Russia's future. Following Ragin and Gromov's beating, Shakhnazarov transforms the brutal Nikita into a more benevolent "father figure," who somewhat grimly hands out presents and invites the patients to celebrate the New Year by dancing with female patients from another ward. We find out here that-unlike in Chekhov's story-Ragin has survived his stroke, although he is expressionless and incapable of speech.

This alteration may seem to be a tacked-on "happy ending": Shakhnazarov is clearly trying to interject a note of hope through the pop tune, the Christmas tree, and "Happy New Year" sign, with their obvious religious and secular associations with birth and renewal. One could argue, though, that several 


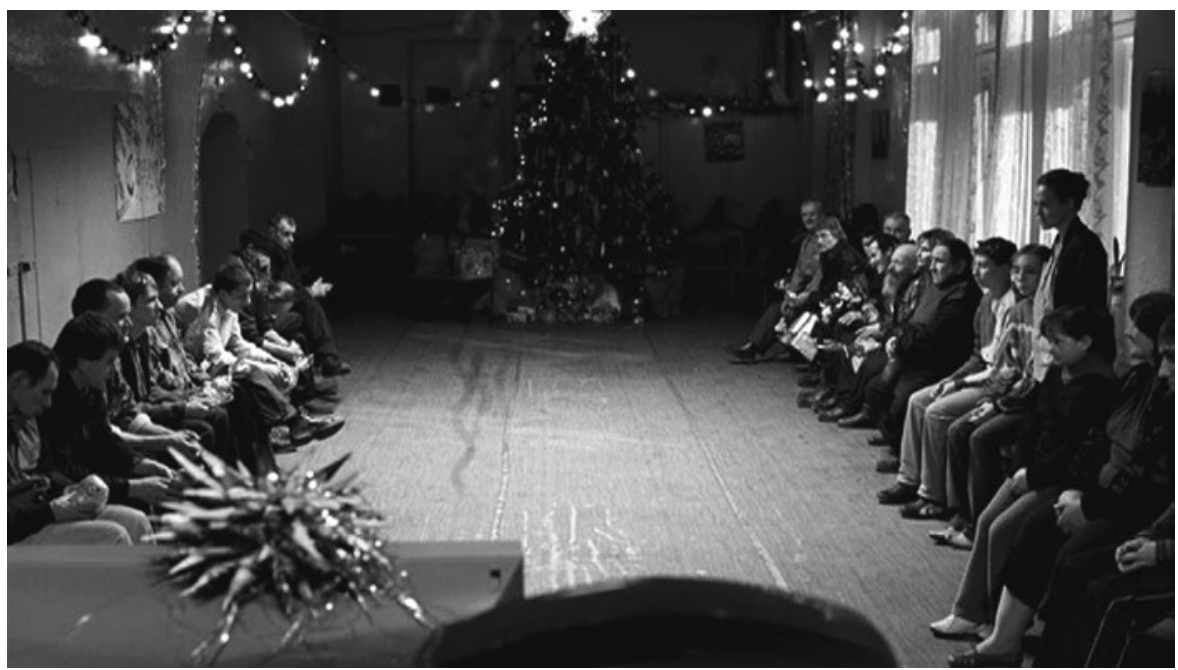

Figure 6.2 The real and fictional patients of the ward at the New Year's party.

factors vitiate this optimism. The image of Nikita leading a celebration, immediately following the scene of his brutal beating of Ragin and Gromov, seems incongruous and even grotesque. Ragin's stunned, uncomprehending expression and slumped posture here and during the dance that follows also add a note of despair. ${ }^{42}$ Arguably, the lasting image is of the patients' continuing infantilization, as they are given what look like children's gifts; the dance that follows seems like a parody of a New Year's celebration, or a secondary school dance. In Chekhov's story, after all, Ragin at one point thinks to himself: "They put on shows and organize dances for lunatics, but still they don't let them go out when they want to," which would seem to indicate a certain futility in the event. ${ }^{43}$

\section{SHAKHNAZAROV'S ENDING}

The final scene of Ward no. 6, which also focuses on the issue of parenting, leaves the film in an uncertain state regarding future generations, and the future of Russia. In this sense, Shakhnazarov marks a position somewhere in between Dostoevskii's hopes for an overcoming of the cycle of father-son strife in the later parts of his novel and the pessimism expressed by Chekhov in his story. In a final "mockumentary" scene, Shakhnazarov films an interview with the widow Belova, whose daughters Ragin used to care for when her drunken, violent boyfriend visited and caused scenes. The scene is drawn from an offhand comment in the hypotext following Ragin's relinquishing of his hospital lodgings in order to become a boarder in a small house in 
town. The narrator reports that the landlady's lover often terrifies her children at night: "Feeling sorry for the weeping children, the doctor would take them to his room and put them to sleep on the floor, which gave him great satisfaction." $" 4$

Shakhnazarov, drawing out the possible implications of this line, expands it into the final scene of the film. Belova, sitting on the couch with her daughters, describes Ragin's kindness to them, asking her daughters about him.

BELOVA: My lover sometimes stayed the night ... Always drunk, he'd install himself in the kitchen, terrifying everyone, clamoring for vodka. My kids were terrified ... and cried ... The doctor would take them into his room and lay them to rest, which gave him great pleasure. (Turning to her younger daughter.) Remember Uncle Andriusha?

DAUGHTER: Yes.

BELOVA: What kind of person was he?

DAUGHTER: Very nice. We loved him very much.

The girls nod, and the younger one controls her mirth with great difficulty, finally bursting into laughter. In the final shot, the camera pans back and forth between the younger sister laughing and the older one showing a more subdued, serious expression with only a faint smile, briefly panning upwards to the 2008 calendar before moving back to Belova and her daughters.

It is possible to interpret the passage to a new year in light of the redemption and regeneration suggested by the New Year's party of the previous scene. The film's final scene may be an attempt to resolve the problem of degeneration in a positive manner, as Ragin's interactions with Belova's daughters have clearly improved a difficult situation in a small way. Shakhnazarov draws out a minor, easy-to-miss comment in Chekhov's story, using it to force the audience to rethink the issue of personal and national degeneration. If our final images of Ragin in Chekhov's story are of his brutal death, slipping into oblivion, and the lack of impact on those around him (his funeral is attended only by Mikhail Averianych and his housekeeper Dariushka), Shakhnazarov leaves us not only with his survival of Nikita's beating but also an image of paternal kindliness to the younger generation. The director implies the possibility, at least, of breaking the cycle of harsh parental behavior. The girls' father is absent, the surrogate father (Belova's boyfriend) is cruel, and Belova herself is damaged by her ill-treatment as a single mother at the hands of a cruel man; however, Ragin's surrogate parenthood, potentially, can contribute toward healing this trauma. The brief shot of the newly begun 2008 calendar, in this light, recalls the celebration at the mental hospital, and reinforces the possibilities of rebirth that it offers. The camera's focus on the older daughter's sad, wistful smile, however, provides a more sobering 
image of the future; Ragin's contribution is most likely too small to affect the problem in any major way. More likely, Shakhnazarov uses the image to note the ongoing nature of alcoholism, broken homes, and abusive mental hospitals and prisons, problems that continue unabated more than a century after Chekhov and Dostoevskii explored them in their literary works. Until the cycle is interrupted at some deeper level, Shakhnazarov seems to imply, the cycle of national tragedy will continue for another century.

\section{CONCLUSIONS}

Shakhnazarov's film reveals some discrepancy between the director's intent and the film's actual effect on the audience. At several points in Ward no. 6, Shakhnazarov attempts to draw out the potential for religious redemption from Chekhov's text. In his first scene after the credits, which follow the opening interviews of the patients, a child voice-over details the history of the monastery, and its transformation into a mental hospital. In this scene, a miracle is reported, as a young girl, thought to be dead, is revealed to be alive in her coffin. The scene ends with several monks and nuns following a deer; one of these nuns is revealed in the final scene to be the attractive girl who invites the mute Ragin to dance with her in the New Year's festivities led by Nikita. These early scenes, like the New Year's celebration to which they are symbolically connected, offer images of resurrection and regeneration, and implicitly suggest the healing potential of Christianity through the monastic tradition.

These passages have a somewhat tenuous connection to Chekhov's narrative. In the story's final paragraphs, Chekhov shows Ragin's final state of mind before descending into oblivion. Ragin thinks of the millions of people who believe in immortality, and wonders if it really does exist.

But he had no desire for immortality and he thought about it for only one fleeting moment. A herd of exceptionally beautiful and graceful deer, of which he had been reading the day before, darted past him; then a peasant woman held out a registered letter to him. Mikhail Averyanych said something. Then everything disappeared and Ragin sank into everlasting oblivion. ${ }^{45}$

Shakhnazarov, in his transposition of these final thoughts, clearly aims to respond in a more positive way to Chekhov's question, answering Ragin's doubts with a vision of possible immortality, and turning the vision of the deer into a key to regeneration. In this manner, he attempts to outline a way in which cycles can be broken, and brutality can be transformed into its opposite. 
The end of the film, however, with the New Year's celebration undermined by the continuing infantilization of the patients, casts great doubt on the possibility of religious or secular regeneration. Shakhnazarov's dialogue with his predecessors regarding cyclical violence and the victimization of children is thus left somewhat open-ended in Ward no. 6. If anything, the nineteenthcentury Russian concern for children and their degeneration at the hands (or due to the hereditary taints) of their parents, is magnified, as the director grafts Chekhov's plot onto a present-day Russia that is burdened by an everincreasing number of children in orphanages. Shakhnazarov, through this recontextualization, suggests that the "vicious circle" of violence and abuse that Chekhov and other writers depicted in a previous century is equally characteristic of contemporary Russia, and that breaking this cycle is still as challenging as it was in the nineteenth century.

\section{NOTES}

I. Tarsis, in his I963 autobiographical novel Ward no. 7 (Palata nomer sem') employs Chekhov's story as its primary intertext in fictionalizing his confinement in Moscow's Kashchenko Hospital. In his 1985 play Walpurgis Night, or the Steps of the Commander (Ostav'te moiu dushu v pokoe: pochti vse), Erofeev, also exploring the theme of psychiatric incarceration in the Soviet Union, creates a ruthless orderly named "Borenka Mordovorov" who resembles Chekhov's brutal Nikita. As Lyudmila Parts points out, the Soviet interpretation of Chekhov's story as a symbol of tsarist Russia, in the latenineteenth century, becomes an anti-Soviet interpretation, as writers protest the Soviet practice of incarcerating dissidents in mental hospitals. Parts, The Chekhovian Intertext.

2. See Parts, The Chekhovian Intertext; Brintlinger, "Introduction."

3. Kirill Serebrennikov filmed the story in 2005, as Ragin. Earlier, Karl Fruchtmann (Krankensaal 6, 1974) and Krzysztof Gruber (Sala nr 6, I987) also produced transpositions of the story.

4. In some ways, this blurring of boundaries recalls the effect of Louis Malle's I994 Vanya on $42 n d$ Street, in which, following an opening scene of actors gathering around an old building to rehearse Uncle Vania, their conversation merges imperceptibly into the rehearsal itself, thus obscuring the lines between life and theater.

5. The film was conceived much earlier than its actual production. Shakhnazarov originally wrote the script with Aleksandr Borodianskii in I 988 for an Italian co-production that was supposed to star Marcello Mastroianni as Ragin. Disagreements with the Italian producers, however, led to the cancellation of the film. Shakhnazarov resisted their desire to use period costumes, as he wanted a contemporary setting. In an interview, he describes the film as "an attempt to immerse Chekhov's plot in a contemporary, authentic atmosphere." Parsegova, "Karen Shakhnazarov." Eventually, he was able to do so, filming it two decades later with Vladimir Il'in in the starring role. The idea of mixing genres, therefore, long preceded the actual making of Ward no. 6. In the intervening two decades, Shakhnazarov continued his exploration of the theme of mental illness. In his I99 I film Assassin of the Tsar, a patient named Timofeev, who believes he has assassinated both Tsars Aleksandr II and Nikolai II, gradually draws his doctor into his web of delusion. But 
Shakhnazarov's updated exploration of the fine line between insanity and "normalcy" in Ward no. 6 raises new concerns in light of the intervening two decades.

6. Chekhov draws a direct parallel between this project and his work as a doctor in a letter to his friend Aleksei Suvorin: "I wanted to write a couple of hundred pages [on Sakhalin], and in this way repay in some small part the debt I owe to medicine, which, as you know, I have neglected like a swine." Chekhov, The Island, xviii.

7. Ibid., 27 .

8. The aging intellectual Aleksandr Serebriakov voices a general sense of confinement with his comment "This place—it's like a prison." Chekhov, The Plays, 220.

9. Chekhov, About Love and Other Stories, I83.

I0. For more on the connection between "Ward no. 6" and Sakhalin Island, see Knapp, "Fear and Pity in 'Ward Six'."

I I. Ibid., I45-7.

I2. Chekhov, "Ward no. 6," 30 .

I3. Meerzon, "Interrogating the Real," 288.

I4. McCarthy, "Ward no. 6."

I5. Although the film was entered as Russia's Oscar nomination for foreign language film, Russian reviews of the film were mostly negative. Dmitrii Zhigalov, for example, calls it a "dry, boring setting of the story," and criticizes Shakhnazarov's deliberate use of a shaking hand-held camera in some scenes. Zhigalov, "Palata bez talantov." Western reviews were more positive, overall. As Amber Wilkinson opines, "Much more complex than it first appears and fully deserving of its selection as Russia's foreign language Oscar nominee this year, Ward no. 6 persuasively prods at our preconceptions of 'madness,' calling on us not to just look at the exposed prejudices of the story's protagonists but to see how closely they mirror our own." Wilkinson, "Ward 6 (2009) Film Review."

I6. White, Degeneration, decadence, and disease.

I7. Ibid., 258.

I8. Ibid., 3I.

19. Finke, Seeing Chekhov, ro6.

20. Ibid., I05-6.

2I. Ibid., I I 5-I6. As Finke remarks, "In terms of the fundamental opposition between 'nature' and 'nurture,' Chekhov lays the groundwork for an environmental rather than a hereditary understanding of the psychopathology of both Gromov and Ragin." Ibid., I I 5.

22. Chekhov, "Ward no. 6," 3 I.

23. As Margarita Odesskaya points out, Chekhov deliberately portrays conditions in the hospital of "Ward no. 6" as worse than the typical such institution in order to make it resemble a prison, and to make a counterargument against those who thought the zemstvos would lead to improvement in social medicine: "in both stories ['Ward no. 6 ' and 'The Black Monk'], Chekhov demonstrated the helplessness of medicine and society in the face of mental illness, as well as people's intolerance toward those who differ in any way from their own understanding of the norm." Odesskaya, “Let Them Go Crazy," 204-5.

24. Here, too, Shakhnazarov may have Dostoevskii in mind. In his quasi-fictional prison memoir, Notes from the House of the Dead ( $186 \mathrm{I}-2)$, Dostoevskii remarks that the prison conditions were not as awful as one might think, emphasizing the lack of freedom as the worst aspect of the convicts' lives.

25. In this sense, Shakhnazarov can be linked to the numerous post-Soviet directors who have made paternity a central focus. This theme has been discussed in depth recently in Helena Goscilo and Yana Hashamova's compilation Cinepaternity, which highlights the ways Russian film has explored the current crisis of absent fathers, failed surrogates, and their 
damaging impact on male adolescents. I would argue that Shakhnazarov shares this focus to an extent, but expands it to include failed mothers as well.

26. From 1992 to 1998 , the annual rate of abandoned children nearly doubled from about 67,000 to I I3,000 (Abandoned to the State, $4-5$ ). At the present time, it is closer to I20,000. See Odynova, "State of the Wards," 30.

27. Abandoned to the State, 3 .

28. Ibid., 25.

29. Shakhnazarov here voices Ragin's approval of Gromov's belief in immortality ('It's good that you believe. With faith such as yours you would be living in clover even if you were bricked up in a wall." Chekhov, "Ward no. 6," 55.

30. Ibid., 6r.

3I. Finke, Seeing Chekhov, I I 5.

32. Durkin, "Chekhov's Response to Dostoevskii," 49-59.

33. Ibid., 54 .

34. See Golstein, "Accidental Families and Surrogate Fathers."

35. Chekhov, "Ward no. 6," 8 o.

36. Ibid., 53 .

37. Ibid., 78 .

38. White, Degeneration, decadence, and disease, 40.

39. Igor Sukhikh, however, emphasizes the importance of Ragin's epiphany: "Various characters, who often have not withstood a test of their humanity, are granted by Chekhov a moment of truth and beauty, on the threshold of death, at a point when they can no longer change anything." Sukhikh, "The Death of the Hero," I $0_{5}$.

40. See Parsegova, "Karen Shakhnazarov." Shakhnazarov claims that Chekhov is no less a religious writer than Dostoevsky, although his views on it are more hidden, more dispersed: "The religious subtext is hidden, but deliberate: Gromov's remarks about immortality, and the reference to Ragin wanting to study in a seminary." Ibid. (my translation).

4I. Foucault, Madness and Civilization, passim.

42. This scene may be a reference to the Christmas party in Milos Forman's One Flem Over the Cuckoo's Nest, in which Jack Nicholson's Randle McMurphy rebels against the strict hospital regime, and is eventually lobotomized.

43. Chekhov, "Ward no. 6," $5 \mathrm{I}$.

44. Ibid., 73 .

45. Ibid., 85 . 


\section{A Slap in the Face of American Taste: Transporting He Who Gets Slapped to American Audiences}

Frederick H. White

Tn I9I5, the author and playwright Leonid Andreev debuted his play $H e$ 1 Who Gets Slapped at the Moscow Art Theater. In the following years, this dramatic work about a vanquished intellectual-turned-circus-clown, more than any of his twenty other plays, achieved spectacular success among American audiences, first as a play in English translation, then when adapted for the silver screen, then as a novel and, finally, as an opera. Andreev had argued in his "Letters on the Theater" that cinema would become the place for action and spectacle, diminishing the popularity of the realist theater. Not surprisingly then, a love affair, betrayal, and humiliation are all vividly on display at the outset of Victor Sjöström's He Who Gets Slapped (1924). At the end of Sjöström's cinematic adaptation, the villains are devoured by a ferocious lion, just the type of spectacle that Andreev had predicted would be possible in the medium of film. Yet, Andreev could not have anticipated a novel adaptation by George A. Carlin (1925), which would attempt to capitalize on the play's cinematic success, or an operatic adaptation by Robert Ward and Bernard Stambler (1956), that would focus on the clown's failed search for love. In retrospect, Andreev's play was astonishingly generative and was easily transported across both temporal and spatial borders, entertaining American audiences as a play, film, novel, and opera.

Of particular interest is how Andreev's panpsyche drama - a type of theater that focused on the psychological development of characters rather than on external action - could be successfully transported for American audiences in so many different forms. Most certainly, a partial answer may be found in the rich cultural tradition of the circus. As the French semiotician Paul Bouissac has written, the circus "is a kind of mirror in which the culture is reflected, condensed and at the same time transcended; perhaps the circus seems to stand outside culture only because it is at its very center."1 He Who Gets Slapped may have been written by a Russian author and located in a provincial French 
town, but the circus was a readily understandable metaphysical space, ripe for intrigue, mystery, and deception in the American imagination. At the beginning of the twentieth century, the circus could bring the massive New York City to a halt, animate small towns like Waterloo, Iowa, and turn provincial communities into bustling temporary tent cities. Andreev's play about betrayal and revenge, seemingly, struck a chord with modern industrial America, during the unscrupulous Gilded Age of robber barons and a period of great social change due to a rapidly increasing immigrant population, a period in American history when the circus crisscrossed the country providing "a vivid cultural window into this era's complex and volatile web of historical changes." 2

At issue for this chapter are several important structural issues. First, we will discuss Andreev's understanding of panpsyche theater and how he applied this theory to his own play. Next, we will consider how Sjöström maintained the underlying psychological motivation, but replaced Andreev's duality of external and internal truths with the more dynamic motifs of revenge and romantic suspense. Briefly, we will turn to Carlin's novelistic hypertext and query as to why the writer's attempt to combine elements of the play and the movie script did not result in a third organizing principle. Finally, we will consider Ward and Stambler's operatic hypertext, which did provide a third organizing principle in its transportation of He Who Gets Slapped into the American context, ignoring both the panpsyche drama of Andreev and the revenge motif of Sjöström.

Secondarily, this chapter will suggest that several factors contributed to the successful transportation of Andreev's play, not the least of which was America's own infatuation with the circus. ${ }^{3}$ More specifically, clown acts deal in dichotomies between the social norm and the lack of that norm that interrupt the shared semantic codes of a society. ${ }^{4}$ As a result, Andreev's panpsyche drama benefits from both America's fascination with the circus and the audience's preparedness to interpret the depiction of a clown on more than one level of semantic meaning. The various hypertexts, in turn, are able to investigate the social norms of American society within a mythopoeic space that is organized by a different set of social rules. Consequently, we can assert that Andreev's hypotext, like the American circus, deals with disrupted daily life, the normalization of abnormality and the destabilization of social codes, making the various hypertexts of He Who Gets Slapped culturally familiar and yet also a novel source of entertainment for American audiences.

\section{PANPSYCHE THEATER}

For the first two decades of the twentieth century, Leonid Andreev was one of Russia's leading cultural figures. His short stories and plays acted like a 
weathervane, responding to and often indicating the most important political and social issues of the day. Much of his original success was predicated on this timeliness of his works and the passionate debates that erupted in the press in response. In the second half of Andreev's career, he began to pay ever more attention to the theater, working with leading figures like Konstantin Stanislavskii, Vladimir Nemirovich-Danchenko and Vsevolod Meierkhol'd. On November I0, I912, Andreev wrote his first "Letter on the Theater," which argued for a new type of theater that would relinquish external action for use in the cinema, while maintaining the internal, psychological and intellectual development of a character for the stage. ${ }^{5}$ Andreev argued that life had moved inward and that the theater of spectacle must be supplanted by a theater of the mind. Although this was certainly a criticism of realist theater, it was also a nod to the promising future of cinema. Two years later, Andreev published a second letter, outlining his ideas for a new type of drama, a theater of the "panpsyche." In this letter Andreev described the power that the cinema was gaining with audiences and suggested that only a theater of the panpsyche, like the productions offered by the Moscow Art Theater, could compete for the public's attention.

In Andreev's opinion, the Russian theater needed to concentrate on plays in which the drama occurred internally, whereby the characters' external actions were driven by the psychological struggles that occurred within them. No longer were plays to be organized around external action, but around the joys and suffering of the human experience. Andreev created a whole series of plays in which the internal action of the play is associated with psychological torment caused by infidelity, deception, dishonesty, and disloyalty. These struggles are displayed in his plays Anfisa, Professor Storitsyn, Ekaterina Ivanovna, Waltz of the Dogs, and Samson in Chains. The most successful of these plays for the Russian (and, eventually, the American) stage (and screen) was He Who Gets Slapped. At the Russian premiere of the play, Andreev responded to fourteen curtain calls. Consequently, it is compelling to examine Andreev's most successful attempt at panpsyche theater and how hypertexts could be transformed for the screen and then as a novel and an opera. Just as fascinating is how this dramatic text could be transported through both space and time to entertain American audiences.

He Who Gets Slapped premiered at the Moscow Art Theater on October 27, I9I 5 and at the Aleksandrinskii Theater in Petrograd a month later. It takes place in a circus in a French city. The character "He" is running from a failed marriage after his wife has left him for their mutual friend. He finds solace in the world of the circus and there is a definite contrast between the real (outside) world and the circus world. In the play there are various references to He's identity prior to entering the circus and what he has become in this new environment. He has clearly suffered from his loss in the outside world 
and now claims to be mad: "Never in your life did you use such a precise expression. I am mad!" ${ }^{6}$ However, the audience is not quite sure if this is the case or if this is another aspect of his performance. This confusion partially stems from the fact that $\mathrm{He}$ is just a role that the intellectual from the outside world is now playing. He admits:

Don't be angry, Jim. It's a play, don't you understand? I become happy when I enter the ring and hear the music. I wear a mask and I feel humorous. There is a mask on my face, and I play. I may say anything as a drunkard. Do you understand? Yesterday when I, with this stupid face, was playing the great man, the philosopher [he assumes a proud monumental pose, and repeats the gesture of the play-general laughter] I was walking this way, and was telling how great, how wise, how incomparable I was - how God lived in me, how high I stood above my head [his voice changes and he is speaking faster] then you, Jim, you hit me for the first time. And I asked you, "What is it, they're applauding me?" Then, at the tenth slap, I said: "It seems to me that they sent me from the Academy?" [Looks around him with an air of unconquerable pride and splendour. Laughter. Fim gives him a real slap. $]^{7}$

In Andreev's play and other works, a performance is employed to hide the main character's true emotions and psychological state. Even as he suffers on the inside, He plays the part of a clown and entertains the audience, demonstrating that people prefer the appearance of normalcy to the truth. As Andreev had suggested in his "Letters to the Theater," this external actionthe life of the circus, the slapping of the face of the clown, the laughter of the audience - is not the dramatic impetus of the play. Rather He's feelings of betrayal, his attempt to lose himself in the artificial world of the circus, his developing love for the circus performer Consuelo, and the desire to inflict psychological pain on her suitor, the Baron (and those like him), are the true, internal drama that informs this panpsyche theater.

In Andreev's earlier literary and dramatic works, the concept of verisimilitude (pravdopodobnost' in Russian) was often an organizing principle. For Andreev, verisimilitude meant giving those around you a truth that they wanted to see, rather than the often painful truth that might lead to anger, disappointment or a sense of betrayal. This concept was articulated very clearly in his story "My Notes" (I908). ${ }^{8}$ Andreev's theory of the panpsyche theater seemingly grew out of this understanding of verisimilitude in which there is an outward acceptable truth, a thin veneer, that often hides a less attractive, psychologically complex truth about the individual. At certain moments, this unattractive truth shows through the veneer and creates dramatic, often psychological, tension. 


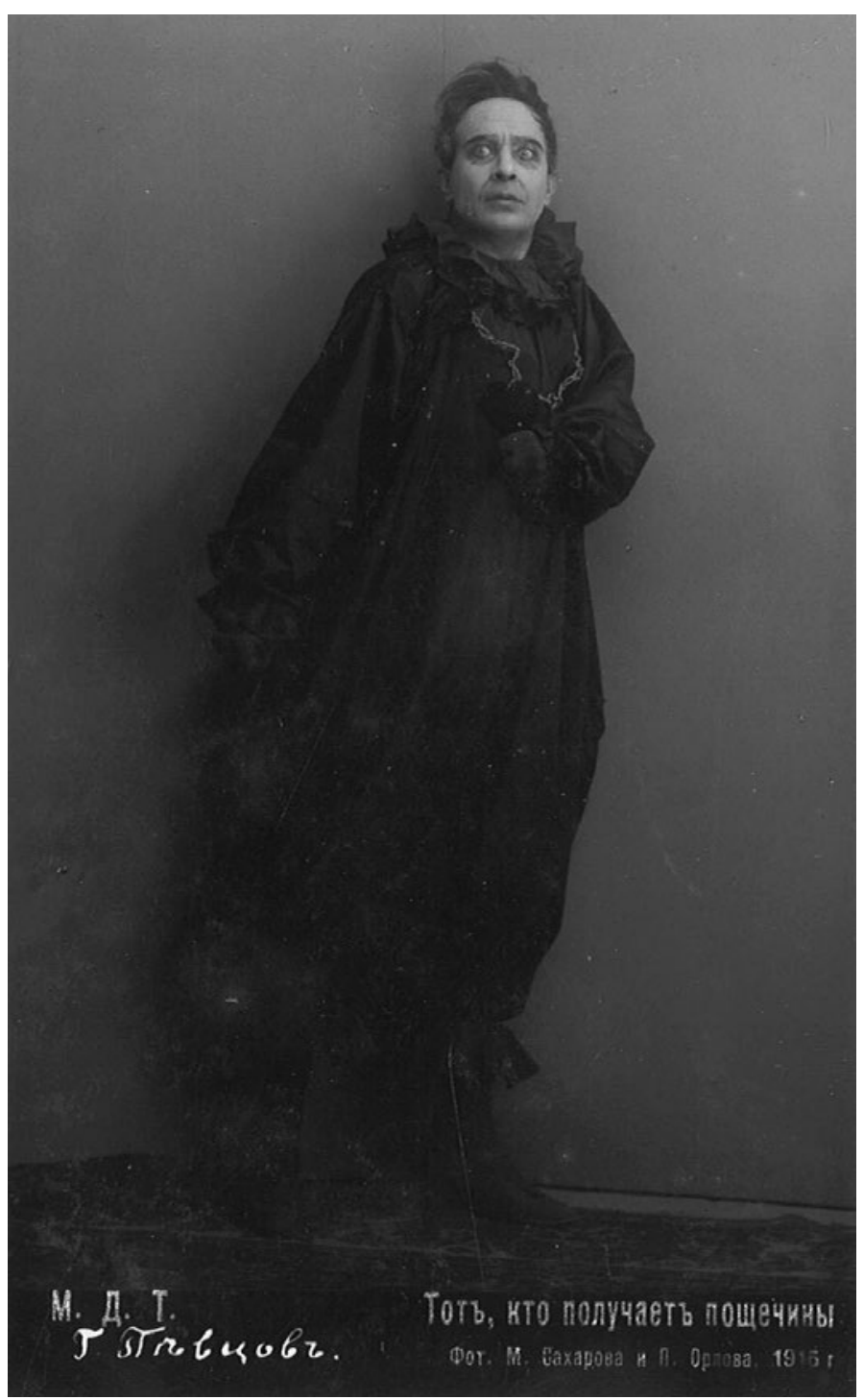

Figure 7.I Postcard of the Art Theater's I9I 5 production of He Who Gets Slapped, featuring Illarion Pevtsov as He.

Andreev's focus on the subtle psychological moments of his characters can be found in his stage directions to the actress who played Consuelo in the Moscow production:

There is nothing simpler than the drama, in which all is on the outside: in movement, cries, tears, sobs, in clearly visible dramatic conflicts. But the difficulty of this role is terribly great, for all the calamity is based 
externally on half-tones, sighs, smiles, on the expression of sadness in the face and eyes, when the soul is hidden from the very person who is experiencing it all. ${ }^{9}$

Significantly, He Who Gets Slapped is populated by individuals who have a circus persona and a real life history that is only revealed for brief moments during the play. The Count is not really royalty. Consuelo is not really Mancini's daughter. The dashing Bezano is actually quite shy and reserved in person. The interplay of external persona and internal psychological drama is, for Andreev, the actual tension and drama of the play itself.

Andreev's theory of the panpsyche theater, organized around a principle of verisimilitude, benefits greatly when placed within the context of the circus. Bouissac argues that the circus is a meta-cultural code system that represents the totality of our perceived universe. The circus is constituted of acts that are symbolic of cultural units that the audience is asked to decode: wild vs. domesticated, repulsive vs. attractive, situations that are exotic, primitive, or historical..$^{10}$ In decoding these cultural units, Andreev's play, similarly, asks the theater audience to unite the various revelations regarding the gentlemanclown's previous life that reproduce universal emotions, such as humiliation, revenge, love, and hate. In this instance, the theater audience is already prepared to view the circus performance as a transgressive manipulation of cultural systems which demands some form of active decoding; therefore, Andreev's panpsyche drama benefits from the audience's preparedness. As a result, the universal quality of the circus also begins to explain why an American film and opera audience might also respond positively to this spatial and temporal transportation of Andreev's panpsyche play.

\section{ANDREEV'S HYPOTEXT}

Andreev's hypotext begins with a gentleman approaching members of the circus, asking to be a clown. The circus entertainers are unsure. They recognize that the stranger is cultured and well educated, but think that he might be drunk. This would-be clown suggests that he might read something literary or make some sort of speech as part of his act. Then, he suggests that his circus name might be "He Who Gets Slapped" and that his act could be to receive slaps from other clowns. This introduction, of course, leaves the theater audience guessing as to the real identity of this strange man and, as the main action of the play develops, the clown's mysterious identity is divulged piecemeal, allowing Andreev to successfully tease out the psychological aspects of the mysterious clown and provide the motivation for his life in the circus. 
In the first act, we learn that this odd gentleman is thirty-nine, well educated, and someone quite well known. The owner of the circus asks for identification so as to register his employees with the police. When the gentleman-clown is finally forced to disclose his real name, the reaction of the circus owner reveals that he is to be respected, but the theater audience gains no further information.

In the second act, $\mathrm{He}$ is already established as a clown and his act is a success. There are still some indications of his education as the other performers warn him against too much talk of politics and religion during his performance. The theater audience also learns that $\mathrm{He}$ is in love with Consuelo and that Count Mancini is trying to marry his daughter to Baron Regnard for financial gain. It is only at the very end of this act that a gentleman visits $\mathrm{He}$ in the circus:

Gentleman: [Humbly]: You have not forgiven me, He? [Silence.]

He: Are you here with my wife? Is she, too, in the circus?

Gentleman: [Quickly]: Oh, no! I am alone. She stayed there!

He: You've left her already?

Gentleman: [Humbly]: No-we have-a son. After your sudden and mysterious disappearance-when you left that strange and insulting letter-

He: [Laughs]: Insulting? You are still able to feel insults? What are you doing here? Were you looking for me, or is it an accident?

Gentleman: I have been looking for you, for half a year-through many countries. And suddenly, to-day-by accident, indeed-I had no acquaintances here, and I went to the circus. We must talk things over ... $\mathrm{He}$, I implore you. [Silence.]

He: Here is a shadow I cannot lose! To talk things over! Do you really think we still have something to talk over? All right. Leave your address with the porter, and I will let you know when you can see me. Now get out. [Proudly.] I am busy. ${ }^{11}$

This revelation still does not answer many of the questions about the clown's past. If anything, it becomes even more mystifying: an insulting letter; He's wife now is married to another man; the former friend and former wife have a child together. The psychological action of the play has become even more complicated, which is what Andreev desired, each circus performer with his or her own secret, each running away from something by living and working in the circus.

At the beginning of the third act, the gentleman returns to the circus and the audience learns that he has stolen the gentleman-clown's wife and his ideas, vulgarizing and publishing them in a book that has been quite 


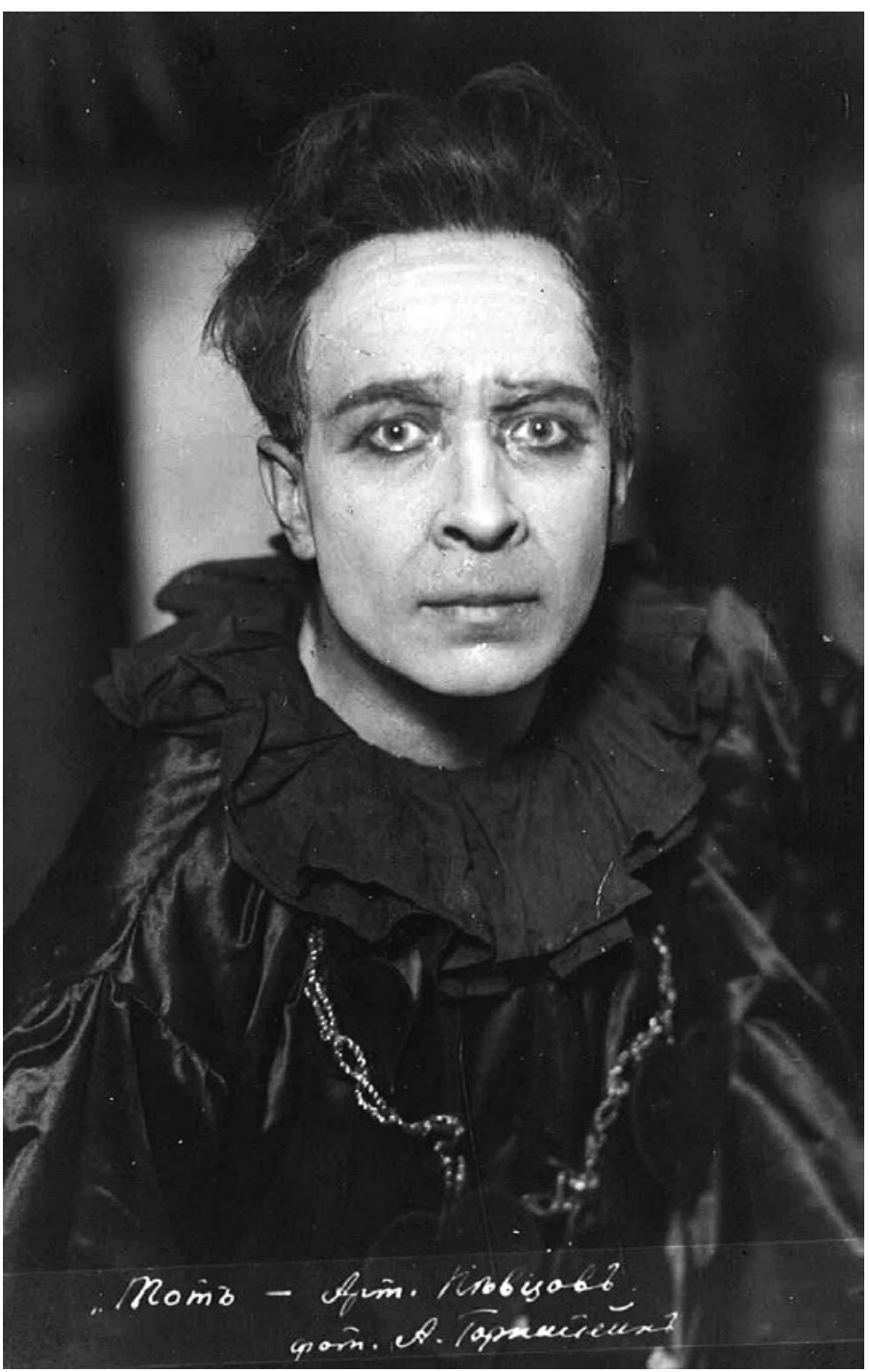

Figure 7.2 Postcard of Illarion Pevtsov as He (I9I 5 ).

successful. Although the gentleman is now a famous figure, appearing often in the press, with a wife and son, he still is haunted by the existence of his former friend $(\mathrm{He})$ and the possibility that the gentleman-clown shall return. The gentleman has searched out this friend whom he has betrayed in order to ascertain if the former friend ever intends to return home. To the gentleman's seeking a promise from his friend-turned-circus-clown that he will not return, He promises as much, making it clear that he has left an intellectual's life behind for good. Andreev finally provides, in part, the psychological 
impetus for why He left behind his life in high society in order to join the circus and to be humiliated each day for the entertainment of strangers. This psychological profile also puts into perspective He's life within the circus and his desire to undermine Count Mancini's attempts to sell Consuelo to Baron Regnard. Having endured once the disappointment of losing his wife to a scoundrel, He's strong desire to save Consuelo from the Baron is now psychologically motivated for the theater audience. As a result, in the fourth act He poisons Consuelo in order to save her from an arranged marriage. Off-stage, the Baron commits suicide. Once He learns of the Baron's death, utterly surprised, he poisons himself, wishing to meet Consuelo in the afterlife before the Baron.

In He Who Gets Slapped the unattractive truth about the clown is that he is running from a failed marriage, betrayed by a good friend and his own wife. He is hiding from this psychological pain within the circus, where he can be a clown whose pain and humiliation are viewed by those around him as part of a humorous act. Those circus colleagues have their own secrets to keep and do not want to know why He suffers so greatly-maybe he is insane or a drunkard. They are more than willing to accept this veneer of a clown who is repeatedly slapped and humiliated as the real man. Tension, therefore, is created by the psychological dissonance found in the appearance of a circus clown, covering the tragic loss and betrayal of an intellectual who has turned his back on his former life. Once this is understood by the theater audience, then the secondary story of He's love for Consuelo gains added meaning as the clown tries to save the young girl from a similar type of betrayal and humiliation. The clown's love is further intensified because his rival for Consuelo's affection is the Baron, the same kind of scoundrel as the former friend who betrayed He's trust and stole his wife.

\section{SJÖSTRÖM'S HYPERTEXT}

Excerpts from Andreev's first "Letter to the Theater" were published in English translation by The New York Times in October I9I9. "Andreyev on the Modern Theater" (October 5) and "Andreyev on Motion Pictures" (October I9) made it possible for American audiences to gain an understanding of Andreev's dissatisfaction with the realist theater and his belief in the future of cinema. Unfortunately, Andreev's second letter was not translated, thereby depriving American audiences of his further developed theories on the panpsyche theater.

He Who Gets Slapped was translated into English by Gregory Zilboorg and published in The Dial in March I92 I. On January 9, I922, as a production of the Theatre Guild, Andreev's play premiered at the Garrick Theatre. From 
its opening night and on through the summer of that year, there were a total of 308 performances of $\mathrm{He}$ Who Gets Slapped in New York City. In I924, the play was performed at Le Petit Thêatre du Vieux Carré in New Orleans where "it was well on its way to being taken into the American national theatre repertory," 12 when Sjöström and Carey Wilson adapted Zilboorg's translation into a movie script.

Sjöström was one of the leading directors, and a major contributor to the "golden age" of Swedish cinema (1917-23). His first important picture had been Ingeborg Holm (1913), about a widow who goes insane when her children are taken from her because she can no longer support them. His Terje Vigen (I916), an adaptation of Henrik Ibsen's classic poem, achieved great international success. The film is about a man who loses everything during the English blockade of the Norwegian coast, but continues to live solely in order to exact revenge on the English ship's commander. He scored another success with a film based on the novel and play of Icelandic author Johan Sigurjonsson. The Outlam and His Wife (I9I7) is about an escaped prisoner who finds love with a young widow on a desolate farm. When the search party approaches, the prisoner escapes with his new family to the mountains where they drown their child in a brook. Eventually, the prisoner and his wife freeze to death during a snowstorm. Sjöström's last important film before leaving for Hollywood was The Phantom Chariot (or in the United States: Thy Soul Shall Bear Witness) (I92 I), based on Swedish author Selma Lagerlöf's novel. In the film, the drunkard David Holm is struck on the head and has a vision in which he must drive a carriage on New Year's Eve to pick up dead souls. The film mixes dream and reality with Holm's past and present in a suggestive pattern. ${ }^{13}$ Such early experiences in Sweden attest to the fact that Sjöström had experience successfully transporting literary works to the silver screen.

Sjöström (now Seastrom for American audiences) was brought to the United States by Goldwyn Pictures in January I923, just when the big Hollywood studios were importing the best European talent. His first film was based on British author Hall Caine's novel The Master of Man (I92I). The film, Name the Man (1924), was a court drama, which displayed none of Sjöström's creative talents, but was still a financial and popular success with American audiences. Swedish critic Ragnar Cederstrand argued that the film was a hit with Americans because Sjöström had turned a boring courtroom drama into a compelling psychological film. American directors would have approached it as a visual thriller, but Sjöström's psychological approach was new for American audiences (though not so revolutionary for Europeans or, particularly, for Scandinavians). ${ }^{14}$ The point made by the critic is quite remarkable given that Sjöström's next film would be He Who Gets Slapped, based on Andreev's panpsyche work in which the action of the play is to be driven by the psychological drama of the main characters. 
In the mid-I920s, Metro-Goldwyn-Mayer emerged as the "Home of the Stars" and dazzled audiences with their big-name celebrities, their high production costs, and the sheer breadth of subject matter. The new studio had hired Irving Thalberg away from Universal to become MGM's production chief. Thalberg had worked with Lon Chaney on The Hunchback of Notre Dame (1923) and was able to convince the actor to sign a one-year contract with his new studio. Thalberg wanted Chaney because his pictures made money and because he could create characters for almost any situation. Thalberg himself was not afraid to spend money both to make money and to maintain artistic integrity. ${ }^{15}$

The first picture made by MGM was Andreev's He Who Gets Slapped. The play had been a success on Broadway two years before with Richard Bennett in the lead role. The studio hired Sjöström and cast Chaney in the lead role of Paul Beaumont. Norma Shearer and John Gilbert were cast in the supporting roles of Consuelo and Bezano. Both actors would go on to earn tremendous popularity in the following years. MGM saw this as a prestige picture (or art film) and the emphasis was on the total picture, rather than as a vehicle for Chaney.

Sjöström took Andreev's play and wrote a first film draft in Swedish, which was then translated into English and polished by Wilson. In this hypertext, there are several elaborations of the hypotext, some more significant than others. In Sjöström's hypertext, the main character's life before the circus and the betrayals that lead to his departure from academic society are significantly augmented, brought forward in the storyline and given nearly sixteen minutes of exposition on screen. In this adaptation, Paul Beaumont $(\mathrm{He})$ is a research scientist, who makes a significant discovery regarding the Origins of Mankind that he intends to present to a gathering of academic colleagues at the French Academy of Sciences. Baron Regnard, who has provided material support to Beaumont and his wife, Marie, betrays his friend thrice-once, by conducting a romantic liaison with Marie behind Beaumont's back, a second time by stealing Beaumont's working papers (with Marie's help), and a third time by presenting Beaumont's scientific discovery to the Academy of Sciences as his own work. Beaumont confronts the Baron at the Academy of Sciences in front of his colleagues, insisting that the scientific findings are his own. Regnard claims that Beaumont is insane, simply a poor student who has aided the Baron in his scientific research. When Beaumont grabs the Baron, enraged by this lie, Regnard slaps Beaumont and the entire gallery of learned men howl in laughter at this intended slight. The inter-title at this moment states: "Laughter-the bitterest and most subtle death to hope-." Sjöström's introduction of the slap and Beaumont's humiliation will become a recurring motif once Beaumont transforms himself into $\mathrm{He}$ and entertains circus patrons, who are in fact, many of the same actors, playing both the circus audience and the gallery of learned men. 


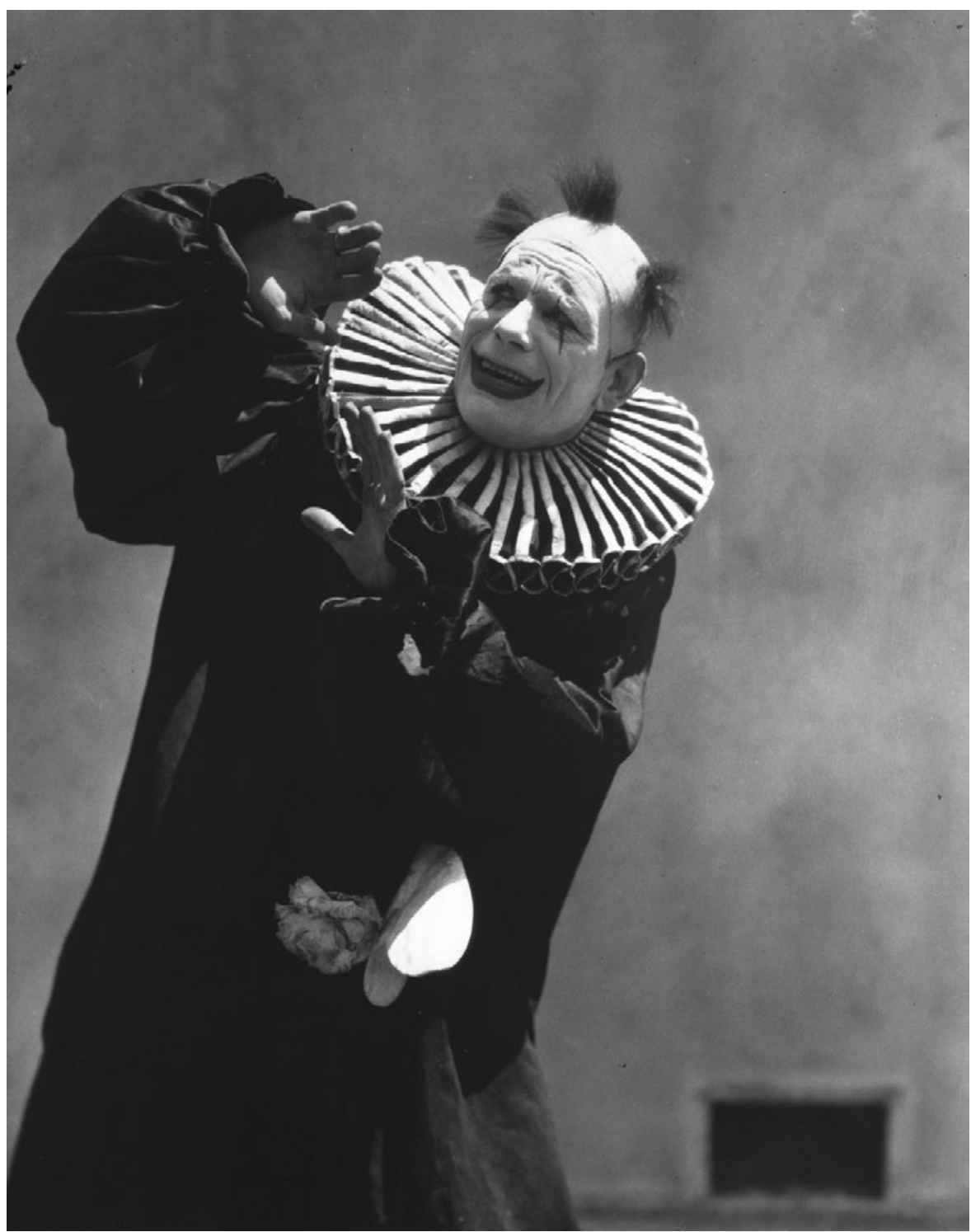

Figure 7.3 Production still of Lon Chaney as He in Sjöström's He Who Gets Slapped (1924).

Beaumont's complete humiliation soon follows, when Marie admits her liaison with the Baron. In this scene, Marie confronts Beaumont, claiming that she is in love with the Baron, especially given Beaumont's infatuation with "silly books"—alluding to both his weak financial and social status. As Marie turns away from Beaumont, she slaps him on the face, the second such occurrence, both associated with Beaumont's humiliation. Marie then says in the 
inter-title: "Fool! Clown!" As Beaumont seemingly loses his mind, he repeats this accusation that he is a fool and a clown as he throws his research papers away. The inter-titles then state that Beaumont lived through a night of agony, but left the Baron's in order to live: "Paul Beaumont lived — to laugh at life. He laughed at his wife and the Baron - and left them to the doubtful joy of each other's society." It is at this point that Sjöström transitions to the circus, where Beaumont is already transformed into He.

At issue is Sjöström's restructuring of Andreev's play so that the impetus for Beaumont to join the circus is revealed at the outset of the film. One simple explanation for this is that Andreev's play relies on dialogue, while Sjöström is working in the visual medium of the silent film. Sjöström must show this betrayal and humiliation, rather than have it be revealed in dialogue; yet by portraying Beaumont's humiliation at the beginning of the film, he must then create psychological tension in other ways in order to sustain the audience's interest. One such way is to conflate from Andreev's play the gentleman/ former friend, who betrayed He and seduced his wife, and Baron Regnard, who wishes to seduce Consuelo. In Andreev's play, these are two different characters, although the audience understands that He's passionate desire to save Consuelo from the Baron is most certainly informed by his earlier failure to stop his wife's infidelity with his former friend. Sjöström turns this implicit understanding into an explicit element of his hypertext - it is Baron Regnard who seduces Marie, betrays Beaumont and then, later, comes to the circus to court Consuelo.

Sjöström, through inter-titles, suggests that it is Consuelo's aristocratic background that rekindles Beaumont's heart. This is emphasized visually in a sequence in which Consuelo re-sews a heart back onto He's clown costume. The rupture of the clown's heart as part of his act has its own semantic meaning, but is even more salient as the intimate moment that Consuelo and He spend together on screen. This scene is directly followed by He's clown act, during which he realizes that Baron Regnard is in the audience. As He attempts to point out the Baron in the circus audience, he receives slap after slap from the collection of supporting clowns. Eventually, his heart, which had just recently been re-sewn by Consuelo, is ripped out by another clown. He falls down dead and a mock funeral is enacted as part of the performance. Significantly, Bouissac argues that the circus act is often a prototype of social behavior that provides a demonstration of what is or should be; therefore, the American cinematic audience certainly understands the meaning of He's humiliation, eviscerated heart and symbolic death as the Baron looks on gleefully. ${ }^{16}$

A few scenes later, Sjöström further emphasizes the Baron's dastardly character with a scene in which we see Marie Beaumont in shock as she watches the Baron collect his hat, gloves, and cane while departing. The camera then focuses on a check, made out to Marie, underlining that the Baron has ended 
the relationship and turned it into a financial, rather than romantic, liaison. In so doing, Sjöström has exacted some revenge on Marie for the enjoyment of the cinema audience, but has also further blackened the reputation of the Baron. In Andreev's play, the revenge factor is abstract, as the Baron and the gentlemanfriend are the same type of men within society, but in Sjöström's hypertext there are clear heroes (He and Bezano) and villains (Baron Regnard and Count Mancini) in a struggle over the affection of Marie and Consuelo. Although the psychological motivation remains as an underlying explanation for Beaumont/ He's desire for revenge, Andreev's duality of external and internal truths is replaced by a more straightforward and immediate exposition of: (I) Revengewill Beaumont/He reveal himself to the Baron and receive satisfaction? (2) Romantic suspense-will Consuelo be sold to the Baron by her father or will she find real love with Bezano or, less likely, with Beaumont/He? As Andreev had argued, the cinema had forsworn the slow unwinding of a psychological drama for the immediate action and spectacle of love and revenge.

Once it has been announced that the Baron intends to marry Consuelo, Sjöström literally locks He, the Baron, and Count Mancini into a room together. Lon Cheney is brilliant in his depiction of psychotic rage, which is first masked as clown's play, but then is directed at Mancini for selling his daughter to the Baron. Mancini throws Beaumont/He out of the room and into an ancillary area where a lion is kept. Lions exist in Andreev's play off-stage (and in the theater audience's imagination), but Sjöström utilizes the lion for the spectacular revenge motif. Beaumont/He strategically positions the cage and re-enters the room through another door, tantalizing the cinema audience with the possible release of the lion into the room with Mancini and the Baron. Sjöström finally realizes the revenge plot in two dissolve shots in which the Baron is confronted with the fact that He is Paul Beaumont.

The tragedy of Andreev's hypotext is found in He's psychological pain and that, after poisoning Consuelo in order to save her from the Baron, he learns that the Baron may have, in fact, loved Consuelo as he has shot himself in the head off-stage. Therefore, He's final act is a desperate one in which he drinks poison in the frantic hope of reaching Consuelo in the afterlife before the Baron. Sjöström decides on a much more visually dazzling conclusion, one in which Mancini stabs He with a knife blade that has been hidden in his cane, a weapon that has been revealed to the cinema audience previously. Fatally wounded, He collapses to the floor and tries to staunch the wound with the fake heart that has been the symbol of his love for Consuelo and of the cruelty of the world around him. Final revenge is realized as Mancini and the Baron decide to leave He dying by exiting through the door, where the lion is awaiting. Sjöström, to the sounds of the William Tell overture, revels in the visual beauty of a large, angry lion with rapid cuts to the horrified faces of the Baron and Mancini as well as to the psychotic laughter of the clown. As Andreev had 


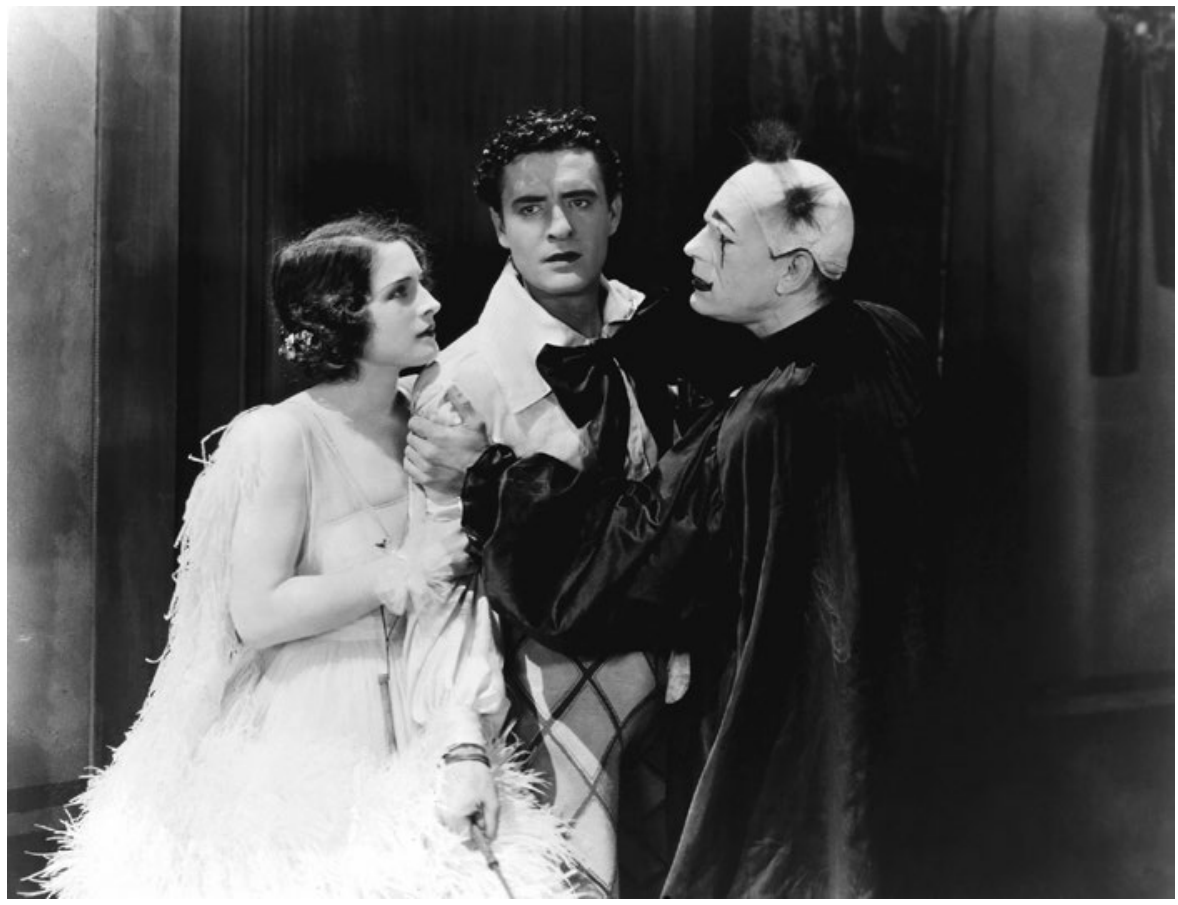

Figure 7.4 Production still of Consuelo (Norma Shearer), Bezano (John Gilbert), and He (Lon Chaney).

predicted, the visual spectacle would be left to the cinema. Mancini is the first to be eaten by the lion behind an overturned table as He laughs and the Baron looks on in horror. The lion then pounces on the Baron and He revels in this final, sweet revenge. The lion then faces $\mathrm{He}$ and the clown invites the lion to come and give him a final slap. Just then, the lion tamer Zinida arrives and drives the beast back into its cage.

Sjöström, having already altered the tenor of the hypertext by reveling in the revenge motif, was forced to decide how he would resolve the second storyline, the suspense created by the many suitors for Consuelo's heart. Sjöström certainly could not marry Consuelo to both Bezano and He. In Andreev's play, Bezano is too shy and too confused to actualize his love for Consuelo, but in Sjöström's hypertext, Bezano is the clear hero-attractive and dynamic — and outwardly expressive of his love for Consuelo. In Andreev's play, Consuelo is an obedient daughter, but Sjöström gives his heroine free will and an obvious preference for Bezano. As a result, Sjöström recaptures the tragic quality of Andreev's hypotext with one last performance by $\mathrm{He}$ for the circus audience, who along with the supporting clowns, do not realize that he has been fatally wounded by Mancini. As He tries to express himself to the audience, he is 
twice slapped and knocked to the ground. As He reveals the bloody heart that he has used to staunch his wound, Consuelo runs out to He and holds him in her arms. The inter-titles that follow suggest that He is now happy to die, having exacted revenge for the Baron's betrayal, and now Consuelo could also find happiness with Bezano.

In Sjöström's hypertext, the psychological motivation is revealed at the outset of the film. In order to sustain the audience's interest, Sjöström makes the revenge motif explicit by making Baron Regnard both the betrayer of Beaumont and the suitor of Consuelo. Sjöström also heightens the romantic suspense by making Bezano more dynamic, by providing Consuelo with free will, and by executing successfully, while continuing to reference, the re-sewn heart scene between He and Consuelo. As Andreev had anticipated, the psychological aspects were diminished for visually spectacular moments, including Beaumont's betrayal, He's circus act, and Baron Regnard's treachery of Marie - none of which are seen in Andreev's play — as well as the final scene involving the lion and He's tragic death in front of the entire circus and their audience. Each is visually stunning and intensifies the internal action of the hypertext.

\section{CARLIN'S HYPERTEXT}

The cinematic He Who Gets Slapped opened on November 3, I924 at the Capitol Theater in New York. It cost relatively little to make for a feature film $(\$ 140,000)$ and was a huge financial success, setting the records for best single day $(\$ 15,000)$, best week $(\$ 7 \mathrm{I}, 900)$ and best two-week $(\$ 12 \mathrm{I}, 574)$ box office return. ${ }^{17}$ The film was also considered an artistic success, which is captured in The New York Times review of November Io, I924:

It is a shadow drama so beautifully told, so flawlessly directed that we might imagine that it will be held up as a model by all producers. Throughout its length there is not an instant of ennui, not a second one wants to lose ... Never in his efforts before the camera has Mr. Chaney delivered such a marvelous performance as he does as this character. $\mathrm{He}$ is restrained in his acting, never overdoing the sentimental situation, and is guarded in his make-up. ${ }^{18}$

He Who Gets Slapped eventually turned a profit of $\$ 349,000$, not a small sum for the studio. It was also critically acclaimed and made The Nem York Times list of the ro Best Productions of 1924.

The following year, He Who Gets Slapped by George A. Carlin was published, transporting the text once again-from stage to screen to book for 
the American audience. On the cover, there is a needed explanation: "The Complete Novel. Illustrated with scenes from the photoplay." Seemingly, the success of Sjöström's film had created a demand for yet another hypertext. By the book's cover description, one would expect, more or less, a faithful rendering of Sjöström's hypertext in novelistic form. Surprisingly, Carlin begins his novel just as Andreev had begun his play, with an odd gentleman approaching the circus, asking for work. As just discussed, Sjöström's film begins with Beaumont's scientific discovery and his excitement in sharing this with his wife and his patron. In fact, Carlin's entire hypertext is an odd mixture of Andreev's play, Sjöström's adaptation, and the author's own creative imagination. For example, Carlin waits until the last third of the novel to reveal the reason for HE's departure from society and his entry into the circus. ${ }^{19}$ Carlin suggests that a Prince Poniatovsky and his wife Olga were deported from Tsarist Russia. The young Prince is enthusiastic about scientific experimentation and Baron Regnard offers the Russian couple a place to stay and his patronage so that the Prince may continue his scientific research. In time, Princess Olga and the Baron become regulars together at social events, while the Prince is busy with his work on the fourth dimension. Sjöström's Paul and Marie Beaumont and the scientist's discovery of the Origins of Mankind are replaced by Carlin's Russian émigrés and a search for an alternate dimension. Even so, there is a still picture from Sjöström's film of the actors Chaney (Beaumont), Gilbert (Regnard), and Ruth King (Marie) in Carlin's book with the caption "The wife he adored and the friend he trusted." 20

Carlin's decision to create a hypertext that draws from both Andreev's hypotext and Sjöström's hypertext elicits the following question: Did Carlin subscribe to Andreev's theory on panpsyche drama, to Sjöström's spectacle of revenge, or did he attempt to fashion a semi-independent hypertext with a third organizing principle? Carlin certainly makes allusions to both texts and both endings, leaving the reader uncertain as to whom he might favor in the end: the notion of poisoning someone's drink is introduced, as are the ferocious lions. For readers aware of both the play and the film, a third organizing principle or some combination of the two texts seems quite possible. Unexpectedly, Carlin blends the two texts into a third, unifying text that might satisfy both the theater audience who had seen Andreev's play and the cinema audience who had watched Sjöström's film. In so doing, Carlin neither recreates a psychological drama nor presents a compelling revenge fantasy for readers. Most disappointingly, Carlin does not claim new territory to truly stake his hypertext's independence from its progenitors. In fact, he seems to strand himself at the border of these two potential territories.

In Carlin's novel, a mysterious man comes to the circus and asks for work. Yet, unlike in Andreev's play, Carlin provides histories for each character so that HE is no more the focus of the novel's development than the whole host 
of circus characters-Jim Jackson, Zinida, Papa Briquet, Tilly, and Polly. Carlin often concentrates on the characters' physical features, drawing from Sjöström's film, but avoids the psychological details provided by Andreev. Occasionally, it is mentioned that HE might be insane, but this motif seems to be a lingering remnant of Andreev's hypotext, rather than an important element of Carlin's hypertext. It is not enough to mention several times that HE might be insane. In comparison, Andreev creates situations in which the humiliation and betrayal experienced by the gentleman-clown has left him a rather unstable and emotionally bankrupt individual. Once well established in the circus as HE, Carlin reveals that the clown is a Russian prince who had been betrayed by the Baron. As noted, this is Carlin's invention, possibly a homage to Andreev's own Russian expatriation when the borders of Finland were reestablished after the revolution and his home remained outside of Russia proper. At this point in the hypertext, Carlin seems to favor Sjöström's revenge motif, but then deemphasizes the most important elements of it. One of the most powerful scenes in Sjöström's hypertext is when the Baron breaks from Marie, leaving her a check for her romantic services. Carlin does not incorporate this dastardly behavior in his hypertext, missing an opportunity to further turn his reading audience against the Baron and create sympathy for HE, which will allow the clown some moral latitude to punish/kill the Baron. Carlin also diminishes the moment of recognition and confrontation between the Baron and HE:

"You lie!" The Baron spoke in a calm voice that had conquered his hysterical protégé before the Academy. After the first stunning shock of recognition and the first impact of HE's tirade, Regnard's powerful selfpossession had returned, and he silenced his adversary with his cutting tone:

"The Princess preferred that an English millionaire should pay her bills." 21

After this slight from the Baron, Carlin does not provide an extended description of HE's psychological humiliation, but rather, turns his attention to Mancini's desire to strike HE with a cane. Even in Sjöström's film, Chaney shows a range of emotions at this moment of confrontation that depicts a mixture of humiliation, vengeance, and madness. In Carlin's hypertext, the Baron restrains Mancini, calling the clown mad. HE, in turn, admits that he is insane. Hardly the full range of emotions one might expect if Carlin had decided to favor the revenge motif.

Just as confounding is the moment of HE's final revenge, when the clown releases the lion into the room. In Sjöström's hypertext, the lion's menacing behavior and, eventually, his devouring of first Mancini and then the Baron 
is the spectacle that Andreev had predicted for use in the cinema. Sjöström lingers on this moment and allows several shots of He's maniacal pleasure in this ultimate revenge as well as the Baron's utter horror of first Mancini's painful death and then his own realization that the lion will devour him as well. In Carlin's hypertext, one is unsure that the lion has even killed anyone. HE releases the lion into the room and then Zinida almost immediately comes in to drive her lion back into the cage. There is one reference to the lion's actions: "But, as she turned and saw the bodies of Mancini and the Baron, her hands went to her face to blot out the sight." 22 As a result, it is difficult to argue that once Carlin decided to highlight the revenge factor, that he, in fact, executed this organizing principle effectively.

\section{WARD AND STAMBLER'S HYPERTEXT}

In I955, the American composer Robert Ward and his Julliard colleague Bernard Stambler wrote and composed the opera Pantaloon, which was re-titled He Who Gets Slapped in I959. Based on Andreev's play, Ward and Stambler transform the character He into Pantaloon, a reference to the clown-character from commedia dell'arte. No longer a story of murder and suicide, Pantaloon is simply rejected by the heroine and condemned to the humiliation of the slap for the rest of his life. Pantaloon first premiered on May I 7, I956, performed by the Columbia University Opera Workshop. The revised version of the opera, under the title He Who Gets Slapped, was produced by the New York City Opera on April I2, I959.

In a recent interview with Opera Lively, Ward recounts how he and Stambler came to select He Who Gets Slapped for adaptation. In search of new material, Ward remembered Andreev's play and reread the first two acts. He liked that it was set in a circus and that most of the action occurs in the ring itself. The characters were colorful and Ward adored the idea of a vanquished intellectual coming to the circus. He called Stambler and asked him to read the play. Ward then went on to read the last two acts and was less inspired. Ward says: "It was very strange, because it was almost as if these two acts were for a different play, and we wondered about that and figured we'd have to make a lot of changes." Stambler adapted a third act from Andreev's final two acts to complete the opera. ${ }^{23}$ From Ward's description of the play, it is quite apparent that he did not favor the deception and humiliation of the intellectual that Sjöström decided to exploit in his adaptation. Ward and Stambler, instead, focused on the story of Mancini and his attempt to marry Consuelo to the Baron. In the third act, Pantaloon reveals to the Baron that Consuelo is not the noble daughter of a Count, but some uneducated waif and that Mancini only meant to profit personally from the marriage. The Baron storms off as Mancini also slinks away, 
leaving Bezano and Consuelo to proclaim their love for each other. The opera begins with an aristocratic stranger entering the circus, wishing to become a clown, and ends with Pantaloon shedding his clown costume to go back out into the real world, still in love with Consuelo.

Andreev's theory of the panpsyche drama and Sjöström's spectacle of revenge give way to Ward and Stambler's third organizing principle. The two composers completely ignore the psychological elements of Andreev's play in order to focus on the world of the circus. For Andreev, the circus is an unreal veneer that provides covers for the tragic, real lives of the performers. For Ward and Stambler, the circus is the only world in this operatic narrative. Their concentration is on the clown's unfulfilled love for Consuelo, without any reference to the outside world. The dastardly behavior of Mancini and his deception of the Baron also are contained within the circus, thereby creating a new organizing principle by elimination and simplification, rather than by addition and magnification. The part of the hypotext that was so important for Sjöström, the spectacle of revenge, is virtually eradicated by Ward and Stambler. Gone are the lion and the poison, leaving everyone still alive at the end of the opera. Again, the gentleman-clown is heartbroken but this time, not due to a cheating wife or the deception of a friend, but simply because Consuelo is in love with the bareback rider Bezano.

At the beginning of the opera, Pantaloon repeats the ironic statement "I am only-what you see." ${ }^{24}$ In fact, he is an intellectual from the upper class, starting life anew in the circus. Once again, this is discovered when Papa Briquet must register his new clown with the police. In the second act, Pantaloon admits that he had lived "a loveless life of wealth and pride and power," while trying to convince Mancini that the Baron will never marry Consuelo. ${ }^{25}$ At the end of this act, Zinida reveals the clown's past:

Pantaloon, young dreamer of heavenly love-

Here, Consuelo, for all to read,

He has written of love transcendent.

But the earthly reward for his heavenly love

Was a beauty, frigid and vain, faithless and jealous,

A marriage broken, public scandal,

And reality's bitter slaps and kicks

To shatter his ardent dream.

Zinida continues to explain that Pantaloon had been a visionary statesman who was not understood by the peasants and was jeered by the nobility. When he finally turned to God, Pantaloon was, once again, ignored by the "squabbling sects." ${ }^{26}$ Each time, Pantaloon received proverbial slaps and kicks. In the third act, playing the role of a drunken court jester, Pantaloon 
undermines Mancini's plan before the Baron. Pantaloon then unites Consuelo and Bezano. Left alone in the ring, Pantaloon admits his eternal love for Consuelo and suggests "This was not the place for me; Perhaps nowhere is the place for me." 27 He then removes his clown's costume and exits by the street door. As noted, little remains of the clown's past to explain his actions in the present. Unfulfilled love is the organizing principle of this opera, not betrayal or revenge.

A brief review of the opera was provided by Irving Kolodin in The Saturday Reviem, just two weeks after the New York premiere. Kolodin suggests that Andreev's play provides "appealing elements" for a musical adaptation: the circus, mysticism, and a love story-although he notes that Ward and Stambler have "take[n] some liberties with the author's morose philosophy." Here is the bulk of Kolodin's review:

For an act and a half, Ward moves in and around the subject with excellent dramatic sense, some appropriately atmospheric circus music, a sufficiently developed command of English word values to make the drama intelligible through its delivery by his stage characters. But there comes the moment when the melodic issue can be evaded no longer, when Pantaloon ("He" who gets slapped) sits down to explain to young Consuelo where she is, emotionally, and soon finds himself in the midst of the situation he is trying to analyze. Ward has plotted resourcefully in the form of a duo da capo, so to speak, but the whole accent and coloration is Tchaikovsky-cum-Rachmaninoff, which lets the listener down rather badly at this crucial point. ${ }^{28}$

Although Ward and Stambler would become well known for their opera The Crucible, it was He Who Gets Slapped that gained the two composers initial credibility in opera circles. Winthrop Sargeant of The New Yorker wrote that the opera "was the surprise of the season," which, in turn gave Ward and Stambler access to Arthur Miller, resulting in their Pulitzer Prize (I962) for the operatic adaptation of Miller's play about the Salem witch trials. ${ }^{29}$

\section{CONCLUSION}

The English film and theater director Peter Brook argues that the difference between a film and a play is the degree of involvement for the audience. A film tends to engulf the audience, as the viewers process only what is visually right before them. The physical distance in the theater forces the audience to supplement what cannot be seen. Intimacy and distance draw the 
theater audience forward and back, metaphorically, challenging their minds to complete the picture. Cinema attempts a similar process with the close-up and the long shot, but the audience is still reliant on being shown the story visually. ${ }^{30}$ If Brook is correct, then this only further supports Andreev and other playwrights like Bertold Brecht who have suggested that film demands "external action and not introspective psychology." ${ }^{1}$ Andreev could draw out the mystery of the gentleman-clown's identity in the theater because the audience is expected to fill in the intentional blanks in the story. It is the gaps between the external and internal truths that created drama for Andreev. This is, according to Brook, part of the theater experience. It also explains why Sjöström was compelled to show the betrayal of Paul Beaumont at the beginning of his cinematic hypertext in order to heighten the revenge factor for his audience. If the visual story must be told completely, there should be no intentional gaps in logic for the cinema audience. Ward, in an interview with Bruce Duffie, was asked if his operas, which were intended for an intimate theater space, would work well on television. Clearly, such a new set of boundaries as opera and television requires a different type of border crossing, but Ward does agree with Brook's line of thinking in stating that the visual distance greatly impacts the perceptions of the audience. Ward argues that he would need to rework his operas to be most effective. Television provides "entirely different values." The ability to focus on two faces is "colossal" but the "massive scenes never really come off on television" as they seem "contrived." 32

More to the point: Why were there so many different American adaptations of a Russian play? What made this border crossing relatively easy? It is safe to say that none of Andreev's other twenty plays has had such an artistic impact in America. Linda Hutcheon offers the premise that "expensive collaborative art forms like operas, musicals, and films are going to look for safe bets with a ready audience - and that usually means adaptations." 33 The suggestion here is that you only invest capital if you are certain that there is a potential for profit. But what was it about this play that allowed for ready success with American audiences?

It is likely that each adaptation had its own specific motivating factors, yet each was underpinned by financial concerns, as Hutcheon argues. MGM was looking to make a prestige film with its newly contracted Scandinavian director. Sjöström was known for his psychological dramas and probably felt comfortable with a play that relied heavily on psychological undercurrents that had already been successful with American theater audiences in New York City. More than likely, Carlin was capitalizing on the financial success of Sjöström's film in providing a novelistic adaptation of Andreev's hypotext and Sjöström's hypertext. Unfortunately, his execution of this particular border crossing was not successful. One of the reasons that Ward and 
Stambler chose to adapt He Who Gets Slapped was that there was no copyright agreement at that time between the United States and the Soviet Union. Therefore, they were free to adapt the play and not have to worry about any of the legal or financial details. ${ }^{34}$

Yet, an even more cogent argument for why there are so many adaptations of this specific play would be the mythopoeic space that the circus holds in the American imagination. There, one finds stable heroic and villainous archetypes as well as a whole host of ready-made and accepted charactersthe lion tamer, ring master, clowns, and acrobats. Andreev's play, in particular, animates basic human emotions - love, betrayal, humiliation, greed, and revenge. For most Americans, running off with the circus meant escaping the problems of your present life; therefore, Andreev's play was readily understandable to potential audiences. For those looking for source material, the circus and the universal quality of the story allowed for successful adaptations, modulated solely by the demands of the genre-play, cinema, novel, or opera.

Bouissac argues that in Western culture, identity is determined by the outward appearance. Yet, the clown often represents two radically different individuals as the same person, thereby modifying the cultural rule of identity. ${ }^{35}$ As a result, the American audience is ready to accept that Paul Beaumont, the scientist researching the Origins of Mankind, can also be the clown $\mathrm{He}$, who is slapped repeatedly for the entertainment of others. The various hypertexts are able to investigate the social norms of American society within a mythopoeic space that is organized by a different set of social rules. In Sjöström's hypertext, it is acceptable that the humiliated and betrayed scientist might punish the Baron and Count Mancini for their dastardly behavior, by setting a ferocious lion upon them. Notably, Ward admits that he was inspired by the possibilities of a reinvented intellectual in this alternative, circus world.

The focus of this chapter is not to evaluate which adaptation was good, better, and best, but instead to view this series of adaptations within the frame of Andreev's own predictions about the growing popularity of cinema and his recommendations for a panpsyche theater of the future. Secondarily, it was important to pose a premise as to why this one particular work of Andreev was so successful in crossing into new cultural territory and lent itself to so many American adaptations. Bouissac suggests that the semiotic system of the circus, both as a form of entertainment and as a way of life, is perceived by audiences as a universe of its own. ${ }^{36}$ As a result, many of Andreev's theories about the audience's desire for verisimilitude were demonstrable within the context of the circus, a ritualistic spectacle that could be read, interpreted, and enjoyed by Russian theater audiences in I915, by American cinemagoers in I924, and by American opera lovers in 1956 . 


\section{NOTES}

I. Bouissac, Circus and Culture, 9 .

2. Davis, The Circus Age, io.

3. For a cogent discussion of the American circus, see Davis, The Circus Age.

4. Bouissac, Circus and Culture, I64-9.

5. Andreev first published "A Letter on the Theater" in the March I9I2 issue of the journal Masks. This letter was republished with a second letter in I9I4 as "Letters on the Theater" in volume 23 of the Shipovnik almanac.

6. Andreev, Tot, kto poluchaet poshchechiny, 347. In English, I use the translation and page references for Andreyev, He Who Gets Slapped, I I 2.

7. Andreev, Tot, kto poluchaet poshchechiny, 329; Andreyev, He Who Gets Slapped, 60.

8. In "My Notes," a doctor of mathematics suggests that people prefer the appearance of truth, rather than truth itself, and this is how he justifies being condemned to prison although, he claims, he did not commit the crime. His theory is that he appeared guilty and, therefore, was guilty in the eyes of the jury. He accepts his sentence and writes his notes to explain how, after being condemned to death, he discovered the great purpose of the universe, expressing disgust that those living free continue to slander life. The mathematician's beliefs are put to the test when he is invited to the warden's house, where he recounts the details of his family's murder that seem to point to his own participation. Just as he is about to lose control, he performs for the warden's family as would be expected of an innocent man-he demands justice and the punishment of the real murderer-restoring the appearance of innocence. This successful performance leads the warden to fight for the mathematician's release and two months later he is liberated from prison. However, in freedom the mathematician realizes that he is losing his mind and decides to recreate for himself the rules and regulations of the prison. In a small house on the outskirts of town he builds a cell and hires a jailer to maintain the prison's rigid regime. In this way he is able to reclaim his sanity although the rest of the town believes that he is insane. Andreev, "Moi zapiski."

9. Quoted in the commentary provided by Mikhail Koz'menko for this play in Andreev, Sobranie sochinenii, vol. 5, 502-3.

Io. Bouissac, Circus and Culture, 6-7.

I I. Andreev, Tot, kto poluchaet poshchechiny, 340-I; Andreyev, He Who Gets Slapped, 95-6.

I2. Rischin, "Leonid Andreev I87I-I9I9," 53.

13. Pensel, Seastrom and Stiller in Hollymood, I I-22.

I4. Ibid., 29-30.

I5. Anderson, Faces, Forms, Films, $4^{2-3}$.

I6. Bouissac, Semiotics at the Circus, 43 .

I 7. Pensel, Seastrom and Stiller in Hollymood, 33.

I8. Quoted in Anderson, Faces, Forms, Films, 87.

I9. In Carlin's novel, He is referred to as HE with capital letters.

20. Carlin, He Who Gets Slapped, I 53.

2 I. Ibid., 246 .

22. Ibid., 270.

23. Almaviva, "Exclusive Interview with Composer Robert Ward."

24. Stambler and Ward, He Who Gets Slapped [Pantaloon], 7.

25. Ibid., I3.

26. Ibid., I 7 .

27. Ibid., 25 . 
28. Kolodin, "Music to My Ears."

29. Sargeant, "Oops!"

30. Brook, The Shifting Point, I90-I.

3I. Brecht, Brecht on Theater, 50.

32. Duffie, "Composer Robert Ward."

33. Hutcheon with O'Flynn, $A$ Theory of Adaptation, 87.

34. Almaviva, "Exclusive Interview with Composer Robert Ward."

35. Bouissac, Circus and Culture, $\mathrm{I} 73$.

36. Ibid., I9I. 


\title{
Against Adaptation? The Strange Case of (Pod) Poruchik Kizhe
}

\author{
Alastair Renfrem
}

It is difficult to find an ambitious person who would not at some point write a screenplay. ${ }^{1}$

We are abstract people. Each day divides us up between ten different activities. That is why we go to the cinema. ${ }^{2}$

$\mathrm{T}$ The rise of the so-called "formal method" in the immediate postrevolutionary years has been associated almost exclusively with questions of literary specificity, and with the search for a methodology that would not only exceed various forms of intentionalism and/or determinism, but would also destroy the pretensions of a general aesthetics to account for the presumably transgredient "essence" of art. ${ }^{3}$ As a consequence, the logical corollary of any claims for the specificity of the literary, namely that this implies also the formal specificity of the other modes of art from which literature is differentiated, has been just as consistently neglected: What does the differentiation of the means available to literature imply for "not literature," whether "not literature" be seen primarily as the broad verbal context against which the literary defines itself ("practical language"), or as the technically variegated forms of art against which, in a sense, it competes - painting, music, theater, and of course cinema? This question takes on yet more practically dramatic dimensions when we consider the extent of the involvement in cinema of the leading Formalists, not just as theorists and critics, but also as writers and, in certain cases, administrators. The present chapter proposes, then, to proceed from a brief account of Formalist engagement with cinema to a more focused examination of the activity of Iurii Tynianov, and, specifically, the screen version of his story "Lieutenant Kizhe," which will allow us to return to the question of artistic specificity, and to reconnect, on a necessarily provisional basis, to a more recent discourse around the relationship between literature and cinema—adaptation. 
It is important in coming to this material to bear in mind two related provisos: The first, as indicated by the use of the qualifier "so-called" in apposition to the Formalists, is that the theorists and critics who have been grouped under the heading "Russian Formalism" do not represent a unified or consistent school or "method" of literary theory; they were characterized as such in the I 920 s chiefly by their opponents, and, conversely and understandably, in the I960s to I980s by their supporters, anxious to recover and champion what had been lost through repression in the "cultural revolution." With regard to the cinema, however, in terms equally of theory and practical involvement, there is even less ground for considering their activities under a broad unified heading. Boris Eikhenbaum, for example, although the most conservative of the leading Formalists with regard to disciplinary and institutional range, not only published on cinema in the mid-I920s, but also taught a course at the State Institute for the History of Art (GIII) on "General Theory of Cinema" and, along with Tynianov and leading literary figures such as Evgenii Zamiatin and Mikhail Zoshchenko, joined the newly formed "Cine-Literary Committee" of the Sevzapkino studio in late I925. ${ }^{4}$ This relative reticence contrasts with the sustained involvement of Osip Brik, as both screenwriter and, for a time at least more significantly, as a "creative administrator" and head of the Script Department at the Mezhrabpom studio. Brik achieved this influential position following the production of his script for Pudovkin's Storm Over Asia (1928), but this would turn out to be the height of his success, creatively and administratively. As a leading figure in Lef (The Left Front in Art), Brik's position at Mezhrabpom became increasingly compromised after 1928, and indeed the difficult production process of his script for The Tmo Buldis (Kuleshov and Agadzhanova, 1929) is an illustrative case of how Mezhrabpom and the studio system in general were "purged" and reorganized as the I93os dawned. Brik's relations with Mezhrabpom and other major studios deteriorated to the point where his scripts were routinely and sometimes mercilessly rejected, culminating on more than one occasion in the threat of legal action for return of fees paid in advance. ${ }^{5}$ Brik's engagement with the cinema in the I930s is restricted largely to documentaries and newsreel, often trading on his former association with Lef's undisputed and now deceased star, Vladimir Maiakovskii. ${ }^{6}$ Brik's involvement in cinema is above all else exemplary of the manner in which the film industry became a domain like any other for the evisceration of the cultural intelligentsia, and is therefore far from being unique.

By way of a very different contrast, Viktor Shklovskii was so prolific, as a writer in general and as a screenwriter in particular, that it becomes impossible to contextualize his film work against the constricted background of his former association with Opoiaz (The Society for the Study of Poetic Language), or of his continuing personal and professional relations with 
either Tynianov or Brik. It is also extremely difficult to correlate his writing on film, with its characteristically polemic and almost occasional manner, ${ }^{7}$ to his work in film, which stretches from screenplays for The Bay of Death (Room, 1926) and the brilliant The Wings of a Serf (Tarich, 1926), all the way to The Ballad of Bering and His Friends (Iurii Shvyrev) in the distant year of 1970. This is exacerbated by the fact that Shklovskii's scripts are often co-authored, his input being of a corrective nature, rewriting a problematic script or developing an early treatment. Shklovskii's name crops up in archival materials on the cinema in the I920s and I930s with astonishing frequency: More than any other writer attracted into the cinema from the I925 literary campaign onwards, Shklovskii became an almost ubiquitous consultant, adviser, and troubleshooter, a role which was not at first undermined by the final "defeat" of Formalism and Shklovskii's very public recantation of his former "errors" in I929. ${ }^{8}$ Shklovskii's adventures in the cinema are in fact best contextualized against the long-running story of the wit and resourcefulness of Shklovskii the personality, a story that can be accessed in its most perfected form in the extensive memoir literature authored by none other than Shklovskii himself. ${ }^{9}$

Tynianov's engagement with the cinema is distinct from that of each of his colleagues in a number of ways, which combine to make him a more productive subject for integrated analysis and, at the same time, a more challenging one. First, the relatively small number of films made from his screenplays were all produced-or, in the case of the exception that will be our main focus of attention, conceived-in the relatively homogeneous period between the I925 "literary campaign" and the onset of "cultural revolution." Second, Tynianov's writing on film, which is more extensive than Eikhenbaum's and more controlled than Shklovskii's, is almost entirely contemporaneous with his practical work as a screenwriter. Tynianov's key essay "The Fundamentals of Cinema" and the shorter "On the Screenplay" and "On Siuzhet and Fabula in the Cinema" not only represent a more coherent and indeed fundamental contribution to film theory than Shklovskii's film writings, but were also written and published in 1926 and ${ }^{1} 927,{ }^{10}$ in the closest possible relationship to the discussions, negotiations, and creative activity that would result in the films The Overcoat (Kozintsev and Trauberg, 1926), S.V.D. (The Club of the Great Deed) (Kozintsev and Trauberg, I928), and Lieutenant Kizhe, the last of which, by a series of twists of circumstance, was not produced until I934. Tynianov's film writings in themselves warrant re-examination as a contribution to film theory, but the temporal coincidence between their composition and the production of his screenplays presents itself as an almost irresistible ground upon which, albeit with appropriate caution, to assess the theory in direct contiguity to the practice. $^{11}$ 
The third reason Tynianov holds such appeal in this context has two particular though by no means distinct aspects, each of which bears on the problem of adaptation. The first of his films, The Overcoat, is an ambivalent response to the vogue for literary adaptations that was in a sense the natural consequence of the literary campaign in the mid-I920s, and which, to some extent, invoked the risk of compromising the drive to develop a specifically cinematic language that united the otherwise disparate elements of the Soviet avant-garde. ${ }^{12}$ Yet Tynianov's career had begun to develop in a way that would further complexify the relation between theory and practice in his work: By the time he and Eikhenbaum had joined Sevzapkino's Cine-Literary Committee in late I925, Tynianov had already published a short story "Brooks's Parrot" under the pseudonym Iuzef Motl', ${ }^{13}$ and was working on a novel on the early nineteenth-century writer and schoolmate of Pushkin, V. K. Kiukhel'beker. The novel, Kiukhlia, was published on December 2, a week after the CineLiterary Committee had met for the first time. ${ }^{14} \mathrm{He}$ had also already delivered the first draft of the screenplay for The Overcoat, for which he had signed a contract on October $\mathrm{I}_{3} \cdot{ }^{15}$

The early part of 1926 sees Tynianov engaged in a range of activities, the sheer volume of which may strike us as remarkable, but it is their interlocking and mutually affective nature that is crucial to an understanding of his work in the cinema in general, and of his significance for adaptation in particular. Tynianov was co-opted as consultant on the production of The Overcoat,${ }^{16}$ a position he retained in a more general capacity until becoming a member of Sevzapkino's Script Department in July. ${ }^{17}$ The script for S.V.D. was conceived and written with Iulian Oksman in January-February, at which time Tynianov, who was also preparing a preface to accompany the republication of his article "The Archaists and Pushkin," 18 actually screen-tested for the role of Pushkin in what would later become The Poet and the Tsar (Gardin, I927). ${ }^{19}$ "On the Screenplay" and "On siuzhet and fabula in the Cinema" were published in March, by which time Tynianov was already at work on what would become his second novel, The Death of Vazir-Mukhtar, which commenced serial publication in the journal The Star in January I927, but would not be completed until March-April I928. ${ }^{20}$ While writing The Death of Vazir-Mukhtar, Tynianov published the story "Lieutenant Kizhe," which later became the ostensible model for the film of the same name. Understood against this background of creative quotidian life the putative comparison between Tynianov-filmtheorist and Tynianov-screenwriter is thus problematized by its imbrication in a second species of comparison, between Tynianov-screenwriter and Tynianov-literary author, an exercise that becomes all the more pregnant when we characterize him, in the specific instance of Lieutenant Kizhe, as adapter of his own work. 


\section{LIEUTENANT KIZHE COMES OUT FROM GOGOL'S OVERCOAT}

The story "Lieutenant Kizhe" was published in the first number of the journal Red Virgin Soil for $1928,{ }^{21}$ and was subsequently produced as a film from Tynianov's own script, directed by Aleksandr Faintsimmer, and released by Belgoskino in 1934. A preliminary comparison of story and film-or even, in fact, a preliminary reading of just the story-immediately points to certain fundamental difficulties in the process of adaptation. The story's central conceit, in a clear invocation of Gogol, is the invention of a shadowy second Lieutenant through a clerk's transcription error in the court of Pavel I. In a list of personnel for a guard rota, the clerk is interrupted at the point where he is about to record additional personnel (Lieutenants) with the Russian plural formula "Poruchiki zhe"; when he returns to his transcription, the plural "poruchiki" becomes a singular ("poruchik") and the syllables "ki" and "zhe" are conjoined and capitalized to form a surname-the eponymous Kizhe. In English, the equivalent would be for the plural "s" to be removed from "Lieutenants" and joined as a capital to "and"; the non-existent Lieutenant Kizhe would become the suitably Hoffmanian Lieutenant Sand.

Rather than suggest that this conceit is somehow definitively textual, and therefore does not transfer intact to the screen, it is more accurate to say that is in fact neither: it is, rather, definitively oral. ${ }^{22}$ What might, somewhat unsatisfactorily, be described as a "device" is in fact a point of the greatest readerly tension, in that it obliges the reader, mentally or even aloud, to rehearse the sequence of enunciations that could lead to such an error; what is given on the page is merely a prompt. In the context of a sound film, however, this tension might have been overcome by a more effective use of the resources of dialogue: The film's juxtaposition of a mumbling clerk and shots of the text on which he is working are less effective than, for example, a repetitious dialogue sequence involving more than a single character might have been (Chico and Harpo Marx spring to mind, as does Roberto Benigni's repetitious play on "I scream" and "ice cream" in Jim Jarmusch's i986 picture Domn By Law). The textual prompt, which is nothing less than the "birth sequence" of the story/ film's main character, is nonetheless more effective on screen than it is on the page. We are now relatively unaccustomed, with the obvious exceptions of silent films and perhaps animated fairy tales, to seeing text on screen, and the framing of the benighted clerk by the hyperbolized imperial decree, hung on the wall and increasingly dominating the shot, renders perfectly the story's sense of how the decree - the Tsar's abstracted but authoritative "word"-has come utterly to oppress and displace the human. The story's and the film's respective means for rendering the motivating device of the transcription error might therefore be compared in the latter's favor. This, however, is an 
isolated example, involving the comparison of a point of readerly tension in the story with what is, despite its failure to take full advantage of the resources of dialogue, a rare moment of strength in the film; but from the moment Kizhe is brought into being, so too are a range of more challenging problems for the process of adaptation.

The dominant device of the story, which is merely facilitated by the clerk's error, is the device of the "absent hero." This might once again be associated with Gogol, whose work abounds with play on absence; in the story "Lieutenant Kizhe," however, Tynianov takes absence as a device to its illogical conclusion. Fiction is more often than not driven by a controlling narrative voice, which establishes a technical point or points of view from which the "events" of the story are organized and represented, these "events" ranging from the straightforwardly situational, the imagined or supposed, all the way to the content of the narrator's and/or various characters' consciousnesses. In this context we can see immediately that the apparent absence of the hero need not present insurmountable difficulties: The fictional narrator is able without particular difficulty to organize a sequence of events and the dynamics of their narration in order to convey to the reader that, to take the present case, "Kizhe did not really exist, although Pavel and others were led to believe he did, and with such-and-such consequences." The absent hero is in fact no kind of problem or difficulty at all, but is rather the primary means by which the story achieves its effect. Thus when Nelidova's lady-in-waiting declares hysterically that Kizhe must have been the officer with whom she had a lovers' tryst, and is later prepared to go through with a phantom wedding on the pretext that her groom's absence has been decreed by Pavel himself, our response, in Tynianov's sub-Gogolian world, is not to disbelieve, but rather to accept his dramatically refracted commentary on the mores of Pavel's court, the sense in which anything is possible in this twilit, enclosed world, which has become severed from any sense of "reality." Similarly, Pavel's serial promotion of the non-existent Kizhe, his lament on learning of Kizhe's "death" that "My best people are dying," 23 and Pavel's final isolation before the death we know will follow, are all intended to emphasize that Pavel, too, does not fully "exist," but has become a phantom or "fake" Emperor, for the people and for his court.

The cinematic medium, which in all but a very few cases dispenses with voice-over narration and in which the expression "point of view" carries more precisely technical—even literal-connotations, clearly presents a different set of difficulties with regard to the absent hero. On screen, to put it simply, we must see that Kizhe does not exist. Or, to be more precise, we do not see a representation of his character. Kizhe's non-existence, which in the story is necessarily counterbalanced by the narrator's representation of the circumstances surrounding him-the fundamental task of narration in the context 
of fantastic realism - is in the film confirmed in the most graphic and almost entirely unavoidable manner. This confirmation is at its most dramatic in four key sequences, which, along with Kizhe's textual/circumstantial "birth," form the spine of his conventional biography: his punishment, exile, wedding, and funeral. In the first, we see an empty space "flogged" on the parade square as the ranks look on; we then witness a pair of bemused soldiers "escorting" an empty space along the Vladimir highway into exile, a conceit that is at least milked for comic potential when the soldiers inform a provincial garrison commander en route that the prisoner "requests vodka." In the wedding sequence, Palen, who orchestrates the circumstances surrounding Kizhe for his own benefit throughout, announces that the groom will not be in attendance "by decree of the Emperor," then himself stands holding the matrimonial crown above the empty space where Kizhe ought to be. In response to the officiating Priest's inquiry as to whether Kizhe is betrothed to any other, Palen moves the crown back and forward, gesturing "no," upon which the bewildered bride is invited to kiss thin air. Finally, once Palen's resourcefulness has been exhausted and it better suits his purpose to declare Kizhe deceased, the funeral procession, led of course by Kizhe's widow, walks mournfully after an empty coffin - with only the subtlest implication that Pavel himself will soon fill it. It might have been possible, as Iampol'skii has suggested, to deal with the problem in all of these sequences by associating the camera's point of view with Kizhe; Iampol'skii's example here is Kurosawa's Throne of Blood (I957), although a more recent and perhaps yet more compelling example is Sokurov's Russian Ark (2003). Another possible solution, to which we will later return, is the introduction of a parallel, "secondary hero," a role that is in the film distributed between Pavel and Palen. Both these solutions might have gone some way to neutralizing the problem posed for the cinema by the device of the absent hero, but both would struggle nonetheless to deal with the implications of the broad literary style that in the present instance produces and contains the absent hero, namely fantastic realism. ${ }^{24}$

Tynianov's use of the device of the absent hero is an indication of his intention in the story to interrogate the entire system of conventions of realist fiction. Here, as indeed in Gogol, "verisimilitude of detail is used in order to gain the reader's trust, which is necessary in order to convince the reader that s/he can regard fantastical elements with precisely the same trust." ${ }^{25}$ Just as in Gogol's "The Nose," for example, Tynianov establishes different "levels of reality," on each of which events - and indeed the existence of characters-are believable in varying degree, the effect of which is to render believable the "merely" unbelievable through its contrast with the downright fantastical. It is not so much the case that the establishment of a differentiated reality is less problematic in the textual medium than it is in the visual-cinema habitually uses variations on "dream sequences," stylistically marked to a greater or 
lesser degree, in order to achieve this - but rather that it is more difficult in the cinema to obscure the boundaries between different levels of reality, to destabilize the viewer's perception of the "realness" of different sequences without undermining the narrative altogether.

It might be instructive in this regard to turn briefly to Tynianov's first screen work, his adaptation of Gogol's "The Overcoat," which will facilitate direct comparison of the literary imperatives of fantastic realism and the means the cinema has at its disposal for their mediation. Tynianov's script in fact also incorporates elements from Gogol's "Nevsky Prospect" and "How Ivan Ivanovich Quarrelled with Ivan Nikiforovich" in order to create a fictional youth for Akakii Akakievich, before reverting in its second part to a more "faithful" rendition of the story. From the point of view of fantastic realism, there are clear examples in the film of how the device of the dream-sequence can be rendered through simple montage, and to much greater effect than in literature: Akakii's fevered imaginings toward the end of the film work very simply in terms of technical construction-in one shot the overcoat-clad "important person" sits at the foot of Akakii's bed, whereas later, when the dream has passed, he has disappeared. Similarly, Akakii is finally persuaded to embark on the ruinous purchase of the luxurious new coat by a "vision" of it that is rendered by means of a simple dissolve. The viewer reads what is "real" for Akakii through the syntax of shot juxtaposition, and the cinematic challenge - to which Tynianov, Kozintsev, and Trauberg admirably rise-is to maintain a balance between verisimilitude and the creation of a liminally fantastical cinematic world in which certain events might be possible; for the viewer will more readily rebel against what is seen, than will the reader against what is read, whether it be a nose in an overcoat deep in prayer, or a crown floating above the head of a non-existent groom.

Perhaps the most telling confirmation of the differential effects of this tension of verisimilitude, which is the engine of fantastic realism, is that for all the willingness of writer and directors to augment Gogol's story with elements that will combine to produce a specifically cinematic narrative, one utterly essential sequence from the story is actually omitted from the film, the concluding "fantastical" resurrection of Akakii Akakievich as vengeful phantom. The Overcoat was roundly criticized in the contemporary press for the equally predictable transgressions of lack of fidelity to the original and its alleged "formalism." The latter of these criticisms is a sign of what was soon to come, in culture generally as much as in the cinema, but the former is directly connected with the literary campaign that first brought Tynianov to the cinema, and to certain related expectations of the function of literary adaptation. It is important here to distinguish two completely different types of "infidelity," and to argue that the addition of alien elements from elsewhere in Gogol, the focus of contemporary complaint, is not motivated by some form of 
crisis of adaptation, in fact quite the contrary; the excision of Akakii's fantastical resurrection, on the other hand, is directly related to an appreciation of the different means available to the cinema and of its different mode of perception. In Gogol's story, the knowingly unsustainable pathos of Akakii's struggle is released, quite literally at the stroke of a pen, in the transition from the narrator's laconic intimation of Akakii's death to the arch rhetoric of

But who could have imagined that this was not the end of Akakii Akakievich, and that he was destined to live noisily for several days after his death, as though in reward for a life that no-one had noticed? But this is what happened and our miserable story unexpectedly takes on a fantastic ending. ${ }^{26}$

In the context of the film, however, as Tynianov was clearly aware, and notwithstanding our earlier remarks about the possibilities of montage, no such unproblematic "progression" is available. As Tynianov wrote in an essay published between the film's completion and release:

Even the cinematic "adaptation" [instsenirovka] of "the classics" should not be illustrative-literary devices and styles can only be stimuli, ferment for the devices and styles of the cinema (and certainly not all literary devices; just as certainly not all "classics" can provide material for the cinema). The cinema can, on its own plane, provide an analogy for literary style. ${ }^{27}$

The film version of The Overcoat does not embody Gogol's poetics of fantastic realism, because, quite simply, it does not attempt to. Tynianov recognizes, like the good "formalist" he is, and as his theoretical essays consistently confirm, that a literary poetics cannot expect to find in the medium of the cinema an "equivalent," but, in the best case, an "analogy." The Overcoat may, as Tynianov's published libretto claims, be a "cine-tale [kinopovest'] in the manner of Gogol," ${ }^{28}$ but the cinematic prefix is as important here as the "privileged object" (Gogol) toward which it is directed.

Tynianov's story "Lieutenant Kizhe" is as perfect an embodiment of the poetics of fantastic realism as was produced in Soviet literature, but it failed to find even an "analogy" in its film adaptation, despite the fact that the latter was produced from a screenplay by the same author. This is partly due, as we have begun to suggest, to fundamental differences in the stylistic and technical repertoire of literature and film, and with specific regard to the three areas we have identified - the story's heightened textuality, its use of the device of the absent hero, and its global challenge to the conventions of realism. It is also related to a factor we have, justifiably in the circumstances, ignored in relation 
to The Overcoat, the broadly sociological aspect of adaptation theory, which focuses on cultural conditions of reception rather than questions of formal "transposition." Our discussion of the formal and aesthetic difficulties in the course of adaptation from literature to film would be incomplete without an analysis of the radical cultural, ideological and industrial changes in Soviet society and in the film industry between I927 and I934. Such analysis would range across factors such as the industrial reorganization of the film industry, the advent of sound (which incidentally demonstrates the inseparability of "formal" and "industrial" factors), and the strengthening of the censorship apparatus, which, along with sound, led to a sharp decline in production numbers. In this respect once again, however, Lieutenant Kizhe presents itself as an exemplary case, chiefly because the film and indeed the story possess an entirely different history from the one implied by their respective dates of publication and production. It is through that history in its specific detail that we might begin to approach the "sociological" aspects of Kizhe's adaptation, and at the same time take its formal analysis to quite another level.

\section{"A SECRET FILM THAT HAS NO HISTORY ...": SCRIPT-TO-SCRIPT}

Over a year before the story appeared in Red Virgin Soil, Tynianov submitted a libretto for Kizhe to Sovkino, perhaps based on an anecdote attributed to Vladimir Dal'. ${ }^{29}$ On February 2, I927 he signed a contract to produce a screenplay on the basis of the libretto, with a delivery date of February $\mathrm{I} 6$, for which he would receive the not inconsiderable sum of 800 rubles. ${ }^{30}$ Between the end of February and the end of March, the studio became locked in the by that time common battle of nerve and will with Glavrepertkom over the script's ratification and permission for production to begin. It was to be directed neither by Kozintsev and Trauberg, nor Faintsimmer, ${ }^{31}$ but by Sergei Iutkevich, for whom this would have been a directorial debut. Iutkevich's redaction of the script was rejected by Glavrepertkom on February 28, for somewhat predictable reasons, relating to what they saw as its historical and ideological deficiencies, summarized in its alleged "lack of social significance" and failure "to do justice to the epoch." 32 Iutkevich then made a final attempt to rescue his first directorial assignment by suggesting a number of changes (including strengthening the geopolitical dimension by involving Palen in a plot against the throne with the former English Ambassador); he also argued, with admirable cheek, that he required the last of the fast disappearing winter weather for his exteriors. ${ }^{33}$ The script was rejected once again on March $19,{ }^{34}$ and Iutkevich, reaping the seeds he had sown in appealing to the weather, formally requested release from the project three days later. ${ }^{35}$ Thus a new front 
has opened up in our analysis of the genesis of Lieutenant Kizhe, one that does not necessarily depend on the film's specifically literary antecedent, but rather on a consideration of (at least) two script treatments.

Tynianov's formal association with Sevzapkino ended at the same time as its reorganization as part of the new Sovkino structure. S.V.D. had, however, been completed in the spring and Tynianov does not initially seem to have been deterred by the difficulties relating to the production of Kizhe, insisting to Eikhenbaum that he intended to continue working in the cinema. ${ }^{36}$ Events were, however, to take a somewhat different turn. Tynianov spent much of the summer in the Crimea, struggling with the ill-health of his wife Elena Aleksandrovna and, briefly, his daughter Inna, and at the same time with the on-going composition of The Death of Vazir-Mukhtar. In a letter to Nikolai Stepanov of September 3, I927, he complains that work on the novel is going badly, but writes also that "unexpectedly even for myself, I have written a short story 'Lieutenant Kizhe'." 37 Shubin suggests that the story was written in May, ${ }^{38}$ but this reference, accompanied by a similar reference in a letter to Shklovskii on the same day, would suggest that it was written in late summer 1927. This can be further narrowed down by a letter written to Pavel Antopol'skii on August I, which throws yet another shaft of light on the genesis of Kizhe: Tynianov, who had been invited to write a stage play for the Vakhtangovskii Theatre, tells Antopol'skii that "the most important question for me is 'Kizhe' or another play." 39 The screenplay for Kizhe, it would seem, was briefly regarded as the basis for a stage play, and only "unexpectedly" became a prose story sometime between August I and September 3; this is a decisive herald of the later direction of Tynianov's career, confirmed in his remark in the same letter to Shklovskii that "I am beginning to really love literature and have given up on cinema."

Leaving aside its implications for Tynianov's engagement with the cinema generally, however, this sequence of events confirms that the conventional dynamic of adaptation from literature to film is in this case reversed, and that Tynianov's story "Lieutenant Kizhe" is in fact an "adaptation" of his earlier film script of the same name. Any comparative reading of story and film must therefore confront another compelling and perhaps even more productive line of inquiry than the script-to-script comparison we have just noted, and focus on the relationship between an original screenplay and what would in other circumstances have been its literary progenitor; when, in other words, the "precursor text" is film and not literature. ${ }^{41}$

The relationship between the 1927 script and the 1934 film is aptly summarized in I. Sepman's characterization of the former as a "tragicomedy" and the latter as a "pamphlet" and, more significantly, a "farce." 42 There is no lack of elements of farce in the 1927 script, including an ill-advised sequence at the beginning of the fourth reel in which Pavel's adjutant Kablukov dresses in 
woman's clothing in order to convince Pavel to pardon her "fiancé," inevitably Kizhe. ${ }^{43}$ This sequence is no doubt present in the 1927 script in order to emphasize the recurrent theme of identity, but also, on another level, simply to motivate such scenes as when Kutaisov, another of Pavel's male courtiers, takes a shine to his erstwhile colleague Kablukov in drag and makes the predictable romantic advances. ${ }^{44}$ The presence of farce in the 1927 script notwithstanding, there are two notable differences in this respect from the 1934 film: The first is that in 1927 even this unsurpassably farcical sequence contains elements necessary to the development of the plot, and indeed is intercut with its dramatic opposite, when Palen learns that the difficulties he is having with the income to his estate are a result of Pavel's trade embargo with England, and makes his personally motivated intentions toward Pavel explicit for the first time: "TITLE: THIS WON'T HELP PUG-FACE [Pavel], AND IT won't hinder us." ${ }^{45}$ Farce here functions as an accumulating preparation for the decisive change in tone that will characterize the second half of the I927 script. Palen's declaration of intent is followed by a sequence, again absent from the 1934 film, in which Pavel plays with mechanical toy soldiers gifted by Bonaparte, which develops seamlessly into a dream-sequence (see above remarks on The Overcoat). Pavel, alone on his throne, is surrounded and saluted by the mechanical grenadiers, who respond to him with a rousing: "TITLE: YOUR GOOD HEALTH, GENERAL KIZHE." ${ }^{46}$ From this point forward all other plot elements are contained by and develop the plot against Pavel and his own headlong, self-blind rush to collude with unfolding events. Pavel himself, for example, decides that Sundukova will marry Kizhe in the 1927 script, because Kizhe has been "betrayed" by his current fiancée-whom we of course know to be the adjutant Kablukov in disguise. And when, in a bravura closure of this plot line, Kablukov drunkenly mistakes Pavel's room for the room of Sundukova after the wedding sequence, the spectacle of Kablukov attempting to get into bed with the Emperor is not primarily motivated by a desire for cheap entertainment ${ }^{47}$ but is rather a bold and consistent means of rendering the tragic-comic pathos of Pavel, who responds to the presence of anyone at all in his quarters at night with unmitigated terror. This is ironically emphasized as we cut immediately to Palen and his conspirators, one of whom asks: "TITLE: AND WHAT IF THE TYRANT RESISTS?" 48 It is typical of the dramatic unity of the I927 script that Kablukov is led into his mistake by one of the mechanical soldiers "posted" outside Pavel's chamber door: Whereas the film builds the wedding sequence around an empty space standing next to the bride, the 1927 script utilizes one of the toy soldiers in this role; and the bride Sundukova, to the indignation of the priest conducting the service, whispers conspiratorially to Kablukov that she will station this "dummy" (bolvan) outside her bedroom door so that Kablukov can find her, and so that the soldier/Kizhe can "guard this night for us." 49 
The I927 script is a tragi-comic tale of Pavel himself, in which "Kizhe" is nothing more than a "device," or, quite literally, an "absent cause." This is reflected most dramatically in each version's contrasting denouements: The film, in which the assassination plot is more implied than explicit, ends on a suitably oblique note, with the repeated intonation "The Emperor sleeps" immediately following Kizhe's funeral; in the I927 script, however, the assassination plot is taken to its literal conclusion, and Kizhe's empty coffin finds an equally literal occupant. The script ends with Pavel alone apart from his toy soldiers, who "triumphantly and welcomingly throw open the doors" for the human shadows creeping along Pavel's walls. ${ }^{50}$ Pavel's death is figured through a shot of his legs, which we have earlier seen failing to reach the floor as he sits on the throne, shaking and collapsing underneath him. ${ }^{51}$ This is followed by the somewhat awkward "TITLE: THE EMPEROR SLEEPS, THE EMPEROR IS RESTING," before a cut to the triumphant Palen closing the lid on Pavel in Kizhe's coffin. ${ }^{52}$ Kizhe's "absence" is thus resolved, and the metaphorical "absence" of Pavel confirmed in a single move, one which at the same time removes any difficulties that may have persisted in the mind of the querulous viewer, forced once again during the funeral to "see" what the other characters in the film cannot. Not satisfied with this brilliant resolution of both plot and theme, which is also a local resolution of the problem of the absent hero, Iutkevich attempted to take advantage of the otherwise frustrating impasse with Glavrepertkom by suggesting a change that would make Palen's triumph yet more explicit: Before closing the lid on Pavel in the coffin, Palen would utter the words, "Sleep tight, Emperor Kizhe." 53

\section{SCRIPT-TO-ST OR Y}

The story Tynianov published as "Lieutenant Kizhe" at the beginning of I 928 is marked by a number of striking points of coincidence with and divergence from the script upon which we now know it to be "based." It is, like the I927 script, more tragi-comedy than comic farce; it is also, however, a tragicomedy with a very different emphasis, both in terms of theme and in terms of its response to the problem of the absent hero. In the 1927 script, as indeed in the I934 film, the absent figure of Kizhe has a pair of doubles: On the thematic level, Pavel himself is Kizhe's double, the latter signaling the emptiness, absurdity, and "surrogacy" (podmenennost') of the former; on a technical level, however, although it is Pavel and his inhuman system of government who in a sense authors Kizhe, Kizhe is also doubled with the figure of Palen, who manipulates Kizhe's effect on the narrative throughout. This is an example of another means by which film can deal with the problem of the absent hero: through the introduction of a parallel "secondary hero." Carol 
Reed's The Third Man (1949) is a well-known example, but a more recent and still more appropriate example is Andrew Niccol's 2002 picture $S_{\text {I }}$ mone, starring Al Pacino and Rachel Roberts. Roberts plays a non-existent female star, computer-generated and gifted to Pacino in order to save his failing career, as coincidence would have it, as a film director. Simone only ever appears on screen, of course, and Pacino is the locus of the drama centering around her absence/presence off it. In both script versions of Lieutenant Kizhe, Palen is to Kizhe what Joseph Cotton is to Orson Welles's Harry Lime, and what, in a more thoroughgoing sense, Pacino is to Simone: Palen is not quite a secondary "hero," but rather a secondary character who acts to maintain the illusion of Kizhe's existence and through whom we experience the "absent cause." In the story, however, these relationships are disordered: Palen is virtually absent from the story, as are all other forms of human agency other than the ironically ineffective Pavel, who is doubled with Kizhe technically as well as, at one end of the spectrum, thematically. At the other end of the story's thematic spectrum, Tynianov replaces Palen with a quite different double for Kizhe, Lieutenant Siniukhaev, who does not appear in either version of the script. In the story, Siniukhaev is in fact born at the same moment as Kizhe, the result of a parallel error by the unfortunate clerk; or, to be more precise, he dies at that same moment. Where Kizhe is conjured into being, Siniukhaev, almost as if the static equilibrium of Pavel's world requires it, is erroneously declared dead. The fact that Siniukhaev stands, living and breathing, on the parade ground at the moment the decree proclaiming his passing is read out is as irrelevant to those around him as Kizhe's non-existence. Both "facts" are accepted because both have been decreed by the law and by the letter, manifestations of Pavel's overweening but essentially groundless authority. Both are thus bound to Pavel in a relation of perfect symmetry, Kizhe a present absence, Siniukhaev an absent presence, a symmetry that is disturbed in both redactions of the script by the interposition of the all too mundanely "real" characters of Palen and Gagarina, whose own relationships to Pavel are driven by simple selfinterest, and who "operate" Kizhe as a device in pursuit of those interests.

In the character of Siniukhaev, Tynianov succeeds in providing the necessary "foil" for the absent Kizhe, a secondary hero with whom the reader is invited to empathize, although the irony is that such a secondary hero is, as we have suggested, less essential in the text than it is on screen. Kizhe, as someone who does not exist, can only be a nominal "hero," occupying the technical space of the hero, but as such he can never quite become a victim. No matter how many times we are told of him being beaten or exiled, hear of his betrayal or even his death, he can never be an object of sympathy, because the entire fiction-text or film-turns on his non-existence. Siniukhaev performs this parallel function in the story, and it is in this sense that his absence not only from the 1927 script, but also, after the publication of the 
story and the resumption of the process of "adaptation," from the I934 film, is particularly damaging. We have seen that one of the predictable criticisms aimed at the abortive 1927 production was its lack of social significance, its failure to expand anecdotal material into a dramatization and critique of the social system of Pavel's Russia. When we consider in addition that the Soviet co-option of Gogol and many other of the nineteenth-century "classics" was, justifiably or otherwise, founded on a sense of their "revolutionary pathos," of the Belinskii-inspired idea of underlying social critique, Siniukhaev's absence from the film seems all the more surprising. And, finally, when we acknowledge that by 1934 one of the key strategies in the nascent sound cinema for expressing social and ideological orientation was its personification in youthful individuality, the irony of the film's rejection of this element of the strategy Tynianov chooses in adapting script to story becomes overwhelming. The story's introduction of Siniukhaev not only broadens the story's ideological and social spectrum, but also endows it with a perfect narrative and thematic balance. Passages of description of Kizhe's "exploits," with their inevitable and deliberate tendency to stretch the reader's credulity, are, dare we say it, intercut with passages of description of the "real" sequence of events that befall Siniukhaev, thus providing a form of verisimilitudinal relief; although, as was the case with the device of the secondary hero, the irony is that such verisimilitudinal relief is all the more necessary in the visual context of cinema than it is in the conventionalized textual world of fiction.

We can see how this functions by returning to the series of challenging visual set pieces described earlier from the film, Kizhe's punishment, exile, marriage, and funeral. The nakedness of the film's punishment scene, with the guards beating "no-one," is slightly mitigated in the 1927 script by the addition of two further "real" arrestees, who are punished at the same time as Kizhe, and one of whom is an entirely innocent victim: the barest seeds, perhaps, of the character of Siniukhaev. In the story, however, Tynianov, protected by the more pliable laws of verisimilitude in literary fiction, is able to emphasize the theme of injustice in altogether darker terms: "because the wood had been buffed by thousands of stomachs, the [punishment] horse seemed not at all empty. Although there was nobody on it, it seemed all the same that there was." ${ }^{54}$ Then, after a brief conversation in which a young soldier doubts the existence of the Emperor, and is reassured that the Emperor exists, but is a "fake" (podmennenyi), we move to a scene in Siniukhaev's quarters that is one part Gogol, three parts Hoffmann, and which, in a further complication of the process of composition "beyond adaptation," as it were, is itself absent from the original published version of the story. ${ }^{55}$ Siniukhaev refers to himself in the third person, before an unknown young man enters his room and, without any explanation, behaves as if he belongs there, cautioning Siniukhaev about his behavior and eventually demanding that he hand over his decent overcoat 
in exchange for the young man's poor one. The fantastic realism of the punishment scene, in which the massed troops behave as if an absent figure actually exists, is here relieved and at the same time reinforced by a different, more subtle shade of fantastic realism, in which two living, breathing individuals conduct a conversation wholly predicated on the idea that one of them no longer exists.

Similarly, the film's reliance on clowning in a somewhat desperate attempt to relieve the palpable inadequacy of the scene with Kizhe's guards and the provincial garrison commander is poor return for the story's sinister reminder of the real fate of exiled prisoners as Kizhe is escorted into exile: "The chains made no sound and there was no need to drive him along with the butts of their rifles. ${ }^{" 56}$ It is here, incidentally, that Tynianov introduces what will later become the signature refrain of the 1934 film, but which is absent from the I927 script, the guards' "explanation" of Kizhe's status: "The prisoner is secret and has no form." 57 This is contrasted and complemented by scenes of Siniukhaev seeking out his father in order to find a way of confirming his own existence, a theme Tynianov also develops in relation to Pavel, but which, incredibly, given who Pavel's parents were and the relationship between them, is entirely absent from both redactions of the script. Siniukhaev tells his father simply that "I am not living" (Ia ne zhivoi), upon which his father deposits him in a hospital, with the sign at the bottom of the bed reading "Mors occasionalis." ${ }^{58}$ And while Siniukhaev, as we are told at the beginning of his story, never had much to do with women, Kizhe is to be married, in description of which Tynianov, once again from the relative safety of textual narration, prefers what will resurface in the 1934 film, the adjutant holding a wedding wreath above the absent groom's head, to the 1927 script's determination to fill the literally empty space by enlisting one of Bonaparte's toy soldiers. Finally, in the story, in contrast to all variants of the script, Kizhe will produce a son, "rumored to look like him," 59 just as Siniukhaev's father will lose one; Kizhe's son will, in the story but not in the later film, accompany his weeping mother at the funeral.

\section{AGAINST ADAPTATION}

While it would be erroneous, as we have suggested, to consider Tynianov's theoretical writing on cinema in isolation from his practical activities as writer and administrator, there is a clear and important sense in which the "theory" is in fact distinct from the "practice." The two broad elements we have describedwriting and administration-are necessarily inadequate to define Tynianov's day-to-day life in the studios, with its shifting and seamless pattern of creative discussions, writing and rewriting, processing and commissioning new scripts; 
the task of the theoretical essay, on the other hand, is to establish some kind of order and clarity among entities that are at once disparate and intimately related. In the present case, as we indicated at the outset, these are nothing less than the fundamental modes of art, the comparative differentiation of which silently motivates Tynianov's turn to the cinema. Tynianov-film-theorist comes to the cinema in terms of the same central aesthetic questions that have driven the rise of literary Formalism, the comparability and non-comparability of the specific technical and formal resources that are available to any given art form and which therefore distinguish it from all others. It is only in the context of this move from a "general aesthetics" to a series of "specifying" aesthetics of different art forms that certain of Tynianov's more unexpected-to modern ears, at least - statements of principle can be understood, for example his pronounced and consistent resistance to sound cinema. Tynianov's rousing objection to the contemporary dismissal of cinema as "the great mute" (velikii nemoi) — "no-one calls poetry "the great blind" 60 — is somewhat undermined by his insistence on equating sound as an innovation with color and even stereoscopic cinema, all of which "excite us very little." ${ }^{11}$ Sound cinema is even characterized on one occasion as "the mongrel offspring of theatre and cinema-a pitiful compromise." ${ }^{\prime 2}$ More important in the present context, however, is the fact that this broad drive toward a "specifying" aesthetics also conditions Tynianov's discourse on adaptation.

Tynianov dwells on this specific problem at greatest length in the otherwise brief 1926 article "On the Screenplay," which establishes the broader aesthetic context before turning to the practicalities of actually producing work for the screen:

The cinema has been slow in freeing itself from the captivity of the neighboring arts - from theatre and painting. Now it must free itself from literature. Three-quarters of cinema is still like the painting of the Travelers [Peredvizhniki] —it is literary. [...] Until the question of the relationship between cinema and literature is re-examined, the best kind of screenplay will be halfway between a spoiled novel and an unfinished drama. And the best kind of screenwriter will be halfway between an unsuccessful dramatist and a belletrist who has tired of belles lettres. ${ }^{63}$

The slightly later essay "The Fundamentals of Cinema" is an attempt at such "re-examination" of the relationship between cinema and literature, and can be characterized as marking the transition from an aesthetics of specificity as such to what will later become the basis for a thoroughgoing semiotic approach to cinema, an approach which in fact aims to reconcile the demands of specificity and difference in a total theory of variously constructed signifying material. Just as the verbal sign carries within it a referent—objectified material—which 
is transformed into "an element of art" through the function it is required to perform in the literary text ${ }^{64}$ so too, to cite Roman Jakobson's later development of Tynianov's postulates, is the optical "thing" (i.e., the object of visual representation) transformed into a sign: "every phenomenon of the external world is transformed on the screen into a sign." ${ }^{65}$ It is in this precise connection, as a proto-semiotician of cinema, that Tynianov begins to be assimilated into Russian theoretical discourses around film in the late I970s and early I980s: "adaptation" is a present but secondary element in that process, little more than a convenient means by which to pursue theoretical (semiotic) ends.

In something of a blind parallel, Western critical discourse on adaptation began to develop into a thoroughgoing aesthetic theory at roughly the same time, based on Western appropriations and reorientations of the core "formalist" principle that had fueled the rise of Opoiaz in the I9Ios and early I920s, now transformed into an all-pervasive structuralist semiotic. Adaptation theory sought to critique inherited assumptions about the relative cultural value of film and literary texts and, perhaps more significantly, about the basis (or lack) of their "formal" relations. The identified and/or resultant bifurcation in studies of adaptation can be summarized in the words of Dudley Andrew, who characterizes adaptation as both "the most narrow and provincial area of film theory" and at the same time "potentially as far-reaching as you like." ${ }^{66}$ The second part of this evokes the formalist/semiotic projection of a new kind of comparative aesthetics, in which specificity and generality are inseparably and even organically interrelated, and for which individual adaptations provide ideal "laboratory" conditions. ${ }^{67}$ Andrew's implication is that, in the hands of the trained (formalist) aesthetic specialist, adaptation might reach as "far as you like" beyond the inconsequential straw men of such concepts as "fidelity" or the "precursor text" toward the theoretical vistas of both cinema as a specific art form and of art "in general." The obverse of this implication, however, given especially that the institutional rise of adaptation is intimately connected with the English Department's (and, more recently, the Modern Language Department's) need or desire to protect and/or extend its teaching base, is that the study of adaptation will pathologically break its "provincial and narrow" teeth on precisely these same (non-)problems of fidelity and anteriority.

Rather than simply suggest, however, that Tynianov, as theorist or as writer and "adapter" of Lieutenant Kizhe, offers a rebuke to this latter tendencywhich would be to substitute a straw man with a vaporous figure akin almost to Kizhe himself-I want to locate Tynianov's continuing utility in what is a quite different "rebuke" to the former. Despite (or perhaps in another sense because of) their later association with a structuralist semiotic in the Soviet Union, Tynianov's essays on the cinema are not entirely consistent with the direction in which his Formalist colleagues, and later Tynianov himself, were developing and in some ways transforming their earlier focus on art and 
literature in narrow or even exclusive terms of formal specificity. Eikhenbaum, Shklovskii, and Brik were all increasingly concerned in the second half of the I 920 s with the extra-literary and even sociological basis for literature ${ }^{68}$ and this only partly as a pragmatic response to external pressures from increasingly belligerent Marxist opponents. Tynianov would take this development to new and quite distinct heights in his 1927 essay "On Literary Evolution," which represents a high-water mark for attempts to synthesize formal and sociohistorical literary methodologies. ${ }^{69}$ Tynianov's essays on the cinema remained, in other words, more "formalist" than the approaches to literature latterly propounded by himself and his "Formalist" colleagues. The brief "sociological turn" in late Formalism and Tynianov's subsequent synthesis were prompted by an awareness of the limitations not only of the immanent study of the work of art in itself, be it literary or cinematic, but also of the limitations of processes in which such immanent study might be opened out through comparison with other forms of art, and other specific artifacts: the "extra-literary" did not primarily refer to other "artistic series" such as film, but rather to the material, experiential, objectified world beyond artistic series as such. The sum implication for adaptation theory of Tynianov's work as a screenwriter and as a theorist of cinema and literature is that the "laboratory conditions" in which the respective cinematic and literary texts are to be examined must be understood as facilitating not simply the identification of a higher theoretical generalization about the forms and functions of film and literature themselves, but also an integrated understanding of how each, inseparably from their relations to one another, articulates with the environment in which it has been produced and with the historical evolution of the mode to which it belongs. This is another way of saying that theory and history, rather than the combatants in the battle for the humanities they are often characterized as being, in fact depend on one another for the realization of their respective projects; or, at one further level of "specification," that the justifiable demand that adaptation theory work harder in developing a sociological aspect need not - in fact cannot-imply the need to sacrifice its "purely" formal dimension.

\section{NOTES}

I. Tynianov, "O stsenarii," 323.

2. Tynianov, "Kino—slovo-muzyka," 322.

3. Accounts of the development of Formalism have understandably varied as material relating to the period has gradually become more accessible. See in particular Erlich, Russian Formalism and Steiner, Russian Formalism.

4. See Tsiv'ian and Toddes, “'Ne kinogramota, a kinokul'tura," 90, 93. Eikhenbaum's most significant theoretical work on the cinema, probably closely related to the theory course at GIII, is the essay "Problems of Cine-Stylistics." 
5. Brik's personal stock reaches its nadir in I 933 during the abortive production of his and his former deputy at Mezhrabpom Oleg Leonidov's script “On Personal Responsibility”; like Storm Over Asia, the film was to be directed by Pudovkin, but the production was halted by the studio manager (and sometime actor) Iakov Zaitsev, who described the script as "hack-work" and expressed the view that Anatolii Golovnia, Pudovkin's cinematographer, could only have accepted it because of a "temporary loss of judgment." Zaitsev would later write threatening legal action and referring to Brik's "script" in devastating inverted commas. Russian State Archive of Literature and Art (RGALI), f. 2852 , op. I, d. 335 , 1l. I-7; d. $332,1.7$.

6. Witness Shklovskii's withering accusation in I932, partly motivated by the personal enmity that had played a significant role in the dissolution of Lef, that Brik and his wife Lilia were "boiling [Maiakovskii] down for glue." Chukovskii, "Iz dnevnika I932-1969," I36.

7. Shklovskii also contributed to the Poetics of Cinema collection, in the form of a characteristically brief and provocative sketch on the relations between "prose" and "poetry" and, respectively, plot and "plotlessness" in the cinema. It is tempting to attribute Shklovskii's participation, and the brevity of his contribution, to the emphasis in Eikhenbaum's invitation on an advance of 50 rubles: see Tsiv'ian and Toddes, “'Ne kinogramota, a kinokul'tura," 92. Shklovskii, "Poetry and Prose in the Cinema," 87-9. See also Shklovskii, Za sorok let.

8. Among countless examples of the demand for Shklovskii's services are his retention as a "script consultant" by Brik during the latter's tenure as Head of the Script Department at Mezhrabpom, on terms that not only guaranteed him additional fees for any original script material he himself submitted, but which also did not prevent him developing scripts for other studios, and all for a salary not much short of Brik's, who was effectively locked into an exclusive contract. RGALI, f. $285^{2}$, op. I, d. 324, ll. I, 2 , 2ob. Other notable examples, both of which have resonance for later discussion, are Shklovskii's engagement in I 928 to write a screenplay based on Tynianov's initial treatment of his own novel, The Death of Vazir-Mukhtar (RGALI, f. 2224, op. I, d. I9I, 1. 5) and his replacement of Tynianov on Esfir Shub's unrealized documentary project on Pushkin in I936 (RGALI, f. 2224, op. I, d. I9I, 1. 7). See also Tsiv'ian and Toddes, “'Ne kinogramota, a kinokul'tura,"” 94-6.

A total of five feature films with scripts written or co-written by Shklovskii were completed and released in the I930s: two silents for Goskinprom in Georgia-The American Girl (Esakiia, I930) and It's Very Simple (Lomidze, I930); two early sound pictures for Mezhrabpom-Horizon (Kuleshov, 1932) and The House of the Dead (Fedorov, I932); and, after a period of politically enforced reticence, Mosfilm's patriotic historical epic Minin and Pozharskii (Pudovkin, 1939).

9. See, for example, Shklovskii, Za sorok let, and Shklovskii, Tret'ia fabrika.

ı. Tynianov, "The Fundamentals of Cinema"; Tynianov, "O siuzhete i fabule v kino"; Tynianov, "O stsenarii." Tynianov also published "Ne kinogramota, a kinokul'tura" and "O feksakh."

I I. This contemporaneity might also serve as a ready-made and highly desirable safety mechanism, preventing us from falling into a trap that has claimed even illustrious commentators such as Iurii Tsiv'ian and Mikhail Iampol'skii, namely the temptation to read Tynianov's films through his earlier, and to some extent canonized literary theory. This, I want to suggest, is merely a different way of falling into the same broad category of error as we will later see in relation to adaptation; it is, moreover, an error that Tynianov himself consistently—if not always successfully—endeavored to avoid. See Iampol'skii, “Poruchik Kizhe' kak teoreticheskii fil'm” and Tsiv'ian, "Paleogrammy v fil'me 'Shinel'." 
I2. It is, moreover, an adaptation of a writer on whom Tynianov—along with at least one other of his Formalist cohorts-was regarded as something of an academic authority; compare the vastly different outcome of Shklovskii's later treatment of Dostoevskii's House of the Dead, the above-noted House of the Dead (Fedorov, I932), which is less an adaptation than a cinematic polemic on its author's place in Russian cultural and literary history.

I3. Shubin, Iurii Tynianov, 3 I.

I4. To pronounce negative judgment on Semen Timoshenko's film Napoleon-Gaz, a verdict which appeared in published form in Rabochii i teatr (Worker and Theatre), 50 (I925), 23; cited from Tsiv'ian and Toddes, “'Ne kinogramota, a kinokul'tura," 90-I.

I 5. RGALI, f. 2224, op. I, d. I9I, ll. I, Iob.

I6. Grigorii Kozintsev describes Tynianov as being utterly consumed in the cinematic process, without in any sense compartmentalizing his literary and cinematic undertakings: indeed, Tynianov acknowledged the common genesis of the film "scenario" and the short story in the situational miniature or anecdote, one of which, involving a sentry "guarding an empty space," is a clear precursor to "Lieutenant Kizhe." Kozintsev paints an appealing, if perhaps somewhat romanticized, picture of Tynianov's involvement with his FEKS (Factory of the Eccentric Actor), in which Tynianov would squeeze readings of his literary and theoretical works in between lessons on clowning and boxing. Kozintsev also recalls Tynianov writing in the editing room, on the back of editing lists, and it is tantalizing to imagine that this was not restricted to his writing for the cinema: Kozintsev, [No Title], in Iurii Tynianov.

I7. Toddes, Chudakov, and Chudakova suggest that Tynianov was in fact Head of the Script Department, until replaced in February 1927 by Adrian Piotrovskii. Tynianov, Poetika, 550.

I8. Shubin, Iurii Tynianov, 34; Tynianov, "Arkhaisty i Pushkin.”

I9. Shubin, Iurii Tynianov, 34 .

2o. Ibid., 35-6, 39-40.

2r. Tynianov, "Podporuchik Kizhe." All citations of the text are from "Podporuchik Kizhe," in Tynianov, Voskovaia persona, 339-70.

22. This is one of the most compelling reasons that Iampol'skii, as already mentioned, could not resist entering the vortex of the relationship between oral and/or everyday speech, poetry and, finally, cinema: Iampol'skii, “'Poruchik Kizhe' kak teoreticheskii fil'm.”

23. Tynianov, "Podporuchik Kizhe," 370.

24. It should at least be noted, however, that this term has a pronounced retrospective character in relation to Tynianov (and to Gogol). Two useful treatments of the fantastic, both of which perhaps not incidentally reference Gogol, are Todorov, Introduction à la littérature fantastique and Cornwell, The Literary Fantastic. A useful introduction to the extensive secondary literature on Gogol is Maguire, Exploring Gogol.

25. Belinkov, Iurii Tynianov, 402.

26. Gogol, "The Overcoat," Iо3 (translation modified).

27. Tynianov, "O stsenarii."

28. Tynianov, "Libretto kinofil'ma «Shinel'»," 78. This is also an echo of Gogol's own characterization of his stories as being "in the manner of Hoffmann."

29. This is made explicit in the "prologue" to the story in the original Krasnaia nov" publication, which was removed in later redactions. Tynianov, "Podporuchik Kizhe," Krasnaia nov', 97. See also Belinkov, Iurii Tynianov, 399-400. For a fuller account of the range of historical and literary sources upon which Tynianov may have drawn, see Toddes, "Posleslovie."

3o. RGALI, f. 2224, op. I, d. I9I, 11. 2-4. 
3I. Faintsimmer worked as assistant director on Vsevolod Pudovkin's The End of St Petersburg (I927) and Iulii Raizman's Penal Servitude (I928), before going on to be Belgoskino's "house director" throughout the i93os.

32. Gosfilmofond-National Film Foundation of the Russian Federation (GFF), f. 2, op. I, d. I 897, 1. 67. Toddes claims that Tynianov completed the script in May, but this would seem highly unlikely in view of the fact that the supposition is based on a remark by Tynianov that envisages Iutkevich continuing to work on the script. See Toddes, "Posleslovie," I64.

33. Iutkevich, "Dokladnaia zapiska ob izmeneniakh v stsenarii 'Podporuchik Kizhe”: GFF, f. 2 , op. I, d. I $897,1.69$.

34. GFF, f. 2, op. I, d. I 897 , 1. I.

35. GFF, f. 2, op. I, d. I897, 1. 70.

36. Eikhenbaum tells Shklovskii in a letter of April 9, I927 that "Iurii insists on working in the cinema." Cited from Tynianov, Poetika, 550. He had also submitted another libretto to Sovkino in March, once again co-authored with Oksman, based on Turgenev's "Asia"; the film would be completed in I928, directed by Aleksandr Ivanovskii, but without any further participation by Tynianov. Ibid., $55^{\circ}$.

37. RGALI, f. 2224, op. I, d. 224, 1. I.

38. Shubin, Iurii Tynianov, 37.

39. Cited from Toddes, "Posleslovie," I 88 (my italics).

40. Cited from Tynianov, Poetika, 550 .

4I. The studio made a number of further attempts to persuade Glavrepertkom to allow the film's production, including an unsuccessful attempt by Arsen Aravskii to invest it with the required "social and historical significance," an unrealized attempt to persuade Shklovskii to rewrite, and, finally, a complete reorientation of the project by the director Aleksandr Razumnyi and the screenwriter Viktor Turkin. Tynianov signed a new contract with Belgoskino on August 8, I932, over five years after abandoning the original project. RGALI, f. 2224, op. I, d. I9I, ll. 6, 6ob. A version of the script for the I934 film has been preserved only in the inaccessible personal archive of Veniamin Kaverin (see Iampol'skii, “"Poruchik Kizhe' kak teoreticheskii fil'm," 29), so we are obliged, just as with the I927 script, to base our analysis on the shooting script.

42. Sepman, "Tynianov—-stsenarist," 75.

43. "Podporuchik Kizhe," Director's Script, 2nd version, sc. 309-89: GFF, f. 2, op. I, d. I 897, 11. 64-8. Henceforth Tynianov/Iutkevich, "I927 script."

44. Tynianov/Iutkevich, "I927 script," sc. 37I.

45. Ibid., sc. $385-6$. All reference to the broader historical dimension of the Napoleonic wars is absent from the 1934 film.

46. Ibid., sc. $4 \mathrm{I} 6-\mathrm{I} 7$.

47. Ibid., sc. 548 .

48. Ibid., sc. $55^{\circ}$.

49. Ibid., sc. $5^{20}$.

5o. Ibid., sc. 624 .

5I. Ibid., sc. 407 , sc. 629.

52. Ibid., sc. 630.

53. Iutkevich, "Dokladnaia zapiska": GFF, f. 2, op. I, d. I897, 1. 69.

54. Tynianov, "Podporuchik Kizhe," 353.

55. Ibid., 355 .

56. Ibid., 357 .

57. Ibid., $35^{8 .}$

58. Ibid., 36 I. 
59. Ibid., 364 .

6o. Tynianov, "The Fundamentals of Cinema," 34.

6I. Ibid., 32.

62. Tynianov, "Kino-slovo-muzyka," 322. Tynianov is far from alone in the Soviet I92os in adopting a cautious and even resistant attitude toward sound, an attitude most famously recorded in Eisenstein, Pudovkin, and Aleksandrov, "Statement on Sound."

63. Tynianov, "O stsenarii." The Travelers (Peredvizhniki) were a group of late-nineteenthcentury painters who broke away from the Russian academic tradition in favor of a socially oriented realistic style.

64. Tynianov, "The Fundamentals of Cinema," 36.

65. Cited from Tynianov, Poetika, 555. Jakobson's essay "Upadok kino?" (The Decline of Cinema?), written in I 933 when the sound cinema had become a reality, exceeds Tynianov in including also "acoustic things" in the broad category of "phenomena of the external world": Tynianov has earlier agonized over the fear that "to fill the cinema with words" will result in "nothing but a chaos of words," and will destroy the constructive relationship between shots that is constitutive of cinematic specificity. Tynianov, "The Fundamentals of Cinema," 34.

66. Andrew, "Adaptation," 28 .

67. Ibid., 29 .

68. Shklovskii published "V zashchitu sotsiologicheskogo metoda" and reproduced that article's argument in his contribution to the pivotal dispute "Marxism and the Formal Method" which took place on March 6, I927. See "Disput o formal'nom metode"; Ustinov, "Materialy disputa 'Marksizm i formal'nyi metod' 6 marta I 927 g." These positions would be developed into a virtual sociology of literature in his I928 book on War and Peace: Shklovskii, Mater'ial i stil' v romane L'va Tolstogo "Voina i mir." Eikhenbaum pursued what was if anything an even more deterministic line in his articles "Literatura $\mathrm{i}$ pisatel" and "Literaturnyi byt."

69. Tynianov, "On Literary Evolution." 


\title{
Chasing the Wealth: The Americanization of Il'f and Petrov's The Topelve Chairs
}

\author{
Robert Mulcahy
}

"Life literally abounds in comedy if you just look around you."

Mel Brooks

"Half is mine, half is ours."

Ostap Bender

"Love is the most important thing in life; riches do not count."

Mel Brooks

Throughout his film career, US comedian, director, and producer Mel 1 Brooks has engaged an amazingly varied assortment of cinematic genres in an irreverent vein: The Producers (I968) is a musical comedy about Adolf Hitler; Blazing Saddles (1974) satirizes the Western; Young Frankenstein (1974) spoofs the horror genre; Silent Movie (1976) takes on the silent film genre, especially its slapstick comedy; and High Anxiety (1977) parodies Hitchcockian suspense films. ${ }^{1}$ Through no-holds-barred parody, as well as gags and slapstick humor, Brooks undermines expectations as he lampoons sundry venerable forms institutionalized in American society of the late i96os and I970s.

As an outsider Jewish-American comic with ethnic roots in Eastern Europe, Brooks has crafted an identity of considerable appeal to a large, diverse audience over his long career. As the son of first-generation immigrants from the former Russian empire, Brooks had an appreciation and image (however idyllic) of the pre-World War II era of his parents' generation. In choosing to base his second film on Il'ia Il'f and Evgenii Petrov's I928 popular Soviet-era novel, The Twelve Chairs, ${ }^{2}$ Brooks not only faced the challenge of adapting a book written in a different language about a specific period in a foreign country, but also had to decide how to translate humor and comic situations specific to Soviet society and make them understandable in an American setting. Brooks 
wisely opted for the generalization of human foibles. The result is a film that focuses on the universal themes of obsessive greed and transnational brotherhood, while also engaging social satire. ${ }^{3}$

This chapter analyzes how Brooks transformed and extrapolated from Il'f and Petrov's plot, character types, humor, and themes, while at the same time stamping the picture with his own brand of humor, personal history, and philosophical outlook. In a sense, Brooks seems to be personalizing Il'f and Petrov's Russia by intermingling Jewish motifs with Russian and American references. ${ }^{4}$ In The Twelve Chairs, Brooks manages to situate US, Russian, Soviet, and Eastern European-Jewish motifs and humor within the same work, effectively dissolving cultural borders. In fact, the scenes and characters that he presents - a conniving con man, an Orthodox priest, an aristocrat made destitute by the Russian Revolution, a drunken peasant, a snow-covered Siberia, smiling townspeople living in small Eastern European villages, Slavictinged urban locations, a frantic treasure hunt to claim a fortune in jewels - all co-exist as a distinctive reinvention of Russia for Americans living during an era of relaxed tensions between the two global superpowers. In other words, in The Tmelve Chairs, Brooks is not simply striving for an authentic representation of the Soviet Union, but is creating his own personal Russian world, which consists not only of an actual Russia/Soviet Union, but also American influences and a hint of the Jewish Russia his parents came from. In essence, Brooks repackages the seminal literary work for an American audience, relying on his tried-and-true comedic devices, astute political commentary, and insightful exploration of the human condition in what ultimately borders on a buddy film, that most American of genres. Brooks emphasizes throughout the film that personal relations are more important than financial gain, and the film's two main protagonists, we are led to believe, are going to continue working together and taking care of each other long after the film is over. This is part of détente-era filmmaking, for the movement toward a buddy film that The Tmelve Chairs traces shows the possibility of cooperation between individuals and collectives.

\section{IL'F AND PETROV'S NOVEL}

Il'f and Petrov's novel can best be understood as part of the focus on satire in the I920s in the Soviet Union, and this is a large part of what Brooks had to negotiate in reworking the film for an American audience. Many Soviet writers relied on satire to depict the shortcomings of contemporary Russia and to represent its citizens as "flawed and fragmented human beings." Satiric writers of the era explored issues such as the quality of life in an industrial society, the necessity for new social values, and moral ineptitude, especially 
among mid-level Soviet bureaucrats and industrial managers. Near the end of the turbulent, contradictory, yet artistically productive New Economic Policy (NEP) era (1922-8), which introduced modified capitalism in order to stimulate a sluggish economy, Il'f and Petrov's The Twelve Chairs (I928) appeared in serialized form in the journal 30 Days. Published in book form the same year, The Twelve Chairs depicts three men racing to find a stash of jewels hidden in one chair of a dining-room set that has been sold. The chase takes the three pursuers - the young con artist Ostap Bender, the fallen aristocrat Ippolit Matveevich Vorob'ianinov, and the money-hungry priest Father Fedor-all across the European part of the Soviet Union. Their encounters and interactions with a variety of character types from the late Soviet NEP period provide rich material for much of the hilarious comedy and acrid satire in the novel. As Alexandra Smith points out, "the clashes between the old and the new worlds, based on strikingly different values, customs, and language, are all depicted in a satirical vein." ${ }^{6}$ The book focuses on technology and a new society in the process of creation, while at the same time highlighting the shortcomings of life in the Soviet Union in a humorous manner. Il'f and Petrov's panorama of their own time showed that, through NEP, a contemporary Soviet Union was on the way to stability and prosperity, "if only some bureaucrats, thieves, and swindlers could be eliminated."

In I927, as part of a government campaign against Trotskyism, ${ }^{8}$ the editor of 30 Days Vladimir Narbut had commissioned The Tmelve Chairs. ${ }^{9}$ He asked the journalist and novelist Valentin Kataev to write the novel; in turn, Kataev recruited his journalist brother, Evgenii Petrov, and Petrov's friend Il'ia Il'f (born Il'ia Fainzil'berger) to help with the project. Eventually Kataev pulled out and the duo-who had both written sketches and reviews for satirical journals - took over the project. Il'f and Petrov had a good ear for the idioms of Soviet ideological language, especially in official and media outlets, and many of Bender's statements and observations play on that discourse. ${ }^{10}$ The two writers also pointed out contradictions in Soviet life; for example, Bender searches for riches and luxury in a society that is officially moving away from bourgeois values, and he is quite adept at exploiting people for his own purposes when official discourse promotes the communal society. The Soviet penchant for renaming streets and creating ponderous acronyms also offers targets for satire: Bender and a taxi driver roam around Stargorod for an hour and a half searching for a street that has been renamed several times, and no one seems to know where it is.

Bender became part of Soviet/post-Soviet literary folklore and he remains popular today. Numerous monuments to Il'f and Petrov (as well as to Bender) have been erected in various cities across the former Soviet Union. Moreover, several Russian screen adaptions of Il'f and Petrov's works have been released over the years: Leonid Gaidai was the first director to adapt The Twelve Chairs, 
in $197 \mathrm{I} ;{ }^{11}$ Mark Zakharov's version was released in 1976 ; and in 2005 Maksim Papernik made a TV mini-series. The coveted role of Bender has been played by a number of well-known actors, including Archil Gomiashvili, Andrei Mironov, Nikolai Fomenko, and, more recently, Oleg Men'shikov in 2006 (in an adaptation of The Little Golden Calf(I93I), the continuation of The Twelve Chairs).

Combining various attractive elements for almost any audience-an elusive fortune in jewels, a nationwide treasure hunt, colorful characters, a fumbling villain, and a gripping storyline-a tale like The Tmelve Chairs simply cries out for cinematic hypertexts. And Mel Brooks was poised to make sure that a classic work of Soviet literature would gain a wider audience. In I970, riding on the success of his first hit movie, The Producers, Brooks was ready to introduce the Soviet con man and former aristocrat to American audiences.

\section{FROM VERBAL TO VISUAL：ADAPTING THE TWEL VE} CHAIRS

When it comes to transposing a comic drama or novel for film-a completely different medium - the director is faced with the difficult task of relaying the comedy in the novel, which is at the verbal level, to a visual representation of what the hypotext portrays with written words. Robert Stam contends that film is quite adept at depicting actual speech and the medium has the ability to convey discourse with its nuances: "in the sound film, we do not only hear the words, with their accent and intonations, but we also witness the facial or corporeal expression that accompanies the words"; ${ }^{12}$ thus the verbal moves to the visual level and conveys meaning. Yet this task becomes more difficult when the original text is in a foreign language. In this case, the translator or adapter has to find a way to convey the essence of the humor, which is often very specific to an individual culture, to the audience. If the medium does not change, such as translating a novel from Russian into English in print, then the task is somewhat easier. In a print translation, the translator can rely on footnotes to explain a certain concept, but this cannot be done in film; rather, the adapter has to come up with various ways to explain the concept.

One of the biggest challenges Brooks faced in adapting the novel and writing the screenplay was how to make the film appealing to American audiences unfamiliar with everyday Soviet life and generally hostile to foreign films. To widen the film's appeal, Brooks relies on the tried-and-true comedic genre of the chase, made popular in cinematic productions by Buster Keaton and Charlie Chaplin, and in animated "Tom and Jerry" and "Road Runner" cartoons. Brooks employs slapstick and lowbrow comedy, in which exaggerated impropriety gives his film a comic boost and makes it more accessible. 
Evoking the silent era of film and Saturday morning cartoons, Brooks includes fast-motion chases and scuffles, high-speed dialogue, and verbal mugging, or close-ups of his actors' faces to depict specific emotions. ${ }^{13}$ He includes visual gags and sequences, such as the in-your-face physical comedy of the Dom DeLuise scenes, where Father Fedor fights his adversaries, chases after various chairs and characters, climbs an insurmountable rocky structure, and prostrates himself on the beach. ${ }^{14}$ Additionally, near the end of the film Bender and Vorob'ianinov escape the Railway Workers' Clubhouse by jumping on a horse, which subsequently collapses to the ground; a visual stunt that evokes those of the Marx Brothers and earlier slapstick comics.

In The Twelve Chairs Brooks depends on comedy and humor to explore the human condition, emphasizing the theme of obsessive greed to show what people are capable of when in the throes of monomania. The nobleman Vorob'ianinov degenerates from a privileged member of society into essentially a mad dog, whose obsession is to find the diamonds; while the priest, Father Fedor, quickly abandons his so-called religious faith once he learns about the jewels and is consumed by treasure fever. Brooks shows that the desire to accumulate wealth and its destructive consequences, as depicted by Il'f and Petrov, are universal, resonating across borders and making for a compelling and universal story that serves as a moral lesson of love conquering greed.

Generally, audiences are drawn to films featuring exciting adventures as the protagonists make their way toward a specific goal, while overcoming obstacles along the way. Frequently, suspense in an adventure/heist movie is created when two rivals, engaged in a desperate race to be the first to find the treasure, resort to trickery and place obstacles in each other's paths. In The Twelve Chairs, Brooks's slower pace and longer scenes reveal a great deal about the psychological motivations of and developing partnership between Bender and Vorob'ianinov, rather than simply being employed as a device to advance the plot. Brooks does not show the two protagonists traveling (except for a few shots of a train, a rowboat, and a long walk back to Moscow); instead he uses a fade-toblack technique between sequences that retards the film's forward momentum, letting the viewer reflect on the events. For instance, an overwhelming sense of sadness and despair is evoked in the more-than-two-minute sequence in which Bender and Vorob'ianinov slowly make their way back to Moscow from Yalta, travelling through the deserted countryside in late autumn and winter. The leisurely pace, long shots, and melancholic music in this sequence emphasize the emotional state of the two treasure hunters - both walk with their heads down, with Bender leading the way. In fact, there is a palpable sense of despair that the duo will not find the final chair and thus the family jewels. Also, the physical distance between them suggests that their partnership is under stress. In contrast, the scenes with DeLuise move more quickly: Brooks speeds up the camera and voices when Vorob'ianinov chases Father Fedor, who runs away with a chair 
twice in the movie. Additionally, the slapstick routines in DeLuise's scenes with Engineer Bruns and his wife are fast-paced and over-the-top. Yet the overall effect of the DeLuise scenes is to distract from the Bender and Vorib'ianinov storyline, and they could have been shortened. In both the novel and Gaidai's hypertext, Father Fedor, while an important character as the villainous rival, does not have as prominent a role as he does in Brooks's film. Instead, the various characters Bender and Vorib'ianinov encounter, the circumstances with which they are forced to cope, and fate itself serve as obstacles on their quest. Clearly, DeLuise is meant to provide much of the comic punch in The Tmelve Chairs, but his raucous and exaggerated antics detract from, rather than add to, the overall atmosphere of the film.

To create a more or less nostalgic, appealing version of the Soviet Union in 1927, Brooks shot The Twelve Chairs in Yugoslavia over four months for $\$$ I.4 million. Several outdoor scenes in the film have a documentary feel that show happy people going about their daily lives (the opening market sequence; a parting scene at a railway station; a policeman directing human traffic in Moscow), which adds to the film's universal appeal by depicting Soviet citizens as "normal" human beings living productive lives in a fictional and personal Slavic world that Brooks created, in a sense, from his own memories of growing up in a Yiddish-speaking environment. The Yugoslav local extras lend the film an "authentic" Slavic feel; Russian phrases are scattered throughout; and Roy Moody assumes a Russian accent (although it disappears periodically). Also, some of the film's opening credits are in Russian. In order to make his patchwork Slavic world believable to an American audience of the Brezhnev era, Brooks decorates the mise-en-scène with typical stereotypes of Russia and Jewish life: The village settings evoke the stories of Sholem Aleichem and Fiddler on the Roof (the Broadway play 1964; the film 197I); the peasants are often shown as drunk after imbibing vodka; and Siberia is depicted as a frozen, inhospitable wasteland (when Father Fedor arrives in Irkutsk by train, he opens his window, which opens into a gigantic snowdrift). Cinematographer Djordje Nikolic deftly captures colorful, bright sets, which in concord with stunning shots of the Adriatic Sea coast and rolling green hills, evoke a Slavic atmosphere. Belgrade stands in for Moscow, and other Yugoslavian cities, including the medieval Dubrovnik, create a pseudoRussian city feel. Vorob'ianinov's flashbacks are tinged in soft focus, lending a nostalgic cast to the upper-class lifestyle in the pre-revolutionary era. The last shots of the film depict Vorob'ianinov, splendid in his new role as beggar, having an epileptic fit on a Moscow street, then the frame freezes and changes into a painting reminiscent of early twentieth-century depictions of village life in the work of Marc Chagall. This final scene suggests that although Bender and Vorob'ianinov did not acquire the jewels, their partnership has been renewed, and the cunning duo will embark on more adventures. 
Attempting to preserve the satire of the Soviet hypotext, Brooks infuses his film with a sophisticated satiric edge that engages with issues familiar to Americans in the late I96os. The film takes on politics, religion, bureaucracy, and specific character types in order to comment on contemporary American society. Brooks drops the specific Soviet satire, but keeps the general satire ironizing man's social, cultural, and political pretensions. ${ }^{15}$ Political satire is universal; for instance, both the Soviet Union and the US strove to make all their citizens equal (at least on paper). Brooks presents the socialist society as a world of cons and hustlers, not unlike the political scene in the United States in the early I970s. It was only a few years after the film was released that US President Richard Nixon, whose criminal actions, cover-ups, and outright lies were headline news, became the first president to resign from office in 1974 . Although political satire permeates Il'f and Petrov's novel through depictions of corrupt government bureaucrats, money-hungry journalists, prop-selling theater workers, fame-seeking provincial chess players, and fashion-conscious Muscovite housewives, Brooks avoids the specifics of Soviet life, such as the cramped living conditions, food shortages, and money-making antics, and instead focuses on more overt and generally recognizable political satire. For instance, Brooks shows names of streets that have been crossed out and changed multiple times; pictures and busts of Lenin (indeed, Vorob'ianinov himself resembles the revered Bolshevik leader, with his cap and goatee); references to class (the Columbus Repertoire Theatre is staging a play called "The Rise and Fall of the Upper Classes: A Comic Spectacle"); displaced aristocrats; and frequent references to "comrade." In Brooks's socialist saga, "the most corrupt self-seekers exploit the slogans of socialist idealism": ${ }^{16}$ both Vorob'ianinov and Father Fedor claim the chairs according to the Soviet principle articulated by the Orthodox priest: "It's not yours. It's nationalized property ... it belongs to the workers." He further observes, "The church must keep up with the times"-a hypocritical rationalization of his greed, which confirms his shifty nature. Although political satire is often difficult to transpose to another culture, Brooks manages to engage with Soviet politics in a way that broaches universal frailties.

As a social institution that crosses borders, the Christian Church has both united and divided believers for centuries. Brooks has famously taken on religion throughout his career, often poking fun at stereotypical Jewish types. The taste of his religious jokes, which are often base and crude, does not really matter; instead, irony and sadness provoke laughter, making it easier to deal with life's hardships. In The Tmelve Chairs, Brooks makes the Russian Orthodox Church-an institution many Americans likely perceive as exotic-familiar to a non-Russian audience by depicting Father Fedor as a corrupt bureaucrat consumed with the pursuit of personal gain instead of the spiritual wellbeing of his parishioners. The film's opening scene shows a cross in the lower 
right part of the frame, with Vorob'ianinov's dying mother-in-law, Madame Petukhova, in the background. A huge icon dwarfs Madame Petukhova when she proclaims, during her final confession, that she had hidden her jewels in a dining room chair. Both Il'f and Petrov and Brooks emphasize the fact that, during a moment traditionally used to cleanse one's soul before death, Madame Petukhova is more concerned that her son-in-law locate the lost jewels than with her immortal soul. Brooks also portrays in Father Fedor an Orthodox priest who is ready to change his allegiances whenever the opportunity presents itself. Yet again, Brooks breaks down barriers by depicting scenes that no doubt resonate with Americans, many of whom surely can recognize aspects of their own collective lives in the antics of Brooks's on-screen characters.

The biggest change Brooks makes is in the ending of his hypertext: Il'f and Petrov have Vorob'ianinov kill Bender so as to keep all of the envisioned loot to himself (though the authors miraculously resurrect the dashing picaro in their sequel The Little Golden Calf). Brooks's ending is in line with his overarching theme of man's need to outgrow his obsessive selfishness and consuming greed: Vorob'ianinov grows and matures throughout the film, and a bond of trust and perhaps real friendship develops between the con man and the aristocrat. The cinematic ending not only reflects this emerging fraternal tie, but also offers the typical Hollywood happy ending: Though the two do not get the treasure, their commercial partnership grows into something resembling a real friendship. Indeed, it looks as if their collaboration will continue; the last scene shows Vorob'ianinov once again faking an epileptic fit, while Bender summons the people to help out a poor sufferer. In line with the communal message of the film, Brooks stresses the celebration at the Railway Workers' Communal House of Recreation, completely refurbished with the proceeds from the jewels discovered in Vorob'ianinov's chair, to indicate that everyone has benefitted from the treasure. Indeed, at the event a starving Vorob'ianinov dives into the free food like a pig, indulging (albeit unknown as yet to him) in the fruits of his own property in a fitting tribute to the maxim "share the wealth." In making a kind of parallel between greed in I920s Soviet Russia and contemporary American times, Brooks translates the notion of socialism to an image to which an American audience could relate.

\section{CONVEYING BROOKS'S CINEMATIC VISION: THE CHARACTERS AND ACTORS}

Arguably one of the most recognized heroes in Soviet literature, Ostap Bender is a crafty, cynical, and witty rogue, whose antics poke fun at corrupt bureaucrats and greedy philistines in the NEP era. Like the picaresque protagonist, Bender understands people's motivations, has a perceptive intuition, 
and knows how to maneuver himself throughout the world. As a genre, the picaresque usually emphasizes "poverty, delinquency, 'upward mobility,' travel as an escape from despair, [and] social satire of a system unresponsive to the needs and desires of a growing active community of 'have-nots"';17 it frequently depicts a lower-class character living by his wits. Bender is intellectually brilliant, charismatic, well informed, possesses a mastery of Soviet language, recognizes people's weaknesses, and has the ability to think quickly on his feet, yet he is not a sympathetic character. He preys on people, using them for his personal gain, and then moves on. The challenge for any actor playing Bender is to convincingly convey these underhanded qualities while simultaneously making the audience believe that Bender is sincere behind the various masks he wears. Yet many of the subtleties of the novel are lost in Brooks's casting choices in The Tmelve Chairs.

In one of his first cinematic roles, New York stage actor Frank Langella plays Bender as a tall, dark, and brooding leading man, who, in addition to finding the jewels, attempts to keep Vorob'ianinov in line. Indeed, Langella is sober in the film, and not very funny; he plays the straight part in a comedy and is usually the one to scold and discipline the childlike Vorob'ianinov. In fact, he is not unlike Dracula in his later romantic embodiment of the vampire as tragic hero. In his performance, Langella removes almost all traces of the picaresque hero from Bender, making him into a one-dimensional, aloof con man cut off from life, whose sole dream is to make money.

Ron Moody, who plays Vorob'ianinov, is a British actor probably best known at the time for his role as Fagin in Lionel Bart's musical Oliver $!^{18}$ Il'f and Petrov describe the fallen aristocrat as a tall ( ${ }_{1} 85$ centimeters, or slightly over six feet), grey-haired old man (although he is only fifty-two), with a full mustache. By contrast, Moody is short, with dark hair and a goatee. Brooks's close-ups of Vorob'ianinov's facial expressions show his selfishness and obsession. Moody often acts doglike: he barks, makes sad eyes, and, at times, essentially runs after his master, Bender, who frequently scolds him. Through this portrayal of Vorob'ianinov as a child out of control, Brooks depicts how greed and obsession infantilize grown men-a transformation that can be funny and frequently induces laughter in an audience. The ridiculous extent of Vorob'ianinov's obsession is portrayed when he obliviously walks a tightrope to confiscate one of the chairs from a Finnish aerialist, dressed, in stereotypical fashion, as a giant black bear. In general, Vorob'ianinov produces most of the laughs in Brooks's adaptation, while the humor stems more or less equally from the two business partners in the novel.

In The Twelve Chairs, Brooks focuses on the evolving relationship between Bender and Vorob'ianinov, both of whom undergo a journey - not unlike in a Bildungsroman or buddy film - and arrive at a new understanding of themselves through their experiences. Brooks transforms the novel in this way in 
order to transpose the situation better for an American audience, for whom the "buddy film" is a familiar genre, and to create a more "positive" picture of Russia for American audiences. In the novel, Vorob'ianinov kills Bender, and, as Mark Lipovetsky points out, he "loses the remnants of his own humanity: 'It was an insane, impassioned wild cry-the cry of a she-wolf shot through the body." ${ }^{19}$ By contrast, in the celluloid hypertext, the two arrive at a kind of humanity through cynicism and deceit. Vorob'ianinov evolves from a selfish, egotistical, and isolated former aristocrat into someone who establishes a human bond with another person and ostensibly overcomes his animal nature. A perceptible change in Vorob'ianinov begins to occur when Bender abandons him on the riverbank after they are cast off the actors' boat. As Vorob'ianinov throws aside his traveling bag and swims to Bender's rowboat, he seemingly undergoes a watery rebirth. No longer eager to engage in yet another battle of wits with Bender, Vorob'ianinov calls his business companion "a good soul" and personifies a lost and shivering child seeking shelter and comfort. Somewhat surprisingly, Bender steps in to provide that service.

One of the more emotionally powerful scenes in both the novel and the film is Bender's irreverent orchestration of Vorob'ianinov's enactment of an epileptic fit to get sympathy money from passers-by, thus finally bringing the proud aristocrat down from his elevated pedestal. Brooks changes this key scene from the hypotext to reflect his ideas on partnership. Unlike in the novel, however, this scene does not take place in Piatigorsk, on the spot where Mikhail Lermontov had his fatal duel with Nikolai Martynov, but in Yalta, in front of a bust of a thinking Dostoevsky, a change that no doubt reflects the Western audience's greater familiarity with the Russian novelist than the Russian romantic poet. Bender's brainwave is prompted by the sight of the nobleman sitting in the same pose as Dostoevsky. Initially Vorob'ianinov's objections take a violent form; he strikes Bender, who, in turn, kicks the aristocrat and calls him a "blood-sucking parasite." ${ }^{20}$ Bender informs Vorob'ianinov that he has begged all of his life and now it is time for the proud nobleman to learn how to do so. Once Bender calms down, he shows compassion for his partner and sits on the ground with him, thus stressing that they have both been brought down to the same level. The scene ends with an overhead shot showing the two men working together in partnership once again. This scene underscores the idea that pride is a luxury that no one can afford in troubled times. In order for Vorob'ianinov to come to terms with his new circumstances and move forward, he needs to let go of his past. Both Bender and Vorob'ianinov grow into friendship, but before they do, they have to redefine what they want and need from each other.

Brooks finds common ground in a Soviet critique of the Church and a critique of greed that American audiences could relate to. Unlike in the novel, the cinematic Father Fedor is solitary, isolated, and wifeless. He is exclusively 
obsessed with acquiring the jewels and it is his greed that eventually destroys him. Although he goes through the motions of a religious figure at the opening of the film (he hears Madame Petukhova's confession, prays on his knees to God, and is constantly blessing people), the treasure hunt results in Father Fedor's complete secularization and descent into monomania. DeLuise's physical appearance fits his role quite well; his "cherubic face and serpentine civilities accentuate his greed," ${ }^{21}$ which destroys any religious feeling that he once had. Father Fedor's plotline ends with the forlorn and despairing priest stranded at the top of a high rock with a chair devoid of jewels, seemingly with no hope of rescue, and utterly alone-his God has abandoned him, his rivals have left him, and his dream of riches has vanished. Fedor's wailing cry: "Oh Lord, you're so strict!" reveals that through his greed and the realization that God has double-crossed him, he almost becomes human again, but he is left to reflect on his enlightenment all by himself, as Bender and Vorob'ianinov trek off to Moscow in search of the final chair. By contrast, in the novel Father Fedor joins the priesthood to avoid conscription and his dream is to open his own candle factory. The novelistic Fedor is eventually rescued from his aerie by the local fire brigade, but he has already descended into madness and is taken to an insane asylum. The image of a corrupt religious figure, who is a person endowed with authority, is another universal motif and presents a harsh critique of the Church.

\section{THE FILM'S MIXED RECEPTION}

Even though The Tmelve Chairs investigates Brooks's (by now) trademark themes of greed, love, and togetherness, his film was not critically or economically as successful as other films he directed, in part because he was trying to combine several worlds into one in order to recreate a nostalgic image of Russia and make a serious movie about overcoming social, economic, and political boundaries. There is an overwhelming atmosphere of sadness throughout The Twelve Chairs that conveys Eastern European sensibilities (epitomized in the theme song "Hope for the Best, Expect the Worst") and conjures up images of a pre-World War II romanticized world that no longer exists. Seemingly, Brooks's juxtaposition of Russian, Jewish, and American cultural themes and depiction of a (largely) sympathetic Slavic world-whose denizens struggle against a number of political, social, and economic obstacles, yet still manage to find humor, understanding, and friendship in the end-was not appealing to American audiences long accustomed to perceiving the Soviet Union as the enemy. ${ }^{22}$ Notably, Brooks's film eschews overt political commentary, instead focusing on universal human traits that bring people together.

In his imagined cinematic world, Brooks shows how people can (and implicitly should) reach across borders in order to work together for the collective 
good. ${ }^{23}$ Bender, the low-class con man, and Vorob'ianinov, the down-on-hisluck aristocrat, manage to put aside their individual interests and prejudices to work together for a common (collective) goal-finding the fortune in jewels. Unexpectedly, they cultivate a partnership cum friendship along the way. Social boundaries are broken down between the lowborn thief and the blueblood nobleman as they find a way to pool their efforts for mutual benefit. In essence, love and friendship win in the end over money and power in a moral fairy tale that eliminates boundaries.

What accounts for the lackluster reception among critics and American audiences? The film lacks a strong audience draw, such as a leading romantic couple to maintain the interest of an American audience that flocks to romantic comedies. Brooks excludes almost all of the female characters in Il'f and Petrov's The Twelve Chairs from his adaptation in a decision that reflects his overarching theme of fraternity and male bonding. ${ }^{24}$ Although buddy films typically privilege male bonding over romance, even if they include male-female relationships, the lack of a strong female lead, along with the film's visual aesthetics and European setting, "where audiences half-expected the movie to be subtitled,"25 may have been off-putting to American audiences. Drawn to the cinema for escapist entertainment, American cinemagoers tend to avoid foreign films, opting for fast-paced Hollywood movies with attractive protagonists and the quintessential happy end. The lack of recognizable Hollywood stars no doubt contributed to the film's less-than-stellar receipts at the box office. Finally, Moody and Langella were known as serious actors, not comedic.

In The Twelve Chairs Brooks combines gags and slapstick humor with a narrative that illustrates the gradual process of achieving accommodation, tolerance, and good will. Overall, Brooks successfully captures the comic situations, political satire, and social critique inherent in Il'f and Petrov's novel, while presenting them in a way that is comprehensible to an American audience. Indeed, by the end of the film there is a sense that Bender and Vorob'ianinov are acting according to a moral code, or a kind of honor among thieves, and the viewer has the impression that a genuine human connection has actually begun to develop between the two. The film's theme song proclaims "hope for the best, expect the worst," yet Brooks provides a hint of optimism that, by recognizing the humanity in someone, people - especially those living in a divided world - can reach out, find their similarities, and try to establish some sort of rapport to co-exist in a hostile world.

\section{NOTES}

I. I would like to thank Helena Goscilo and Alexander Burry for reading earlier versions of this chapter. Their insightful comments, suggestions, and overall support are much appreciated. 
2. Brooks's adaptation is actually the fourth remake of the novel in English to date. The first two loose adaptations are Keep Your Seats, Please (1936), a British comedy directed by Monty Banks, and the US film It's In the Bag! (directed by Richard Wallace, I945). The third adaptation is an Italian-French production called $I 2+{ }_{I}$ (directed by Nicolas Gessner and Luciano Lucignani, I969), starring Sharon Tate (in her last film before her murder) and Orson Welles.

3. Not only Brooks, but also critics have pointed out frequently that the major themes in his movies are friendship and love. Accordingly, in a reversal of the quintessential Hollywood happy end, Brooks's protagonists do not get the riches in The Producers or The Twelve Chairs. And in Life Stinks (I99I), Brooks's character comes to realize that love, not material gain, is the most important thing in life.

4. For instance, the film's theme song juxtaposes Lev Tolstoi, a famous Russian novelist, and Fannie Hurst, a forgotten Jewish-American one; several of the actors speak with New York accents or are identified with the city (DeLuise, Langella, Brooks), and the narrative focuses on get-rich schemes and rags-to-riches (in this case failed) dreams that historically have fueled America's capitalist society and the immigrant community. Based on Brooks's work on the stage and television, and his first feature film, audiences likely expected another upstart, obnoxious, and slapstick adventure comedy rather than a film that mixes highbrow aspirations with broad farce.

5. Maguire, "Introduction," xvi.

6. Smith, "Il'ia Il'f and Evgenii Petrov," I 5 I.

7. Ibid., I 53 .

8. Lev Trotsky ( $1879-1940)$, a prominent Bolshevik and one of the leaders of the October Revolution in I9I7, disagreed with the policies of Josef Stalin (I878-I953), who was consolidating his power in the late I 920 after the death of Lenin in I924. His beliefs differed from Stalin's increasing dictatorial tendencies and growing bureaucracy, and Trotsky advocated a global revolution, rather than building socialism in one country. Trotsky was removed from power in 1927 (he was one of the first members in the ruling Politburo) and went into exile. He was killed on Stalin's orders in August I940 in Mexico. Il'f and Petrov were enlisted as part of an official campaign against Trotsky's policies.

9. Odesskii and Fel'dman, "Legenda o velikom kombinatore"; Lipovetsky, Charms of the Cynical Reason, 9I-3.

Iо. Henry, Classics of Soviet Satire, 28.

I I. The Brooks and Gaidai versions of The Twelve Chairs include some scenes and cinematic techniques that are remarkably similar, making one wonder whether the two were aware of each other's work. Brooks was filming in Yugoslavia from September-December I970, while Gaidai filmed near the Black Sea. Both directors use speeded-up action during some of the chase scenes between Vorob'ianinov and Father Fedor. Also, the scenes where Father Fedor finally pesters the Bruns into selling him the chairs are remarkably similar: both are shot on a patio overlooking the Black Sea (in Brooks's case, the Adriatic Sea substitutes); Father Fedor prostrates himself before the married couple and also appears in the trees above the patio.

I2. Stam, "Introduction," I9.

13. In his movies Mel Brooks's humor is visual, physical, and slapstick, and, at times, extremely vulgar. Consider the physical interplay between Bialystock and Bloom in The Producers; the scuffles between Father Fedor and the Bruns in The Twelve Chairs; and the fireside bean eating scene of flatulence in Blazing Saddles.

I4. New York comic actor Dom DeLuise plays the money-grubbing priest Fedor, who is used as a contrast to Bender and Vorob'ianinov. 
I5. Yacowar, Method in Madness, 90.

I6. Ibid., 89 .

I7. Sieber, The Picaresque, 9 .

I8. The musical opened in London's West End in I960 and on Broadway in I962.

19. Lipovetsky, Charms of the Cynical Reason, 97-8.

20. By contrast, in the hypotext Bender describes Vorob'ianinov as being transformed. "He [Ippolit Matveevich] puffed up his chest until it stuck out as much as the Palace Bridge in Leningrad, his eyes flashed fire, and a thick smoke came boiling out of his nostrils—or at least that's what it looked like to Ostap. His mustache slowly began to rise." Il'f and Petrov, The Timelve Chairs, 453.

2I. Yacowar, Method in Madness, 93.

22. Brooks's films evidence just how attuned he is to social and political currents in American life. In the early I96os, the United States and the Soviet Union, as the two global superpowers, stood on the brink of nuclear war, a time epitomized by the 1962 Cuban Missile Crisis. A decade later, however, attitudes in the US had changed, with the Nixon-Kissinger policy of détente largely replacing the "good vs. evil" attitudes that had dominated during the peak of the Cold War in the I95os. In fact, by the end of the I96os, the more tolerant US political stance in relation to the Soviet Union was reflected in Hollywood's portrayal of the Soviets, who, although still perceived with suspicion, were no longer demonized. Three films of that era highlight those changing outlooks: Stanley Kubrick's Dr. Strangelove (1964) depicts the bilateral idiocy of bringing the world to a nuclear standoff; Norman Jewison's The Russians Are Coming The Russians Are Coming ( 1966) shows that it is possible for Americans and Russians to work together, while David Lean's Doctor Zhivago (1965) takes a more neutral stand on Soviet politics, choosing instead to focus on personal melodrama. The general atmosphere was more optimistic. For more on these films, see Chapter I by Thomas Leitch in this volume.

23. Mel Brooks has a hilarious cameo in the film as Vorob'ianinov's loyal, drunken, and faithful servant Tikhon. Brooks invigorates a role that is not very developed in the novel by relying on slapstick comedy and over-exaggerated antics in such a way that prompted Nem Yorker film critic Pauline Kael to remark that the film "never quite recovers" from the loss of "fervid enthusiasm" and "comic tension" when his role as Tikhon is over. Kael, "The Twelve Chairs," I 80.

24. Not one to eschew female roles in his work, Brooks has cast a number of female actors in his films: Lee Meredith as Ulla, the Swedish bombshell secretary in The Producers; Madeline Kahn as a Marlene Dietrich-like cabaret singer in Blazing Saddles and the sexaddicted wife who falls in love with the monster in Young Frankenstein; and Cloris Leachman as the psychotic, sadomasochistic Nurse Diesel in High Anxiety. In contrast to Brooks's adaptation of The Twelve Chairs, Il'f and Petrov saturated their novel with zany female characters representing different types of women living in Russia in the I920s. Perhaps two of the most memorable women are the Widow Gritsatsueva, whom Bender marries in order to gain one of the chairs, then abandons at the wedding reception, and the self-absorbed Ellochka the cannibal (Liudoedka Ellochka), a celebrity-obsessed housewife with a lexicon of a mere thirty words who is a caricature of petite-bourgeoisie mentality. Brooks's film could have benefitted from the inclusion of such delightful female roles and added a comedic flourish that might have resonated with audiences, who likely would have recognized such universal character types.

25. Kalat, "The Twelve Chairs." 


\title{
Fassbinder's Nabokov From Text to Action:
} Repressed Homosexuality, Provocative Jewishness, and Anti-German Sentiment

\author{
Dennis Ioffe
}

R ainer Werner Fassbinder's film Despair was shot in 1977 and was proudly R premiered at the Cannes International Film Festival in $1978 .{ }^{1}$ The film is based on one of Vladimir Nabokov's major Russian novels, Despair. ${ }^{2}$ The eminent British playwright Tom Stoppard prepared the screenplay for Fassbinder, carefully adapting Nabokov's text for cinematic staging. The hypotext Despair was originally published in 1934 in Contemporary Letters, a major Russian-Parisian literary journal of the pre-war emigration, and further issued as a separate book in Berlin (by Petropolis) in 1936. The original storyline was set in Berlin at the beginning of the r 93 os.

Fassbinder's Despair has enjoyed wide scholarly attention over the years. ${ }^{3}$ Of particular importance are the works of the British scholar Ewa Mazierska and the film historian Thomas Elsaesser. ${ }^{4}$ Most recently, the Russian critic Nina Savchenkova organized a special roundtable focused on the film's reception in Russia which was hosted by the Nabokov museum in St. Petersburg. ${ }^{5}$ The ontological discongruity between the two artists was one of the dominant themes of this roundtable. In what follows, I will analyze Fassbinder's hypertext along with Nabokov's hypotext in order to address the dramatic dialectical collision that occurs when Fassbinder transports Nabokov's hypotext to a different cultural territory-namely Nazi Germany. The main differences between these artistic sensibilities are related to two major spheres: "the territory of homosensuality," as opposed to the heterosexual universe of Nabokov, and the "territory of nascent Nazism" as explored by Fassbinder, which is opposed to Nabokov's "neutral" German environs. The point is not to illustrate the affinity between the two artists, but 
rather to highlight the personal and aesthetical differences that emerge with this border crossing.

\section{WRITTEN AND CINEMATIC TEXTS}

Before we start the discussion, it is important to account for all of the available versions of the author's text (the Russian hypotext and then Nabokov's own modified English translation and the English script-adaptation of the film by Stoppard-both hypertexts of the original). This will allow us to gain the fullest understanding of the movie's ultimate contextual message, and to differentiate between the latent possibilities of Nabokov's texts and the actual motifs found (and expanded upon) in Fassbinder's film. In order to do this, we might examine the original Russian narrative as created by Nabokov along with his English hypertext against the resulting cinematic hypertext of Fassbinder/Stoppard. ${ }^{6}$ Identifying keen distinctions between the versions is one of the major analytical challenges a film critic might pursue in this case. To compare and to see the possible differences between the multiple narratives in question appears to be much more intellectually intriguing than to just turn our scholarly attention toward one version of the film's plot. At the same time we know that as early as 1972, Fassbinder read an English translation of Despair, which was published by Paragon Books (1965). ${ }^{7}$ The English translation represents a modified version of the Russian hypotext with some minor additions. To make use of only the English translation or of only Stoppard's screenplay for analysis of this film would be an artificial and unwarranted restriction.

Vladimir Nabokov's prose has left a profound imprint on Western modernist literature in general and Russian modernism and postmodernism in particular. ${ }^{8}$ Having emigrated from Russia- his family departed from the Crimean peninsula during the Russian civil war-Nabokov embarked on an illustrious career in letters and academia in Europe. His career started with well-received novels in Russian, published in France, that were then translated by the author himself for American and international audiences into English (often with content changes to suit a non-Russian readership). ${ }^{9}$ After emigrating to the United States and failing to satisfy the Harvard Slavic search committee, ${ }^{10}$ Nabokov began to teach at Cornell University. At this time, he also began writing almost exclusively in English. His universal literary fame came with his provocative novel Lolita (I955). Multi-dimensional irony and radical individualism seem to be the two main distinctive traits of Nabokov's unique narrative style.

Rainer Werner Fassbinder in his turn is one the most celebrated German film directors of the modern age. Just as Nabokov never formally (or academically) 
learned how to write novels, Fassbinder never academically studied hom to shoot movies. ${ }^{11}$ Yet, even without this formal training, both Nabokov and Fassbinder reached the very top of their professions. Despite Fassbinder's premature death in 1982 , he left an abundant number of feature films, along with various theoretical writings and interviews that shed an explanatory light on his cinematic oeuvre. Relevant for this particular discussion is Fassbinder's constant obliterating of the boundaries between art and life; between imaginary fiction and a perceived reality. Also germane to the topic is Fassbinder's preoccupation with various troubling social issues of his time, which can be found in the ideological fabric of his films as an anti-bourgeois social stance. As Anthony Kinik puts it, Fassbinder's general aesthetics were based on agitational, confrontational, anti-bourgeois politics. ${ }^{12}$ Fassbinder was generally following in the footsteps of another major German modernist director and playwright, Berthold Brecht, who maintained a sharp social activist agenda. As one critic has justly put it, the main difference between Brecht and Fassbinder lies in the fact that Brecht, as a "positive materialist," stretches his argument somewhat further than Fassbinder, "believing idealistically that man can change unjust social conditions for the better and that this needs to be portrayed." But according to Kinik, Fassbinder, "a negative materialist," definitely "lacks Brecht's optimism." 13 At times this combative political stance would lead Fassbinder to polemical statements on Jewish topics as well. By equating Jews with the rich bourgeois world, Fassbinder eventually was accused of latent anti-Semitism. ${ }^{14}$

Consequently, this kind of political/artistic activism is found in the German director's adaptation of Nabokov's novel. Fassbinder dedicated Despair to the famous Dutch painter Vincent van Gogh, to the French Surrealist author Antonin Artaud and to the troubled, German avant-garde artist Unica Zürn. The common thread among these three is a history of mental illness and the taint of suicide, both of which occur in this cinematic adaptation. Fassbinder's particular ideological innovations, however, are elaborations on the homosexual and Jewish themes found in Nabokov's text. Fassbinder augments these rather subdued themes in the literary text by emphasizing the dreadful rise of the National Socialist Party in Germany in the r 930 os. This is the main "deviation" of the film version, a historical perspective that Nabokov could not have completely foretold at the time of the novel's writing. ${ }^{15}$ After all, it is debatable whether Nabokov tried to embed in this work some of his own anti-German sentiments. ${ }^{16}$ We do not know whether Nabokov could have really anticipated Adolf Hitler's future crimes against humanity, whereas Fassbinder crafted his cinematic hypertext consciously exploiting the full horror of Nazism.

Significantly, the filmic medium offers a unique opportunity for Fassbinder to create excursions into alternate cultural and temporal spaces. As both Alfred Appel and Barbara Wyllie have convincingly shown, cinema bore an immense 
importance for Nabokov the writer as well as Nabokov the human being. ${ }^{17}$ Yuri Leving has also aptly observed that "the saturation of prose with visual effects are hallmarks of Nabokov's narrative technique in general; he was the king of the detail, the king of the particular." 18 This attitude brings him closer to the main representatives of the nouveau roman such as Marguerite Duras and, particularly Alain Robbe-Grillet, who later became involved with the Left Bank film movement (often labelled as part of the French New Wave). Nabokov often assumed a position of "someone who watches the watcher" (nabliudatel' za nabliudatelem). This strategy suggests a mirror effect in which one action has multiple layers of meaning as it passes through the perception of several different participants. These potential visual allusions, which remained dormant in Nabokov's verbal text, became ripe for Fassbinder's cinematic vision and allowed for innovative meanings.

Nabokov's allusive multi-layered narrative style offers a particular challenge to Fassbinder, who observes:

Nabokov handles language as something that reflects, mirrors and in turn re-reflects. If I use glass and reflections in this film, it's derived from Nabokov's linguistic structure. The significance of glass in this film is that it's transparent and yet it closes in on the character-and that's Nabokov's style. ${ }^{19}$

One scholar has noted Nabokov's "deliberately ambiguous artistic images" that create an "intense pictorial polysemy." ${ }^{20}$ It is just this pictorial polysemy that seems to attract Fassbinder to Nabokov's works with its many "potential" narratives. As a result, Fassbinder exploits some of Nabokov's concealed metaphors for his own cinematic benefit.

\section{FASSBINDER'S HERMANN：JEWISH (HOMO)SENSUALITY}

Nabokov's novel depicts the story of a well-to-do German bourgeois entrepreneur, whose name is Hermann Karlovich. He occasionally encounters a mysterious vagabond rather ironically named Felix, who, to Hermann, seems to resemble his own reflection in the mirror. Hermann persuades Felix to impersonate him in order to eventually assassinate this poor vagabond. Hermann's business in Berlin is failing and the substantial life-insurance payment would let him start a new life. As it turns out, Felix looks nothing like Hermann, and it does not take long for the police to determine who murdered the vagabond. Readers only fully realize the extent of Hermann's self-deception once the police find Felix's body and reveal the murderer's mental illness. 
Fassbinder's film narrates the very same linear storyline with several noticeable alterations: The plot's chronotope is transferred to early Nazi Germany, Hermann Karlovich becomes Hermann Hermann (a direct reference to the main protagonist, among others, of Lolita), his family is Jewish, and he is now a transparently closeted homosexual. A question that might arise here is how does Fassbinder allude to Hermann Hermann's secret sexual identity? Similarly to Fassbinder's own "open secret," the viewer is invited to speculate on the hero's orientation based on two "iconographical clusters" that generate the relevant meaning. These "clusters" of visual imagery are conveyed through Hermann's ambivalent relationship with his wife Lydia, and his obsession with the masculine physique of Felix Weber-his "double." Nothing is pronounced openly, as Fassbinder opts for leaving Hermann's sexuality as unclear as possible, provoking his viewers to ruminate endlessly on the arising ambiguities of plot and play. The situation is all the more suggestive as the actor who portrayed Hermann, Dirk Bogarde, was an open homosexual in his "real life."

All other major details remain, more or less, exactly as they are portrayed in Nabokov's book. At issue then is how placing a hidden Jewish homosexual in Nazi Germany changes the trajectory of a text as it is transported from the pages of an émigré Russian novel into a post-war German film. What might have been a simple border crossing suddenly becomes a distinctively more complex cultural exchange in which sexual orientation and religion commingle with the hypotext's original emphasis on madness.

At first glance, the issue of Hermann Hermann's religious background and sexual preference might seem entirely disconnected. Yet, an awareness of the historical attitudes toward Russian Jews and homosexuality immediately enhances our understanding of Fassbinder's film. ${ }^{21}$ The German tradition of Brüderschaft and homosocial male-male friendships informs Fassbinder's own cultural journey. According to Harry Oosterhuis, during the Sturm und Drang, a proto-Romantic cultural period in Germany, men among the intellectual elite engaged in all kinds of sensual and passionate relationships. ${ }^{22}$ Love

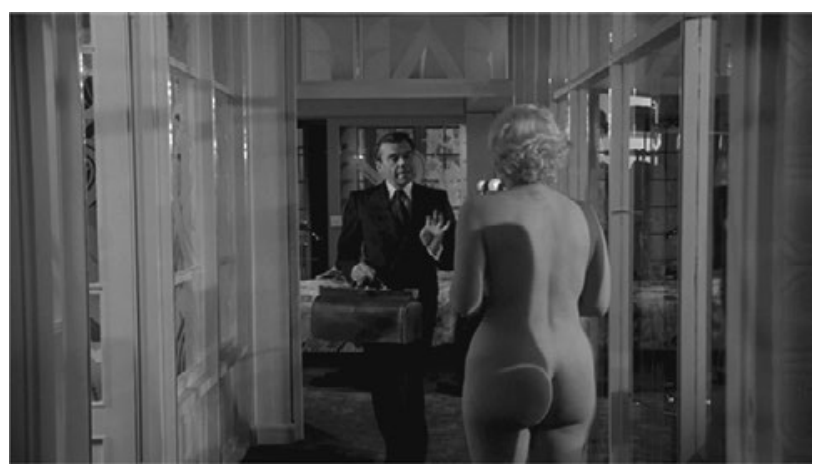

Figure Io. I Hermann parts sexual ways with Lydia. 
between a man and a woman was not distinct from male friendships as the ideal emotional and intellectual relationship was tinged in both instances with physicality. As a result, Greek male love and pedagogical Eros were in vogue within certain communities at the time. It was not until the late nineteenth century that romantic friendships between men, even those without sexual overtones, became suspect. At this time, the institution of marriage and the nuclear family began to usurp the intimacy once shared between individuals outside of the home..$^{23}$

During this time as well, homosexuality in popular culture was transformed and manipulated by psychiatrists. In Europe, the leading theorists associated mental degeneration (Entartung) with sexual perversion and psychopathology. Degeneration theory gained relevancy for intellectual communities across Europe and into Russia as scientific and medical investigation began to address the perceivable problems caused by the fast pace of modern society. ${ }^{24}$ These theoreticians on degeneration did not discuss sexual perversion as though it constituted primarily a religious or philosophical problem but as an empirically demonstrable medical or biological fact. The Viennese psychiatrist Richard von Krafft-Ebing published Psychopathia Sexualis in I 886 which included hundreds of case histories of deviant sexual behavior. For him, homosexuality was an issue of identity rather than a specific sex act.

Not all psychiatrists at the time, however, believed that homosexuality should be equated with degenerate behavior. Havelock Ellis wrote the first English medical textbook on homosexuality entitled Sexual Inversion (I897). In this book, the author notes how many sexual practices that had long been common, or at least tolerated, were suddenly viewed as problematic. In many ways, it was a plea for tolerance. ${ }^{25}$ What developed was a broad understanding of male relationships with claims of deviant sexual perversion as one extreme and defense of meaningful male friendships on the other. Fassbinder, by not overtly suggesting Hermann's sexual orientation, plays on this spectrum moving between homosexual desire and homosocial friendship.

In Russia of the fin de siècle, there was a tendency to link together homosexuality and degeneracy, but to blame it on foreign influences and suggest that it was only a problem in larger cities such as St. Petersburg. Although sodomy was legalized in 1922 by the Bolsheviks, who saw it as a medical, not a legal problem, by I934 it was again outlawed and vaguely connected with other degenerative diseases - alcoholism, syphilis, and hysteria. According to Dan Healy, Russia in modern times has understood itself as untainted by sexual perversity, while at the same time surrounded by degenerate Europe and the depraved and backward East. ${ }^{26}$ As to the Nazis' specific understanding of homosexuality's illegitimacy ${ }^{27}$ - it hardly deserves special attention here, being a well-acknowledged part of their common cultural policy geared against all things "degenerate," especially "degenerate art" (Entartete Kunst), along 
with homosocial sexual and non-sexual relationships. The term of Entartete Kunst was de facto applied to nearly all "experimental" (or "modernist") culture, maintaining that the very foundations of such irreverent avant-garde art are obviously non-German and Jewish or Bolshevist (i.e., revolutionary/ leftist). ${ }^{28}$ The "ideal" degenerate artist according to Nazi cultural stereotype should be altogether Jewish, homosexual, and engaged in some kind of subversively "experimental" avant-garde activity.

In Despair, we meet the corresponding theme of repressed homosexual (and homosocial) realities which came into being during the early phase of German Nazism. The crypto-theme of "experimental" homosexuality as expressed in the movie is associated with a possible "coming out" of the main actor as well as the director. Fassbinder deliberately blurs the boundary between the "real" identity of the one who plays (and directs) and his cinematic character. In principle, the actor and the character are supposed to be two different entities. However, in this particular case, both Bogarde, the actor, and Fassbinder, the director, were in a process of "coming out," thereby embedding this theme within the consciousness of the film audience. Fassbinder's own sexual orientation would be confirmed with his final film-a "queer" cinematic piece Querelle. ${ }^{29}$ At present, the gayness of Fassbinder is a commonly acknowledged topic within scholarly and critical discourse and adds relevance to the present discussion. ${ }^{30}$ Thus, Fassbinder draws on his own and Bogarde's sexual identity in his transformation of Nabokov's Hermann. It is not surprising then that this non-Aryan, closeted member of German society might want to create an elaborate escape from Nazi oppression, even before the formulation of the "Final Solution" to the so-called Jewish Question at the Wannsee Conference in I942.

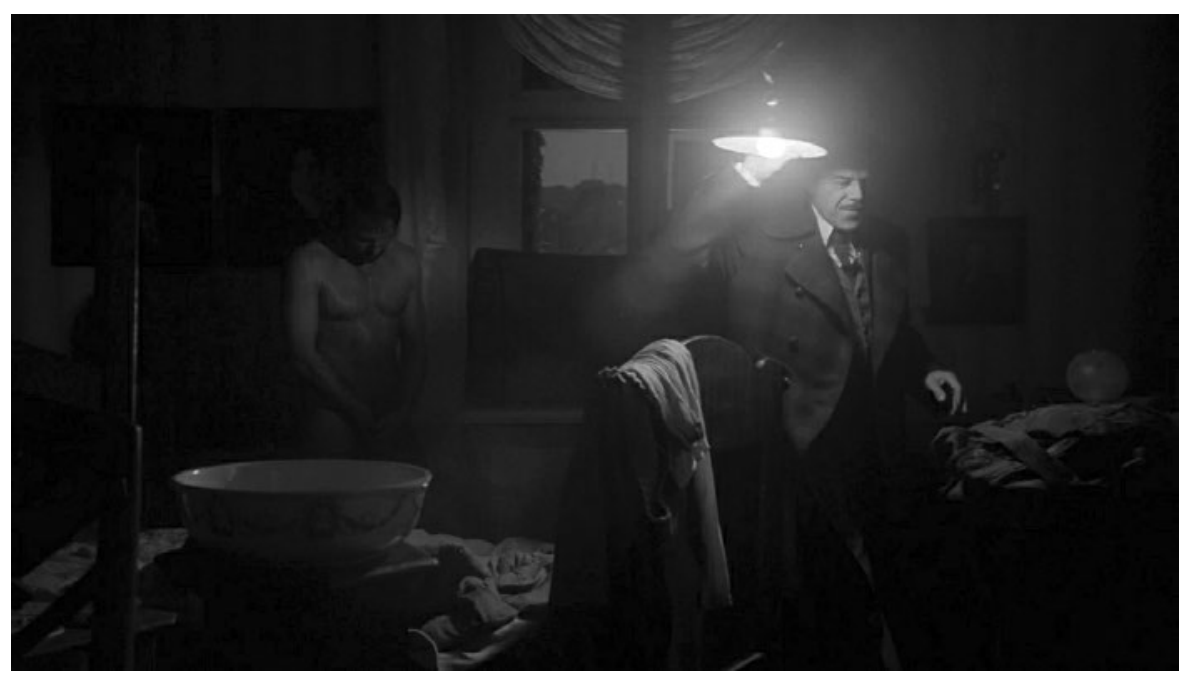

Figure I0.2 Hermann and the naked Felix, taking a bath. 
Being situated within the newly emerging Nazi regime, Hermann will imminently find himself under a double danger, so to speak. He will be doomed for being (half) Jewish, but also for being homosexual. As is well known, homosexuals were officially persecuted by the Nazi legislative regulations, which included hunting those who were Party members. Both Jews and homosexuals were forcibly sent to the concentration camps and a great majority of them eventually perished. ${ }^{31}$ Some studies even draw a conceptual comparison between the Gay Holocaust and the Jewish one. ${ }^{32}$

Fassbinder's protagonist's trouble is correspondingly more intricate. In this case, the matter of Hermann's homosexuality is further complicated by the matter of Jewish (homo)sensuality. Although it is quite clear that homosexual relationships are strictly forbidden in the Torah (the Pentateuch), we may conclude that homosexual relationships were not completely alien to old Hebrew culture and, possibly as a result, became part of the Jewish mythos, especially exploited by those with anti-Semitic inclinations. In this particular instance, Hermann Hermann is an axiomatic example of an effeminate Russian/German Jew. Homosexual overtones are not alien to Christian gospel narrative as well, particularly hinting at the ambiguous sexuality of Christ (the born Jew) and the community of his (exclusively male) disciples-apostles (all of whom were Jews).

Fassbinder may, in fact, have intended to call upon this archetypal figure of a suggestive effeminate "gay" Jew known to us from a plethora of cultural contexts. After all, the "femininity" of the Jews was discussed in late imperial Russian society, reaching its apogee in the abundant writings of the premier Russian literary critic Vasilii Rozanov, possibly influencing Nabokov on some level as a true contemporary of this period. ${ }^{33}$ Fassbinder, in his turn, of course did not know much about this internal Russian debate and most certainly was not well familiar with Rozanov. It is at this point that the archetype of cultural territory shifts in a significant way. In exploring Nabokov's textual terrain, Fassbinder (more than Stoppard, who was at a certain point "alienated" from the script) brings his own cultural associations to the two major subtexts of the cinematic hypertext (Jews and homosexuals within the German context), even as he retraces Nabokov's steps.

Aside from expressing himself on the topic of homosexuality, Rozanov had famously maintained that Jewish "religious ethnicity" should be generally grasped as receptive and passive, viewing the entire nation and particularly its males as fundamentally effeminate and accommodating. ${ }^{34}$ At the very same time, the generalized effeminate image of Jesus and the receptive suffering of the Jews was quite common in European cultures and would have appealed to Fassbinder in this specific instance as well. Most likely, Fassbinder (and his scriptwriter Stoppard) would have heard of Sebastiane (1976), a highly influential art-house film created by Derek Jarman and Paul Humfress, released 
two years prior to Despair. Sebastiane provocatively depicts dramatic events taken from the troubled life of Saint Sebastian and, especially, his tragic martyrdom brought about by sharp phallic arrows, which penetrated his body of sorrow. Jarman and Humfress bring forth the image of an effeminate, androgynous Christ in this work, mirroring the cultural discourse around the feminine/effeminate Jew. ${ }^{35}$ The androgynous Lord of the fews might well have offered a unique subtext for Hermann, who is afraid of his ultimate destruction at the hands of powerful forces. Fassbinder certainly was aware of how the Nazis had dealt with transgressive religious and sexual behaviors, which he chose to explore for his film adaptation.

We know that Hermann's mother was Jewish: "My father was a German speaking Russian from Reval. My mother was a Rothschild." Hermann's homosexuality in Fassbinder's film, as mentioned above, is largely an interpretative conjecture on my part. For instance, there is the following typical exchange: "You know we are ... we are strangers. We have, as ... as you might say, a ... a bond.-You can see it?-Yes. We are as alike as ... as two peas. It's a freak of nature." The special bond that the characters seem to have might naturally suggest the deliberate blurring of the continuum on the homosexualhomosocial continuum described earlier. In the context of Fassbinder's own homosexuality, and the earlier representation of homosexuals in his I975 film Fox and his Friends (1975), this bond seems to suggest some kind of same-sex attraction.

\section{ALIENATION, DEVIANCE, AND TRANSGRESSIVE HOMOSEXUALITY}

One critic of Despair has given special attention to the film's noticeable overall feeling of alienation which results in Hermann's loss of his real physical body. ${ }^{36}$ Such an approach raises questions about the main character's place within society, his desire to avoid detection, and an inability to assimilate. Alienation, or a dissociated personality disorder, as Thomas Elsaesser suggests, should be the key concept in this respect, and it is no coincidence that Fassbinder decides to reinforce that estrangement by adding the aspect of Jewish identity, absent in Nabokov's text, to Hermann's background.

Hermann's feelings of alienation in the film are most certainly enmeshed with the religious and sexual issues, not to mention that he ultimately intended to commit murder in order to start his life anew. Speaking to his wife Lydia in one scene, Hermann states his life credo: "Philosophy is an invention of the rich. So is religion ... poetry. I don't believe in love either." In this scene Hermann also develops a "Franciscan" theme of embracing the birds as God's finest creatures, worthy of being preached to. He confesses that he 
likes sparrows and he understands them as well as the street painters. $\mathrm{He}$ says that he likes squirrels, too, and "moles are all right." He tells us that he would like the world to be full of squirrels and moles "because they are against landlords." This statement fits well within Fassbinder's general activist "philosophy of life," aimed at the bourgeois and their exploitation of day workers. Animal and bird imagery also has some meaningful sexual as well as social connotations in this respect. Hermann continues: "Now ... friendship ... that's a different thing. I'd like to have a friend. I'd work for him ... as a gardener. And afterwards, his garden would become mine, and ... I'd live in joy, and ..."

Hermann seems to clearly envision a homosensual friendship with Felix in the context of a garden. The garden might well serve as the symbol of their "freakish" bond. What garden does Fassbinder's Hermann have in mind in this particular scene of the film? What is the potential remote allusion he plays with here? What garden activities would bring an ultimate carnal joy to Hermann? What is this allusive meta-physical garden that would become his? Hieronymus Bosch's Garden of Earthly Delights contains some clear (some would say explicit) imagery.

Bosch's art bears a direct importance for Fassbinder's oeuvre. ${ }^{37}$ One of Fassbinder's favorite collaborators, German actor Harry Baer, describes how the director wanted to create certain visual effects in the style resembling that of Bosch. ${ }^{38}$ We might assume that by mentioning the "garden $\Leftrightarrow$ carnal delight" kind of nomenclature, the German director might have alluded to Bosch, who happens to be the author of the most powerful imagery created on this topic of human "filthy sin." Fassbinder's cinema, and especially Despair, is abundant with cultural and artistic allusions, so it would not be too odd to bring Bosch's peculiar iconography as a possible explanation of Hermann's above-mentioned enigmatic words. We find several notable homosexual allusions in this major painting of Bosch, the most prominent of which is called "floral sodomy" (see Figure Io.3), which is well acknowledged in art criticism. ${ }^{39}$

What kind of friend does Hermann imply here with whom he would entertain himself as a gardener? A friend whose private garden would become his own, where he would live and dwell in utmost joy. This theme is related to the transgressively erotic topic of the "garden of love" known from the Persian poet Hafiz onwards. Using the provocatively allusive iconographic imagery of this picture, one might imagine Hermann referring to the anal private garden of Felix where he would be keen to implant some seeds of his own carnal flowers. Exactly as with the entire topic of Hermann's crypto-homosexuality, there is no "solid" way for us to actually prove that the main protagonist has anal sex in mind. It surely can be just an innocent image of friendship. Exactly as innocent as, say, Hermann's remarkable tolerance of Lydia's promiscuity, exactly as innocent and friendly as his attraction to Felix's rough masculine physique. All these signs might easily designate "normality" in any heterosexual sense of this 


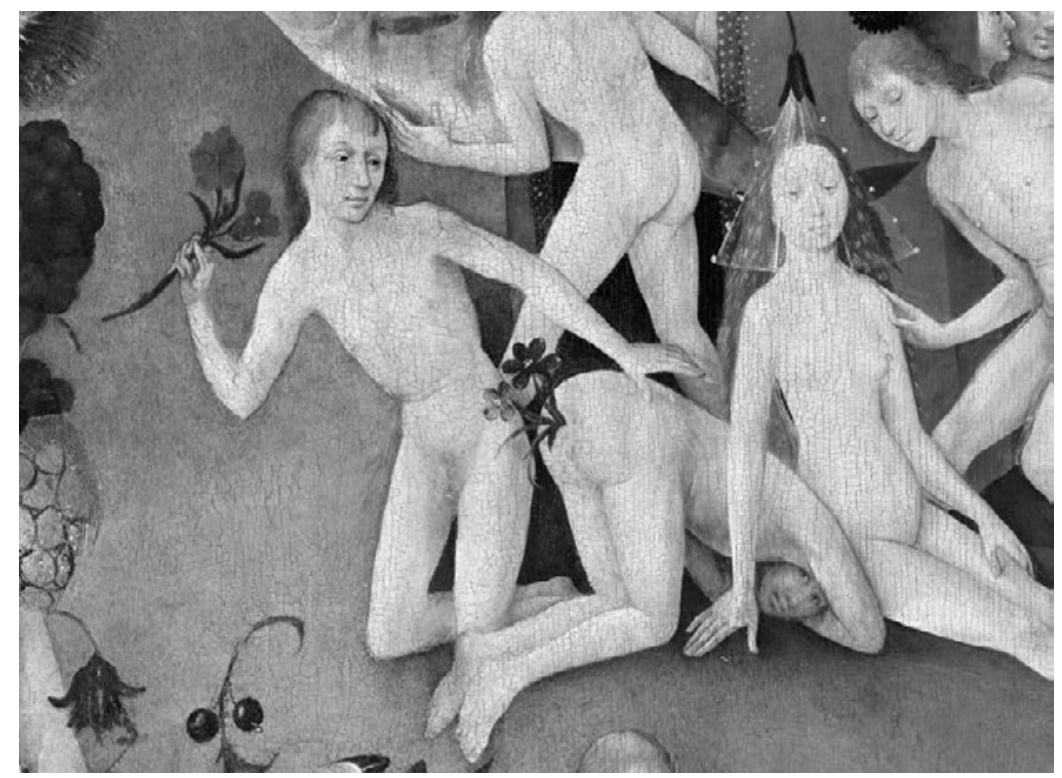

Figure ro.3 Hieronymus Bosch, a Fragment from The Garden of Earthly Delights, Museo del Prado in Madrid ( $\left.\mathrm{I}_{5} \mathrm{IO}\right)$.

term. It is our hermeneutical choice to unfold a hidden homosexual orientation that stands behind Fassbinder's hypertext. Proceeding in this interpretative vein, carefully gardening the flowers of joy with Felix definitely presents one of Hermann's inner aspirations and hidden carnal hopes.

In Despair, Hermann first passionately detects Felix on the dark streets of Berlin near cheap hotels, in a manner that is reminiscent of urban prostitution - a world abundantly depicted in Russian literature, including the works of Fedor Dostoevskii and Aleksandr Blok. ${ }^{40}$ In Hermann's own verbal definition he was searching for: "[a] handsome, virile man, if possible, of simple background." 41 As Ewa Mazierska points out, on another occasion, Hermann (both in the novel and in the film) mentions that his brother "loved to put on his shirt when it was still warm and the two shared a bed with a pillow at each end until it was discovered that the 'brother' could not go to sleep without sucking Hermann's big toe." ${ }^{42}$ Fassbinder's cinematic Hermann elaborates on this intimate closeness with the imagined brother of his Russian youth:

My dead brother, whom I was so close to ... so close, he was almost my second self ... This sweet-natured boy that I've known all my life ... This sensitive boy-this musician - the youngest musician - the youngest violinist in the Bolshoi ... where our mother used to dance before Emperors! The same boy. This same boy ... Ah, he was a cheat ... 
One wonders if that imaginary boy who was "corrupted" (in the Platonian sense of same-sex pleasure) was not the adolescent Hermann during the remote times of his troubled Russian youth? Departing from Nabokov's text, Fassbinder provides abundant representations of Hermann's "repressed identity" - namely of being a Jew in a German proto-Nazi environment as well as being a homosexual in the world of so-called "normality."

\section{THE DARK WORLD OF CINEMATIC AND LITERARY DOUBLES}

As noted, Fassbinder's Despair interacts with a mixture of allusions offered by Nabokov's semantically layered text. The main protagonist Hermann Hermann has two possible predecessors from Russian culture. Fassbinder may be making an allusion to Lolita's Humbert Humbert, with a secondary reference to Aleksandr Pushkin's suggestively nocturnal Hermann of The Queen of Spades. Lolita impishly describes the frustrated love of an elderly troubled male, Humbert, toward an attractive prepubescent girl. In its turn, The Queen of Spades is one of Pushkin's major prosaic texts concerned with the issues of destiny, chance, aging, fate, and, to a certain degree, the sexual complexities of the young vs. the old. More importantly The Queen of Spades also raises the issue of the ghostly dark-doubles as exploited in the main canon of Russian classic literature (e.g., Nikolai Gogol and Dostoevskii).

Fassbinder's character (as did Nabokov's Hermann Karlovich) gradually grows delusionary and self-destructive. Is this because of his financial troubles or is this driven by his perplexed sexual relationship with his wife Lydia? Hermann acknowledges the intellectual poverty of Lydia as well as her blatant infidelity, but for some unexplained reason he does not consider leaving her until he meets Felix. A common vagabond, Felix is perceived by Hermann as his mysterious double. Is this attraction to Felix entirely part of Hermann's delusional state or is it driven by his closeted desire? A characteristic scene from the film illustrates the way Hermann first meets Felix, showing how Fassbinder constructs this particular ocular moment. There is hardly any visibly noticeable homoerotic aspect in it, but it still tells a lot about the way Hermann interprets Felix:

Are you blind, or ...? You have my face.-If you say so, mister.-With a haircut and a shave, we would be indistinguishable. ... Do you know what a double is? You have been to the cinema? A double, Felix, is a person who, in an emergency, can stand in ... for a given actor.

Lydia's sexual promiscuity and transgressions contribute to Hermann's deepening psychological discomfort. His mental dissociation from his own 
identity is forcibly stressed by Hermann's recurrent obsessive thoughts of his own self performing violent sex acts with his promiscuous wife. All the while, his double is sitting at the other end of their apartment. This seeing double testifies to Hermann's troubled state of mind as well.

The murder of Felix in the film is, as Thomas Elsaesser pointedly observes, a symbolic suicide, in which Hermann can effectively punish himself-assuming the role of dominance and submission simultaneously. By killing his standin, Hermann eliminates his own inadequate identity, in order to be reborn, so to speak, on the other side of life in some other locality-remote from the financial, marital, and social problems that plague him. Devising and employing false identities was not at all unfamiliar to Fassbinder's Hermann, who (as is described in the hypotext) escaped Soviet territory by using some sort of obscure illegal papers. Hermann's Jewish facet seems to somehow integrate with his artistic interests: In the same vein as he was dissatisfied with Russia's harsh and impossibly atrocious realities, he is displeased with German Ordnung too.

In a rather delusional state of mind, Hermann maniacally conceives of a perfect financial crime (involving a "staged" murder), which would also eventually symbolize his physical rebirth. The idea of some kind of resurrection is noted by critics due to Fassbinder's original title for the film: "his trip towards the light." ${ }^{43}$ In the movie, there are a variety of suggestive hints: "Lydia!-Did you have a good trip? Yes? Can I help you? Your ... Pushkin ... letter. Thank you. Life Insurance. 'New Life'." They continue to discuss the topic of insurance and of (an imaginary) brother who is supposed to die for Hermann's benefit. Lydia wonders: “Isn't it a swindle? A swindle? The insurance money,

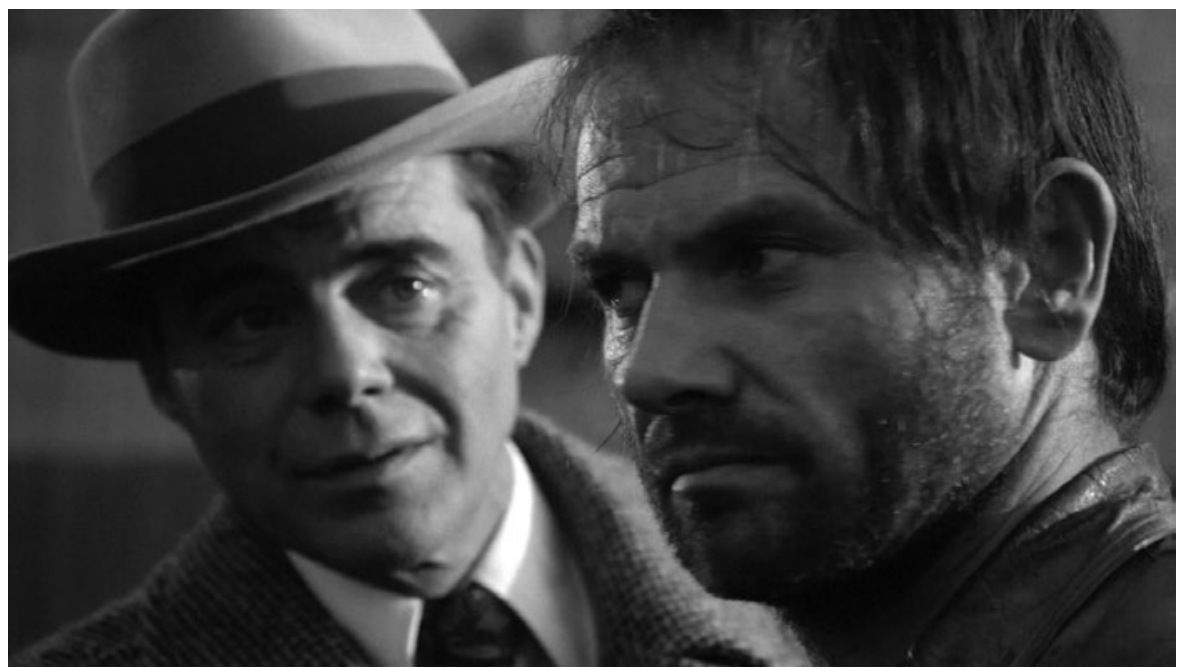

Figure ro.4 Hermann and Felix. 
Hermann. The insurance money is not the point. We have reached a higher spiritual level." There seems to be no ethical contradiction between Lydia and Hermann at this point, as for various reasons they have a certain goal to pursue, though a different one for each.

The implied highness of the spiritual quest for this enlightenment constitutes the main agenda of Hermann's manipulatory criminal actions. Pushkin's playful masquerade of criminality as depicted in some of his texts, especially in The Queen of Spades, provides a well-motivated background for Hermann's self-fashioning. Being sexually transgressive as well as "socially" criminal is in the tradition of Pushkin. ${ }^{44}$

Both Nabokov and Fassbinder rely on the rich cultural strata of doubles. In mythology, doppelgängers are usually quite sinister characters, who bring bad luck or an omen of death to their original's identity. These evil characteristics were consistently found in the doubles of German Romanticism that, rather directly, influenced Russian writers. The stories of E. T. A. Hoffmann and Ludwig Tieck fed the imaginations of writers like Pushkin, Gogol, and Dostoevskii, who, in turn influenced Aleksei Tolstoi and Nabokov. Marina Grishakova observes: "Nabokov's mirror texts (The Eye, Despair) are structured by the partial or false identity of the doubles. An encounter with a cinematographic unrecognizable double is a leitmotif of Nabokov's fiction." 45 Nabokov's Hermann in particular is influenced by Dostoevskii's Goliadkin from The Double. Goliadkin, a petty clerk, is quickly replaced at his place of work by his double, so to say, another Goliadkin, who is smarter and much more brutally ruthless. This is very troubling for the original Goliadkin, who eventually goes insane. It is rather unclear whether a real double exists or if this is just the perception of a rapidly deteriorating mind, an issue that Nabokov quite clearly found intriguing. ${ }^{46}$

Nabokov added a mock-ironic attack on Dostoevskii and Goliadkin in his English translation of Despair, which was more or less absent in the Russian hypotext. ${ }^{47}$ During his literary career, Nabokov regularly displayed complete cynicism for many of Dostoevskii's ideas and motifs. The most evident is Nabokov's criticism of Dostoevskii's troubled literary personae and their desperate attempts to escape their social positions, psychological limitations, and torturous pasts. Possibly this is one of the reasons that Nabokov's (and in turn Fassbinder's) Despair could have been regarded as a gloomy Dostoevskian mock parody. ${ }^{48}$ In fact, we find the name of Dostoevskii ironically pronounced in the second part of the film:

What do you think, Mr. Weber? Hmm? The murder mystery. Oh, I'm afraid I gave up reading those a long, long time ago. Over the years ... Conan Doyle, Dostoevsky, Edgar Wallace. So childish! All that worrying about clues and alibis. ${ }^{49}$ 
Dostoevskii and his "poor detective fiction" are the constant object of Nabokov's negative presentiment and resentment, which seems to play well with Fassbinder's overall mocking stylization as expressed in the movie. Joking about the novel's title, Nabokov writes in the final chapter of his text: "What should I call my book then? 'The Double'? But Russian literature possessed one already. 'Crime and Pun'? Not bad—a little crude, though. 'The Mirror'? 'Portrait of the Artist in a Mirror'?" ${ }^{50}$ By just one short passage he seems to satirize Gogol, Dostoevskii, and even James Joyce altogether (those who by virtue of their erudition are able to understand will enjoy, others who lack this faculty will wonder in a pitiable bewilderment).

Proceeding in the same direction, strengthening the obsessive "doubles" that are already present in Nabokov's text, Fassbinder also engages this doppelgänger motif, adding his own characteristic twist to this identity crisis. In Nabokov's text, Hermann carefully prepares a special life insurance policy in order to try to benefit from the future assassination of his alleged "physicospiritual double." It is only at the very end of the novel that it becomes rather clear that Hermann's double is a figment of his demented imagination and looks nothing like him according to the official police point of view. Fassbinder, working in a visual medium, could not delay the issue of the double's (in)congruency, forcing him to reimagine this dilemma for the cinema. It has been reported that Fassbinder originally planned to use Bogarde for both characters, but then decided to have Bogarde play only Hermann. Fassbinder invited another actor to impersonate Felix, Klaus Löwitsch, who looked nothing like Bogarde.

Nabokov intended to leave the issue of resemblance as opaque as possible, thus keeping his reader constantly guessing (Nabokov's favorite narratological "device"). Was it only Hermann Karlovich who was so delusional that he believed that Felix was his double? Did other people perceive a physical difference? Was there any affinity between the two? Nabokov does not give any concrete answers to these questions, preferring to leave this completely ambiguous right up to the end. Even then, the German police did not see much resemblance between the two, but maybe Felix's face and body were disfigured during his murder? Or maybe the officers, in order to close the case, simply deliberately refused to acknowledge the obvious similarity in Felix and Hermann (German)? Thinking on a related matter, playing with the various possibilities of the most appropriate title Nabokov ruminates: "what about 'The Likeness'? 'The Unrecognized Likeness'? 'Justification of a Likeness'? No-dryish, with a touch of the philosophical. Something on the lines of 'Only the Blind Do Not Kill'?'51

In Nabokov's hypotext it remains extremely vague and provocatively suggestive as regards the "real" state of affairs of Hermann's physical resemblance with Felix. Hermann Karlovich playfully laments that the police did not want 


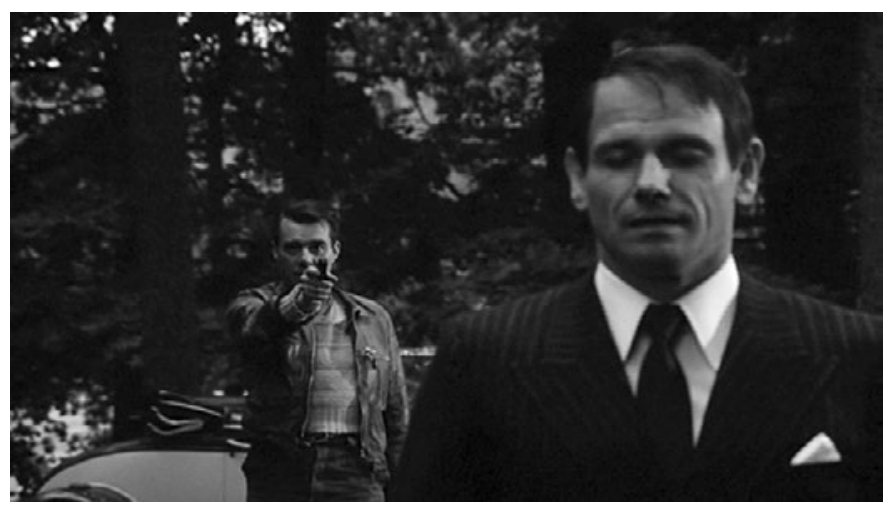

Figure I0.5 The scene of the murder. Hermann kills Felix, his imaginary double.

to focus on his obvious similarities with the deceased Felix, trying (on the contrary) to stress their physical minor differences. Nabokov writes:

Not only taking for granted, with strange prejudication, that the dead man could not be I; not only failing to observe our resemblance, but, as it were, a priori, excluding its possibility (for people do not see what they are loath to see), the police gave a brilliant example of logic when they expressed their surprise at my having hoped to deceive the world simply by dressing up in my clothes an individual who was not in the least like me. The imbecility and blatant unfairness of such reasoning are highly comic ... In getting into their heads that it was not my corpse, they behaved just as a literary critic does ... faced by the miracle of Felix's resemblance to me, they hurled themselves upon such small and quite immaterial blemishes as would, given a deeper and finer attitude towards my masterpiece, pass unnoticed, the way a beautiful book is not in the least impaired by a misprint or a slip of the pen. They mentioned the roughness of the hands, they even sought out some horny growth of the gravest significance, noting, nevertheless, the neatness of the nails on all four extremities. ${ }^{52}$

Here Nabokov does everything in his power to show the blurred boundaries between Hermann and Felix, to underline their confused closeness which evaporated only because of the police's intentional malice and ignorance. Nabokov implies that any objective and unbiased watcher/observer would not fail to notice the very close resemblance that allegedly existed between the two.

Yet, Fassbinder eliminates any possible ambiguity immediately and directs the cinematic attention to the mental (in)stability of the film's protagonist. He then further complicates the issue with the theme of Jewish homosexuality, mentioned above, in which there is a hidden desire to appear as someone 
else, someone normal, employing an invented identity at a time when Jews of all types were attempting to hide in plain sight from Nazi scrutiny. Unfortunately, the movie does not provide one single scene in which all of these themes-Nazism, Jewish identity, and homosexual desire-come together. We can only unite them within one conceptual continuum in our mind as a viable hermeneutic critique crafted in order to convincingly interpret this film ad hoc as a whole.

Situated in the increasingly hostile German reality and seeking an existence of some sort, Hermann addresses Felix in Fassbinder's hypertext and tries to persuade him to take part in the enterprise on his behalf:

Felix, please. Felix, Felix, now ... now listen. Do you know what a double is? .. A double, Felix, is a person who, in an emergency, can stand in ... for a given actor. ... I've walked a long way to meet you ... What do I find?-Filth! Actors ... actresses ... pimps ... harlots ...

Hermann is desperately searching for such a double that would fit easily in the context of a future "role." However, the very context of their meeting dictates a chain of associated metaphors and allusions, which are linked with pimps and harlots. This indeed seems quite suggestive and also touches upon the overall deviant erotic theme that is explored by Fassbinder in many of his movies.

Inherent in this discussion of actors and harlots is an identification of Felix and Hermann with individuals who provide false identities for a specific audience. This particular association again investigates issues of class, social status, and power, or how homosexual desire is reflected as deviant criminality within the film. The male-female relationship in most cultures is usually defined as a single gender with a marginalized subset. ${ }^{53}$ Here, Felix is a "stand-in" for Hermann - not much more than a filthy prostitute in Hermann's opinion. As noted by Eve Kosofsky Sedgwick, the male-male relationship is usually maintained as two distinct individuals, while the male-female relationship is organized as a united couple. Hermann's desire to see Felix as his double is probably only a weak attempt to unite with Felix as his androgynous twin, as his ideal pair, a divine lover. Obviously Felix is incapable of accommodating such high hopes, being nothing but a plain uneducated day-worker. Hence his destiny to pass away (from Hermann's point of view) can be only logical.

Lydia's promiscuity complicates Hermann's deteriorating mental condition. His psychological dissonance is confounded by imagined brutally energetic intercourse with his voluptuous wife. During this process his "estranged persona" is quietly present, patiently staring, creating a remarkably voyeuristic scene. This obsessive scopophilic process of voyeurism informs Hermann's stumbling state of nervousness and dysfunctional unwellness. Alienation or a "dissociated personality" disorder, as Thomas Elsaesser suggests, should be 
the key concept in this respect, and it is no coincidence that Fassbinder decides to reinforce that estrangement by adding the Jewish aspect to Hermann's identity. As is noted above, the murder of Felix represents a "symbolic suicide," in which Hermann can effectively punish himself — simultaneously assuming the role of alleged dominance and painful submission.

In the final dramatic scene of the movie, Hermann Hermann tells the viewers about his hidden inclinations and passions. "I am a film actor. I am coming out. Don't look at the camera. I am coming out." ${ }^{54}$ Brigitte Peucker has noted that Bogarde himself is, in some sense, "coming out" as a homosexual, and perhaps Fassbinder for his own part is also doing the same thing by creating a sort of self-identification with the main protagonist of the story. Fassbinder is potentially associating himself with Hermann's "closeted" desire impersonated by Bogarde's dramatic play..$^{55}$ But even more meaningful is that we ought to perceive Hermann's performed monologue rather "literally." Hermann as played by Bogarde and directed by Fassbinder appears to be a really potent, "transgressive" character who is able to exist beyond the traditional boundaries of the artistic text. The "cinematic text" is hermeneutically grasped here in the Ricoeurian fashion as a "meaningful event" standing on its own discursive right, ${ }^{56}$ as if "the screen has become permeable, and the [filmic] image is leaving the screen as the actor." ${ }^{57}$ Fassbinder discursively relates his main protagonist's troubled mental state with what is the German "diseased social order" - one that should be forcibly cured in its turn. ${ }^{58}$ If Germany is ill beyond any reparation or cure, then how can anyone living in this country be saved? The German director expands on these ideas of "liberation and anarchy" in a particularly important text titled: "Of Despair, and the Courage to Recognize a Utopia and to Open Yourself Up to It," ${ }^{59}$ which can be read along with the film itself. This text offers several possible insights for dealing with the movie as well, being, however, quite remote from Nabokov's core idea of doubles, mirrors, and madness.

\section{CONCLUDING REMARKS}

At issue is the desire of Hermann to achieve a new and alternative life in both the textual and cinematic versions. The most obvious reason for Hermann's murder of Felix involves an economic motive. Hermann's chocolate factory is heavily in debt and he hopes to recover the insurance money once his (really Felix's) body is discovered, so that he can live comfortably in Switzerland. In so doing, Hermann would also be able to end his failed marriage to Lydia. By killing his outdated identity, Hermann endeavors to commit an ideal murder and, in this way, to give birth to a new self - one that might live in the relative safety of a neutral country, away from the social and political repression of Nazi Germany. ${ }^{60}$ 
Nabokov exploited the themes of homosexual desire and mental illness in Pale Fire in 1962. In Despair, these themes remain just below the surface. In Fassbinder's adaptation, the possibilities for Hermann's mental collapse are augmented by the psychological pressures of sexual and religious identity. In this version, murder not only allows Hermann to escape financial troubles, but it might also assist him with his sexual liberation. Yet, in both the textual and the cinematic versions, Hermann eventually loses his case and (in the ruthless hands of the German police) is forced to admit his ultimate personal failure.

One may conclude that as a cinematic hypertext, Despair offers a playful intersection of the two attitudes of its creators, Nabokov and Fassbinder. ${ }^{61}$ Despite their ultimate differences, they do share a number of important features, such as their profound interest in the matter of human doubles, as well as their brave exploration of the various puzzles of human sexuality and its possible conceptual borders. More directly, Fassbinder's hypertext, upon relocation within Nazi Germany, allows for a more intricate cultural map of sexual and religious identity.

\section{NOTES}

I. On the movie, see in particular Ruppert, "Fassbinder's Despair"; Plater, "Fassbinder's 'Despair"; Elsaesser, "Murder, Merger, Suicide”; Chamberlin, "Emigrating to Madness"; Burdick, "The Line Down the Middle."

2. On Despair's various interpretations and allusions, see in particular Dolinin, "The Caning of Modernist Profaners"; Smock, "Mistaken Identities"; Troubetzkoy, "Vladimir Nabokov's 'Despair"; Golynko, "Favority otchaianiia"; Anemone, "Nabokov's 'Despair”; Smirnov et al., Hypertext; Saburova, "Avtor i geroi v romane 'Otchaianie' V. Nabokova”; Egorova, "Igra slov v romane Nabokova 'Otchaianie”; Lachmann, "Semiotika mistifikatsii”; Arana, “"The Line Down the Middle' in Autobiography”; Luxemburg, "Koshmary Germana Karlovicha”; Glynn, Despair; Arsen'eva, "Eksplitsitnyi i implitsitnyi metatekst v romane V. Nabokova 'Otchaianie"; Carroll, "The Cartesian Nightmare of Despair”; Connolly, "The Function of Literary Allusion in Nabokov's 'Despair”; Kimney, "The Three Voices of Nabokov's 'Despair'."

3. See the especially fascinating scholarship of Brigitte Peucker.

4. Mazierska, "Escape into a Different Person, Escape into a Different Reality"; Elsaesser, "Murder, Merger, Suicide."

5. See her collection rendered in Savchenkova, "Kruglyi stol 'Portret avtora v zerkale: Fassbinder i Nabokov.' 'Otchaianie'.” See also a German/Russian collection edited by Igor P. Smirnov and his various colleagues: Smirnov et al., Hypertext.

6. It has been reported that the two quarreled over the process of filmmaking. This is given some credence as Fassbinder's film has largely disregarded some of Stoppard's concerns. See this discussed in detail in Watson, "Rewriting Nabokov," I94; this is also mentioned by Peucker, The Material Image, 291. For additional information see also Chamberlin, "Emigrating to Madness."

7. Peucker, The Material Image, $29 \mathrm{I}$.

8. Nabokov's poetry is of somewhat less notable quality than is his widely celebrated prose. 
9. Nabokov spoke nearly fluent English with the help of a nanny at a very young age—long before his arrival at the University of Cambridge.

Io. Nabokov was denied a position at Harvard after Roman Jakobson, who chaired the search committee, apocryphally remarked that Harvard must not let elephants teach the zoology of elephants.

I I. Fassbinder never formally studied cinematography and did not hold any official qualifications as a film director.

I2. Kinik, "Rainer Werner Fassbinder's Curious Dialectic of Enlightenment," 290.

I3. Tyson, "LOLA."

I4. See in particular Vicari, "Fragments of Utopia" and Calandra, "Politicized Theatre."

I 5. Nabokov's own attitude toward homosexuality represents a separate topic, which is rather problematic and difficult to engage in this particular essay. In the simplest terms, homosexuality and sexual proclivities in general gain a greater place in his later novels, Lolita, Pale Fire, and $A d a$, but remain undercurrents in some of his earliest works, including Despair.

I6. On this issue see Urban, Vladimir Nabokov.

I7. Wyllie, Nabokov at the Movies; Appel, Nabokov's Dark Cinema. See also Melnikova, "The Gorris Defence, or Nabokov on Screen"; Frank, Nabokov's Theatrical Imagination.

I8. Leving, "Filming Nabokov," 8.

I9. Yakir, "The Director Explains"; quoted also in Peucker, The Material Image, 29I.

20. Govedić, "When the Eye Refuses to Blind Itself," 237.

2I. These same issues are examined regarding Pavel Lungin's film Taxi Blues: see Ioffe and White, "Taxi Blues."

22. Oosterhuis, Stepchildren of Nature, $245^{-8}$.

23. Ibid., 245-8.

24. For more on this, see White, Degeneration, decadence, and disease.

25. Spencer, Homosexuality in History, 304-5. Originally written with John Addington Symonds, the book was finished by Ellis after Symonds's death. Symonds's family was outraged and his name was removed from the English language version published in 1897 .

26. Healy, "What Can We Learn From the History of Homosexuality in Russia?"

27. On this topic see Rozec, Le IIIe Reich et les homosexuels.

28. On this topic see the valuable collection in Barron, "Degenerate Art."

29. This film is based on Jean Genet's I 947 provocative queer-themed novel Querelle de Brest, making it Fassbinder's last movie (it was posthumously released in June I982).

30. LaValley, "The Gay Liberation of Rainer Werner Fassbinder."

31. Heger, The Men with the Pink Triangle.

32. Spurlin, Lost Intimacies.

33. Vasilii Rozanov ( $185^{6}$-I9I9) was one of the most influential essayists of Russia's Silver Age. He was especially prolific on many controversial subjects such as gender, family life, nationhood, sex, and religion. Being a steady supporter of family procreation as the only hope of humankind, he was a passionate accuser of homosexuality in its various cultural expressions.

34. Rozanov, Liudy lunnogo sveta, 27-39.

35. This particular depiction is not unknown within medievalist scholarship, notably Caroline Walker Bynum's study fesus as Mother.

36. Elsaesser, "Murder, Merger, Suicide," 75-6.

37. On this see Watson, Understanding Rainer Werner Fassbinder, 253-4.

38. Baer, Schlafen kann ich, wenn ich tot bin, $\mathbf{I}^{\mathbf{2}-3}$.

39. See for instance Smalls, Homosexuality in Art, 49. 
40. Ioffe, "The Discourses of Love."

4I. See the context described in Mazierska, "Escape into a Different Person, Escape into a Different Reality."

42. Nabokov, Despair, I27.

43. As described in media dispersed at the Cannes Film Festival.

44. The most recent collection on this subject is Alyssa Dinega Gillespie's valuable volume, Taboo Pushkin.

45. Grishakova, The Models of Space, Time and Vision in V. Nabokov's Fiction, 77-8.

46. For more on this, see Patterson, "Nabokov's Use of Dostoevsky."

47. We can relate Nabokov's attitude regarding Dostoevskii to the unique Russian tradition of stiob: an indigenous Russian mocking irony of a peculiar intellectual form. On Nabokov's critique of Dostoevskii in Despair, see essays by Connolly, "Dostoevsky and Vladimir Nabokov" as well as Dolinin, "Nabokov, Dostoevsky, and 'Dostoevskyness'."

48. See on that matter once more Connolly, "Dostoevsky and Vladimir Nabokov" and Dolinin, "Nabokov, Dostoevsky, and 'Dostoevskyness'."

49. On Nabokov's mocking of the detective genre and Conan Doyle in particular see Oakley, "Disturbing Design."

50. Nabokov, Despair, 237.

5I. Ibid., 237.

52. Ibid., 249 .

53. Sedgwick, Between Men, 47.

54. Nabokov's final phrase in the novel reads as follows: "Les preneurs de vues, my technicians and armed advisers are already among you. Attention! I want a clean getaway. That's all. Thank you. I'm coming out now." Nabokov, Despair, 2 I 7.

55. This tendency will be reinforced in creating the film In a Year of Thirteen Moons, which bears obvious autobiographical homosexual features. This film (In einem fahr mit I3 Monden) was created in 1978 and is related to the suicide of Fassbinder's intimate friend Armin Meier. The movie depicts the sad story of a certain transsexual person Elvira who once was Erwin.

56. Ricoeur, "The Model of the Text."

57. Peucker, "In Despair," 308-9.

58. For a good scholarly study of Fassbinder's troubled relations with his homeland, see Elsaesser, Fassbinder's Germany.

59. Fassbinder, The Anarchy of Imagination.

6o. Trubetzkoy, L'Ombre et la différence. For an alternative critical and philosophical view, see Sartre, "Despair by Vladimir Nabokov."

6r. On this matter, see Savchenkova, "Kruglyi stol 'Portret avtora v zerkale: Fassbinder i Nabokov.' 'Otchaianie"' for a more elaborated and detailed argument. 


\section{"The Soviet Abroad (That We Lost)": The Fate of Vasilii Aksenov's Cult Novel A Starry Ticket on Paper and on Screen}

Otto Boele

$\mathrm{O}$ ne piece of information with which we like to startle our students when teaching film and adaptation theory is that at least half of all films produced worldwide can trace their origin to some literary text. Statistically, one out of two movies we watch is not a "film," but a "book-to-film adaptation."1 Usually, we like to add another piece of information that is equally revealing, namely that quite often successful and popular films are based on mediocre and forgotten novels. How many people are aware of the fact that it was a short story by Daphne du Maurier (1952) that inspired Alfred Hitchcock to make his classic The Birds (1963)? How many Western viewers of Andrei Tarkovskii's Stalker (I979) are familiar with the sci-fi novel by the Strugatskii brothers on which it is based? ${ }^{2}$

If the one-out-of-two-films argument is intended to trigger preconceived notions about the superiority of literature, the film-might-be-better-thanthe-book argument has the opposite function: It questions the primacy of literature and, by implication, the "derivative" nature of film adaptions. Is the difference between the two really that substantial, especially where the perception of the viewer is concerned? Is not the lasting popularity of films based on forgotten novels evidence of their artistic self-sufficiency and independence from their source texts?

Posing these questions in such general terms may be a legitimate way of starting a theoretical discussion in class, but what about the specific historical context in which film adaptations are produced and then received? Some novels (or plays for that matter) may initially enjoy considerable success and then be eclipsed by their screen versions. In Russian cinema, the classic example is 
The Cranes Are Flying (I957), based on Viktor Rozov's moderately successful play Forever Alive (1956), which earned such international accolades that the source text was almost entirely forgotten. A forgotten text, however, can also be "resurrected" when it is successfully adapted for the screen. This is what happened to Fridrikh Gorenshtein's novel Expiation (1967) when Aleksandr Proshkin used it for his critically acclaimed 2012 film, thereby reintroducing to a wider audience a writer who had been known only among a small circle of samizdat specialists. ${ }^{3}$

What these examples tell us is that the presence of a book lurking behind a film adaptation is perceived at various times in varying degrees of intensity and that it can even be completely annulled. Thirty- or forty-year-old film adaptations showing contemporary life "back then" may be valued by subsequent generations of viewers as historical documents, rather than as faithful or creative screen versions of some literary original. Indeed, as I hope to show in this chapter, post-Soviet viewers of the 1962 film My Younger Brother, an adaptation of Vasilii Aksenov's cult novel $A$ Starry Ticket (I96r), ${ }^{4}$ appear to be less interested in discussing the differences between the hypertext and the original than in vicariously experiencing "the time when my parents were young," as one viewer put it. ${ }^{5}$ Owing to the richness of its audio-visual possibilities, film is arguably better equipped than literature to facilitate such an experience offering not only visual, but verbal and aural information as well. ${ }^{6}$ The setting of My Younger Brother (Estonia, then still a part of the Soviet Union), the main actors (stars at a later stage of their careers, but making their debut in this film), and the lavish use of diegetic and non-diegetic music add to the film's overall impression of a "window to the past," a snapshot of the "Soviet abroad that we lost." While still looking at a book-to-film adaptation, today's Russian viewers seem to experience My Younger Brother primarily as a crossing of both temporal and national borders and less as an engagement with Aksenov's novel.

In what follows, I will corroborate the above thesis, amongst others, by scrutinizing viewer reactions on kino-teatr.ru, a Russian cinephilic website where viewers can not only download films, but also discuss them, and exchange anecdotes, facts, and opinions, thus "creating and sustaining cinema/cultural memory." 8 In order to do so, however, I must begin by examining the production history of $M y$ Younger Brother, in particular the ideologically motivated changes that Aksenov (one of the co-authors of the screenplay) was forced to accept. Here we touch on an aspect of film adaptation that, to my knowledge, adaptation theory has not really addressed, focusing its attention mostly on Western film and the technicalities of film adaptation. That overlooked aspect is the ideological vigilance of the Soviet state and its power to oversee and interfere with the very process of film adaptation. My Younger Brother presents itself as a rewarding case study, allowing us to see how state officials 
could exercise "damage control" by having a controversial novel turned into a relatively harmless film and how these acts of ideological fine-tuning mostly go unnoticed or are ignored by post-Soviet viewers.

\section{A STARRY TICKET AND THE SOVIET YOUTH NOVEL}

Beginning in the mid-I950s and continuing into the early I960s, Soviet literature saw the emergence of the so-called "youth novel." To define it as an entirely new genre would be an overstatement since it continued to rely on the master plot of socialist realism, including such motifs as the rite of passage (by which the hero passes from a state of "spontaneity" to one of "consciousness") and the supporting figure of the mentor who provides the hero with moral guidance. ${ }^{9}$ The youth novel is different from "classical" socialist realism, however, in that it features a very young protagonist (usually a high school graduate) and that the movement of the plot, in contrast to the hackneyed stories of high Stalinism, is "centrifugal"; the hero, a born Muscovite or Leningrader, decides to leave the capital and test himself by seeking employment at some construction site, usually in Siberia. Even if he does not settle permanently in his new environment (which he often does), but decides to return to Moscow or Leningrad and continue his education, the reader is left in no doubt that the hero has significantly matured and will soon become a worthy member of Soviet society.

Although the rise of the youth novel and youth theater during the Thaw has received its share of scholarly attention, it is often overlooked that a significant number of the most popular youth texts were swiftly adapted for the screen. Viktor Rozov's play Good Luck (I954), one of the biggest successes on stage in the I95os and one of the earliest texts to introduce the hero's flight from the center, was made into a film only two years after it premiered in the Central Children's Theater. ${ }^{10}$ The screen version of Aksenov's debut novel Colleagues was released in December 1962, less than three years after its initial publication. Preparations for the shooting of My Younger Brother began even before the novel was published in the literary journal Youth in the summer of I96r. If the production of film adaptations during the immediate postStalin years was dominated by early Soviet literature, then by the turn of the decade filmmakers increasingly turned to contemporary texts not only to capitalize on their success, but also sometimes to "correct" the ideological flaws of the hypotext. ${ }^{11}$ Not surprisingly, the practice of removing moral ambiguities was especially widespread in late Stalinism, but it was also adhered to during the most liberal spells of the Thaw.

Owing to the complexities of the production process, film was even more vulnerable to ideological interference than literature. If the publication of a 
novel could depend on the judgment of three or four individuals (including the authoritative voices of such chief editors as Valentin Kataev or Aleksandr Tvardovskii), the release of a film required the approval of a plethora of officials and organizations ranging from the studio director to the Secretary of the Komsomol, from the Cultural Section of the Central Committee to the KGB, and from the Minister of Culture to the Party leader himself. ${ }^{12}$ In $A$ Theory of Adaptation Linda Hutcheon poses the reasonable question: What exactly is adapted in a film adaptation and how is it done ${ }^{13}$ In the context of Soviet film we may want to add: What officials and organizations had a say in the process? The genre of the film adaptation put the authorities in a position to control the "damage" done by the publication of recent, controversial novels. This is true of the Thaw in general with its unstable political climate and its many inconsistent cultural policies; it is particularly true in the case of $A$ Starry Ticket/ My Younger Brother, the publication of which received a warm welcome from younger readers, but also provoked fierce criticism from high-ranking party officials, literary critics, and high school teachers.

A Starry Ticket tells the story of three high school graduates from Moscow who, much to the dismay of their parents, decide not to prepare for next year's entrance exams, but to take a well-deserved vacation in the city of Tallinn instead. Joining them at the last moment is their peer and aspiring actress Galia who has a crush on the central character of the trio, Dima Denisov. Boisterous and used to male friendships, Dima initially has trouble expressing his feelings for her, insisting provocatively that, like his friends, love should be "free." According to Alik Kramer, the intellectual of the group, the three young friends "only recognize the satisfaction of sexual requirements." 14

Made at the beginning of the story, statements like these are a clear reminder that the main characters are still immature and will have to change in order to become conscious Soviet citizens. Aksenov has Dima and his friends go through various trials that seem conducive to their maturation: shady offers from a black marketeer (which the trio resists), poker games gone wrong, and, worst of all, Galia's decision to leave Dima for an aging playwright. Eventually, the financial situation of the young tourists becomes so desperate that they must find jobs at a collective fishing farm, the final step, it would seem, toward acquiring "consciousness." For two of the three friends, the outcome of this confrontation with hard work follows established patterns. A would-be writer, Alik eventually comes to recognize the lacunae in his knowledge of Russian literature. He has not even read Anna Karenina and is now prepared to continue his education. Basketball player Iurii, the third member of the trio, wants to settle down in Tallinn, work as an apprentice at the Volta factory, and marry the local girl with whom he has fallen in love. Even Galia, who returns to Dima in the closing chapters, appears to be chastened by the events. She no longer hopes for a flying start to her acting career, which the aging playwright 
could have helped her to achieve, but seems prepared to enroll modestly in the Leningrad school of acting. Only Dima still has not found a clear goal in life. Echoing the official rhetoric of Soviet ideology, in the very last chapter he ironically concludes: "Dmitrii Denisov plans his life by chance ... What a fine subject that would make for a Komsomol debate." 15

Katerina Clark discusses $A$ Starry Ticket on an equal footing with Anatolii Kuznetsov's 1957 novel The Continuation of a Legend, the youth novel's "official progenitor," she contends. ${ }^{16}$ More recently, however, Aleksandr Prokhorov has argued that Aksenov's novel should not be seen as an attack on the epic wholeness of Stalinist literature, but rather as an ironic engagement with the very genre of the youth novel. ${ }^{17}$ It is telling, for example, that Dima and his friends poke fun at the symbols of Thaw culture and do not go to Siberia to work, but to Estonia, the most Western republic of the Soviet Union, simply to have a good time. ${ }^{18}$

Knowing how hostile the relations between Aksenov and the authorities would eventually become, we may be tempted to read too much irony into a novel that was completed in early i 96 I, more than a year before the Communist Party began its campaign to bring artists and writers more closely to heel. ${ }^{19} \mathrm{But}$ irony certainly plays a role in the depiction of the story's two potential mentor figures: the fisherman Igor Baulin, Dima's captain at the kolkhoz, and Dima's older brother Viktor, a promising young scientist. Igor possesses all the physical characteristics of the ideal Stalinist hero ("a man of cast-iron with steel jaw and armored concrete logic"20), but it is Dima who suggests-and who succeeds in persuading the crew - to refrain from drinking vodka at sea. If they stay completely sober, they may win the labor contest of the kolkhoz and be rewarded for it by going out on a big trawler on the Atlantic. Thus Igor and Dima temporarily swap roles. The subordinate tells his superior what to do and the superior complies.

Similarly, Dima's older brother, the ideal son and conformist Viktor, tries to talk him out of traveling to Estonia, advising him to channel his youthful energy in a more productive direction. As befitting a seventeen-year-old, Dima reacts by ridiculing his brother's bourgeois lifestyle and his reluctance to take any risks in life. But the irony of this situation is that it is precisely that which Viktor ends up doing. His personal dilemma — play it safe by defending his "old-school" dissertation or antagonize his institute by going public with his own ground-breaking experiments-is finally resolved in favor of the more rebellious option. Like Dima, whose independence he admires, Viktor decides to take a "first slippery step aside, off that straight main road prepared for me." 21 At the end of his report to the Science Council, the dramatic climax in Viktor's story, he demonstrates a defiance that we would more readily associate with Dima. Addressing the declared enemies of his recent work, he exclaims: "Anything new is a risk. But what of that? If we never risk anything, what will 
come of the work we are doing?" 22 What this means for Viktor's career remains obscure. He tragically and somewhat mysteriously dies in an airplane crash while on duty and yet here again we see that the distribution of the roles of mentor and disciple are reversed.

The failure of the mentor figures in A Starry Ticket is indicative of what is arguably the novel's main theme: the estrangement between generations in terms of cultural preferences and social practices. Dima and his friends mock the values of their parents and teachers by wearing jeans, listening to jazz and rock music, and by rejecting the strict labor ethos that society imposes on them. Viktor, who is ten years older, belongs to a different generation (at least in Dima's perception), but as a teenager he too listened to boogie-woogie on $\mathrm{X}$-ray film. Significantly, the generational conflict that divides his institute is not only about scholarly issues: Viktor's opponents also criticize him for once bringing a "painted-up hussy" to a party and "dancing the rock-'n'-roll with her." ${ }^{23}$ Most importantly, however, the character that could serve as Viktor's mentor, his immediate supervisor at the institute, does his pupil a disservice. He first supplies him with an unimaginative hypothesis for his dissertation and then advises him to go ahead with the defense anyway so as to secure a position at the institute. Encouraging careerism over scientific integrity, Viktor's supervisor is anything but a proper mentor. Once again, the novel appears to dispute the traditional role of the older generation as moral leader of the young.

Although some of the irony in Aksenov's novel may have been lost on its readers, for conservative critics there was plenty about which to feel offended. A Starry Ticket is the first Soviet novel in which youth is represented as speaking a language of its own, a vocabulary of slang words or "argotisms" incomprehensible to the older generation and therefore conducive to the creation of youth identity. The suggestion that Soviet youth, or at least a substantial part of it, talked like Dima and his friends was unacceptable to language purists who reacted by arguing that the characters were not representative of Soviet youth in general and that, consequently, there was no need to write about them; or that if Soviet youth did use slang, it had no place in high literature. Less conservative readers admitted that the characters were drawn from life, including their slang and infatuation with Western music, but they questioned Aksenov's eagerness to immortalize them in literature. The fact that Aksenov had devoted an entire novel to these youngsters raised the suspicion that the author approved of their walk of life and wanted to hold them up as a model for imitation.

Even more alarming than the use of youth vernacular in the novel was the very idea of a generational divide running through Soviet society. Although this would become a major issue only after the release of Marlen Khutsiev's film $I$ Am Twenty in 1964 (also a film about three young Muscovites), ${ }^{24} A$ Starry Ticket did significant groundwork, so to speak, by portraying parents 
and children as living in different worlds, but without necessarily condemning that situation. Dima's claim to autonomy is presented as quite legitimate, and the moral authority of his parents as practically non-existent. Both at readers' conferences and at the editorial office of Russian Writer, which was planning to publish the novel as a separate book edition, Aksenov was repeatedly criticized for depicting the members of the older generation as rude and primitive, while idolizing the waywardness of the young.

The novel's most disturbing aspect, however, was the lack of personal development in the main character, who fails to become the politically conscious and socially integrated individual that socialist realism liked to showcase. Even if it is undeniable that Dima has matured as a result of his experiences in Estonia, at the end of the novel he is as clueless about his future as he was at the beginning. When, two days after Viktor's funeral, Dima pays a visit to his old, already half-demolished apartment building, he discovers that the starry patch of sky that Viktor liked to gaze at from the window seat of his room resembles a punched railway ticket, a "starry ticket." Dima ponders the deeper significance of staring at the view his brother loved so much and concludes that Viktor's "starry ticket" is now his (a cliché of the Soviet novel: The mentor dies, but leaves a sign for the hero who will continue his work). ${ }^{25}$ This potentially solemn moment fails to instill in Dima the optimism and sense of direction with which the hero of the youth novel is usually rewarded. The very last sentence of the novel ("But to what destination would that ticket take me?") especially infuriated the critics, unpleasantly reminding them of Holden Caulfield, the teenage narrator and main character of The Catcher in the Rye, which had been published in the Soviet Union a year earlier. That American society was producing cynical good-for-nothings was only natural given the political system, but such a character was incompatible with Soviet reality, even if Aksenov was suggesting the opposite. As Evgeniia Levakovskaia, one of the editors of Russian Writer, put it in her in-house review in February I965:

Salinger's hero, also a young lad, is plunged into despair by the reality that surrounds him, but Salinger shows us the immediate events that lead his hero to this state. In the biography of Dima Denisov we are not presented with any such events and yet he constantly grumbles at everything. ${ }^{26}$

\section{FROM HYPOTEXT TO HYPERTEXT}

What options did the makers of the screen version, including Aksenov himself, have to preserve the spirit of the hypotext, while simultaneously preventing the myth of the big Soviet family from disintegrating altogether? How could 
they create a hero that was rough around the edges, youthfully rebellious, but not in a threatening manner? Not surprisingly, these options turned out to be very limited. In a 1993 interview, Aksenov stated that the Central Committee of Komsomol demanded that the hypertext be considerably different from the hypotext; if not, it would block its release. Such was the pressure on Aksenov-from Komsomol and from Nikita Khrushchev personally-that he publicly recanted, admitting that he had not succeeded yet in creating the positive hero and role model that his readers supposedly asked for. ${ }^{27}$ An obligatory exercise in self-criticism that today seems anything but convincing, the recantation in Truth testifies to how little leeway the filmmakers had when they turned to adapting $A$ Starry Ticket for the screen.

As Julian Graffy has shown, the generational conflict that is so crucial in the novel is successfully removed in the film by presenting the youthful rebellion of Dima and his friends as a natural stage in their maturation. ${ }^{28}$ Of crucial importance here are the characters of Igor and Viktor who take on the role of understanding adults and who, I would add, can influence the young, but cannot be influenced by them. In an invented scene toward the end of the film, Captain Igor Baulin praises the group for having "worked quite well" on the fishing farm, a compliment suggesting that they have developed from simple "phrasemongers" into real workers. Predictably, the episode in which Dima persuades Igor not to drink vodka was omitted in the film.

My Younger Brother does not simply smooth out the differences between the teenagers and the more mature twenty-somethings Igor and Viktor; it almost completely removes the older generation. Galia's mother almost violently wiping lipstick off her daughter's mouth, Iurii's father repeating several times that "we have used the rod too little, comrades," and finally, Dima's mother bemoaning the cruelty of children - all these reactions of the parents did not make it into the film. As a result, the group's stay in Tallinn looks more like a poorly planned, but essentially harmless vacation, than an attempt by teenagers to escape the stifling control of their parents. The only scene in the film in which generations do seem to clash is also substantially altered so as to dissociate Dima and his friends from "vulgar" Western culture. If in the novel Dima and Galia actually dance to rock 'n' roll music in the courtyard of the apartment building and Dima mocks one of the older tenants by inviting her to dance, then in the film this scene is reduced to a neighbors' quarrel over noise pollution that the trio merely happens to be witnessing.

Graffy has observed that the film's most significant departure from the hypotext lies in the reduction of Viktor's role. ${ }^{29}$ In the novel, he is as important as Dima, and they take turns narrating the story. By and large, this structure is preserved in the film: The narration in the first person by either Dima or Viktor is simply transposed by adding a voice-over. But if the novel lets us in on Viktor's personal and professional doubts - whether he should settle 
down and marry his girlfriend, how he should respond to Dima's scorn or the schemers at work - the cinematic hypertext marginalizes him to such an extent that these questions become irrelevant. He is simply Dima's older, more experienced brother. In the novel, Viktor's death is all the more shocking because Dima still feels ill-prepared for life (a point to which I will return); in the film, Viktor's death signals that he has fulfilled his function as mentor and that Dima will now take the next step on his path to maturity.

For Aksenov, the decision to reduce Viktor to a secondary character and turn him into a "function" of Dima's story must have been hard to swallow. At a readers' conference in September I96I, he had shown himself to be slightly annoyed at discovering that the discussion centered almost completely on Dima, whereas the character of Viktor was hardly brought up at all. The two brothers were equally important in the novel, Aksenov insisted, the influence between the two generations they represent being mutual: "No matter how strange it may seem, but it appears to me that the generation of 17 -year-olds exerts a significant influence on us." ${ }^{30}$ As we have seen, the ironical reversal of the mentor-pupil relationship is indeed one of the novel's more surprising aspects and one that was deemed unacceptable in the hypertext.

Once it was decided that the film would revolve around Dima and his friends, the main challenge was to deal with the hero's persistent lack of purpose in his life. Changing the title from A Starry Ticket to My Younger Brother seemed justified in light of Dima's central role, but it also removed the notion of a destination not yet reached. To further neutralize the inconclusiveness of the novel, the filmmakers also drastically changed the sequence of events. Dima's half-ironic words that he still has not worked out a "program for life," addressed to Viktor in the penultimate chapter of the novel, are moved considerably forward in the hypertext so as to set up a contrast between his immature behavior before his departure from Moscow and his more serious attitude toward life after his return. Thus, the trip to Tallinn becomes a logical step in a search for personal self-fulfillment.

Enhancing the goal-oriented direction of the plot even further is the removal of the very last sentence of the novel ("But to what destination would that ticket take me?"). Although the film too remains silent on exactly what Dima is going to do with his life, the closing shot makes it clear that he shares his friends' healthy optimism and looks at life more confidently than ever before. We see Dima, Alik, Iurii, and Galia slowly moving away from the rubble of the old apartment building in the direction of a construction site with new buildings and cranes. The shot shows the four friends walking from the bottom corner on the left of the screen to the top corner on the right so that they seem to be moving upward, presumably to some "higher goal." By using immediately recognizable images of progress and social renewal, the film replaces the ambiguous conclusion of the novel with a more optimistic open ending. 
Finally, the urge to both simplify and sanitize $A$ Starry Ticket manifested itself in the reduction of those dialogues that contained too much youth slang. At the readers' conference mentioned earlier, Aksenov had defended its functionality, claiming that the story would be unconvincing if Dima and his friends spoke standard Russian. Young readers present at the conference supported him, expressing their admiration for the novel and emphasizing that it was precisely the language that made them recognize it as a work of art "about us." According to one young reader, "A Starry Ticket is written in a truthful and true-to-life manner. And it's written in a language you will encounter in our milieu at every corner. (...) The majority of our peers support this work." 31 "From guys of my age I have heard only positive things about it (applause)." ${ }^{32}$ Probably for this reason, the officials (or Aksenov's co-authors of the scenario) deemed it necessary to intervene; youth slang, especially when it was directed at the characters' parents, was largely banned from the film. Kon' (literally "horse") as a derogative term for father and khata for apartment were banned, as was the distinctly stiliagi-like (or hipster-like) expression chuvikha ("girl," or rather "bird"); molotok (a pun on the generally acceptable molodets, "well done") and derzhi khvost pistoletom ("don't lose heart") were preserved.

Considering all these excisions and adjustments, how successful was $M y$ Younger Brother? With twenty-three million tickets sold, its performance at the box office was not impressive; it certainly did worse than the screen version of Aksenov's debut novel Colleagues, which sold over thirty-five million tickets. On the other hand, these figures tell us little about how the film was received by those viewers who actually went to see it. It is possible that, because My Younger Brother was based on a controversial novel, it received a considerably lower rating, and consequently, was less widely distributed. Kristin Roth-Ey points out that limiting distribution practically guaranteed small audiences and that the authorities employed this strategy throughout the post-war period ${ }^{33}$ Possibly, this was also the case with My Younger Brother.

Limiting ourselves for the moment to the reactions of officials and critics, we observe that these professionals were usually highly outspoken, and in most cases, negative. Graffy adduces two diametrically opposed reactions, one from Art of Cinema critic Vera Shitova who thought that the film was far more naive and "good-natured" than the novel, and one from two conservative critics of Our Contemporary who rejected the film on the grounds that, in their opinion, the characters had preserved their irresponsibility. ${ }^{34}$ The critic of Soviet Screen also considered My Younger Brother a failure as it offered only visual "illustrations of the novel," but no real insight into the characters' inner lives. Oleg Dal', who played Alik, was nonetheless complimented on his performance, as was cameraman Anatolii Petritskii. ${ }^{35}$ In Soviet Culture, critic Vadim Sokolov came to a similar verdict. Claiming to be uninterested in the film as an adaptation, he concluded that the makers had not succeeded in showing what makes 
the characters tick. As a tool to explain and understand contemporary Soviet society, My Younger Brother was anything but a success. ${ }^{36}$

Perhaps the only critic to like the film better than the novel was writer Lev Kassil', author of numerous books for children and adolescents, and an outspoken critic of stiliachestvo (or hipster culture) and "bad taste" on the pages of Youth ${ }^{37}$ Although Kassil' also would have preferred to see Viktor being allocated more screen time, he complimented the makers for ignoring the "stiliagi [hipster] lexicon" and for explicitly passing judgment on such "deviations in language and behavior." Particularly the phrase "We dread banalities and therefore we are afraid of simplicity," Kassil' argued, was quite an improvement. Absent in the original, "this very profound, wise and accurate thought provides the key to a correct understanding of this work" (i.e., A Starry Ticket). Kassil' also had no doubt that Dima fully understood the significance of Viktor's starry ticket being bequeathed to him as he was now aware of the responsibility resting on the shoulders of his generation. ${ }^{38}$ Published in Truth and expressing the Party line, the review by Kassil' was soon promoted as the only correct interpretation of the film. At a meeting between young writers and the Ideological Commission of the Central Committee in December I962, Committee Chairman Leonid Ilichev praised Aksenov for having put the criticism of $A$ Starry Ticket to good use by adding a few "specifications and corrections" to the film. To contradict those writers and critics who continued to favor the book over the film, Ilichev explicitly referred to the review by Kassil' in Truth in which the main characters were given "a more proper assessment." 39

Understandably, Aksenov himself was disappointed, especially because he felt that he had let the audience down. In his own words, readers were shocked at the "outrage committed against our novel." ${ }^{40}$ Determined not to make any further compromises, Aksenov then refused to rewrite the novel for Soviet Writer, the publishing house with which he had signed a contract for a separate book edition in July I962. Over the course of three years, he missed several deadlines and when he finally submitted the manuscript in January 1965, the publisher received only one copy instead of the two to which he was entitled, which delayed the reviewing and editing process even further. At this point, Soviet Writer even threatened to cancel the contract. It is unknown if Aksenov eventually complied and sent a second copy, but the in-house reviews written as late as 1965 and 1967 reveal that the author had made no substantial changes to enhance the novel's political reliability. On the contrary, growing more peevish as the negotiations dragged on, Aksenov even managed to squeeze in a reference to the infamous exhibition of abstract art at the Manege exhibition hall that took place in December 1962, more than a year and a half after the publication of $A$ Starry Ticket in Youth. ${ }^{41}$ What ensued was a stalemate: The editors demanded that Aksenov rework 
the novel; Aksenov stubbornly refused. This situation lasted until I970 when the entire manuscript was sent back to the author. In Russia, A Starry Ticket would never be published as a separate edition until the breakup of the Soviet Union.

\section{MY YOUNGER BROTHER FIFTY YEARS ON}

In the previous section, I concentrated on the published reactions to the film, positive or negative, suggesting that they might not have entirely coincided with the full spectrum of possible responses from ordinary viewers. Was $M y$ Younger Brother really a failure, as most of Aksenov's supporters seem to have claimed, or was it an improvement, as Lev Kassil' wanted his readers to believe? Were the admirers of $A$ Starry Ticket really that outraged when they saw its adaptation for the screen? According to Aksenov, they were, but he was looking back from a distance of thirty years when he made this comment, and the reaction he registered may not have been characteristic of the audience in general.

Though it is impossible to reconstruct the film's reception by ordinary viewers when it was released, thanks to the discussion lists now available on the Internet, at least some first-hand impressions can be accessed. While those viewers who were genuinely disappointed by $M y$ Younger Brother in the early I96os may not want to discuss the film, the variegated reactions that were posted by other early viewers on kino-teatr.ru suggest that the general reception was more positive than Aksenov remembered it to be. One "vladimir grechko" remembers reading $A$ Starry Ticket in I96I when he was still a high school student. Even if he did perceive the cinematic hypertext as "something secondary," he still liked it: "It was impossible not to like it by definition." 42 Another list member writing under the alias "SneP" admits having been "too young" to understand what the film was about when he saw it at the age of ten in I962, but "[the music by Mikael Tariverdiev] moved me so much that I went to see the film again the very next day." ${ }^{43}$ Five months later, SneP posted a more forthright reaction in which he stated that the hypertext's release in I962 "was a real event." "Perhaps this was the first time (Soviet) youth was shown as it really was and not as the ideologues wanted to see it." 44

Of course, it is ironic that the hypertext could be perceived (or is now remembered) as not complying with the ideological demands of Party officials, considering that men such as Ilichev and Kassil' favored the adaptation over the hypotext. But SneP's comment is also interesting for another reason: It shows that the film has come to share the subversive aura of the novel and is no longer perceived as a bleak adaptation of it. For Russian viewers watching the film today, My Younger Brother is a way of engaging with or reliving the Soviet 
past, a sensation that is fueled as much by Tariverdiev's extraordinary music as by black-and-white images of a former Soviet republic. Characteristically, most comments do not mention the novel at all, centering instead on the moods and memories that the hypertext triggers: "Nice film, nice ... reflecting the calm, post-war realities of the Khrushchev area" (Zhravlik); "The film is absolutely not boring. In the ig6os it aroused an inexplicable subconscious bright sadness. Now it's nostalgia for those times" (Starikov Evgenii) ${ }^{46}$ "Nostalgia for those times when we weren't afraid to live. As a child you could travel somewhere with the greatest of ease. You could land a job, the union did not leave youth to your own devices" (Irina K.); "My favorite film of the I96os. After watching it you feel wings growing on your back and you want to run, no, fly somewhere and to hum Tariverdiev's beautiful melody" (Tori) ${ }^{48}$ Although a few members of the discussion list compare the film with the novel and are inclined to view the latter as "more honest, more truthful," they claim they can still value the hypertext as an independent work of cinematographic art (Evgenii Geindrikh). ${ }^{49}$

If the elated comments quoted above give the impression that My Younger Brother appeals mainly to "older" viewers with active memories of the early I96os, then quite a few admirers explicitly identify themselves as being born substantially later. "This is not only a film for the young generation of the I96os," a certain Oksana comments. "I watched it when I was seventeen (at the end of the 1990s)." 50 Sergei Dement'ev from Moscow, who was born in I984, regrets having missed that "wonderful time," but it did not prevent him from "literally falling in love with this film as an adolescent." ${ }^{51}$ For Evgenii Geindrikh, one of the most prolific commentators on the discussion list, Dement'ev's year of birth is an unpleasant reminder of his own advanced age: 'I read your reaction, Serezha, and I immediately felt 'ancient.' As a matter of fact, although I'm older than you are, I didn't see that blessed time either (I was born in 1967$). " 52$

The recognition that a once trendy film can also appeal to later generations is not unusual, of course. Browsing the discussion on Walking the Streets of Moscom, another youth film of the Thaw period, we find very similar comments that ooze nostalgia and favorably juxtapose the film to post-Soviet cinema. In this respect, Sudha Rajagopalan is absolutely right when she states that the site kino-teatr.ru provides the "tools to contribute to collective memory of old cinema." ${ }^{33}$ What is remarkable in the case of My Younger Brother, though, is that its link with its hypotext has become much weaker over the years so that it is no longer perceived as an adaptation. The beautiful shots of Tallinn's medieval town, Estonian beaches, and nightlife show a world from which Russian viewers are now separated by temporal and national borders. It is not the novel, but the assumed historical reality of the early ig6os that provides the framework for judging the hypertext. 
The question of whether My Younger Brother is true to the spirit of A Starry Ticket has been replaced by another one: Is the film historically accurate? To Evgenii Geindrikh, it apparently is. He thought Dima and Galia were very similar to his parents "both in age and in their way of thinking." ${ }^{54}$ The ensuing argument with a certain "ecva," who claimed that the film gave a distorted picture of life in the I96os and that Aksenov "had made it all up," 55 did not so much address the issue of fidelity as that of realism. Did Soviet youth really live it up in the early ig6os like Dima and his friends, or was this the privilege of a happy few? This question, which occupied critics and Komsomol officials fifty years ago, is still relevant today, only now it is the film rather than the novel that is seen as containing the answer.

\section{CONCLUSION}

On reflection, the adaptation of $A$ Starry Ticket resulted in the crossing of both temporal and spatial borders. In 1962, My Younger Brother was negatively impacted by the ever-changing political demands of the Soviet government. Elements of the hypotext, deemed politically acceptable at one moment during Krushchev's Thaw, were perceived as regrettable sometime after the refreeze. As for so many Soviet writers of the Thaw period, the constant vacillation between liberal and conservative cultural agendas within the Soviet government made the creative works of Aksenov constantly available for reevaluation. The borders between acceptable and unacceptable cultural and political positions were in a permanent state of flux. By the late I980s and certainly after the break-up of the Soviet Union, the political correctness of these works became less of an issue for discussion. Today, they are perceived as historical artifacts of a brief moment in Russian history-representative of the Thaw or, in particular, of temporal and spatial markers of the ig6os. The final point may be that My Younger Brother is just that, an invitation to take a journey through space and time, for students and film lovers to cross boundaries in order to relive a youth that no longer exists.

\section{NOTES}

I. Linda Hutcheon adduces even more impressive evidence. According to I992 statistics, 85 percent of all Oscar-winning Best Pictures are adaptations. Hutcheon with O'Flynn, A Theory of Adaptation, 4 .

2. Arkadii and Boris Strugatskii, Roadside Picnic. The novel was published in I97I.

3. For a discussion of Proshkin's film adaptation, see Boele, "Aleksandr Proshkin."

4. My Younger Brother, directed by Aleksandr Zarkhi, premiered on August 20, I962. <http:// www.kino-teatr.ru/kino/movie/sov/396o/annot/> (last accessed November 25, 20I3). 
5. <http://kino-teatr.ru/kino/movie/sov/3960/forum/print/>, no. 5I (last accessed March 3, 20I4). For the sake of convenience, I give the link to the print version (versiia dlia pechati) of this discussion list. This allows one to read all the reactions on one page instead of having to visit the electronic version on various pages. All reactions were checked for the last time on March 3, 20I4.

6. McFarlane, Novel to Film, 26; Leitch, "Twelve Fallacies in Contemporary Adaptation Theory," I 53-4.

7. "The Soviet abroad that we lost" is a term of my own invention combining the title of Stanislav Govorukhin's highly tendentious 1992 documentary The Russia That We Lost and the expression the "Soviet abroad" that designated Estonia when it was still a part of the Soviet Union. For a discussion of Estonia as a popular destination for Soviet tourists, see Anne Gorsuch's study All This Is Your World, 50-77.

8. Rajagopalan, "Kino-teatr.ru: contemporary cinephiles at work," $8 \mathrm{I}$.

9. Clark, The Soviet Novel, 226-8.

Io. For a discussion of Rozov's incredible success in the mid-I950s, see Manon van de Water, Moscom Theatres for Young People. The screen version of Good Luck premiered in February I957 (directed by Georgii Natanson and Anatolii Efros).

I I. Hutchings and Venitski, "Introduction, The ekranizatsiia in Russian Culture," Io.

I2. Roth-Ey, Moscom Prime Time, 30-2.

I3. Hutcheon with O'Flynn, $A$ Theory of Adaptation, 9-10.

I4. Aksenov, A Starry Ticket, 58.

I5. Ibid., 220 (original italics).

I6. Clark, The Soviet Novel, 228-9.

I7. Prokhorov, Unasledovannyi diskurs, 2 Iо-I I.

I8. Ibid., 2 I I.

I9. For a detailed discussion of this campaign, see Johnson, "The Politics of Soviet Culture, I962-I964," I-89.

20. Aksenov, A Starry Ticket, 174.

2I. Ibid., I42.

22. Ibid., I6o.

23. Ibid., I 54 .

24. On the generation issue in I Am Tmenty, see Buttafava, "Interview with Marlen Khutsiev," 28.

25. Clark, The Soviet Novel, 3 o.

26. Russian State Archive of Literature and Art (RGALI), f. I234, op. 20, d. 6I, 1. 7.

27. Vasilii Aksenov, "Search for a Positive Hero."

28. Graffy, "Film Adaptations of Aksenov," I I I-I 2.

29. Ibid., I I2.

30. RGALI, f. 2924, op. 2, ed. khr. $28,1.67$.

3I. RGALI, f. 2924, op. 2, ed. khr. 28, 1. 6 o.

32. RGALI, f. 2924, op. 2, ed. khr. 28, 1. 62. Some young readers were more ambivalent, however: "About the novel's language. In general I like it very much, it's part of life, but, of course, it's not the way in which you talk to your parents. We don't constantly talk like that among ourselves either, it's a bit exaggerated (in the novel) or it's done on purpose to emphasize. But I think it shouldn't be the norm (applause)." RGALI, f. 2924, op. 2, ed. khr. 28, 1. 57 .

33. Roth-Ey, Moscom Prime Time, $5^{2}$.

34. Graffy, "Film Adaptations of Aksenov," I I I-I 2.

35. Kuznetsov, "Starshie i mladshie ('moi mladshii brat')," I 9. 
36. Sokolov, “Mal'chiki iz 'Barselony,” 2.

37. See, for example, his article "Pogovorim o vkusakh."

38. Kassil', "Moi mladshii brat," 6.

39. "Iz stenogrammy zasedaniia Ideologicheskoi komissii TsK KPSS," 376.

40. Quoted from Graffy, "Film Adaptations of Aksenov," i I I. The information was taken from an interview with Aksenov on Channel One (Russian television) in the mid-I 99os.

4I. When Party Leader Nikita Khrushchev visited the "Thirty Years of Moscow Art" exhibition at the Manege exhibition hall, he was outraged by a collection of non-figurative paintings. His reaction has gone down in history as the signal for the "most far-reaching crack-down on the creative arts in the Soviet Union since the Zhdanov purge of

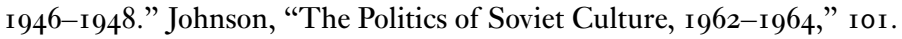

42. <http://kino-teatr.ru/kino/movie/sov/396o/forum/print/>, no. I6I (last accessed March 3, 20I4).

43. Ibid., no. 86 .

44. Ibid., no. 86 .

45. Ibid., no. 3

46. Ibid., no. 9 .

47. Ibid., no. Io.

48. Ibid., no. I2.

49. Ibid., no. $4 \mathrm{I}$.

50. Ibid., no. 5 I.

5I. Ibid., no. 2 I.

52. Ibid., no. 23.

53. Rajagopalan, "Kino-teatr.ru: contemporary cinephiles at work," 84 .

54. <http://kino-teatr.ru/kino/movie/sov/396o/forum/print/>, no. 3 I (last accessed March 3, 20I4).

55. Ibid., nos. 33, 34 . 


\section{Conclusion: \\ Passport Control \\ Departing on a Cinematic Journey}

Frederick H. White

R ussian literature has inspired film directors at home and abroad for over R a century, and continues to do so today. American, British, French, German, and Italian cinema all have important film classics that were drawn directly from Russian literature. Some, such as French filmmaker Robert Bresson or Japanese filmmaker Akira Kurosawa, turned to Russian writers more than once in creating their own distinctive cinematic style. Kurosawa reimagined Fedor Dostoevskii's The Idiot (Hakuchi, I95I); Maksim Gor'kii's Lomer Depths (Donzoko, I957); incorporated elements of Dostoevskii's The Insulted and Injured in his film Akahige (1965); and animated Vladimir Arsen'ev's autobiographical work Dersu Uzala (1972), which won the Academy Award for Best Foreign Language Film, for Mosfilm. Throughout the years, Russian directors have expressed their own admiration for the literary works of Dostoevskii, Anton Chekhov, Mikhail Bulgakov, Aleksandr Pushkin, Lev Tolstoi, Mikhail Sholokhov, and many, many others.

The topic of this collection of essays has been the cultural border crossings that occur when the text is transported to another country, another time, or both. Each one of these migrations involves a new semantic language. The metaphor of crossing from one temporal or spatial territory into another in which language, customs, cultural identity, social attitudes, and political systems are often different is applied in this case as Russian texts are transposed in order to suit new cinematic environments. Thomas Leitch borrows from Cristina Della Coletta in positing the idea of a cinematic border crossing as a process that enables viewers to gain a greater perspective on the world in which they live. This collection of essays confronts many of the matters involved in transporting a narrative into a narration, making the cinematic out of the theatrical, or expanding the short story into a full-length feature. Border Crossing: Russian Literature into Film explores the question of what makes Russian texts adaptable for such diverse audiences with dissimilar cultural sensibilities. This collection 
only touches the surface of a much larger topic, providing points of scholarly reference for around twenty films. The number of cinematic hypertexts is much greater and in this concluding chapter, a broad survey of the many films is provided, positioning the essays found in this collection into the larger, potential discussion to be had in the future. This is not an exhaustive survey of the topic, but should provide some perspective on future areas of scholarly exploration.

As the Introduction states, adaptation studies is still finding its way and our intention is to show that transpositions of cultural meaning offer a new layer for scholarly consideration. We acknowledge that our present excursion has been a short one, but we suggest in the following pages many more potential journeys for interested scholars and students. After all, border crossings involving Russian hypotexts cannot be reduced easily to a few examples. Therefore, this final chapter attempts to demonstrate the breadth of the subject and to position the present essays within a very large (and ever-expanding) scholarly territory. The selection of specific national cinemas (namely, the ones the contributors to this volume analyze) for discussion below is also arbitrary, but boundaries must be created to organize our discussion, just as the establishing of national borders is sometimes arbitrary. ${ }^{1}$

As a result, this concluding chapter provides several functions: (I) It offers a survey of the topic more broadly than might be possible in individual essays. (2) It situates the present essays within this larger context, recognizing that other films provide similar points of discussion. (3) It recognizes that border crossings are fraught with issues relating to language, national cultures, political histories, and much more that cannot be reduced to formulaic theories or final conclusions. Each new film based on a Russian hypotext opens new territories (new hypertexts) for consideration and provides a new set of temporal and spatial markers. (4) It posits that the adaptation of text into film must also consider many of the semantic issues of cultural meaning, how time and space influence that transposition, and how scholars can go beyond the fidelity issue in order to become more like tour guides, explaining the complexities of cultural meaning to those who employ a different cultural and semantic language. Just as a brief excursion to a foreign country often excites the tourist's senses and inspires future travel, this collection of essays is a brief introduction to all of the possible explorations, excursions, and trips that may be had in the future. Similar to a travel agent, this final chapter offers a guide for potential discoveries.

\section{RUSSIAN CINEMA}

Russian film production began with Aleksandr Drankov's Picturesque Russiashort documentary films about the lives of ethnic groups and their regional habits. This led to the first Russian feature in 1908 by Drankov's production 
company-Stenka Razin — which marked the birth of Russian cinema. At the same time other Russian production companies, often with foreign partners, began to produce their own films. Many producers turned to classical Russian literature, especially the works of Pushkin, Nikolai Gogol, and Chekhov. Ghost stories and romantic tales were particularly popular with Russian audiences. This early adaptation of poems and literary works was often for practical reasons - audiences already knew these stories, so there was no need to gain consent from the author and none of these published works aroused the attention of the censor. ${ }^{2}$ Paul Theimann's film company promoted a Golden Series of movies that were based on literary works, which included Anna Karenina, War and Peace, and the blockbuster The Keys to Happiness.

Iakov Protazanov became famous for his big-budget screen versions of literary works such as The Keys to Happiness (1913), War and Peace (I915), The Queen of Spades (1916), Father Sergius (1917), Aelita (1924), The Forty-First (1927), The Man from the Restaurant (1928), The White Eagle (1928), Ranks and People (1929), and Without Domry (I937). For cinematic material, Protazanov had turned to authors as diverse as Anastasiia Verbitskaia, Tolstoi, Pushkin, Aleksei Tolstoi, Boris Lavrenev, Ivan Shmelev, Leonid Andreev, Chekhov, and Aleksandr Ostrovskii. These were not the montage films of the Soviet avant-garde, but the "reactionary" and "socially primitive" films of a director who adapted the bourgeois traditions of pre-revolutionary Russia for the cinema that Soviet audiences actually wanted to see. ${ }^{3}$

In the I93os, even with the advent of Socialist Realism, the nineteenthcentury classics remained popular sources for Soviet films. Once again, Chekhov, Gogol, and Pushkin were the most frequent source texts for filmmakers, but even Dostoevskii, Mikhail Lermontov, Mikhail Saltykov-Shchedrin, and Ostrovskii were used as source material. In fact, some of the best films of the decade were hypertexts. Chapaev (1934) was drawn from Dmitrii Furmanov's novel. Grigorii Aleksandrov's Circus (1936) was a transposition of Il'ia I'lf and Evgenii Petrov's play Under the Big Top. Mark Donskoi's films were based on Gor'kii's autobiographical trilogy: The Childhood of Maksim Gor'kii (1938), My Apprenticeship (1939), and My Universities (1940).

In the present collection of essays, Alastair Renfrew illuminates how Iurii Tynianov amended his own literary work (based on an anecdote by Vladimir Dal') for the silver screen. The fact that Tynianov was a literary and film theorist makes this adaptation all the more intriguing. Under the influence of Gogol's short stories and the 1926 film version of his The Overcoat, Tynianov's Lieutenant Kizhe (1934) can be understood as a direct response to the vogue of transposing literary classics.

In the following decade, the war placed new pressures on the film industry. After Stalin's death, however, filmmakers experienced a reprieve of sorts and began making films about the individual experience. Even with this relative 


\section{MEЖРЯБП口М-РУСЬ}

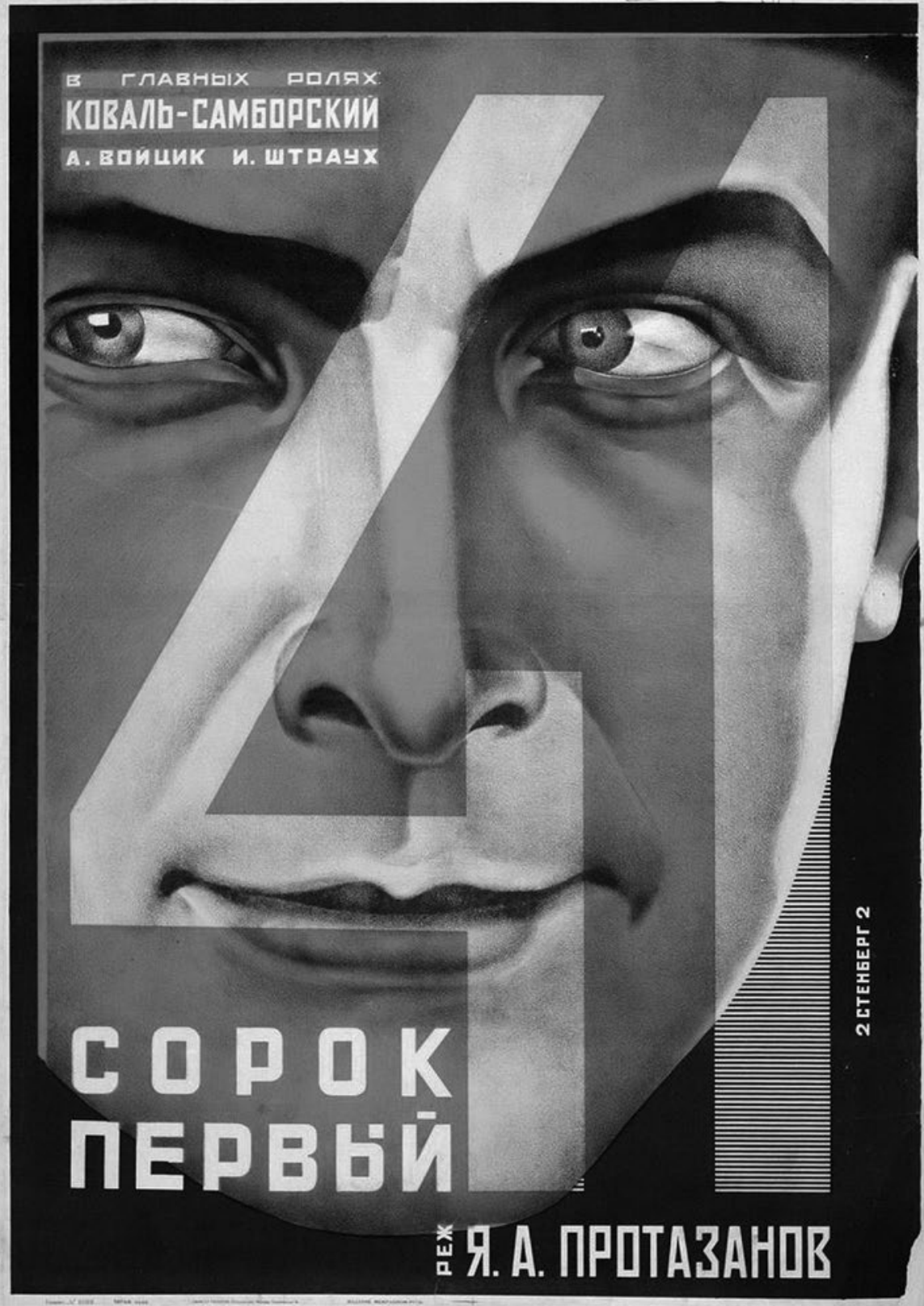

Figure C.I Movie poster for Iakov Protazanov's The Forty-First (I927). 
freedom, filmmakers continued to transport hypotexts to the silver screen. Of the four Civil War films created to commemorate the forty-fifth anniversary of the Revolution, only one was based on an original screenplay. Pavel Korchagin (1956) was a hypertext of Nikolai Ostrovskii's How the Steel Was Tempered. Grigorii Chukhrai remade Protazanov's silent film The Forty-First, which had been based on Lavrenev's novella. Sergei Gerasimov transported Sholokhov's epic novel The Quiet Don into a film of three parts, which were released in 1957 and $195^{8}$. Significantly, Gerasimov's film was also a cinematic hypertext of the I93 I silent film version directed by Olga Preobrazhenskaia and Ivan Pravov. Similarly, many of the Thaw films about World War II were also hypertexts. The Cranes Are Flying (1957) was transported from Viktor Rozov's play Eternally Alive. Sergei Bondarchuk's The Fate of Man (1959) was adapted from a Sholokhov short story which had been suppressed in 1946 . Aleksandr Ivanov's Soldiers (1957) was based on the play In the Trenches of Stalingrad by Viktor Nekrasov. Andrei Tarkovskii's first feature film, Ivan's Childhood (I962), animated Vladimir Bogomolov's short story "Ivan." Denise Youngblood argues, "The ties between Soviet literature and Soviet cinema, always strong, became stronger yet during the Thaw."

Although transpositions of Soviet literary works of the USSR's first halfcentury were highly popular, directors continued to turn to nineteenth-century classics in the post-Stalin era. Bondarchuk's War and Peace (1967) won the Oscar for Best Foreign Film in I969. At this same time, there were also versions of Tolstoi's Resurrection (I960-I) and Anna Karenina (i967). Ivan Pyr'ev transported several of Dostoevskii's texts-The Idiot (1965), White Nights (1959), and The Brothers Karamazov (I968). Chekhov also received attention with both The Cricket (1955) and The Lady with a Lapdog (1960). These literary hypotexts, as in the early part of the century, were particularly attractive for filming since they had already been passed by the censorship board and it was, therefore, easier to gain approval for the film script.

This did not mean, however, that censors did not at times require extensive reworkings, even in the case of a recent hypotext. As Otto Boele argues, My Younger Brother (I962) was negatively impacted by the changing cultural demands of the Soviet government after one of the many political refreezes. Constant vacillation between liberal and conservative cultural agendas during the Thaw Period opened up the possibility of a reevaluation of Vasilii Aksenov's A Starry Ticket, the book upon which the film was based. The text and film are now considered historical artifacts of the i960s, offering an invitation to journey through space and time to relive a period of youthful enthusiasm that did not last for long.

The Stagnation period of the late I96os to I97os reintroduced conservatism into the Soviet film industry. As before, the Russian literary classics provided a safe cover for filmmakers. Andrei Konchalovskii, whose Asia's Happiness 
(made in $1965^{-6}$ ) had been banned, turned his attention then to transpositions of Ivan Turgenev's A Nest of Gentlefolk (1969) and Chekhov's Uncle Vania (I970). Nikita Mikhalkov also retreated into what has been called a "retro" style during this time with films such as An Unfinished Piece for a Mechanical Piano (1977) and A Fem Days from the Life of I. I. Oblomov (1980). ${ }^{5}$ Other such classics were transported to Soviet cinemas including Bulgakov's The Flight (1970), Chekhov's My Tender and Affectionate Beast (1978), Gor'kii's Queen of the Gypsies (1976) and Vassa Zheleznova (1983), Tolstoi's Father Sergius (1978), Ostrovskii's Without Dowry (1984), and Pushkin's The Station Master (1972) and Little Tragedies (1979). ${ }^{6}$ Although some may associate Stagnation cinema mainly with Andrei Tarkovskii's auteur offerings, even his Solaris (1972) was based on the Polish science fiction novel by Stanisław Lem and Stalker (1979) was a hypertext of a science fiction story by the Russian Strugatskii brothers.

Transportation of classical Russian literature into theaters almost disappeared during the glasnost era as directors finally had the creative license to discuss social problems, but returned in post-Soviet, Yeltsin-era filmmaking in order to engage with Russia's cultural heritage. Birgit Beumers argues that "they often took a parodic and critical approach to the originals, in line with the postmodernist deconstruction of realist narratives that affected much of the literature and visual arts of the i99os." Vasilii Pichul tackled The Golden Calf in Idiot's Dreams (1993), while Roman Balaian reimagined both Nikolai Leskov and Turgenev in Lady Macbeth of Mtsensk (1989) and First Love (1995). Sergei Gazarov's The Inspector General (1996) and Roman Kachanov's Domn House (200I) revised Gogol and Dostoevskii, respectively. Sergei Ursuliak deconstructed Gor'kii's Summer Folks (I995) and Valerii Todorovskii also drew from Leskov's tale in Evenings in Moscom Suburbs (1994). ${ }^{7}$ Sergei Bodrov Sr. successfully conveyed Tolstoi's Prisoner of the Mountains (I996) to the present day, resulting in a nomination for an Oscar for Best Foreign Language Film. Vladimir Sorokin parodied Chekhov's Three Sisters in the film script for Aleksandr Zeldovich's Moscom (2000). In many cases, these films transported the classical Russian novels into a more contemporary cinematic space and time.

In the Putin era, Russian filmmakers have continued to express their admiration for Russian literature. These films were guided by a distinctly political imperative to recall Russian classics in order to inspire patriotic feelings as part of Putin's effort to restore national pride. This, after the disastrous loss of national prestige stemming from the collapse of the Soviet Union, unsuccessful campaigns in Afghanistan and Chechnya, and many more perceived national defeats: Sergei Bondarchuk made a new version of Sholokhov's Quiet Flows the Don (2006); Aleksei Balabanov offered to movie audiences Mikhail Bulgakov's Morphia (2008); Karen Shakhnazarov directed Ward no. 6 (2009) 
based on Anton Chekhov's short story of the same name. In this collection, Alexander Burry notes that Shakhnazarov's indictment of national issues such as alcoholism and abuse of mental inmates are indicative of larger, systemic issues in Russia. With references to Dostoevskii and, specifically, Chekhov's short story, Shakhnazarov intimates that the problems of the 1870 and I 890 s are still present in contemporary Russia, challenging cinema audiences to consider the trajectory of a nation in peril.

As the Russian economy stabilized, film production and distribution also began to flourish once again. Film adaptations of Russian classics helped to consolidate a sense of national pride within a flourishing domestic film market. At this time, television mini-series gained in popularity with many revising well-known literary texts. Films of Anatolii Rybakov's Children of the Arbat (2004) and Boris Pasternak's Doctor Zhivago (2006) enjoyed success with viewers. Oleg Menshikov played Ostap Bender in the 2005 version of The Golden Calf. Bortko serialized both Dostoevskii's The Idiot (2003), with Evgenii Mironov playing Myshkin, and Bulgakov's Master and Margarita (2005). Established filmmakers like Pavel Lungin and Gleb Panfilov also made contributions with Gogol's Dead Souls (2005) and Aleksandr Solzhenitsyn's In the First Circle (2006), respectively.

Hypertexts of the popular novelist Boris Akunin, especially those of his detective Erast Fandorin, became regular occurrences including the television movie Azazel' with Sergei Bezrukov (Brilling) and Marina Neelova (Lady Esther); Dzhanik Faiziev's Turkish Gambit (2005) grossed over $\$ 18$ million and was nominated for several Russian MTV movie awards; The State Counsellor (2005) offered a star-studded cast with Menshikov as Fandorin, Mikhalkov as Count Pozharskii, and Vladimir Mashkov as Kozyr; the 2009 television miniseries Pelagiia and the White Bulldog was the first Akunin celluloid offering without Fandorin. Long rumored in pre-production is Fydor Bondarchuk's version for Western markets of Azazel', known as The White Queen in English translation, that has been said to star Milla Jovovich (Bezhetskaia) and Angelica Huston (Lady Astair). How will Western audiences respond to the multi-national production of this Russian Sherlock Holmes?

Russia recognizes and frequently references its literary and cultural traditions; therefore it is not surprising to find a rich tradition of cinematic hypertexts. As noted, these literary works often were selected for political reasons, as they provided a "safer" hypotext when beginning a film project than an original screenplay that might offend ever-changing political realities. Still, much more scholarly work should be done on the role of the cinematic migrations at different times in the evolution of Russian and Soviet cinema. 


\section{AMERICAN AND BRITISH CINEMA}

In the United States and the United Kingdom, movies came mainly from vaudeville and burlesque routines until 1907, when Vitagraph in America began to release films that were based on historical, literary, and biblical sources. Among the Russian sources, Tolstoi was the most popular in what John Belton calls the "bourgeoisification of the movies." ${ }^{8}$ D. W. Griffith filmed Resurrection (1909), Herbert Brenon made The Kreutzer Sonata (1915), J. Gordon Edwards tackled both Anna Karenina (1915) and A Woman's Resurrection (I9I5), Barry O'Neil reimagined The Weakness of Man (1916), Edward Jose revised Resurrection (I918), and William Humphrey adapted The Living Corpse in making Atonement (I9I9). In the UK, the teens became known as the "stage and page" period in which filmmakers selected popular plays and novels to transport to the silver screen. ${ }^{9}$

Although Tolstoi was easily recognized by Western audiences, other Russian writers were also successfully transported to the US and UK during this period. It has been noted in this collection of essays that He Who Gets Slapped (1 924) was MGM's first prestige film and was a huge financial success, setting the records for best single day, best week, and best two-week box office return. A little-known fact is that this film was also the first to feature the MGM lion at the start of the film, which would become an enduring symbol of the studio. Could it be that Andreev's play and Sjöström's addition of the lion for the violent revenge scene of his cinematic hypertext left this indelible mark?

The following year, Rudolph Valentino starred in Clarence Brown's The Eagle (1925) based on Pushkin's novel Dubrovskii. In spite of his considerable popularity after the success of The Four Horsemen of the Apocalypse (I92 I) and The Sheik (1921), Valentino was in need of a hit, especially after the failure of Monsieur Beaucaire (I924). Fortunately, critics and audiences applauded Valentino's performance in The Eagle for his more active, masculine persona, representing a minor comeback in his cinematic career. Much of the success of the film, however, can be attributed to Brown, who was one of Hollywood's most versatile filmmakers during the studio era and was successful with other adaptations such as The Last of the Mohicans (I920) and William Faulkner's Intruder in the Dust (1949). Brown would also direct Greta Garbo in Anna Karenina in $1935 .^{10}$

A few years earlier, Garbo had starred in Edmund Goulding's Love (I927), based on Anna Karenina, with her real-life paramour John Gilbert as Vronskii. Significantly, Gilbert starred in George W. Hill's The Cossacks (I928), also a Tolstoi hypertext, the following year. Although Love had been a solid success at the box office, Garbo had been dissatisfied with the happy ending of the film, in which Anna no longer commits suicide, but is reunited with Vronskii. 


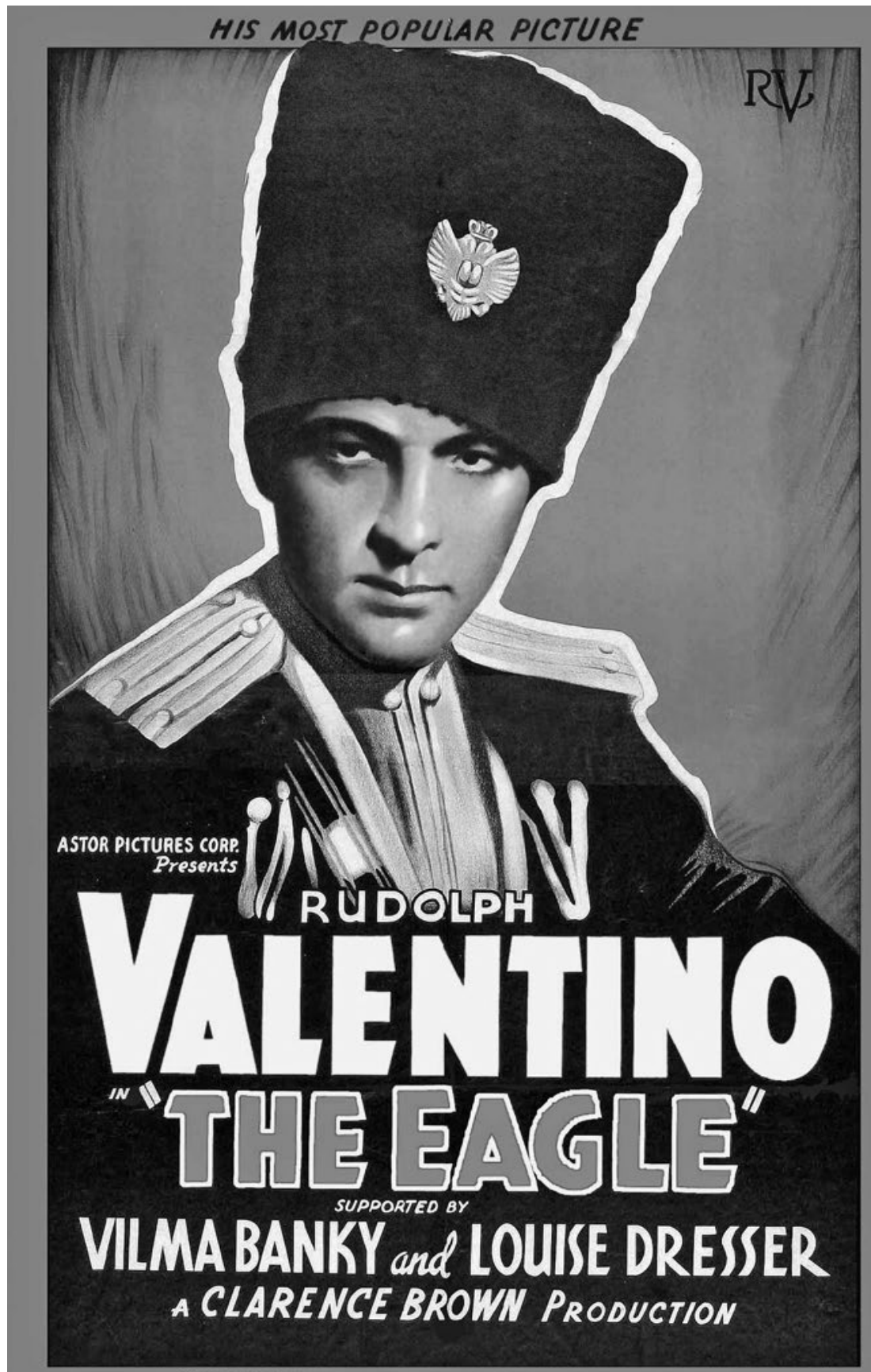

MODERNIZED WITH MUSIC AND SOUND

Figure C.2 Movie poster for The Eagle (1925), based on Aleksandr Pushkin's novel Dubrovskii. 
Therefore, as lavish variations of classic novels came into vogue in the midI93os, Garbo approached MGM about making a more faithful version of Tolstoi's novel. Although producer David O. Selznick was originally against the idea, he reluctantly agreed rather than casting Garbo as Joan of Arc or trying to transform Oscar Wilde's The Picture of Dorian Gray (both suggested by Garbo as alternatives). This time, the role of Vronskii was played by Fredric March, who had starred in another Tolstoi hypertext, We Live Again, the previous year. Although it was profitable at the box office, Anna Karenina received mixed reviews from the critics. Nevertheless, several important newspapers begrudgingly recommended the film due to the immense popularity of Garbo with movie-going audiences. ${ }^{11}$

The eleventh silver screen version of Anna Karenina (1948) stared Vivien Leigh, who was still very popular after playing Scarlett O'Hara in Gone with the Wind (1939). Unexpectedly, the movie was a failure, possibly due to Garbo's successful reprisal of the role years earlier and the great expectations audiences had for Leigh in this particular role. The plan had been to pair Leigh with her husband, Laurence Olivier, as the couple's off-screen romance paralleled the story of Tolstoi's characters (they had both left spouses after meeting each other). Unfortunately, Olivier was filming Hamlet (I948) and was unavailable. The Irish actor Kieron Moore could not rise to the occasion in love scenes with Leigh and was generally disappointing as Vronskii. Further problems developed over how to adapt Tolstoi's novel. Director Julien Duvivier favored the French playwright Jean Anouilh's hypertext that placed the film in modernday France and glorified Anna's suicide as her only option for living a free life. Producer Alexander Korda favored Guy Morgan's version that did not migrate far from the original novel. This UK production did not perform well at the box office, but it hardly affected the Tolstoi brand going forward. ${ }^{12}$ Jacqueline Bisset would again play Anna Karenina in 1985 with Christopher Reeve as Vronskii. Sophie Marceau played the lead role in Bernard Rose's I997 hypertext. Most recently, Tom Stoppard provided the screenplay for Joe Wright's Anna Karenina starring Keira Knightley and Jude Law as Karenin.

Yuri Leving examines in this collection the many versions of Anna Karenina's suicide and argues that major visual symbols have accumulated in the cinematic language around this one scene. One of these images is that of the eye, an exquisite homage to the Russian cinematic tradition rooted in Dziga Vertov's Cine-Eyes (Kinoki) movement. In particular, Vertov's Man with a Movie Camera (1929), establishes various relations between female sexuality and urban-based machines, especially the train and the camera that are repeated in various versions. Yet, it is violence that dominates the cinematic versions of Anna Karenina, especially in Sergei Solov'ev's gruesome 2009 vivisection. Leving concludes that a new visual language has emerged that has successfully transported Anna beyond the pages of Tolstoi's novel to 
a different cinematic terrain in which meaning is ascribed to what is seen (and no longer to what was written).

Although Anna Karenina received the majority of Western filmmakers' attention, in 1956 an Italian-US Dino De Laurentiis co-production of War and Peace starred Audrey Hepburn, Henry Fonda, and Mel Ferrer. The movie was epic in scope, although Tolstoi's numerous plotlines had been significantly scaled down. Hepburn's Natasha and Ferrer's Prince Bolkonskii were able to overcome a somewhat stilted performance by Fonda as Pierre. Director King Vidor received praise for his expert pacing of the film, maintaining the feeling of an epic without getting lost in the plot. Undoubtedly, any attempt at a hypertext of War and Peace (in the past or in the future) will be compared with Bondarchuk's 1967 masterpiece, except possibly, when watching Woody Allen's Love and Death (I975). In fact, the film is a satire of not only Tolstoi, but also of much of Russian culture, including Dostoevskii and Sergei Eisenstein. Allen plays Boris the pacifist and Diane Keaton is Sonja, who is getting married out of patriotic duty during Russia's war with Napoleon. Both Sonja and Boris decide to assassinate the French leader. Despite being a dense intellectual comedy, it remains one of Allen's more successful films.

Although Tolstoi's large novels may have lent themselves frequently to border crossings, Dostoevskii received his fair share of attention as well. Crime and Punishment was an obvious choice for many filmmakers with its themes of murder, madness, and redemption. The first production in the United States was Lawrence B. McGill's I9I 7 version. Peter Lorre played Raskolnikov in Columbia Pictures' 1935 version, one of the more successful adaptations of the crime novel. Although some associate the film and its cinematic style with the director, Josef von Sternberg, the film played to the natural strengths of Lorre, who seemed expressly made for the part. The movie strays from Dostoevskii's novel in the strictest sense, concentrating on the crime, guilt, confession, and arrest, but ignoring the punishment and the larger philosophical issues, although Sternberg and Lorre provide a hypertext that is hauntingly congruent with the hypotext, especially with Lorre's ability to create a disturbing, yet sympathetic anti-hero. George Hamilton played a similar role in Crime and Punishment, U.S.A. (I959) and John Hurt reprised the lead role in a UK television miniseries in I979. Hurt returned in a 2002 version directed by Menahem Golan as the detective Porfirii along with Crispin Glover (Raskolnikov), Vanessa Redgrave (Raskolnikov's mother), and Margot Kidder (Katerina Marmeladov).

The Brothers Karamazov (I958), starring Yul Brynner as Dmitrii and William Shatner as Aleksei, remains one of the more memorable American hypertexts of Dostoevskii's novel. In Richard Brooks's version, the primary focus is on the passionate relationship of Dmitrii and Grushenka (Maria Schell) and the murder of Fedor Karamazov (Lee J. Cobb). The moral 
dilemmas represented in the characters of Ivan (Richard Basehart) and Aleksei remain undeveloped in this cinematic version. Brynner took the role very seriously and received, as part of his contract, private lessons about Russia from Count Andrei Tolstoi, the nephew of the novelist. However, it was Cobb who was nominated for an Academy Award as the debauched father. ${ }^{13}$ Leitch argues at the start of this collection of essays that Brooks's adaptation offered a more nuanced view of a multi-faceted Russia than most Cold War films.

The i96os provided some of the more memorable adaptations of Russian texts for Western cinema. Beginning with Stanley Kubrick's Lolita (1962) and ending with Mel Brooks's Tmelve Chairs (1970), which is discussed here by Robert Mulcahy, the decade was embroiled in a counterculture movement that was reflected in these films. Significantly, the feature film industry was in a state of transition, and it was not until the end of the decade that the Hollywood feature would reemerge as a form of entertainment for an increasingly affluent population. One of the reasons for Kubrick's decision to film Lolita in England was to avoid the American studio system that was struggling to regain its footing. More to the point, Hollywood was forced to react to the European film market and the perception that foreign productions were setting new standards for sophistication and artistic achievement. Art-house films were being dominated by European directors who were still struggling with the moral legacy of World War II. ${ }^{14}$ Can we see the increased interest in Russian literature as a reaction to the aesthetics of the European art films of neo-realism, auterism, and New Wave?

Kubrick's Lolita, about a middle-aged man's obsession with a prepubescent girl, was a significant development in the filmmaker's career. It was the first film over which Kubrick had complete creative control. He and producer James B. Harris had purchased the film rights to Vladimir Nabokov's novel in 1958. Nabokov himself tried several times to adapt his own hypotext, but the author and filmmaker could not come to an agreement. Although Nabokov received the sole credit for the screenplay, Kubrick and Harris extensively revised the script. Sue Lyon, who was thirteen, played the part of Lolita and although she was older than Nabokov's "nymphet," it was as far as Kubrick could push the censors on this delicate issue. James Mason played Humbert Humbert and Shelley Winters was Charlotte, Lolita's mother. Peter Sellers expanded the role of Clare Quilty and nearly stole the entire film with his mimicry and improvisation.

When released, Lolita was criticized for lacking psychological depth even though it had been made under strict censorship limitations. Kubrick himself was particularly disappointed with the finished product. Even so, the film received an Oscar nomination for Best Adapted Screenplay. ${ }^{15}$ It was not until I997, when Adriane Lyne directed Jeremy Irons (Humbert), Melanie Griffith (Charlotte), Frank Langella (Quilty), and Dominique Swain (Lolita) in Lolita 
that the film could contain "aberrant sexuality, a strong scene of violence, nudity and some language," as described by the Motion Picture Association of America, capturing the deviant sensuality of Nabokov's original.

Only four years removed from his role as Dmitrii Karamazov, Yul Brynner appeared in the large-scale Hollywood epic Taras Bulba (1962). At the height of his popularity, after The King and I (1956) and The Magnificent Seven ( I960), Brynner specifically selected Gogol's novella about a Cossack warlord who raises his son Andrei to infiltrate and kill the Polish enemy to avenge the Cossack people. Unexpectedly, Andrei falls in love with a Polish princess (Christine Kaufmann) creating absolute mayhem and violence on screen, executed with nearly ı, 000 Argentinian extras. According to Nathaniel Thompson,

The fact that Polish Jews were the victims of Bulba's attacks proved to be an early sticking point when Brynner recruited popular historical novelist Howard Fast to write the screenplay. When Fast refused to soften the implications of the borderline ethnic cleansing involved in the story, blacklisted writer Waldo Salt and Karl Tunberg were brought in to write the final script, with Harold Hecht producing. ${ }^{16}$

The film suffered from post-production choices in editing, but was nominated for an Oscar for Franz Waxman's musical score in I963. No matter what the possible criticisms of this film, it can be no worse than the 2009 Russian version of Taras Bul'ba. As Ian Appleby states, "Vladimir Bortko's film adaptation is faithful [as an adolescent adventure story] inasmuch as it largely fails to engage on any more sophisticated level — despite a big budget, period costumes and some respected actors." The film, which takes a very anti-Western/ pro-Russian position, essentially acts as an "adolescent nationalist fantasy." 17

One of the most popular adaptations with Western audiences was Doctor Zhivago (1965) starring Omar Sharif (Zhivago), Julie Christie (Lara), Rod Steiger (Komarovskii), and Alec Guinness (Evgraf). Producer Carlo Ponti bought the film rights to Boris Pasternak's novel from the Italian publisher in 1963 and hired David Lean as director due to his masterful handling of Lamrence of Arabia (1962). Doctor Zhivago was the first major Western film to depict the Russian Revolution, with later epics such as Nicholas and Alexandra (I97I) and Reds (I98I) to follow. The majority of Doctor Zhivago was shot in Spain over the course of two years and it cost \$I 4 million to make. Frank Miller notes that along with the reissue of Gone with the Wind (1939), Doctor Zhivago saved MGM from bankruptcy.

It also marked a new path for the historical epic. Previous films had simply focused on the scope of world-shaping events. With Zhivago director 
David Lean and scriptwriter Robert Bolt brought a new romantic sensibility to the epic. That Victorian ideal would inform such later blockbusters as Mary, Queen of Scots (I97I), Lady Gray (1986) and Titanic (1997). ${ }^{18}$

Doctor Zhivago was nominated for ten Academy Awards. It won for Best Adapted Screenplay, Best Cinematography (Freddie Young), Best Art Direction (John Box), Best Costumes (Phyllis Dalton), and Best Score (Maurice Jarre). ${ }^{19}$ This is certainly the most successful Zhivago hypertext, although there have also been Giacomo Campiotti's 2002 television miniseries starring Keira Knightley (Lara) and Sam Neill (Komarovskii) and the 2006 Russian mini-series with Menshikov (Zhivago), Chulpan Khamatova (Lara), and Sergei Garmash (the senior Antipov).

In 1968 Sidney Lumet, the director of theatrical adaptations such as Twelve Angry Men (1957) and Long Day's Fourney Into Night (1962), decided to film Chekhov's The Seagull. Lumet assembled a stellar cast with James Mason (Trigorin), Vanessa Redgrave (Nina), David Warner (Treplev), Denholm Elliot (Dorn), and the French actress Simone Signoret (Arkadina). Unlike Konstantin Stanislavskii, who perfected the Chekhovian drama ${ }^{20}$ Lumet and his cast could not capture the tragi-comedic elements and most critics faulted the film for its austere tragedy and dramatic intensity.

In I970, Mel Brooks adapted Il'f and Petrov's The Tmelve Chairs, which satirizes Russian society in the early NEP years. Ostap Bender is played by Frank Langella and Dom DeLuise is Father Fedor. Mulcahy argues in his essay that the film is an important step in Brooks's development and a clear attempt by him to make an intellectual and aesthetic departure from his earlier films. Brooks personalizes the Russian satire by providing stereotypes of the Slavic and Jewish cultures that an American audience might recognize and find entertaining. Along with Brooks, The Twelve Chairs has been filmed by Tomás Gutiérrez Alea in Cuba in I962, as a Soviet television mini-series in I976, and by Leonid Gaidai in I97 I for Mosfilm.

Scholarship on Russian hypotexts in US and UK cinema is lacking, although there are many examples of successful films, as noted above, in need of attention. Of interest is the cultural baggage that is often smuggled through customs and then reimagined by Hollywood and London producers. This cultural baggage most often depicts Russia as an exotic and untamed place with passionate and slightly dangerous people, while revolution, war, love, and suffering are recurrent themes. However, as Leitch posits in this collection, these cinematic offerings are often in such universalistic terms that Western audiences never are asked to leave the comfort of their own culture and they rarely cross any borders (real or imagined) even when watching the Russian literary classics. 


\section{FRENCH CINEMA}

In the I930s, French cinema had become highly experimental, viewing film as art, creating a cinema of "intellectuals for intellectuals." The filmmakers of this period anticipated the groundbreaking French New Wave of the I 960 ..$^{21}$ During this Golden Age of French cinema and, with the introduction of "talkies," many authors and playwrights began to transport their works to the silver screen. In particular, the French embraced their own literary tradition with cinematic versions of Stendhal, Honoré de Balzac, Gustave Flaubert, Emile Zola, and Guy de Maupassant. Out of this trend, a cinematic current called poetic realism developed with film adaptations of French literary naturalism found in the works of Balzac, Victor Hugo, Eugène Sue, and Zola. The films concentrated on a working-class individual who experienced disillusionment and disenchantment. Rémi Fournier Lanzoni argues that "A succinct summary of major themes in poetic realism could be presented as follows: the representation of the popular hero, the pessimistic atmosphere, the (doomed) quest for happiness, and finally the tragic destiny." 22 All of this sounds quite Russian, in fact.

Consequently, it should not be surprising that Jean Renoir chose to work with Gor'kii's Lomer Depths in I936. Renoir was considered the most "authentically French" filmmaker at the time and had already transported Flaubert's Madame Bovary (1933) and Maupassant's Une partie de campagne (1936; released I946), and would later film Zola's La Bête Humaine (1938). ${ }^{23}$ With help from the Russian writer Evgenii Zamiatin, Renoir and Charles Spaak wrote the screenplay for Les bas-fonds. The film won the Louis Delluc Prize as selected by the Young Independent Critics of France. Although not Renoir's most famous film, as French film theorists in the I950s searched for a new filmic language that rejected old-fashioned concepts of literary adaptation for a more fluid personal reading of the literary canon, Les bas-fonds became an inspirational model for New Wave directors. ${ }^{24}$

French cinema of the I950s produced a group of young film critics and future filmmakers who in the I96os would challenge established conventions and the outdated aesthetics of the studio system. Robert Bresson was one of the early directors of cinéma d'auteur - most often quoted by the following generation of directors for his originality. Of particular interest for this discussion is Bresson's fascination (if not obsession) with Dostoevskii, which resonated with the filmmaker's own individual spirituality and asceticism. As discussed in this collection, Bresson's Pickpocket is viewed as a hypertext of Dostoevskii's Crime and Punishment. Olga Hasty argues here that Dostoevskii and Bresson let their characters go free (within the ideational sphere) at the end of their respective works in order to embrace the unknown and the unforeseeable that lies beyond human control. Both the Russian writer and the French filmmaker proffer the regenerative power of 
love, while representing the forces that obstruct the experience. Bresson's specific approach to Dostoevskii in Pickpocket is to mute the writer's narrative qualities in order to establish a uniquely French cinematographic experience. Bresson engages Dostoevskii's ideational sphere but creates a film that obfuscates the original narrative source in order to avoid the direct comparison of novel with film. In contrast, S. Ceilidh Orr argues that Crime and Punishment and Albert Camus's The Stranger serve as important intertexts for Bresson's Pickpocket, which she understands as a confessional narrative. Bresson's confession, in this modernist context, is a rejection of determinism and causality. Orr suggests that Bresson positions his film Pickpocket in direct dialogue with the hypotexts of Dostoevskii and Camus, in order to present the crime of picking pockets as a confessional act.

Inspired by The Idiot, Bresson then made Au Hasard Balthazar in I966, which examines the life and death of the donkey Balthazar. The donkey is used by Bresson as a symbol of Christian faith and both Balthazar and his first owner, the young Marie (Anne Wiazemsky), suffer at the hands of people in the village. It is through Balthazar's eyes that the audience sees that the people in the village are weak and often cruel. Bresson's film opened the I966 Venice Film Festival and won both the OCIC (International Catholic Organization for Cinema) Award and the Jury Hommage.

Une fermme douce (1969) was Bresson's first color film and was based on Dostoevskii's short story “The Meek One.” Loosely based on Dostoevskii's White Nights, and contrasting sharply with Luchino Visconti's Le notti bianche (1957), Bresson made Quatre nuits d'un rêveur in I97I. One night, Jacques (Guillaume des Forêts) sees a young Marthe (Isabelle Weingarten) as she tries to commit suicide. When Jacques prevents her from jumping from a bridge, Marthe tells him that she has become desperate after waiting for her lover for over a year. Jacques asks Marthe to meet him the next night and they spend the following three nights wandering through Paris. Jacques falls in love, but Marthe eventually finds her elusive lover, leaving Jacques heartbroken.

Similar to Bresson, Jean-Luc Godard also turned to Dostoevskii for inspiration. The Possessed was transported by Godard for his La Chinoise (1967). The film takes place in a small apartment in France and dramatizes the political ideologies of five university students who belong to a radical Maoist group. Among their many topics, the characters discuss the need for political assassinations in order to achieve their revolutionary goals. At the end of the film, Véronique (Anne Wiazemsky) mistakenly reverses the room number of the Soviet Minister of Culture and kills the wrong man. Ironically, La Chinoise is concerned with French political interests that rejected labor unionization and the Marxist theory of class struggle, even as it does advocate for a broad range of reforms that were initiated by Vladimir Lenin's October Revolution.

Paradoxically, many Russians came to France while fleeing Lenin's 
revolution and contributed greatly to French filmmaking. The director Iakov Protazanov and the actor Ivan Mozzhukhin are two such examples. Mozzhukhin had begun his cinematic career in a hypertext of Tolstoi's The Kreutzer Sonata (I9I I) and starred in several of Protazanov's other cinematic hypertexts including The Possessed (1915) and The Queen of Spades (1916). Mozzhukhin arrived in France at the end of I9I9 with an entire company of Russian artists who established themselves in an old Pathé studio in Paris where they began making films as the Albatross production company. Mozzhukhin rapidly became a leading actor in French silent films as well as the author of eleven screenplays.

Mozzhukhin played the lead role in Marcel L'Herbier's masterpiece $\mathrm{Feu}$ Mathias Pascal in I926. L'Herbier was one of the preeminent silent film directors of the period and transported two of Tolstoi's works-Resurrection (1923) and The Living Corpse (1937). Tolstoi remained a popular source for French cinematic hypertexts with the filming of The Kreutzer Sonata by both Jean Dréville (1938) and Eric Rohmer (1956); Father Sergius was made by Lucien Ganier-Raymond in I945. One of the more successful hypertexts, however, was Bresson's L'Argent (1983) based on the first part of The Forged Coupon. This was Bresson's last masterpiece and reflects the filmmaker's disillusionment with the modern age of materialism, as The Forged Coupon reflected that of Tolstoi at the end of his life. A chain reaction is caused by a forged 500 franc note by which Bresson confronts materialist society's obsession with money and the improbable things that people are willing to do to get it. Bresson, who first began to adapt the film script in 1977, received the Director's Prize at the I983 Cannes Film Festival, tying with Tarkovskii for Nostalghia (I983).

With the early French and Russian cinema so tightly intertwined, there are research opportunities in the area of border crossings between two countries associated with revolution. How do French political sensibilities depict the Russian struggle under Tsarism, found in so many of the Russian realist novels? How much of the Russian cultural discourse remains in French adaptations when filmmakers, like Bresson, are providing their own personalized readings of these hypotexts?

\section{GERMAN CINEMA}

French cinema of the late I920s and I 930 s was negatively impacted by turbulent financial forces and a countless number of experienced actors and technicians were forced to seek work in Germany during these years. Hollywood produced an overwhelming amount of films that they used to flood the market, while the Germans made prestige films to be promoted internationally, especially within the European market. The advent of sound further influenced 
French cinema adversely as both Germany and the United States were the largest manufacturers of cinematographic equipment and held most of the patents.

The Russian-French actor Mozzhukhin, as an example, appeared in six German films between 1928 and 1932 , including a version of Tolstoi's Hadji Murat in 1930. Der meiße Teufel was directed by another Russian, Aleksandr Volkov, who began his cinematic career as an actor in one of Protazanov's films in I9r3. Volkov and Mozzhukhin would work on nine films together. Der weiße Teufel was the first of Mozzhukhin's to include a synchronized soundtrack with limited sound effects, but no dialogue. Prior to Der weiße Teufel there had been nine other cinematic hypertexts of Tolstoi's works: Die Erkenntnis (I9I 5) directed by Max Mack; Richard Oswald's Der lebende Leichnam (I9I8); Lebendig tot (1918) by Alwin Neuß; Frederic Zelnik's Anna Karenina (1919); Die Kreutzersonate directed by both Rolf Petersen (I922) and Veit Harlan (1937); Rudolf Walther-Fein's Bigamie (1922); Der Mensch am Wege (1923) by William Dieterle starring Marlene Dietrich; and Conrad Wiene's Die Macht der Finsternis (1924) with a predominantly Russian cast. Robert Wiene helped his brother write the screenplay for Die Macht der Finsternis a year after adapting and filming Raskolnikow (I923). Prior to Wiene's hypertext, Rudolf Biebrach had filmed Dostoevskii's The Gambler in Die Rollende Kugel (1919) and Carl Froelich had filmed Die Brüder Karamasoff(I92 I) with Emil Jannings as Dmitrii.

Much like Volkov, there were several more Russian filmmakers who transported their own literary tradition to European cinema audiences. Petr Chardynin made over ıoo silent films including Dubrowsky, der Räuber Ataman (I92 I). Aleksandr Razumnyi filmed Chekhov's Überflüssige Menschen (I926) and Pushkin's Pique Dame (I927). A German-Soviet joint venture called the Deutsch-Russische Film-Allianz (Derussa) was founded in Berlin in late I927. Derussa brought Soviet features to Germany and then sold them to other European countries. Russia also supplied émigré actors, directors, set designers, and scenarists to make "Russian" films in Germany. As already mentioned, many of these Russians, in fact, came from Paris and the French cinema industry. After financial mismanagement, Derussa suspended payment to all of its projects in September 1929. ${ }^{25}$ Fedor Otsep came to Germany in 1929 to film Tolstoi's The Living Corpse with Vsevolod Pudovkin playing the lead role as a joint German-Soviet production. Remaining in Germany, Otsep and Erich Engels released Der Mörder Dimitri Karamasoff in I93I. The film was shot twice, once with German actors in German and once with French actors in French. The lead actress for both versions was Anna Sten, who got her start in the Soviet film The Girl with the Hatbox (1927), which was distributed in Europe by Derussa. Sten also starred in Protazanov's adaptation of Andreev's “The Governor" (The White Eagle, I928) and, after 
going to the United States, in Rouben Mamoulian's We Live Again (1934), based on Tolstoi's Resurrection.

World War II eventually brought an end to Soviet-German film cooperation, for a time. After the war, the Universum Film AG (UFA) studios were in the Soviet occupation zone and were reopened almost immediately after German capitulation. The film production company Deutsche Film-Aktiengesellschaft (DEFA) became a state-owned monopoly for East Germany. In the East, filmmaking remained centralized. For the most part, DEFA films were made by communists and leftists who had not prospered under the Nazis. ${ }^{26}$ The first hypertext of a Russian hypotext by DEFA was Die Mutter (1958). In fact, this was Bertold Brecht's I93 I theatrical adaptation of Gor'kii's Mother that was filmed by Manfred Wekwerth, who used many of Brecht's actors for his cinematic version. Hypertexts of Gor'kii's works were also popular on East German television: Die Letzten (1963; 1977); Kinder der Sonne (1967); Die Kleinbürger (1968); Nachtasyl (1971; 1974; 1980); Somow und andere (1974); Die Mutter (1981); Fegor Bulytschom und die Anderen (I982); and Barbaron (1989).

In West Germany, film production was slower to recover and with the advent of regular television service in $\mathbf{1 9 5 2}$, many Russian literary texts were transported to the small screen. As in East Germany, Gor'kii ${ }^{27}$ was particularly popular as was Dostoevskii. ${ }^{28}$ On the big screen, Rolf Hansen made Auferstehung (1958), a hypertext of Tolstoi's Resurrection. In 1969, Scarabeawieviel Erde braucht der Mensch? by Hans-Jürgen Syberberg was based on Tolstoi's i 886 short story "How Much Land Does a Man Require?" West German filmmakers also adapted the works of Nabokov: David Niven played Charles Dreyer in a US-West German co-production of Jerzy Skolimowski's King, Queen, Knave (1972); Rainer Werner Fassbinder filmed Despair (1978); in another co-production, John Goldschmidt made Maschenka (I987), based on Nabokov's first novel, written while living in Berlin. Dennis Ioffe argues that Fassbinder builds upon the homosexual and Jewish themes found in Nabokov's Despair. Although these are rather subdued within Nabokov's text, Fassbinder exploits the rise of the Nationalist Socialist Party in Germany to heighten the dramatic suspense of his film. According to Ioffe, this is the main innovation of the cinematic hypertext, a historical perspective that Nabokov could not have completely foretold at the time of the novel's publication.

Prior to the war, German film studios were second only to the Hollywood studios in production and technology levels. It was at this time that German film companies drew from émigrés with experience in the Russian film industry, those who readily transported Russian literary classics into German cinemas. In turn, this experience in German studios proved valuable for Soviet actors, directors, and screenwriters. German Expressionism, developed in the I920s, eventually penetrated Soviet film production as seen in 
Eisenstein's Ivan the Terrible (I944). Following the war, the Soviet Union quickly reestablished the East German film industry. Many Soviet hypertexts were then brought, once again, to German cinemas. Given the interruption of film production it is understandable why post-war German filmmaking has been concerned with identity formation. New German Cinema emerged in the i96os, including Fassbinder and Syberberg, who rejected the commercial studio system in order to achieve artistic freedom. However, as German film production has evolved, literary adaptations have mainly focused on German authors engaged in the German historical experience and how it relates to their national identity. ${ }^{29}$ In this search for German distinctiveness, Russian literary texts seem to offer few answers to these questions.

\section{ITALIAN CINEMA}

The Cold War weighed heavily on Italian society. In I948, elections were held for a new parliament in a rancorous political atmosphere that led to the shooting of the secretary of the Italian Communist Party by a right-wing extremist. Further acrimony resulted from Italy joining the North Atlantic Treaty Organization (NATO) in I949. That same year, the Vatican excommunicated all Communists and their supporters. Political purges in Eastern Europe and McCarthyism in the United States continued to disrupt Italian society. As if this were not enough, Nikita Khrushchev's revelations at the Twentieth Party Congress caused yet deeper crisis in the Italian Communist Party.

This Cold War period coincided with the height of Italian neorealist cinema. Important cinematic hypertexts of this period included Riccardo Freda's Aquila Nera, based on Pushkin's Dubrovskii and a remake of Valentino's adaptation, The Eagle (1925), Freda's sequel La vendetta di Aquila Nera (I95I), and Mario Camerini's La figlia del capitano (I947). Carlo Testa argues that Camerini selected Pushkin's The Captain's Daughter at a time when Italian political forces were wavering between an American-led Western bloc and a pro-Soviet Eastern bloc. The threat of a Slavic horde, especially after conflicts around the Italo-Yugoslav border, informed the filmmaker's depiction of the Pugachev revolt. ${ }^{30}$ Nearly a decade later, Carmine Gallone provided another movie loosely based on Pushkin's text-Michel Strogoff (1956). This large-scale, widescreen production also depicted hordes of Yugoslav cavalrymen disguised as Tartar rebels and bears dancing at a county fair by the Danube. ${ }^{31}$ The negative depiction of the Slavic marauders hit their intended mark with Italian audiences and won support for the Western bloc.

La tempesta (1958) was directed by Alberto Lattuada and was also based in part on Pushkin's The Captain's Daughter, but was made once Italy was 
safely underneath the protection of NATO. Lattuada's Russians were less barbaric and Italian audiences "watched a different world on the screens of their cinemas." 32 Lattuada received the Academy of Italian Cinema's award for Best Director for this film that has been referred to since as a Pushkinian "spaghetti eastern." ${ }^{33}$ Lattuada showed a special affinity for Russian literary texts throughout his cinematic career. In $195^{2}$, he had created the scribe Carmine De Carmine in Il cappotto drawing from Gogol's The Overcoat. A decade later, he filmed La steppa inspired by Chekhov's The Steppe: The Story of a Trip from I888. The film was shot in Yugoslavia and told the tale of a young boy who, during a trip through the steppe, witnessed disease, old age, religious zeal, and the greed for gold. Lattuada's intention was to present life as a struggle for survival. ${ }^{34}$ In 1976 , Lattuada adapted Bulgakov's Heart of $a$ Dog for Italian audiences. Cuore di cane attempted to transform Bulgakov's grotesque elements into a more humane story, yet while still conveying the deep pessimism that Italians were feeling about their own struggle for civil liberties. ${ }^{35}$

Luchino Visconti also turned to the Russian classics, Dostoevskii in particular. Visconti filmed Le notti bianche, which Testa argues "aptly symbolized the dysphoric mood of Italian democrats amid the many political disappointments of a country that, in I957, still appeared in impotent provincialism." Three years later, Visconti filmed Rocco e $i$ suoi fratelli, which borrowed narrative elements from Dostoevskii's The Idiot. The film represents the mass migration of Italians from the South to Northern cities in the I950s. ${ }^{36}$ Marcello Mastroianni starred in Visconti's Le notti bianche and, thirty years later, in Nikita Mikhalkov's Oci ciornie (I987). In Le notti bianche Mastroianni played Mario, a shy young man new to Livorno, who falls in love with Natalia after accompanying her about the city for three nights. Natalia was played by Maria Schell, whose next role would be Grushenka in Richard Brooks's The Brothers Karamazov (1958). Ronald Meyer has argued in this collection of essays that the Italian hypertext of Le notti bianche, along with Bresson's Quatre nuits d'un rêveur, has added an entirely new semantic layer of meaning to Dostoevskii's hypotext, making it difficult for future filmmakers to ignore these cinematic versions. On the other hand, Oci ciornie was a Russian-Italian co-production, which was based on several of Chekhov's stories, most notably "Lady with the Pet Dog." Mastroianni received the Best Actor Award at the Cannes Film Festival for his role as Romano. ${ }^{37}$

Italian cinema, like those national cinemas already mentioned, seemed to favor transpositions of both Tolstoi ${ }^{38}$ and Dostoevskii. ${ }^{39}$ In particular, it is worth mentioning Paolo and Vittorio Taviani, brothers who several times adapted Tolstoi's works for the silver screen. In I97I, they reimagined The Divine and the Human as San Michele aveva un gallo, which was praised by film critics. Their Il sole anche di notte (1990) was based on Father Sergius. Testa 


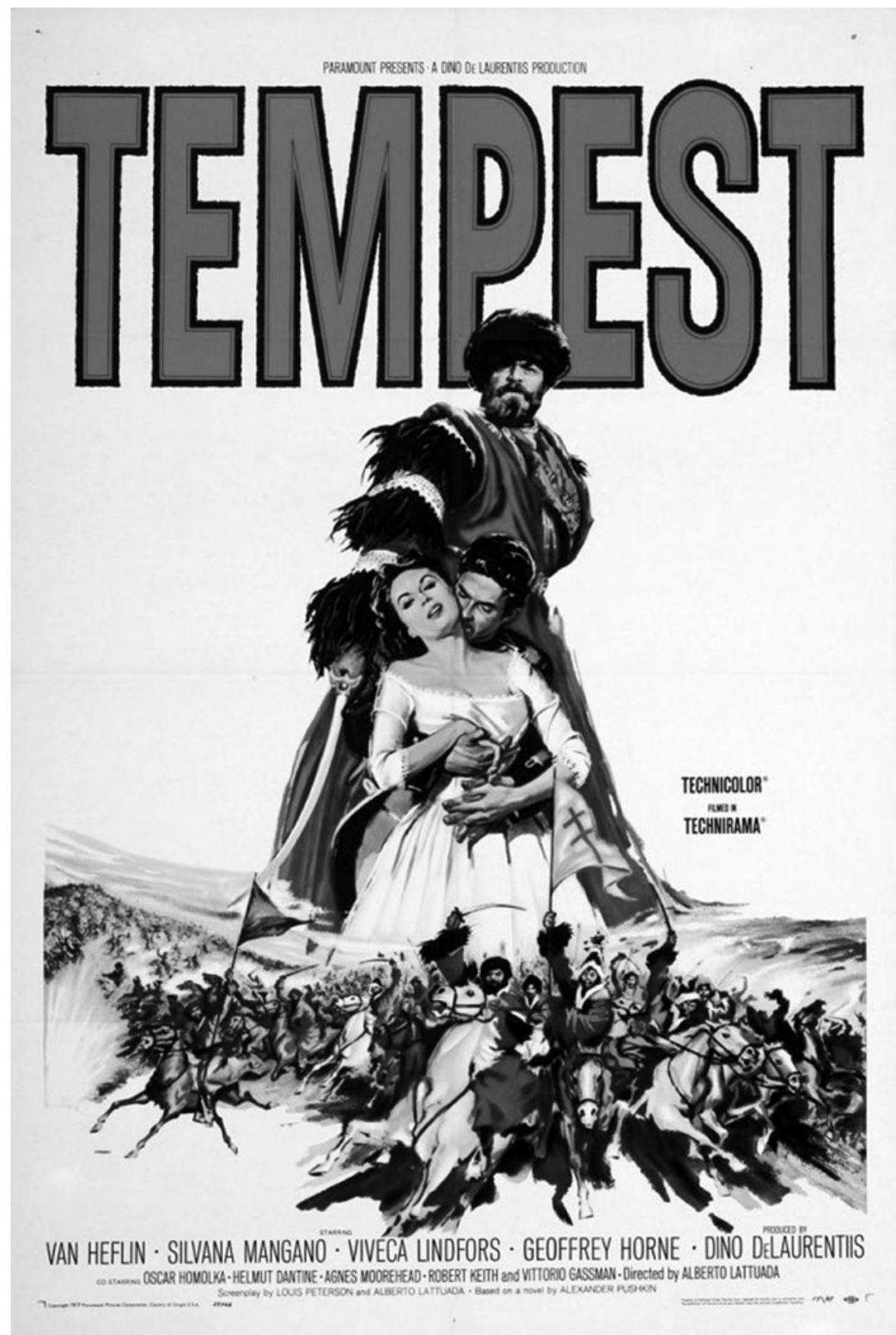

Figure C.3 American movie poster for the Dino De Laurentiis production of La tempesta (1958). 
explains: "A society imbued with the quick, abundant, and vulgar money of private TV empires clearly acts here as the Tavianis' cultural subtext." ${ }^{40}$ In 200I, the brothers also directed a television mini-series which drew inspiration from Resurrection.

Bernardo Bertolucci filmed Partner in I968, a transference of Dostoevskii's The Double. The novella depicts a government clerk who goes mad, obsessed by the idea that a fellow colleague has usurped his identity. In Partner, Pierre Clémenti plays the dual roles of the acting teacher Giacobbe and his deranged double. This was one of Bertolucci's less successful films, followed by the more critically acclaimed Il conformista (1970) and Last Tango in Paris (1972). Testa suggests that Partner embodies the revolt of I 968 and can be interpreted as an exhaustive anthology of Italian filmmaking during a period of cultural transition. ${ }^{41}$

Other notable Italian transpositions include Renato Castellani's animation of Pushkin's "The Shot" from The Tales of Belkin in Un colpo di pistol (1942); Marco Bellocchino's Il gabbiano (I977), which captured the struggle of Italian intellectuals in the dialogue of Chekhov's The Seagull; Andrei Platonov's novella The Third Son, which inspired Francesco Rosi's Tre fratelli (I98I); and Lamerica (1994), which was Gianni Amelio's reimagining of Gogol's Dead Souls. Testa concludes that Russian literature and culture in the decades immediately following World War II seemed to present to Italians an uncomplicated commercial product, which they desired, and that later it allowed Italian society to explore revolutionary themes. In the I980s, both of these trends faded and we find fewer and fewer representations of those Russian themes in contemporary Italian cinema. ${ }^{42}$

\section{CONCLUSIONS}

Once you hear the "thunk, thunk," you know that your passport has been stamped and that you will be allowed legally to cross the border into a different country. Experienced travelers understand that this crossing involves more than just intersecting political lines and demarcations. Entering a different country means interacting with a dissimilar culture, often speaking a different language, and, sometimes, negotiating a contradictory understanding of the surrounding world. This transportation into different cultural territories is complicated further if this passage takes you to eighteenth-century Moscow or nineteenth-century St. Petersburg or to the shores of the Volga, to Nizhnii Novgorod, at the beginning of the twentieth century. How can a German or Italian cinematographer interact with this new and unfamiliar territory? How does an American or Japanese producer transport Communist revolutionaries to movie theaters in Salt Lake City or Tokyo in a meaningful way? Can a 
British or French actress truly find her way into the role of Anna Karenina? These questions have less to do with the theory of adaption and much more to do with the issue of cultural communication. Yet, it has worked, when done well-Lean's Doctor Zhivago and Bresson's Pickpocket are examples.

Not every border crossing causes a cultural and physical dislocation. In some instances, especially in Russia itself, the borders are unexpectedly realigned, causing a different type of cinematic migration. Films from literary hypotexts are preferred in this case because as the political landscape changes, culture becomes an anchor by which one can hold firmly onto one's past. Bondarchuk's War and Peace is a timeless classic for this reason. In fact, many of the films that are still discussed in Russian film courses are hypertexts of literary works: Chapaev, Circus, The Cranes Are Flying, A Fem Days from the Life of I. I. Oblomov, Stalker, and Prisoner of the Mountains. The more unknown the political terrain, the more comforting it is to travel that topography with a trusted friend-Pushkin, Tolstoi, Chekhov, or Bulgakov.

Border Crossing: Russian Literature into Film invites further investigation of the transportation of a literary text to another time and place. Crossing from one temporal or spatial territory into another alters the cinematic environment as film versions of literary texts are involved in a dialogical process. In most instances, audiences know that they will be entering a new territory, one that may look different from the one they remember (or imagined). As a result, the conversation should not be bound to fidelity, but to how the new cinematic territory communicates, interacts with, and interprets Gogol, Dostoevskii, or Nabokov. After all, how can you ask Kubrick to restrain Sellers as the two joyfully begin their voyage together, even if it means making Clare Quilty the most dynamic character of Lolita - the film, not the book? Adapting, transporting, migrating, conveying, transferring, transposing-whatever words best describe the action of crossing into new cinematic territories with often an entirely different semantic language, this collection of essays argues that the metaphor of travel across spatial and temporal borders is best used when visiting your favorite Russian classic at your local movie theater.

\section{NOTES}

I. The French sociologist Pierre Bourdieu offered the term "cultural capital" that has been employed by scholars in discussions of canon formation. Such a discussion about the constitution and distribution of cultural capital (associated with both literary and cinematic production) and how it applies to consumption should eventually be had within the context of both the Russian literary canon and the films that have resulted from those works, those films that create symbolic and/or ideological capital for a particular purpose. This concluding chapter, however, avoids any explicit attempt to form a cinematic canon of Russian-inspired cinematic hypertexts in order to expand, rather than reduce, the 
scholarly conversation. That said, there is a large body of actors (producers, directors, scriptwriters, actors) within the cinematic process who often collude with cultural merchants (critics, theater owners, merchandisers) to project an aesthetic value (art-house film, literary classic) for purely economic or ideological reasons. The following discussion will more closely track toward the historical and economic drivers of film production than the specific debate over canonicity. See Bourdieu, The Rules of Art; Bourdieu, The Field of Cultural Production.

2. Beumers, A History of Russian Cinema, 8-I 5. As Beumers states, 53 percent of Russian films in the I9 Ios were adaptations. Ibid., I 8.

3. Youngblood, "Iakov Protazanov, the 'Russian Griffith," I05-2 I.

4. Youngblood, Russian War Films, i I8.

5. Beumers, Nikita Mikhalkov, 40-66.

6. Beumers, A History of Russian Cinema, 164 .

7. Ibid., 225-6, at 225.

8. Belton, American Cinema/American Culture, I3.

9. Sargeant, British Cinema, 30-7.

Io. Steffen, "The Eagle."

I I. Neuhaus, "Anna Karenina (I935)."

I2. Miller, "Anna Karenina (I948)."

I3. Steinberg, "The Brothers Karamazov (I958)."

I4. Monaco, The Sixties, 3.

I5. Stafford, "Lolita."

I6. Thompson, "Taras Bulba (I962)."

I7. Appleby, Vladimir Bortko.

I8. Miller, "Doctor Zhivago."

I9. Ibid.

20. Some debate exists as to the assertion of Stanislavskii's role in "perfecting" the "Chekhovian drama"; however, in this instance Lumet's hypertext was unsuccessful in striking the delicate notes between tragedy and comedy or for capturing the mood of a dissatisfied society on the eve of revolution for which Stanislavskii's theatrical hypertexts are credited. An earlier reference to Bourdieu and canon formation could offer an interesting research project considering the way in which Stanislavskii and the Moscow Art Theater built a reputation on perfecting the "Chekhovian drama," against which all other hypertexts (theatrical and cinematic) are now compared. How has the Moscow Art Theater co-opted and branded Chekhov's plays so successfully and why is no other interpretation possible in the estimation of cultural merchants?

21. Lanzoni, French Cinema, $45^{-7}$.

22. Ibid., 75 .

23. Ibid., 84 .

24. Ibid., 207.

25. Saunders, "The German-Russian Film (Mis)Alliance (DERUSSA)," i68-88.

26. Brockmann, A Critical History of German Film, 192-4.

27. Nachtasyl (1959; 1982); Wassa Schelesnowa (1963); Der Alte (1967); Die Letzten (1967); Langweile (1969); Die Kleinbürger (1969); Menschen (1970); Die Mutter (1971); Feinde (1976).

28. Raskolnikow (1953); Helle Nächte (1964); Die Sanfte (1964); Onkelchens Traum (1965); Die fremde Frau und der Mann unter dem Bett (1968); Der emige Gatte (I969); Die Ballade von der Geige (1972); Die Dämonen (1977).

29. For more on this subject see Rentschler, German Film and Literature. 
30. Testa, Italian Cinema, 2-I4.

31. Ibid., I9-20.

32. Ibid., I4.

33. Ibid., 30.

34. Ibid., 3 I-2.

35. Ibid., $84-9$.

36. Ibid., $3^{6-8 .}$.

37. Mastroianni was originally cast to be the lead role in Shakhnazarov's Ward no. 6, which he first tried to produce in 1988 .

38. La sonata a Kreutzer (Umberto Fracchia, I920); Il cadaver vivente (Pier Angelo Mazzolotti, I92 I); Resurrezione (Mario Caserini, I9 I 7; Flavio Calzavara, I944); Amante senza amore (Gianni Franciolini, I948); Polikuschka (Carmine Gallone, I958); Agi Murad il diavolo bianco (Riccardo Freda, I959); Teorama (Pier Palo Pasolini, I968).

39. L'idiota (Salvatore Aversano, I9I9); Il principe idiota (Eugenio Perego, I920); Nella morsa della colpa (Aleksandr Uralsky, I92 I); I fratelli Karamazoff(Giacomo Gentilomo, I947); Bianca (Nanni Moretti, 1984).

40. Testa, Italian Cinema, I49.

4I. Ibid., 59 .

42. Ibid., I95. 


\section{Bibliography}

Abandoned to the State: Cruelty and Neglect in Russian Orphanages. New York: Human Rights Watch, I998.

Adler, Bill, and Jeffrey Feinman. Mel Brooks: The Irreverent Funnyman. Chicago: Playboy Press, 1976 .

"Ahista Ahista (dir. Shivan Nair, 2006)." "Totally Filmi: West Meets East-The Musings of a Canadian Fan of Hindi Cinema [Anonymous blog]." <http://www.totallyfilmi.com/ 20I I /03/ahista-ahista-dir-shivam-nair-2006.html> (last accessed September 22, 2015).

Aksenov, Vasilii. "Search for a Positive Hero." Pravda (April 3, I963). In Khrushchev and the Arts. The Politics of Soviet Culture, I962-1964. Edited by Priscilla Johnson and Leopold Labedz, 209. Cambridge, MA: MIT Press, I 965.

A Starry Ticket. Translated by Alec Brown. London: Putnam, i962.

"Zvezdnyi bilet." In Sobranie sochinenii, I85-347. Ann Arbor: Ardis, I987.

Alexandrov, Vladimir E. Limits to Interpretation: The Meanings of Anna Karenina. Madison: University of Wisconsin Press, 2004.

Almaviva, Luiz Gazzola. "Exclusive Interview with Composer Robert Ward." Opera Lively (February 26, 2012). <http://operalively.com/forums/content.php/354-Interview-withRobert-Ward > (last accessed December I, 2013).

Al'tman, M. S. Chitaia Tolstogo. Tula: Priokskoe knizhnoe izdatel'stvo, i 966.

Anderegg, Michael A. David Lean. Boston: Twayne, I984.

Anderson, Robert G. Faces, Forms, Films: The Artistry of Lon Chaney. New York: Castle Books, I97I.

Anderson, Zoë. “Anna Karenina, Royal Opera House, London.” The Independent (August I2, 20I I). <http://www.independent.co.uk/arts-entertainment/theatre-dance/reviews/annakarenina-royal-opera-house-london-2336r6o.html> (last accessed September 22, 2015).

Andreev, Leonid. "Moi zapiski." In Sobranie sochinenii v shesti tomakh, vol. 3, I I3-82.

Moscow: Khudozhestvennaia literatura, I994.

"Pis'ma o teatre." In Literaturno-khudozhestvennyi al'manakh izdatel'stva "Shipovnik," vol. 23. St. Petersburg: M. V. Popov, I9 I4.

—. Sobranie sochinenii $v$ shesti tomakh, vol. 5. Moscow: Khudozhestvennaia literatura, I995.

Tot, kto poluchaet poshchechiny. In Sobranie sochinenii v shesti tomakh, vol. 5, 309-73.

Moscow: Khudozhestvennaia literatura, 1995.

Andrew, Dudley. “Adaptation." In Film Adaptation. Edited by James Naremore, 28-37. New Brunswick: Rutgers University Press, 2000. 
. Concepts in Film Theory. Oxford: Oxford University Press, I984.

. "The Economies of Adaptation." In True to the Spirit: Film Adaptation and the Question

of Fidelity. Edited by Colin MacCabe, Kathleen Murray, and Rick Warner, 27-39. New

York: Oxford University Press, 20 I I.

Andreyev, Leonid. He Who Gets Slapped: A Play in Four Acts. Translated by Gregory Zilboorg. New York: Samuel French, I92 I.

Anemone, Tony. "Nabokov's 'Despair' and the Criminal Imagination.” In O Rus'! Studia litteraria slavica in Honorem Hugh McLean. Edited by Simon Karlinsky, James Lee Rice, and Barry Scherr, 753-5. Oakland: Berkeley Slavic Specialties, 1995.

Appel, Alfred. Nabokov's Dark Cinema. New York: Oxford University Press, I974.

Appleby, Ian. Vladimir Bortko: Taras Bul'ba (2009). Kinokultura, 26 (2009). <http://www. kinokultura.com/2009/26r-bulba-ia.shtml > (last accessed April 4, 20I3).

Arana, R. Victoria. “'The Line Down the Middle' in Autobiography: Critical Implications of the Quest for the Self." In Fearful Symmetry: Doubles and Doubling in Literature and Film. Edited by Eugene J. Crook, I25-37. Tallahassee: University Press of Florida, I982.

Armstrong, Judith M. The Unsaid Anna Karenina. New York: St. Martin's Press, I 988.

Arnes, Roy. "Robert Bresson." In Great Film Directors: A Critical Anthology. Edited by Leo Braudy and Morris Dickstein, 9I-6. New York: Oxford University Press, I978.

Arsen'eva, Darina. "Eksplitsitnyi i implitsitnyi metatekst v romane V. Nabokova 'Otchaianie'.” In Vestnik Sankt-Peterburgskogo universiteta. Ser. 9, Filologiia, vostokovedenie, Zhurnalistika, vol. 3, 3-6. St. Petersburg: Izd-vo St. Peterburgskogo universiteta, 2 o Iо.

Axthelm, Peter. The Modern Confessional Novel. New Haven: Yale University Press, 1967.

Baer, Harry. Schlafen kann ich, wenn ich tot bin: das atemlose Leben des Rainer Werner Fassbinder, aufgeschrieben von Harry Baer; unter Mitarbeit von Maurus Pacher. Köln: Kiepenheuer \& Witsch, 1982.

Bakhtin, M. M. The Dialogic Imagination: Four Essays. Edited and translated by Michael Holquist. Austin: University of Texas Press, I98I.

Barron, Stephanie. "Degenerate Art": The Fate of the Avant-Garde in Nazi Germany. New York: Harry N. Abrams, I99I.

Barthes, Roland. "The Metaphor of the Eye." In Critical Essays. Translated by Richard Howard, 239-47. Evanston, IL: Northwestern University Press, 1972.

Baudelaire, Charles. The Painter of Modern Life and Other Essays. Translated by Jonathan Mayne. London: Phaidon Press, I964.

Beck, Sandra L. "Pickpocket." < http://www.encyclopedia.com/topic/Pickpocket.aspx > (last accessed September I4, 20 I5).

Belinkov, A. Iurii Tynianov. Moscow: Sovetskii pisatel', I96o.

Belton, John. American Cinema/American Culture. 3 rd edn. New York: McGraw-Hill, 2009.

Benjamin, Walter. "The Task of the Translator." In Selected Writings, Volume I, I9I3-1926. Edited by Marcus Bullock and Michael W. Jennings, 253-63. Cambridge, MA: The Belknap Press of Harvard University Press, I996.

_ . "The Translator's Task." Translated by Steven Rendall. In Translation Studies Reader. 3 rd edn. Edited by Lawrence Venuti, 75-83. New York: Routledge, 20 I 2.

Beumers, Birgit. A History of Russian Cinema. Oxford: Berg, 2009.

—. Nikita Mikhalkov: Between Nostalgia and Nationalism. The Filmmakers' Companion I.

London: I. B. Tauris, 2005.

Bluestone, George. Novels into Films: The Metamorphosis of Fiction into Cinema. Berkeley:

University of California Press, I957.

Boele, Otto. “Aleksandr Proshkin: Expiation (Iskuplenie, 20 I2)." Kinokultura, 38 (2012). 
<http://www.kinokultura.com/2012/38r-iskuplenie.shtml> (last accessed November 25, 2013).

Bordwell, David and Kristin Thompson. "Three Nights of a Dreamer." Observations on Film Art. <http://www.davidbordwell.net/blog/category/directors-guerin/> (last accessed September 2I, 20I5).

Bouissac, Paul. Circus and Culture: A Semiotic Approach. Bloomington: Indiana University Press, 1976.

- Semiotics at the Circus. Berlin: Walter de Gruyter, 20 Iо.

Bourdieu, Pierre. The Field of Cultural Production. Essays on Art and Literature. Edited and introduced by Randal Johnson. New York: Columbia University Press, I993.

- The Rules of Art: Genesis and Structure of the Literary Field. Translated by Susan Emanuel. Stanford: Stanford University Press, 1996.

Brecht, Bertolt. Brecht on Theater. Translated and edited by John Willet. New York: Methuen, I964.

Bresson, Robert. "Interview with Bresson from Cinépanorama." (i 960). In Pickpocket, film, directed by Robert Bresson. USA: The Criterion Collection DVD, 2005.

- Notes on the Cinematographer. Translated by Jonathan Griffin. Copenhagen: Green Integer, 1997.

- Notes on Cinematography. Translated by Jonathan Griffin. New York: Urizen Books, I975.

Brintlinger, Angela. "Introduction." In Madness and the Mad in Russian Culture. Edited by Angela Brintlinger and Ilya Vinitsky, 3-I9. Toronto: University of Toronto Press, 2007.

Brintlinger, Angela and Carol Apollonio, eds. Chekhov for the 2Ist Century. Bloomington: Slavica, 2012.

Brintlinger, Angela and Ilya Vinitsky, eds. Madness and the Mad in Russian Culture. Toronto: University of Toronto Press, 2007.

Brockmann, Stephen. A Critical History of German Film. New York: Camden House, 20 I 2.

Brook, Peter. The Shifting Point. New York: Harper \& Row, 1987.

Brooks, Mel. "Mel Brooks-Serious Jibber-Jabber with Conan O'Brien [interview]." Teamcoco.com (October 2I, 20I3). <http://teamcoco.com/video/mel-brooks-seriousjibber-jabber> (last accessed September 22, 2015).

Brown, Julie. "Afterword.” In Madness and the Mad in Russian Culture. Edited by Angela Brintlinger and Ilya Vinitsky, 283-300. Toronto: University of Toronto Press, 2007.

Brustein, Robert. “Puttin' On the Spritz: Mel Brooks' America.” In The Incredible Mel Brooks: An Irresistible Collection of Unhinged Comedy. Mel Brooks and Jordan Fields, 29-43. Los Angeles: Shout! Factory, 2012.

Buckler, Julie A. "Reading Anna: Opera, Tragedy, Melodrama, Farce." In Approaches to Teaching Tolstoy's Anna Karenina. Edited by Liza Knapp and Amy Mandelker, I3 I-6. New York: Modern Language Association of America, 2003.

Burdick, Dolores. "The Line Down the Middle: Politics and Sexuality in Fassbinder's 'Despair'." In Fearful Symmetry: Doubles and Doubling in Literature and Film: Papers from the Fifth Annual Florida State University Conference on Literature and Film. Edited by Eugene J. Crook, I38-48. Tallahassee: University Presses of Florida, I982.

Burry, Alexander. Multi-Mediated Dostoevsky: Transposing Novels into Opera, Film and Drama. Evanston, IL: Northwestern University Press, 20 I I.

Buttafava, Giovanni. "Interview with Marlen Khutsiev." In The Soviet Cinema of the Sixties/ De Sovjetcinema in de jaren zestig. Edited by Gennadi Sjpalikov, 26-32. Rotterdam: Film Festival Rotterdam, I990. 
Bynum, Caroline Walker. Fesus as Mother: Studies in the Spirituality of the High Middle Ages.

Berkeley: University of California Press, 1982.

Calandra, Denis. "Politicized Theatre: The Case of Rainer Werner Fassbinder's Garbage, The City and Death." Modern Drama, 3I(3) (Fall I988): 420-8.

Camus, Albert. The Stranger. Translated by Matthew Ward. New York: Vintage International, I988.

Carlin, George A. He Who Gets Slapped. New York: Grosset and Dunlap, I925.

Carroll, William C. "The Cartesian Nightmare of Despair." In Nabokov's Fifth Arc. Edited by J. E. Rivers and Charles Nicol, 82-104. Austin: University of Texas Press, I982.

Chamberlin, Carloss James. "Emigrating to Madness: Despair (Eine Reise ins Licht)." Cinémathèque Annotations on Film, 27 (2003). <http://sensesofcinema.com/2003/cteq/ despair/> (last accessed September 23, 20 I5).

Chapple, Richard L. Soviet Satire of the Tmenties. Gainesville: University Press of Florida, I980.

Chekhov, Anton. About Love and Other Stories. Translated by Rosamund Bartlett. Oxford/ New York: Oxford University Press, 2004.

—. The Duel. Translated by Constance Garnett. New York: Modern Library, 2003.

. The Island: A fourney to Sakhalin. Translated by Luba Terpak and Michael Terpak.

New York: Washington Square, i967.

—. The Plays of Anton Chekhov. Translated by Paul Schmidt. New York: HarperCollins, I 998 .

—. Sobranie sochinenii v shesti tomakh. Moscow: Leksika, I995.

—. "'Ward. No. 6' and Other Stories, I $892-1895$." Translated by Ronald Wilks. London:

Penguin, 2002.

Chukovskii, Kornei. "Iz dnevnika I932-I969.” Znamia, I I (г992): I35-94.

Clarens, Carlos. "'Four Nights of a Dreamer' [Interview with Robert Bresson]." Sight and Sound, 4I(I) (Winter I972): 2-4.

Clark, Katerina. The Soviet Novel. History as Ritual. 3 rd edn. Bloomington: Indiana University Press, 2000.

Cole, Jake. "Two Lovers [Blog]." <http://armchairc.blogspot.com/2009/ I2/two-lovers. html > (last accessed April I, 20I4).

Collins, Jim. Bring on the Books for Everybody: How Literary Culture Became Popular Culture. Durham, NC: Duke University Press, 20 Io.

Connolly, Julian W. "Dostoevsky and Vladimir Nabokov: The Case of 'Despair'.” In Dostoevsky and the Human Condition After a Century. Contributions to the Study of World Literature, Book I6. Edited by A. Ugrinsky and V. Ozolins, I55-62. New York: Praeger, I986.

—. "The Function of Literary Allusion in Nabokov's 'Despair'." Slavic and East European Fournal, 26 (I982): 302-I3.

- "Madness and Doubling: From Dostoevsky's The Double to Nabokov's The Eye." Russian Literature Triquarterly, 24 (1990): I29-39.

Corber, Robert J. In the Name of National Security: Hitchcock, Homophobia, and the Political Construction of Gender in Postmar America. Durham, NC: Duke University Press, I993.

Cornwell, Neil. The Literary Fantastic: From Gothic to Postmodernism. London: Harvester Wheatsheaf, r99o.

Crick, Robert Alan. The Big Screen Comedies of Mel Brooks. Jefferson, NC: McFarland, 2002.

Cruise, Edwina. "Women, Sexuality, and the Family in Tolstoy." In The Cambridge

Companion to Tolstoy. Edited by Donna Tussing Orwin, I9I-205. Cambridge: Cambridge University Press, 2002. 
Culbert, David, ed. Mission to Moscom. Madison: University of Wisconsin Press, I980.

Daly, Nicholas. Literature, Technology, and Modernity, I860-2000. Cambridge: Cambridge University Press, 2004.

Davidson, Ray. Camus: The Challenge of Dostoevsky. Exeter: University of Exeter Press, I997.

Davis, Janet M. The Circus Age. Culture and Society Under the American Big Top. Chapel Hill: The University of North Carolina Press, 2002.

Deleuze, Gilles [and Leopold von Sacher-Masoch]. Masochism: An Interpretation of Coldness and Cruelty. Translated by Jean McNeil. New York: Braziller, I97 I.

Della Coletta, Cristina. When Stories Travel: Cross-Cultural Encounters Between Fiction and Film. Baltimore: Johns Hopkins University Press, $20 \mathrm{I} 2$.

"Disput o formal'nom metode." Novyi Lef, 4 (I927): 45-6.

Dolinin, Alexander. "The Caning of Modernist Profaners: Parody in Despair." Cycnos, I2(2) (I995): 43-54.

_. "Nabokov, Dostoevsky, and 'Dostoevskyness'." Russian Studies in Literature, 35(4) (I999): 42-6o.

Doniol-Valcroze, Jacques and Jean Domarchi. "Visconti [interview]." Monthly Film Bulletin, 28(3-4) (Summer/Autumn I959): I44-7, I9 I.

Dostoevsky, Fyodor. The Brothers Karamazov. Edited by Susan McReynolds. New York: W. W. Norton, 20 I I.

—. The Brothers Karamazov. Translated by Richard Pevear and Larissa Volokhonsky. New York: Vintage Classics, I990.

- Crime and Punishment. Translated by Richard Pevear and Larissa Volokhonsky. New York: Vintage, I992.

—. "The Gambler." Translated by Constance Garnett. In Great Short Works of Fyodor Dostoevsky, 379-519. New York: Perennial Classics, I968.

- Memoirs from the House of the Dead. Translated by Jessie Coulson. Oxford/New York: Oxford University Press, 200I.

—_. "White Nights." In The Gambler and Other Stories, 3-57. London: Penguin Classics, 2010.

Duffie, Bruce. "Composer Robert Ward. The First of Two Conversations with Bruce Duffie." (May 20, I985). <http://www.bruceduffie.com/ward I985.html > (last accessed December I, 2012).

Durgnat, Raymond. "The Negative Vision of Robert Bresson.” In Robert Bresson. Edited by James Quandt, 4I I-52. Toronto: Toronto International Film Festival, 20 I I.

Durkin, Andrew. "Chekhov's Response to Dostoevskii: The Case of 'Ward Six'." Slavic Reviem, 40(I) (Spring I98I): 49-59.

Ebert, Roger. "The Twelve Chairs.” Rogerebert.com (December 22, I970). <http://www. rogerebert.com/reviews/the-twelve-chairs-I970> (last accessed September 22, 20I 5).

Egorova, E. V. “Igra slov v romane Nabokova 'Otchaianie'.” Russkaia rech', 2 (2012): I4-20.

Eikhenbaum, Boris. "Literatura i pisatel'.” Zvezda, 5 (I927): I 2 I-40.

—_. "Literaturnyi byt." In Moi vremennik/Marshrut v bessmertie, 49-59. Moscow: Agraf, $200 \mathrm{I}$.

—. "Problems of Cine-Stylistics." In The Poetics of Cinema. Russian Poetics in Translation, vol. 9. Edited by Richard Taylor, 5-3 I. Oxford: RTP Publications, I982.

Eisenstein, Sergei. "Dickens, Griffith, and the Film Today." In Film Form: Essays in Film Theory. Translated by J. Leyda, I95-255. New York: Houghton Mifflin Harcourt Trade \& Reference Publishers, I949. 
Eisenstein, Sergei, Vsevolod Pudovkin, and Grigorii Aleksandrov. "Statement on Sound.” In The Film Factory: Russian and Soviet Cinema in Documents, I886-I939. Edited by Richard Taylor and Ian Christie, 234-5. London: Routledge, I988.

Elsaesser, Thomas. Fassbinder's Germany: History, Identity, Subject. Amsterdam: Amsterdam University Press, I996.

— . "Murder, Merger, Suicide: The Politics of Despair." In Fassbinder. Edited by Tony Rayns, 73-95. London: British Film Institute, i980.

Erlich, Viktor. Russian Formalism: History-Doctrine. The Hague: Mouton, I980.

Erofeev, Venedikt. Ostav'te moiu dushu v pokoe: pochti vse. Moscow: Izdatel'stvo “Kh. G. S.," I 995 .

Fanger, Donald. Dostoevsky and Romantic Realism. Cambridge, MA: Harvard University Press, 1965.

Fassbinder, Rainer Werner. The Anarchy of Imagination. Baltimore: Johns Hopkins University Press, I992.

Finke, Michael C. Seeing Chekhov: Life and Art. Ithaca: Cornell University Press, 2005.

Fleming, Ian. From Russia with Love. London: Jonathan Cape, 1957.

Foucault, Michel. Madness and Civilization: A History of Insanity in the Age of Reason. Translated by Richard Howard. New York: Vintage, I988.

Frank, Joseph. Dostoevsky: The Seeds of Revolt, I82I-I849. Princeton: Princeton University Press, 1976.

Frank, Siggy. Nabokov's Theatrical Imagination. Cambridge: Cambridge University Press, 2012.

Frazier, Melissa. "Sun-bathed Steppes in French Prisons: Bresson Reading Dostoevsky." Ulbandus, I 5 (2013): $133-52$.

Genette, Gérard. Palimpsests: Literature in the Second Degree. Translated by Channa Newman and Claude Doubinsky. Lincoln, NE: University of Nebraska Press, I997.

Gillespie, Alyssa Dinega, ed. Taboo Pushkin: Topics, Texts, Interpretations. Madison: University of Wisconsin Press, 20 I2.

Gillespie, David. “Adapting Foreign Classics: Kozintsev's Shakespeare.” In Russian and Soviet Screenings of Russian Literature, 1900-200I: Screening the Word. Edited by Stephen Hutchings and Anat Vernitski, 75-88. New York: Routledge, 2005.

Glynn, Michael. Vladimir Nabokov: Bergsonian and Russian Formalist Influences in His Novels. New York: Palgrave Macmillan, 2007.

Godard, Jean-Luc and Michel Delahaye. "The Question. Interview.” In Robert Bresson. Edited by James Quandt, 453-83. Toronto: Toronto International Film Festival, 20 I I. Gogol, Nikolai. Diary of a Madman and other Stories. Translated by Ronald Wilks. Harmondsworth: Penguin, 1972.

—. "The Overcoat." In Diary of a Madman and other Stories. Translated by Ronald Wilks, 7I-I08. Harmondsworth: Penguin, I972.

Gogol', N. V. Sobranie sochinenii v shesti tomakh. Moscow: Gosudarstvennoe izdatel'stvo khudozhesvennoi literatury, I949.

Golstein, Vladimir. "Accidental Families and Surrogate Fathers: Richard, Grigory, and Smerdyakov." In A New Word on "The Brothers Karamazov." Edited by Robert Louis Jackson, 90-I06. Evanston, IL: Northwestern University Press, 2004.

Golynko, Dmitrii. "Favority otchaianiia ('Otchaianie' Vladimira Nabokova: preodolenie modernizma)." In $V$. $V$. Nabokov: pro et contra, vol. 2. Edited by B. V. Averin and A. A. Dolinin, 75 I-6o. St. Petersburg: RHGA, $200 \mathrm{I}$.

Gorsuch, Anne. All This Is Your World: Soviet Tourism at Home and Abroad after Stalin. Oxford: Oxford University Press, 20 I I. 
Goscilo, Helena. "Motif-Mesh as Matrix: Body, Sexuality, Adultery, and the Woman Question.” In Approaches to Teaching Tolstoy's Anna Karenina. Edited by Liza Knapp and Amy Mandelker, 83-9. New York: Modern Language Association of America, 2003. Goscilo, Helena and Yana Hashamova, eds. Cinepaternity: Fathers and Sons in Soviet and Post-Soviet Film. Bloomington: Indiana University Press, 20 го.

Gottlieb, Stephen. "The Twelve Chairs." The Village Voice (December io, I970): 73, 76.

Govedić, Natalia. "When the Eye Refuses to Blind Itself: Nabokov's Writing on Literature." Slavica Tergestina, 9 (2007): 235-64.

Graffy, Julian. "Film Adaptations of Aksenov. The Young Prose and the Cinema of the Thaw." In Russian and Soviet Film Adaptations of Literature, I900-200I. Edited by Stephen Hutchings and Anat Vernitski, roo-r 5. New York: Routledge, 2005.

Griffith, James John. Adaptations as Imitations: Films from Novels. Newark, DE: University of Delaware Press, 1997.

Grishakova, Marina. The Models of Space, Time and Vision in V. Nabokov's Fiction: Narrative Strategies and Cultural Frames. Tartu: Tartu University Press, 2012.

Gupta, Charu. "Visual Pleasures for the Female Gaze." Economic and Political Weekly, 42(50) (December I5-2I, 2007): I9-20.

Hanlon, Lindley. Fragments: Bresson's Film Style. Rutherford, NJ: Fairleigh Dickinson University Press, I986.

Hansen-Löve, Aage. Russkii Formalizm. Metodolgicheskaia rekonstruktsiia razvitiia na osnove printsipa ostraneniia. Moscow: Iazyki russkoi kul'tury, $200 \mathrm{I}$.

Hasty, Olga Peters. "Bresson and Dostoevskii: Crimes and Punishments." In Dostoevskii's Overcoat: Influence, Comparison and Transposition. Edited by Joe Andrew and Robert Reid, 3 I7-33. Amsterdam: Rodopi, 2013.

Healy, Dan. "What Can We Learn From the History of Homosexuality in Russia?" History Compass, I(I) (2003): 3-4.

Heger, Heinz. The Men with the Pink Triangle. Hamburg: Melin-Verlag, I980.

Hennessey, Brendan. "Theatrical Space in Luchino Visconti's Le notti bianche (I957)." MLN, I26(I) (January 20 I I): I 57-78.

Henry, Peter, ed. Classics of Soviet Satire. London/Wellingborough: Collet's, 1972.

Hutcheon, Linda with Siobhan O'Flynn. A Theory of Adaptation. New York: Routledge, 2012.

Hutchings, Stephen and Anat Vernitski. "Introduction: The ekranizatsiia in Russian culture." In Russian and Soviet Screenings of Russian Literature, I900-200I: Screening the Word. Edited by Hutchings, Stephen and Anat Vernitski, I-24. New York: Routledge, 2005. Hutchings, Stephen and Anat Vernitski, eds. Russian and Soviet Screenings of Russian Literature, I900-200I: Screening the Word. New York: Routledge, 2005.

Iampol'skii, Mikhail. “Poruchik Kizhe' kak teoreticheskii fil'm.” In Tynianovskii sbornik: vtorye tynianovskie chteniia. Edited by M. O. Chudakova, 28-43. Riga: Zinatne, 1986. Il'f, Il'ia and Evgenii Petrov. Dvenadtsat' stul'ev $i$ Zolotoi telenok. Moscow: Eksmo, 2004. - The Twelve Chairs. Trans. Anne O. Fischer. Evanston, IL: Northwestern University Press, $20 \mathrm{I}$ I.

Ioffe, Dennis. "The Discourses of Love: Some Observations Regarding Charles Baudelaire in the Context of Brjusov's and Blok's Vision of the Urban Woman." Russian Literature, 64(I) (July 2008): I9-45.

__. "Zhiznetvorchestvo modernizma i 'kineticheskii personazh' v rakurse bakhtinskoi teorii." In Literature and Beyond: Festschrift for Willem G. Weststeijn. Pegasus Oost-Europese Studies: POES I I. Edited by Eric De Haard, Wim Honselaar, and Jenny Stelleman, 347-6I. Amsterdam: Pegasus, 2008.

Ioffe, Dennis, ed. Discoursy telesnosti i erotisma. Epokha modernizma. Moscow: Ladomir, 2008. 
Ioffe, Dennis G. and Frederick H. White. "Taxi Blues: The Anxiety of Soviet Masculinity." Fournal of European Studies, 44(3) (September 2014): 263-80.

Iutkevich, Sergei. "'Sinematograf' Robera Bressona." Iskusstvo kino, 2 and 3 (February and March I979): $\mathrm{I}_{45}{ }^{-5} 8$ and $\mathrm{I} 45^{-5}$.

"Iz stenogrammy zasedaniia ideologicheskoi komissii TsK KPSS s uchastiem molodykh pisatelei, khudozhnikov, kompozitorov, tvorcheskikh rabotnikov kino i teatrov Moskvy, 24, 26 dekabria I962.” In Ideologicheskie komissii Tsk KPSS. 1958-1964: Dokumenty. Edited by E. S. Afanas'eva, Vitalii Iur'evich Afiani, L. A. Velichanskaia, Zoia Konstantinovna Vodop'ianova, and E. V. Kochubei, 293-38r. Moscow: ROSSPEN, I998.

Jump, John D. Burlesque. London: Methuen, I972.

Kael, Pauline. $500 \mathrm{I}$ Nights at the Movies. New York: Holt, Rinehart, and Winston, 1982.

—. "The Twelve Chairs." In Deeper into Movies: The Essential Kael Collection: From '69 to '72, I80-I. London: Marion Boyars, 2000.

Kalat, David. "The Twelve Chairs." Tcm.com. <http://www.tcm.com/this-month/article. html?id=6270 I9 $\mid 627025^{>}$(last accessed September 23, 2015).

Kassil', Lev. "Moi mladshii brat." Pravda (November I8, I962): 6.

—. "Pogovorim o vkusakh." Iunost', 6 (I957): 76-8.

Kennan, George. "The Sources of Soviet Conflict." Foreign Affairs, 25 (I947): 566-82.

Kimney, John. “The Three Voices of Nabokov's 'Despair'.” Russian Language Journal, 34(I I9) (I980): Io I-9.

Kinik, Anthony. "Rainer Werner Fassbinder's Curious Dialectic of Enlightenment." Seminar: A Journal of Germanic Studies, 33(4) (1997): 290-306.

Kirby, Lynne. Parallel Tracks: The Railroad and Silent Cinema. Durham, NC: Duke University Press, I997.

Klein, Michael and Gillian Parker. The English Novel and the Movies. New York: Ungar, I98I. Kline, T. Jefferson. "Picking Dostoevsky's Pocket: Bresson's Sl(e)ight of Hand.” In Robert Bresson. Edited by James Quandt, 299-337. Toronto: Toronto International Film Festival, 20 II.

Knapp, Liza. "Fear and Pity in 'Ward Six': Chekhovian Catharsis." In Reading Chekhov's Text. Edited by Robert Louis Jackson, I45-54. Evanston, IL: Northwestern University Press, I993.

Kolodin, Irving. "Music to My Ears: Floyd of 'Wuthering Heights'—Ward, Foss." The Saturday Reviem (April 25, 1959): 24.

Kozintsev, Grigorii. [No Title]. In Iurii Tynianov: Pisatel' i uchenyi. Vospominaniia. Razmyshleniia. Vstrechi. Edited by V. Kaverin, I66-75. Moscow: Molodaia gvardiia, I966.

Kranz, David. "Trying Harder: Probability, Objectivity, and Rationality in Adaptation Studies." In The Literature /Film Reader: Issues of Adaptation. Edited by James Welsh and Peter Lev, 77-I02. Lanham, MD: Scarecrow Press, 2007.

Kuznetsov, M. "Starshie i mladshie ('moi mladshii brat')." Sovetskii ekran, 23 (I962): 6-I9.

Lachmann, Renate. "Semiotika mistifikatsii: Otchaianie Nabokova." In Polytropon: k 7o-letiiu Academika Vladimira Nikolaevicha Toporova. Edited by Tat'iana Mikhailovna Nikolaeva and V. N. Toporov, 750-62. Moscow: Indrik, I998.

Lanoux, Andrea. “Anna Karenina through Film.” In Approaches to Teaching Tolstoy's Anna Karenina. Edited by Liza Knapp and Amy Mandelker, I8o-4. New York: Modern Language Association of America, 2003.

Lanzoni, Rémi Fournier. French Cinema. From Its Beginnings to the Present. New York: Continuum, 2002.

Lary, N. M. Dostoevsky and Soviet Film. Ithaca: Cornell University Press, I986. 
LaValley, Al. "The Gay Liberation of Rainer Werner Fassbinder: Male Subjectivity, Male Bodies, Male Lovers." Nem German Critique, 63 (Autumn I994): Io8-37.

Le Dantec, Mireille Latil. "Bresson, Dostoevsky.” In Robert Bresson. Edited by James Quandt, 4I3-25. Toronto: Toronto International Film Festival, 20 I I.

Leitch, Thomas. Film Adaptation and its Discontents: From Gone with the Wind to The Passion of the Christ. Baltimore: Johns Hopkins University Press, 2007.

—. "Twelve Fallacies in Contemporary Adaptation Theory." Criticism, 45(2) (Spring 2003): I49-7I.

Leving, Yuri. "Filming Nabokov. On the Visual Poetics of the Text." Russian Studies in Literature, 40 (3) (Summer 2004): 6-3I.

—.Vokzal-Garazh-Angar. V. Nabokov i Poetika russkogo urbanizma. St. Petersburg: Ivan Limbakh, 2004.

Lipovetsky, Mark. Charms of the Cynical Reason: The Trickster's Transformation in Soviet and Post-Soviet Culture. Boston: Academic Studies Press, 20 I I.

Lönnqvist, Barbara. “Anna Karenina.” In The Cambridge Companion to Tolstoy. Edited by Donna Tussing Orwin, 80-95. Cambridge: Cambridge University Press, 2002.

López, Ignacio Javier. "Film, Freud, and Paranoia. Dalí and the Representation of Male Desire in An Andalusian Dog." Diacritics, 3 I (2) (200I): 35-48.

Luxemburg, A. "Koshmary Germana Karlovicha: neizvestnyi russkomu chitateliu epizod romana Vladimira Nabokova 'Otchaianie'.” In $V$. $V$. Nabokov: pro et contra, vol. 2. Edited by B. V. Averin and A. A. Dolinin, 76I-5. St. Petersburg: RHGA, $200 \mathrm{I}$.

MacCabe, Colin. "Introduction." In True to the Spirit: Film Adaptation and the Question of Fidelity. Edited by Colin MacCabe, Kathleen Murray, and Rick Warner, 3-25. New York: Oxford University Press, 20 I .

McCarthy, John P. "Ward no. 6." <http://pro.boxoffice.com/news/20i o-I 2-wardno-6> (last accessed September 2 I, 20 I 5).

McElhinney, Andrew. "Remaking Hollywood with Forced Entry (I973 and I98I), Despair (1978) and Raiders of the Lost Ark: The Adaptation (1989)." In Second Takes: Remaking Film, Remaking America, I59-8I. Jefferson, NC: McFarland, 20I3.

McFarlane, Brian. Novel to Film: An Introduction to the Theory of Adaptation. Oxford: Clarendon Press, 1996.

Maguire, Robert A. Exploring Gogol. Stanford: Stanford University Press, I994.

—_. "Introduction." In Russian Literature of the I 920 : An Anthology. Edited by Robert A. Maguire, vii-xvii. Ann Arbor: Ardis, 1987.

Makoveeva, Irina. "Anna Karenina on Page and Screen." In "Anna Karenina” on Page and Screen. Studies in Slavic Cultures II. Edited by Helena Goscilo and Petre Petrov, I I I-34. Pittsburgh, PA: Department of Slavic Languages and Literatures and Center for Russian and East European Studies, University of Pittsburgh, 200I.

- Visualizing Anna Karenina. Unpublished Ph.D. dissertation submitted to the Graduate Faculty of Arts and Sciences of the University of Pittsburgh, 2007. <http://d-scholarship. pitt.edu/8448/ I /makovirina_etd2007.pdf $>$ (last accessed September 22, 20 I 5).

Malle, Louis. "With Pickpocket Bresson Has Found.” In Robert Bresson. Edited by James Quandt, 73I-4. Toronto: Toronto International Film Festival, 20 I I.

Mandelker, Amy. Framing Anna Karenina: Tolstoy, the Woman Question, and the Victorian Novel. Columbus: Ohio State University Press, I 993.

Mangolte, Babette. "The Models of Pickpocket." (2003 documentary). In Pickpocket, film, directed by Robert Bresson. USA: The Criterion Collection DVD, 2005.

Marshall, David. The Figure of Theater: Shaftesbury, Defoe, Adam Smith, and George Eliot. New York: Columbia University Press, I986. 
Matich, Olga. Erotic Utopia: The Decadent Imagination in Russia's fin-de-siècle. Madison: University of Wisconsin Press, 2005.

Mazierska, Ewa. "Escape into a Different Person, Escape into a Different Reality: Despair by Vladimir Nabokov and Rainer Werner Fassbinder." Journal of Adaptation in Film E్ Performance, 3(I) (2010): 29-42.

Meerzon, Yana. "Interrogating the Real: Chekhov's Cinema of Verbatim. 'Ward no. 6' in Karen Shakhnazarov's 2009 Film Adaptation.” In Adapting Chekhov: The Text and its Mutations. Edited by J. Douglas Clayton and Yana Meerzon, 274-94. New York: Routledge, 2012.

Melnikova, Irina. “The Gorris Defence, or Nabokov on Screen." Respectus Philologicus, 20(25) (20I I): 94-IO3.

Merchant, Moelwyn. Comedy. London: Methuen, I972.

Millar, Daniel. "Pickpocket." In The Films of Robert Bresson. Amédée Ayfre, Charles Barr, André Bazin, Raymond Durgnat, Daniel Millar, Phil Hardy, and Leo Murray, 82-9. New York: Praeger, I970.

Miller, Frank. “Anna Karenina (I948).” Turner Classic Movies. <http://www.tcm.com/ tcmdb/title/67425/Anna-Karenina/articles.html> (last accessed April 6, 20I3).

. "Doctor Zhivago." Turner Classic Movies. <http://www.tcm.com/this-month/ article/72502 | o/Doctor-Zhivago.html> (last accessed April 6, 2013).

Miller, Robin Feuer. "Dostoevsky and Rousseau: The Morality of Confession Reconsidered." In Dostoevsky: Nem Perspectives. Edited by Robert Louis Jackson, 82-98. Englewood Cliffs, NJ: Prentice-Hall, I984.

Mishra, Sudesh. "News from the Crypt: India, Modernity, and the West.” Nem Literary History, 40 (2009): 315-44.

Mishra, Vijay. "Spectres of Sentimentality: The Bollywood Film." Textual Practice, 23(3) (2009): 439-62.

Monaco, James. How to Read a Film: Movies, Media, and Beyond: The World of Movies, Media, Multimedia: Language, History, Theory. Oxford: Oxford University Press, 2000.

Monaco, Paul. The Sixties: 1960-1969. Berkeley: University of California Press, 2003.

Mulvey, Laura. "Visual Pleasure and Narrative Cinema." Screen, i6(3) (Autumn 1975): 6-I 8 .

Nabokov, Vladimir. Despair. New York: Putnam, i 966.

- Lectures on Russian Literature. Edited by Fredson Bowers. New York: Harcourt Brace Jovanovich/Bruccoli Clark, I98I.

Nachman, Gerald. "Bawdy and Soul: Mel Brooks." In Seriously Funny: The Rebel Comedians of the I950s and I960s, 463-79. New York: Pantheon Books, 2003.

Nadel, Alan. Containment Culture: American Narratives, Postmodernism, and the Atomic Age. Durham, NC: Duke University Press, 1995.

Naiman, Eric. Nabokov, Perversely. Ithaca: Cornell University Press, 20 io.

Nepomnyashchy, Catharine Theimer. “'Imperially, My Dear Watson': Sherlock Holmes and the Decline of the Soviet Empire." In Russian and Soviet Screenings of Russian Literature, 1900-200I: Screening the Word. Edited by Stephen Hutchings and Anat Vernitski, I64-77. New York: Routledge, 2005.

Neuhaus, Mel. “Anna Karenina (I935).” Turner Classic Movies. < http://www.tcm.com/thismonth/article/532|o/Anna-Karenina.html > (last accessed April 5, 20I3).

Nowell-Smith, Geoffrey. Luchino Visconti. 3rd edn. London: BFI, 2003.

Oakley, Helen. "Disturbing Design: Nabokov's Manipulation of the Detective Fiction Genre in Pale Fire and Despair." The Fournal of Popular Culture, 36(3) (January 2003): 480-96.

Odesskaya, Margarita. “'Let Them Go Crazy': Madness in the Works of Anton Chekhov.” In 
Madness and the Mad in Russian Culture. Edited by Angela Brintlinger and Ilya Vinitsky, 192-207. Toronto: University of Toronto Press, 2007.

Odesskii, Mikhail and David Fel'dman. "Legenda o velikom kombinatore, ili Pochemu v Shankhae nichego ne sluchilos'." In Dvenadtsat' stul'ev. Edited by Il'ia Il'f and Evgenii Petrov, 5-17. Moscow: Vagrius, I997.

Odynova, Alexandra. "State of the Wards." Russian Life (March/April 20I3): 28-35.

Oosterhuis, Harry. Stepchildren of Nature. Krafft-Ebing, Psychiatry, and the Making of Sexual Identity. Chicago: University of Chicago Press, 2000.

Paperno, Irina. Suicide as a Cultural Institution in Dostoevsky's Russia. Ithaca: Cornell University Press, I997.

Parish, James Robert. It's Good to be King: The Seriously Funny Life of Mel Brooks. Hoboken, NJ: John Wiley \& Sons, 2007.

Parsegova, Galina. "Karen Shakhnazarov snial fil'm o vere i shizofrenii." Vecherniaia Moskva (June 29, 2009). <http://vm.ru/news/79522.html?page=826> (last accessed September 2I, 20I5).

Parts, Lyudmila. The Chekhovian Intertext: Dialogue mith a Classic. Columbus: Ohio State University Press, 2008.

Patterson, Galina. "Nabokov's Use of Dostoevsky: Developing Goliadkin Symptoms in Hermann as a Sign of the Artist's End." Canadian Slavonic Papers, 40(I-2) (1998): 107-24.

Pensel, Hans. Seastrom and Stiller in Hollywood. Two Swedish Directors in Silent American Films 1923-1930. New York: Vantage Press, 1969.

Peucker, Brigitte. "In Despair. Performance, Citation, Identity.” In A Companion to Rainer Werner Fassbinder. Edited by Brigitte Peucker, 290-3 I2. Chichester/Malden, MA: WileyBlackwell, 2012.

- The Material Image: Art and the Real in Film. Palo Alto: Stanford University Press, 2007.

Phelan, James. "Why Narrators Can Be Focalizers and Why It Matters." In Nem Perspectives on Narrative Perspective. Edited by W. van Peer and S. Chatman, 5I-64. Albany: SUNY, 2001.

Pickpocket, film, directed by Robert Bresson. USA: The Criterion Collection DVD, 2005.

Pipolo, Tony. Robert Bresson: A Passion for Film. Oxford: Oxford University Press, 2010.

Plater, Edward. "Fassbinder's 'Despair': A Political Allegory.” Literature/Film Quarterly, 4 (I985): 223-32.

Prédal, René. “Robert Bresson: L’Aventure intérieure.” In Robert Bresson. Edited by James Quandt, 73-I I6. Toronto: Toronto International Film Festival, 20 I I.

Prokhorov, Aleksandr. Unasledovannyi diskurs: paradigmy stalinskoi kul'tury v literature $i$ kinematografe "ottepeli." St. Petersburg: Akademicheskii proekt, 2007.

Quandt, James. “Audio Commentary to Pickpocket." In Pickpocket, film, directed by Robert Bresson. USA: The Criterion Collection DVD, 2005.

—. Robert Bresson. Toronto: Toronto International Film Festival, [I998] 20 I I.

Rajagopalan, Sudha. "Kino-teatr.ru: Contemporary Cinephiles at Work." Digital Icons. Studies in Russian, Eurasian and Central-European Nem Media, 5 (201 I): 8I-6. <http://www. digitalicons.org/issueo5/sudha-rajagopalan/> (last accessed September 28, 201 5).

Ramachandran, Naman. "Saawariya." Sight and Sound, I 8( I) (January 2008): 83.

Rancour-Laferriere, Daniel. Tolstoy on the Couch: Misogyny, Masochism, and the Absent Mother. New York: New York University Press, I 998.

Reader, Keith. Robert Bresson. Manchester: Manchester University Press, 2000. 
"Relying on His Own Tastes: Director James Gray on Two Lovers." Indiemire (February I3, 2009). <http://www.indiewire.com/article/director_james_gray_on_two_lovers> (last accessed June I6, 2015).

Rentschler, Eric, ed. German Film and Literature. New York: Routledge, 20 I 2.

Ricoeur, Paul. "The Model of the Text: Meaningful Action Considered as a Text." Nem Literary History, 5(I), What Is Literature? (Autumn I973): 9 I-I I 7.

Rischin, Ruth. "Leonid Andreev I87I-I9 I9." In Encyclopedia of Literary Translation into English, vol. I. Edited by Olive Classe, 50-4. Chicago: Fitzroy Dearborn, 2000.

Rosenbaum, Jonathan. "The Last Filmmaker: A Local, Interim Report.” In Robert Bresson. Edited by James Quandt, I7-26. Toronto: Toronto International Film Festival, 20 I I.

—. "Two Nights of an Extra: Working with Bresson." < http://www.jonathanrosenbaum. net/ I97 I/o4/two-nights-of-an-extra-working-with-bresson/> (last accessed October 29, 20I3). (Originally published in Village Voice, April 25, I97I).

Roth-Ey, Kristin. Moscom Prime Time: How the Soviet Union Built the Media Empire that Lost the Cultural Cold War. Ithaca: Cornell University Press, 20 I I.

Rozanov, Vasilii. Liudy lunnogo sveta: metafizika khristianstva. Moscow: Druzhba narodov, I990.

Rozec, Thomas. Le IIIe Reich et les homosexuels. Paris: Hermann, 20 I I.

Ruppert, Peter. "Fassbinder's Despair: Hermann Hermann through the Looking Glass." Post-Script: Essays in Film and the Humanities, 2 (I984): 48-64.

Rushdie, Salman. The Satanic Verses. New York: Viking, 1989.

"Russian Literature on the Silver Screen (I)." Russian Studies in Literature. Edited by John Givens, 40(2) (2004): 3-97.

"Russian Literature on the Silver Screen (II)." Russian Studies in Literature. Edited by John Givens, 40(3) (2004): 3-94.

Rydel, Christine, ed. Dictionary of Literary Biography, vol. 272. Russian Prose Writers Between the World Wars. Detroit: The Gale Group, 2003.

Saburova, O. “Avtor i geroi v romane 'Otchaianie' V. Nabokova." In $V . V$. Nabokov: pro et contra, vol. 2. Edited by B. V. Averin and A. A. Dolinin, 74I-50. St. Petersburg: RHGA, $200 \mathrm{I}$.

Sanders, Julie. Adaptation and Appropriation. London: Routledge, 2006.

Sandomirskaia, Irina. "Cinema Thinking the Unthinkable: Cold War Film and the NonReality of Russia." In Russia and Its Other(s) on Film: Screening Intercultural Dialogue. Edited by Stephen Hutchings, I30-47. Basingstoke: Palgrave Macmillan, 2008.

Sargeant, Amy. British Cinema. A Critical History. London: British Film Institute Publishing, 2005.

Sargeant, Winthrop. “Oops!” The Nem Yorker, 35(I2) (May 9, I959): I6I-3.

Sartre, Jean-Paul. “Despair by Vladimir Nabokov.” In Critical Essays (Situations I).

Translated by Chris Turner, 58-6r. New York: Seagull Books, 20 Io.

Saunders, Thomas J. "The German-Russian Film (Mis)Alliance (DERUSSA): Commerce \& Politics in German-Soviet Cinema Ties." Film History, 9(2) (I997): I68-88.

Savchenkova, Nina. "Kruglyi stol 'Portret avtora v zerkale: Fassbinder i Nabokov.'

'Otchaianie': metafora literatury ili eidos kino?” In Antropopraksis. Ezhegodnik gumanitarnykh issledovanii, vol. 4. Edited by B. D. El'konin and S. F. Sirotkin, 76-Io8. Izhevsk: ERGO, 2012.

Schrader, Paul. "Introduction.” In Pickpocket, film, directed by Robert Bresson. USA: The Criterion Collection DVD, 2005.

. "Robert Bresson, Possibly." In Robert Bresson. Edited by James Quandt, 693-705.

Toronto: Toronto International Film Festival, 20 I I. 
Schultze, Sydney. The Structure of Anna Karenina. Ann Arbor: Ardis, 1982.

Sedgwick, Eve Kosofsky. Betmeen Men: English Literature and Male Homosocial Desire. New York: Columbia University Press, 1985.

Sepman, I. “Tynianov—-stsenarist.” In Iz istorii Lenfil'ma, vyp. 3. Edited by M. Iu. Bleiman, 5 I-77. Leningrad: Iskusstvo, I973.

Shklovskii, Viktor. Material i stil' v romane L'va Tolstogo "Voina i mir." The Hague: Mouton, [1928] 1970.

—. "Poetry and Prose in the Cinema." (1927). In The Poetics of Cinema. Russian Poetics in

Translation, vol. 9. Edited by Richard Taylor, 87-9. Oxford: RTP Publications, I982.

- Tret'ia fabrika. Moscow: Krug, 1926.

—_. "V zashchitu sotsiologicheskogo metoda." Novyi Lef, 3 (I927): 20-5.

—. Za sorok let. Moscow: Iskusstvo, 1965.

Shubin, V. F. Iurii Tynianov: Biobibliograficheskaia khronika (I894-I943). St. Petersburg:

Ardis, I994.

Sieber, Henry. The Picaresque. London: Methuen, I977.

Silver, Alain, and James Ursini. David Lean and His Films. 2nd edn. Los Angeles: SilmanJames, I99I.

Sinyard, Neil. The Films of Mel Brooks. New York: Exeter Books, 1987.

Sitney, P. Adams, "The Rhetoric of Robert Bresson: From Le Journal d'un curé de campagne to Une femme douce." In Robert Bresson. Edited by James Quandt, I I7-4I. Toronto: Toronto International Film Festival, 20 I I.

Skonechnaia, Olga. "'People of the Moonlight': Silver Age Parodies in Nabokov's 'The Eye' and 'The Gift'." Nabokov Studies, 3 (1996): 33-52.

Smalls, James. Homosexuality in Art. New York: Parkstone Press, 2003.

Smirnov, Igor, ed., with Harry Raiser, Natalja Sander, and Lora Schlothauer, Internet eds.

Hypertext. Otchaianie: sverkhtekst. Despair: Studien zu Vladimir Nabokovs Roman-Rätsel.

München: Verlag O. Sagner, 2000.

Smith, Alexandra. "Il'ia Il'f and Evgenii Petrov." In Dictionary of Literary Biography, vol. 272.

Russian Prose Writers Between the World Wars. Edited by Christine Rydel, I47-6o. Detroit:

The Gale Group, 2003.

Smock, Ann. “Mistaken Identities. Nabokov's 'Despair'.” In Double Dealing, 45-70. Lincoln,

NE: University of Nebraska Press, 1985.

Smurthwaite, Nick and Paul Gelder. Mel Brooks and the Spoof Movie. New York: Proteus

Books, I982.

Sokolov, Vadim. "Mal'chiki iz 'Barselony'." Sovetskaia kul'tura, I38 (November I 5, I962): 2.

Sontag, Susan. "Spiritual Style in the Films of Robert Bresson." In Robert Bresson. Edited by James Quandt, 57-72. Toronto: Toronto International Film Festival, 20 I I .

Spencer, Colin. Homosexuality in History. New York: Harcourt Brace, I 995.

Spurlin, William J. Lost Intimacies: Rethinking Homosexuality Under National Socialism. New

York: Peter Lang, 2009.

Stadler, Eva Maria. "Bresson, Dostoevsky, Bakhtin: Adaptation as Intertextual Dialogue." Quarterly Reviem of Film E Video, 20 (2003): I 5-22.

Stafford, Jeff. "Lolita." Turner Classic Movies. < http://www.tcm.com/this-month/article. html? isPreview $=\& i d=544428 \mid$ I2484\&name $=$ Lolita $>$ (last accessed April 4, 20I3).

Stam, Robert. "Beyond Fidelity: The Dialogics of Film Adaptation." In Film Adaptation. Edited by James Naremore, 54-76. New Brunswick, NJ: Rutgers University Press, 2000. "Introduction: The Theory and Practice of Adaptation." In Literature and Film: A Guide to the Theory and Practice of Film Adaptation. Edited by Robert Stam and Alessandra Raengo, I-52. Malden, MA: Blackwell, 2005. 
- Literature through Film: Realism, Magic, and the Art of Adaptation. Malden, MA:

Blackwell, 2005.

—. Subversive Pleasures: Bakhtin, Cultural Criticism, and Film. Baltimore: Johns Hopkins University Press, I989.

Stam, Robert and Alessandra Raengo, eds. Literature and Film: A Guide to the Theory and Practice of Film Adaptation. Malden, MA: Blackwell, 2005.

Stambler, Bernard and Robert Ward. He Who Gets Slapped [Pantaloon]. An Opera in Three Acts Based on Andreyev's Play. Libretto by Bernard Stambler. Music by Robert Ward. New York: Highgate Press, I959.

Steffen, James. "The Eagle." Turner Classic Movies. <http://www.tcm.com/this-month/ article/29927|o/The-Eagle.html> (last accessed April 5, 2013).

Steinberg, Jay. "The Brothers Karamazov (I958)." Turner Classic Movies. < http://www.tcm. com/this-month/article/ 88567 o/The-Brothers-Karamazov.html $>$ (last accessed April 4, 2013).

Steiner, Peter. Russian Formalism: A Metapoetics. Ithaca/London: Cornell University Press, I984.

Stenbock-Fermor, Elisabeth. The Architecture of Anna Karenina. Lisse: de Ridder, I975.

Stoichita, Victor I., ed. Das Double. Wiesbaden: Harrassowitz in Kommission, 2006.

Stone, Rob. "En la ciudad de Sylvia/In the City of Sylvia (José Luis Guerín, 2007) and the durée of a derive." In Spanish Cinema I973-20IO. Edited by Maria M. Delgado and Robin Fiddian, I69-82. Manchester: Manchester University Press, 20 I3.

Stott, Andrew. Comedy. New York and London: Routledge, 2005.

Studlar, Gaylyn. In the Realm of Pleasure: Von Sternberg, Dietrich, and the Masochistic Aesthetic. New York: Columbia University Press, I993.

Sukhikh, Igor. "The Death of the Hero in Chekhov's World." Translated by Carol Apollonio. In Chekhov for the 2Ist Century, 89-107. Bloomington: Slavica, 2012.

Tarkovsky, Andrei. Interviems. Edited by John Gianvito. Jackson: University of Mississippi Press, 2006.

Tarsis, Valerii. Palata nomer sem'. Frankfurt: Posev, I966.

Taylor, John Russell. Cinema Eye, Cinema Ear: Some Key Film-Makers of the Sixties. New York: Hill and Wang, I964.

__. "Robert Bresson." In Cinema Eye, Cinema Ear: Some Key Film-Makers of the Sixties, I I 5-37. New York: Hill and Wang, I964.

Testa, Carlo. Italian Cinema and Modern European Literatures, 1945-2000. London: Praeger, 2002.

Thiher, Allen. "Bresson's Un condamné à mort: The Semiotics of Grace.” In Robert Bresson. Edited by James Quandt, 287-97. Toronto: Toronto International Film Festival, $20 I I$.

Thompson, Nathaniel. "Taras Bulba (I962)." Turner Classic Movies. <http://www.tcm.com/ tcmdb/title/I 7795/Taras-Bulba/articles.html> (last accessed April 4, 2013).

Toddes, Evgenii. "Posleslovie.” In Iu. N. Tynianov, Podporuchik Kizhe, I87-200. Moscow: Kniga, I98I.

Todorov, Tzvetan. Introduction à la littérature fantastique. Paris: Éditions du Seuil, I970.

Tolstaia, S. A. Dnevniki v dvukh tomakh, vol. I, I862-190o. Moscow: Khudozhestvennaia literatura, 1978 .

Tolstoy, Leo. Anna Karenina. Norton Critical Editions Series. Edited by George Gibian.

Translated by George Gibian and Aylmer Maude. New York: W. W. Norton, I 995.

Troubetzkoy, Wladimir. La Figure du double, textes réunis et présentés par Wladimir

Troubetzkoy. Paris: Didier erudition, 1995. 
L'Ombre et la différence: le double en Europe. Paris: Presses Universitaires de France, I996.

—. "Vladimir Nabokov's 'Despair': The Reader as April's Fool." Cycnos, I2(2) (I995): $55^{-62 .}$

Tsivian, Yuri. Early Cinema in Russia and its Cultural Reception. Translated by Alan Bodger.

Chicago: University of Chicago Press, I998.

Tsiv'ian, Iurii. "Paleogrammy v fil'me 'Shinel'." In Tynianovskii sbornik: Vtorye Tynianovskie chteniia. Edited by M. O. Chudakova, I4-27. Riga: Zinatne, I986.

Tsiv'ian, Iurii and Evgenii Toddes, “Ne kinogramota, a kinokul'tura': kino i literatura v tvorchestve Iuriia Tynianova." Iskusstvo kino, 7 ( I986): 88-98.

Turgenev, Ivan. Fathers and Children. Edited and translated by Michael R. Katz. Norton Critical Editions Series. New York: W. W. Norton, 2009.

Tynianov, Yuri. "The Fundamentals of Cinema." In The Poetics of Cinema. Russian Poetics in Translation, vol. 9. Edited by Richard Taylor, 32-54. Oxford: RTP Publications, I982.

_ . "On Literary Evolution." In Readings in Russian Poetics: Formalist and Structuralist Viems. Edited by Ladislav Matejka and Krystyna Pomorska, 66-78. Ann Arbor: Michigan Slavic Publications, 1978.

Tynianov, Iurii. “Arkhaisty i Pushkin.” In Arkhaisty i novatory, 87-227. Leningrad: Priboi, I929.

—_. "Kino-slovo—muzyka." In Poetika. Istoriia literatury. Kino, 320-2. Moscow: Nauka, I977.

. "Libretto kinofil'ma 'Shinel".” In Iz istorii Lenfil'ma, vyp. 3. Edited by M. Iu. Bleiman, 78-8o. Leningrad: Iskusstvo, I973.

—. "Ne kinogramota, a kinokul'tura." Kino (September 7, I926).

—. "O feksakh." In The Film Factory: Russian and Soviet Cinema in Documents, I886-I939. Edited by Richard Taylor and Ian Christie, 257-9. London: Routledge, I 988.

_ . "O siuzhete i fabule v kino." In Poetika. Istoriia literatury. Kino, 324-5. Moscow:

Nauka, I977.

—_. "O stsenarii.” In Poetika. Istoriia literatury. Kino, 323-4. Moscow: Nauka, I977.

. "Podporuchik Kizhe.” Krasnaia nov', I (I928): 97-I I9.

__. "Podporuchik Kizhe.” In Voskovaia persona, 339-70. St. Petersburg: Limbus Press, 200 I.

-. Poetika. Istoriia literatury. Kino. Moscow: Nauka, I977.

Smert' Vazir-Mukhtara. Moscow: Vagrius, 2006.

Tyson, Peter K. "LOLA: Love \& Marriage; Fassbinder and Brecht.” Acidemic Fournal of Film

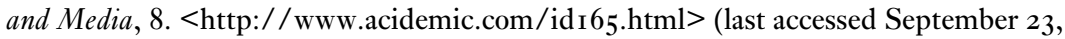
2015).

Urban, Thomas. Vladimir Nabokov: blaue Abende in Berlin. Berlin: Propyläen, I999.

Ustinov, D. “Materialy disputa 'Marksizm i formal'nyi metod' 6 marta 1927 g." Novoe literaturnoe obozrenie, 50 (200I): 247-78.

Van de Water, Manon. Moscom Theatres for Young People: A Cultural History of Ideological Coercion and Artistic Innovation, I9I7-2000. New York: Palgrave Macmillan, 2006.

Vardoulakis, Dimitris. The Doppelgänger: Literature's Philosophy. New York: Fordham University Press, 20 Io.

Venuti, Lawrence. “Adaptation, Translation, Critique." Fournal of Visual Culture, 6 (2007): $25-43$.

Vicari, Justin. "Fragments of Utopia: A Meditation on Fassbinder's Treatment of AntiSemitism and the Third Reich.” Postmodern Culture, I6(2) (2006): 2-29. 
Visconti, Luchino. "White Nights.” In Three Screenplays. Translated by Judith Green, I-9I.

New York: Orion Press, i97o.

Wagner, Geoffrey. The Novel and the Cinema. Rutherford, NJ: Farleigh Dickinson University Press, 1975 .

Wasiolek, Edward. Tolstoy's Major Fiction. Chicago: University of Chicago Press, 1978.

Watson, Wallace. "Rewriting Nabokov: The Stoppard/Fassbinder Despair." In Understanding Rainer Werner Fassbinder: Film as Private and Public Art, 189-205. Columbia: University of South Carolina Press, I996.

- Understanding Rainer Werner Fassbinder: Film as Private and Public Art. Columbia: University of South Carolina Press, I996.

Webber, Andrew. The Doppelgänger: Double Visions in German Literature. Oxford: Clarendon Press, 1996.

Weitz, Eric. The Cambridge Introduction to Comedy. Cambridge: Cambridge University Press, 2009 .

White, Frederick H. Degeneration, decadence, and disease in the Russian fin de siècle.

Neurasthenia in the Life and Work of Leonid Andreev. Manchester: Manchester University Press, 2014.

Wilkinson, Amber. "Ward 6 (2009) Film Review." Eye for Film (November 6, 2009). <http:// www.eyeforfilm.co.uk/review/ward-6-film-review-by-amber-wilkinson> (last accessed September 2I, 20I5).

Wöll, Alexander. Doppelgänger. Frankfurt am Main/New York: P. Lang, I999.

Woll, Josephine. Real Images: Soviet Cinema and the Tham. London: I. B. Tauris, 2000.

Wyllie, Barbara. Nabokov at the Movies: Film Perspectives in Fiction. London: McFarland, 2003.

Yacowar, Maurice. Method in Madness: The Comic Art of Mel Brooks. New York: St. Martin's Press, I98I.

Yakir, Dan. "The Director Explains.” The Boston Phoenix (October 24, 1978).

Youngblood, Denise J. "Iakov Protazanov, the 'Russian Griffith'.” In Movies for the Masses: Popular Cinema and Soviet Society in the I920s, 105-24. Cambridge: Cambridge University Press, I992.

- Russian War Films: On the Cinema Front, I9I4-2005. Lawrence: University of Kansas Press, 2006.

Zhdanov, V. A. and E. E. Zaidenshnur. "Istoriia sozdaniia romana 'Anna Karenina'.” In L. N. Tolstoy, Anna Karenina: Roman v vos'mi chastiakh, 803-33. Moscow: Nauka, I970.

Zhigalov, Dmitrii. "Palata bez talantov ('Palata No. 6')." Novosti Kino (July 9, 2009). <http:// www.kinonews.ru/article_4868/> (last accessed September 2 I, 20 I 5).

Zorkaya, Neya. The Illustrated History of Soviet Cinema. New York: Hippocrene Books, 1985. 


\section{Filmography}

Aelita (Russia; Iakov Protazanov, 1924)

The American Girl/Amerikanka (USSR; Leonard Esakiia, I930)

An Andalusian Dog/Un chien andalou (France; Luis Buñuel, I929)

Anna Karenina (Russia; Maurice Maître, I9I I)

Anna Karenina (Russia; Vladimir Gardin, I9I4)

Anna Karenina (USA; J. Gordon Edwards, I9I 5)

Anna Karenina (Hungary; Márton Garas, I9 I8)

Anna Karenina (Germany; Frederic Zelnik, I9I9)

Anna Karenina (USA; Clarence Brown, I935)

Anna Karenina (UK; Julien Duvivier, I948)

Anna Karenina (UK; Rudolph Cartier, I96I)

Anna Karenina (USSR; Aleksandr Zarkhi, 1967)

Anna Karenina (Italy; Sandro Bolchi, I974)

Anna Karenina (UK; Basil Coleman, I977)

Anna Karenina (USA; Simon Langton, I985)

Anna Karenina (USA; Bernard Rose, I997)

Anna Karenina (UK; Margarita Pilikhina, 200o)

Anna Karenina (Russia; Sergei Solov'ev, 2009)

Anna Karenina (UK; Joe Wright, 20I2)

My Apprenticeship/V liudakh (USSR; Mark Donskoi, I939)

L'Argent/Money (France; Robert Bresson, I983)

Arrival of a Train at La Ciotat/L'arrivée d'un train en gare de La Ciotat (France; Auguste

Lumière, Louis Lumière, I895)

Assassin of the Tsar/Tsareubiitsa (USSR; Karen Shakhnazarov, I99I)

Asia (USSR; Aleksandr Ivanovskii, I928)

Asia's Happiness/Istoriia Asi Kliachinoi (USSR; Andrei Konchalovskii, I966)

L'Atalante (France; Jean Vigo, 1934)

Atonement (USA; William Humphrey, I9I9)

Au Hasard Balthazar (France; Robert Bresson, I966)

Azazel' (Russia; Aleksandr Adabashian, 2002)

The Ballad of Bering and His Friends/ Ballada o Beringe i ego druz'iakh (USSR; Iurii Shvyrev, I970)

Barbaron (East Germany; Annelies Thomas, I989) 
The Bay of Death/Bukhta smerti (USSR; Abram Room, 1926)

La Bête Humaine (France; Jean Renoir, I938)

Big Fim McLain (USA; Edward Ludwig, 1952)

Bigamy/Bigamie (Germany; Rudolf Walther-Fein, I922)

The Birds (USA; Alfred Hitchcock, I963)

Black Eagle/Aquila Nera (Italy; Riccardo Freda, I946)

Blazing Saddles (USA; Mel Brooks, I974)

Blonde Venus (USA; Josef von Sternberg, I932)

The Brothers Karamazov/Die Brüder Karamasoff(Germany; Carl Froelich, I92 I)

The Brothers Karamazov (USA; Richard Brooks, 1958)

The Brothers Karamazov/Brat'ia Karamazovykh (USSR; Ivan Pyr'ev, I968)

The Captain's Daughter/La figlia del capitano (Italy; Mario Camerini, I947)

Chapaev (USSR; Georgii Vasil'ev, Sergei Vasil'ev, I934)

The Childhood of Maksim Gor'kii/Detstvo Gor'kogo (USSR; Mark Donskoi, I938)

Children of the Arbat/Deti Arbata (Russia; Andrei Eshpai, 2004)

La Chinoise (France; Jean-Luc Godard, I967)

Circus/Tsirk (USSR; Grigorii Aleksandrov, Isidor Simkov, I936)

The Conformist/Il conformista (Italy; Bernardo Bertolucci, I970)

The Cossacks (USA; George W. Hill, I928)

The Cranes Are Flying/Letiat zhuravli (USSR; Mikhail Kolotozov, I957)

The Cricket/Poprygun'ia (USSR; Samson Samsonov, I955)

Crime and Punishment (USA; Lawrence B. McGill, I9I7)

Crime and Punishment (USA; Josef von Sternberg, I935)

Crime and Punishment/ Crime et châtiment (France; Georges Lampin, I956)

Crime and Punishment (UK; Michael Darlow, 1979)

Crime and Punishment (USA, Poland, Russia; Menahem Golan, 2002)

Crime and Punishment, U.S.A. (USA; Denis Sanders, I959)

A Cruel Romance/Zhestokii romans (USSR; Eldar Riazanov, I984)

Dark Eyes/Oci ciornie (Italy; Nikita Mikhalkov, I987)

A Day in the Country/Une partie de campagne (France; Jean Renoir, I946)

Dead Souls/Mertvye dushi (Russia; Pavel Lungin, 2005)

Dersu Uzala (USSR, Japan; Akira Kurosawa, I972)

Despair (Germany; Rainer Werner Fassbinder, I978)

Destiny of a Man/Sud'ba cheloveka (USSR; Sergei Bondarchuk, I959)

Dr. Strangelove, or, How I Learned to Stop Worrying and Love the Bomb (USA; Stanley

Kubrick, 1964)

Doctor Zhivago (USA; David Lean, I965)

Doctor Zhivago (UK; Giacomo Campiotti, 2002)

Doctor Zhivago/Doktor Zhivago (Russia; Aleksandr Proshkin, 2006)

Down by Law (USA, West Germany; Jim Jarmusch, I986)

Down House/Daun Klaus (Russia; Roman Kachanov, 200I)

Dubromsky, der Räuber Ataman (Germany; Peotr Chardynin, I92 I)

The Eagle (USA; Clarence Brown, 1925)

Earth/Zemlia (USSR; Aleksandr Dovzhenko, I930)

The End of St Petersburg/Konets Peterburga (USSR; Vsevolod Pudovkin, I927)

Die Erkenntnis (Germany; Max Mack, I9I5)

Evenings in Moscom Suburbs/Pod moskovnye vechera (Russia; Valerii Todorovskii, I994)

Everything You Almays Wanted to Knom about Sex *But Were Afraid to Ask (USA; Woody

Allen, I972) 
Expiation/Iskuplenie (Russia; Aleksandr Proshkin, 2012)

Fail-Safe (USA; Sidney Lumet, 1964)

The Fate of Man/Sud'ba cheloveka (USSR; Sergei Bondarchuk, I959)

Father Sergius/Otets Sergii (Russia; Iakov Protazanov, I9 I7)

Father Sergius/Le père Serge (France; Lucien Ganier-Raymond, I945)

Father Sergius/Otets Sergii (USSR; Igor Talankin, I978)

A Fem Days from the Life of I. I. Oblomov/Neskol'ko dnei: iz zhizni I. I. Oblomova (USSR;

Nikita Mikhalkov, I98o)

Fiddler on the Roof (USA; Norman Jewison, I97I)

First Love/ Pervaia liubov' (Russia; Roman Balaian, I995)

The Flight/Beg (USSR; Aleksandr Alov, Vladimir Naumov, I970)

The Forty-First/Sorok pervyi (USSR; Iakov Protazanov, I927)

Four Nights of a Dreamer/Quatre nuits d'un rêveur (France; Robert Bresson, I97I)

Fox and his Friends (West Germany; Rainer Werner Fassbinder, I975)

From Russia with Love (USA; Terence Young, I963)

A Gentle Woman/ Une femme douce (France; Robert Bresson, I969)

The Girl with the Hatbox/Devushka s korobkoi (USSR; Boris Barnet, I927)

The Golden Calf/Zolotoi telenok (Russia; Uliana Shilkina, 2005)

Goldfinger (USA; Guy Hamilton, I964)

Gone with the Wind (USA; Victor Fleming, I939)

Good Luck/V dobryi chas (USSR; Georgii Natanson, Anatolii Efros, I957)

He Who Gets Slapped (USA; Victor Sjöström, I924)

Heart of a Dog/Cuore di cane (Italy; Alberto Lattuada, I976)

High Anxiety (USA; Mel Brooks, I977)

Horizon/Gorizont (USSR; Lev Kuleshov, I932)

The House of the Dead/Mertvyi dom (USSR; Vasilii Fedorov, I932)

The Hunchback of Notre Dame (USA; Wallace Worsley, I923)

I Am Twenty/Mne dvadtsat' let (USSR; Marlen Khutsiev, I964)

I Married a Communist (The Woman on Pier 13) (USA; Robert Stevenson, I950)

I Was a Communist for the FBI (USA; Gordon Douglas, I95I)

The Idiot/Hakuchi (Japan; Akira Kurosawa, I95I)

The Idiot/Idiot (USSR; Ivan Pyr'ev, I965)

The Idiot/Idiot (Russia; Vladimir Bortko, 2003)

Idiot's Dreams/Mechty idiota (Russia; Vasili Pikhul, I993)

In a Year of Thirteen Moons/In einem Fahr mit I3 Monden (West Germany; Rainer Werner Fassbinder, 1978 )

In the City of Sylvia/En la ciudad de Sylvia (Spain; José Luis Guerín, 2007)

In the First Circle/V kruge pervom (Russia; Aleksandr Seryi, 2006)

The Incredible Mel Brooks: An Irresistible Collection of Unhinged Comedy (USA; Mel Brooks, Jordan Fields, 20 I2)

Ingeborg Holm (Sweden; Victor Sjöström, I9 I3)

The Inspector General (USA; Henry Koster, I949)

The Inspector General/Revizor (Russia; Sergei Gazarov, I996)

Intruder in the Dust (USA; Clarence Brown, 1949)

Invasion of the Body Snatchers (USA; Don Siegel, I956)

Invasion USA (USA; Alfred E. Green, I952)

The Iron Curtain (USA; William Wellman, I948)

It's In the Bag! (USA; Richard Wallace, I945)

It's Very Simple/Ochen' prosto (USSR; Grigorii Lomidze, I930) 
Ivan the Terrible/Ivan Groznyi (USSR; Sergei Eisenstein, 1944)

Ivan's Childhood/Ivanovo Detstvo (USSR; Andrei Tarkovskii, I962)

Jegor Bulytschow und die Anderen (East Germany; Manfred Wekwerth, I982)

fet Pilot (USA; Josef von Sternberg, I957)

Journal d'un curé de campagne / Diary of a Country Priest (France; Robert Bresson, I95I)

Karz (India; Subhash Ghai, I980)

Keep Your Seats, Please (UK; Monty Banks, I936)

The Keys to Happiness/Kliuchi schast'ia (Russia; Iakov Protazanov, I9I3)

Kinder der Sonne (East Germany; Fritz Göhler, I967)

The King and I (USA; Walter Lang, I956)

King, Queen, Knave (USA; Jerzy Skolimowksi, I972)

Die Kleinbürger (East Germany; Fritz Göhler, I968)

The Kreutzer Sonata/Kreitserova Sonata (Russia; Petr Chardynin, I9I I)

The Kreutzer Sonata (USA; Herbert Brenon, I9I 5)

The Kreutzer Sonata/Die Kreutzersonate (Germany; Rolf Petersen, 1922)

The Kreutzer Sonata/Die Kreutzersonate (Germany; Veit Harlan, I937)

The Kreutzer Sonata/Les nuits blanches de Saint-Pétersbourg (France; Jean Dréville, I938)

The Kreutzer Sonata/La sonate à Kreutzer (France; Eric Rohmer, I956)

Lady Gray (USA; David Lean, I986)

Lady Macbeth of Mtsensk/Ledi Makbet Mtsenskogo uezda (USSR; Roman Balaian, I989)

The Lady with a Lapdog/Dama s sobachkoi (USSR; Iosif Kheifits, I96o)

Lamerica (Italy; Gianni Amelio, I994)

The Last of the Mohicans (USA; Clarence Brown, I920)

Last Tango in Paris/Ultimo tango a Parigi (France, Italy; Bernardo Bertolucci, I972)

Lawrence of Arabia (UK; David Lean, I962)

Der lebende Leichnam (Germany; Richard Oswald, I9г 8)

Lebendig tot (Germany; Alwin Neuß, I918)

Die Letzten (East Germany; Klaus Gendries, 1963)

Die Letzten (East Germany; Wolfgang Heinz, Karin Hercher, 1977)

Lieutenant Kizhe/ Poruchik Kizhe (USSR; Aleksandr Faintsimmer, I934)

Life Stinks (USA; Mel Brooks, I99I)

Little Tragedies/Malen'kie tragedii (USSR; Mikhail Shveitser, I979)

The Living Corpse/Zhivoi trup (USSR; Fedor Otsep, I929)

The Living Corpse/ Nuits de feu (France; Marcel L'Herbier, I937)

The Living Dead Man/Feu Mathias Pascal (France; Marcel L'Herbier, I926)

Lolita (USA; Stanley Kubrick, I962)

Lolita (USA; Adrian Lyne, I997)

Long Day's fourney Into Night (USA; Sidney Lumet, 1962)

Love (USA; Edmund Goulding, 1927)

Love and Death (USA; Woody Allen, 1975).

The Lower Depths/Les bas-fonds (France; Jean Renoir, I936)

The Lomer Depths/Donzoko (Japan; Akira Kurosawa, 1957)

The Lower Depths/Nachtasyl (East Germany; Peter Kupke, I97 I)

The Lower Depths/Nachtasyl (East Germany; Fritz Bornemann, I974)

The Lower Depths/Nachtasyl (East Germany; Albert Hetterle, I980)

Die Macht der Finsternis (Germany; Conrad Wiene, I924)

Madame Bovary (France; Jean Renoir, I933)

The Magnificent Seven (USA; John Sturges, I96o)

Man by the Roadside/Der Mensch am Wege (Germany; William Dieterle, I923) 
Man with a Movie Camera/Chelovek s kino-apparatom (USSR; Dziga Vertov, I929)

The Man from the Restaurant/Chelovek iz restorana (USSR; Iakov Protazanov, I928)

A Man There Was/Terje Vigen (Sweden; Victor Sjöström, I9I6)

Mary, Queen of Scots (UK; Charles Jarrott, I97I)

Maschenka (UK, Germany; John Goldschmidt, I987)

The Master and Margarita/Master i Margarita (Russia; Vladimir Bortko, 2005)

Mel and His Movies (Part I). The Incredible Mel Brooks: An Irresistible Collection of Unhinged

Comedy (USA; Mel Brooks, 20I2)

Mel Brooks: Make a Noise (USA; Robert Trachtenberg, 2013)

Michael Strogoff/ Michel Strogoff(France; Carmine Gallone, 1956)

Minin and Pozharskii/Minin i Pozharskii (USSR; Vsevolod Pudovkin, I939)

Mission to Moscom (USA; Michael Curtiz, I943)

Der Mörder Dimitri Karamasoff(Germany; Erich Engels, Fedor Otsep, I93 I)

Morocco (USA; Josef von Sternberg, I930)

Morphine/Morfii (Russia; Aleksei Balabanov, 2008)

Moscom/Moskva (Russia; Aleksandr Zeldovich, 200o).

Mother/Die Mutter (East Germany; Harry Bremer, Manfred Wekwerth, I958)

Mother/Die Mutter (East Germany; Wolfgang Heinz, I98I)

My Love/Saamariya (India; Sanjay Leela Bhansali, 2007)

My Son Fohn (USA; Leo McCarey, I952)

My Tender and Affectionate Beast/Moi laskovyi i nezhnyi zver' (USSR; Emil Loteanu, I978)

My Younger Brother/Moi mladshii brat (USSR; Aleksandr Zarkhi, I962)

Name the Man (USA; Victor Sjöström, I924)

A Nest of Gentlefolk/Dvorianskoe gnezdo (USSR; Andrei Konchalovskii, I969)

Never Let Me Go (USA; Delmer Daves, I953)

Nicholas and Alexandra (USA; Franklin J. Shaffner, I97I)

Night Sun/Il sole anche di notte (Italy; Paolo and Vittorio Taviani, I99o)

Ninotchka (USA; Ernst Lubitsch, I939)

North by Northmest (UK; Alfred Hitchcock, 1959)

The North Star (USA; Lewis Milestone, I943)

Nostalgia/Nostalghia (Italy, USSR; Andrei Tarkovskii, I983)

Notes from Underground (USA; Gary Walkow, I995)

One Flem Over the Cuckoo's Nest (USA; Milos Forman, 1975)

The Outlaw and His Wife/Berg-Ejvind och hans hustru (Sweden; Victor Sjöström, I9I7)

The Overcoat/Shinel' (USSR; Grigorii Kozintsev, Leonid Trauberg, I926)

The Overcoat/Il cappotto (Italy; Alberto Lattuada, I952)

Partner (Italy; Bernardo Bertolucci, I968)

Pavel Korchagin (USSR; Aleksandr Alov, Vladimir Naumov, I956)

Pelagiia and the White Bulldog/Pelagiia i belyi bul'dog (Russia; Iurii Moroz, 2009)

Penal Servitude/Katorga (USSR; Iulii Raizman, I928)

The Phantom Chariot (Thy Soul Shall Bear Witness)/Körkarlen (Sweden; Victor Sjöström, I92 I)

Pickpocket (France; Robert Bresson, I959)

Pickup on South Street (USA; Sam Fuller, 1953)

A Pistol Shot/Un colpo di pistol (Italy; Renato Castellani, I942)

The Poet and the Tsar/Poet i tsar (USSR; Vladimir Gardin, 1927)

The Possessed/ Besy (Russia; Iakov Protazanov, I9 I5)

Prisoner of the Mountains/Kavkazskii plennik (Russia; Sergei Bodrov, I996)

The Producers (USA; Mel Brooks, I968)

The Queen of Spades/Pikovaia dama (Russia; Iakov Protazanov, I9I6) 
The Queen of Spades/Pique Dame (Germany; Aleksandr Razumnyi, 1927)

Queen of the Gypsies/Tabor ukhodit v nebo (USSR; Emil Loteanu, I976)

Querelle (West Germany; Rainer Werner Fassbinder, I982)

Quiet Floms the Don/Tikhii Don (Russia; Sergei Gerasimov, 1957)

Quiet Flows the Don/Tikhii don (Russia; Sergei Bondarchuk, 2006)

Ragin (Russia; Kirill Serebrennikov, 2005)

Ranks and People/Chiny i lindi (USSR; Iakov Protazanov, Mikhail Doller, I929)

Raskolnikom (Germany; Robert Wiene, I923)

Rasputin and the Empress (USA; Richard Boleslawski, I932)

Red Beard/Akahige (Japan; Akira Kurosawa, 1965)

The Red Danube (USA; George Sidney, 1949)

Red Dawn (USA; John Milius, I984)

The Red Menace (USA; R. G. Springsteen, I949)

Reds (USA; Warren Beatty, I98I)

Resurrection (USA; D. W. Griffith, I909)

Resurrection (USA; Edward Jose, I9I8)

Resurrection/Résurrection (France; Marcel L'Herbier, I923; unfinished)

Resurrection/Auferstehung (Germany; Rolf Hansen, I958)

Resurrection/Voskresen'e (USSR; Mikhail Shveitser, I960-I)

Resurrection/Resurrezione (Italy; Paolo and Vittorio Taviani, 200I)

Revenge of the Black Eagle/La vendetta di Aquila Nera (Italy; Riccardo Freda, I95I)

Rocco and His Brothers/Rocco e i suoi fratelli (Italy; Luchino Visconti, I960)

Die Rollende Kugel (Germany; Rudolf Biebrach, I9I9)

The Russia That We Lost/Rossiia, kotoruiu my poteriali (Russia; Stanislav Govorukhin, I992)

Russian Ark/Russkii kovcheg (Russia; Aleksandr Sokurov, 2003)

The Russians Are Coming the Russians Are Coming (USA; Norman Jewison, I966)

St. Michael Had a Rooster/San Michele aveva un gallo (Italy; Paolo and Vittorio Taviani, 1972)

Scarabea-mieviel Erde braucht der Mensch? (West Germany; Hans-Jürgen Syberberg, I969)

The Scarlet Empress (USA; Josef von Sternberg, I934)

The Seagull (UK; Sidney Lumet, I968)

The Seagull/Il gabbiano (Italy; Marco Bellocchino, I977)

Sebastiane (UK; Derek Jarman, Paul Humfress, I976)

Shanghai Express (USA; Josef von Sternberg, I93I)

Shree 420 (India; Raj Kapoor, I955)

The Sickle or the Cross (USA; Frank R. Strayer, I949)

Silent Movie (USA; Mel Brooks, I976)

Silk Stockings (USA; Rouben Mamoulian, I957)

Simone (USA; Andrew Niccol, 2002)

Slowly Slomly/Ahista Ahista (India; Shivam Nair, 2007)

Solaris (USSR; Andrei Tarkovskii, I972)

Soldiers/Soldaty (USSR; Aleksandr Ivanov, I957)

Somom und andere (East Germany; Gerd Keil, I974)

Song of Russia (USA; Gregory Ratoff, 1944)

Stalker (USSR; Andrei Tarkovskii, I979)

The State Counsellor/Statskii sovetnik (Russia; Filipp Iankovskii, 2005)

The Station Master/ Stantsionnyi, Smotritel' (USSR; Sergei Solov'ev, I972)

Stenka Razin (Russia; Vladimir Romashkov, I908)

The Steppe/La steppa (Italy; Alberto Lattuada, I962)

Stolen Kisses/Baisers volés (France; François Truffaut, I968) 
Storm Over Asia/Potomok Chingis-Khana (USSR; Vsevolod Pudovkin, I928)

Strangers on a Train (USA; Alfred Hitchcock, I95I)

Summer Folks/Letnye liudi (Russia; Sergei Ursuliak, I995)

Superfluous People/ Überflüssige Menschen (Germany; Aleksandr Razumnyi, I926)

S.V.D. (The Club of the Great Deed) (USSR; Grigorii Kozintsev, Leonid Trauberg, I928)

Taras Bulba (USA; J. Lee Thompson, I962)

Taras Bul'ba (Russia; Vladimir Bortko, 2009)

Tempest/La tempesta (Italy; Alberto Lattuada, I958)

The Third Man (UK; Carol Reed, I949)

Three Brothers/Tre fratelli (Italy; Francesco Rosi, I98I)

Throne of Blood/Kumonosu-jô (Japan; Akira Kurosawa, I957)

Titanic (USA; James Cameron, I997)

Tovarich (USA; Anatole Litvak, I937)

The Turkish Gambit/Turetskii gambit (Russia; Dzhanik Faiziev, 2005)

Twelve Angry Men (USA; Sidney Lumet, 1957)

The Tmelve Chairs/Dvenadtsat' stul'ev (Cuba; Tomás Gutiérrez Alea, I962)

The Twelve Chairs/Dvenadtsat'stul'ev (USA; Mel Brooks, I970)

The Tmelve Chairs (USSR; Leonid Gaidai, I97I)

The Tmelve Chairs (USSR; Mark Zakharov, 1976)

I2 + I (Italy, France; Nicolas Gessner, Luciano Lucignani, I969)

The Two Buldis (USSR; Lev Kuleshov, Nina Agadzhanova, 1929)

Two Lovers (USA; James Gray, 2009)

The Ugly American (USA; George Englund, I962)

Uncle Vania/Diadia Vania (USSR; Andrei Konchalovskii, I97o)

An Unfinished Piece for a Mechanical Piano/Neokonchennaia p'esa dlia mekhanicheskogo pianino

(USSR; Nikita Mikhalkov, I977)

My Universities/Moi universitety (USSR; Mark Donskoi, 1940)

Vanya on 42nd Street (USA; Louis Malle, 1994)

Vassa Zheleznova (Finland; Mauno Hyvönen, I983)

Vertigo (USA; Alfred Hitchcock, I958)

Walking the Streets of Moscom/Ia shagaiu po Moskve (USSR; Georgii Daneliia, I964)

War and Peace/Voina i mir (Russia; Iakov Protazanov, I9I 5)

War and Peace (USA; King Vidor, I956)

War and Peace/Voina i mir (USSR; Sergei Bondarchuk, I967)

War and Peace (UK; John Davies, I972)

Ward no. 6/Krankensaal 6 (West Germany; Karl Fruchtmann, I974)

Ward no. 6/Sala nr 6 (Poland; Krzysztof Gruber, I987)

Ward no. 6/Palata no. 6 (Russia; Karen Shakhnazarov, 2009)

Watch on the Rhine (USA; Herman Shumlin, I943)

We Live Again (USA; Rouben Mamoulian, 1934)

The Weakness of Man (USA; Barry O'Neil, I9I6)

The White Devil/Der weiße Teufel (Germany; Aleksandr Volkov, I930)

The White Eagle/Belyi orel (USSR; Iakov Protazanov, I928)

White Nights/Le notti bianche (Italy; Luchino Visconti, I957)

White Nights/Belye nochi (USSR; Ivan Pyr'ev, I959)

The Wings of a Serf/Krylia kholopa (USSR; Iurii Tarich, I926)

Without Dowry/Bespridannitsa (USSR; Iakov Protazanov, I937)

A Woman's Resurrection (USA; J. Gordon Edwards, I9I 5)

Young Frankenstein (USA; Mel Brooks, I974) 


\section{Index}

Films are listed by director. Literary works are listed by author. Italicized page numbers indicate illustrations.

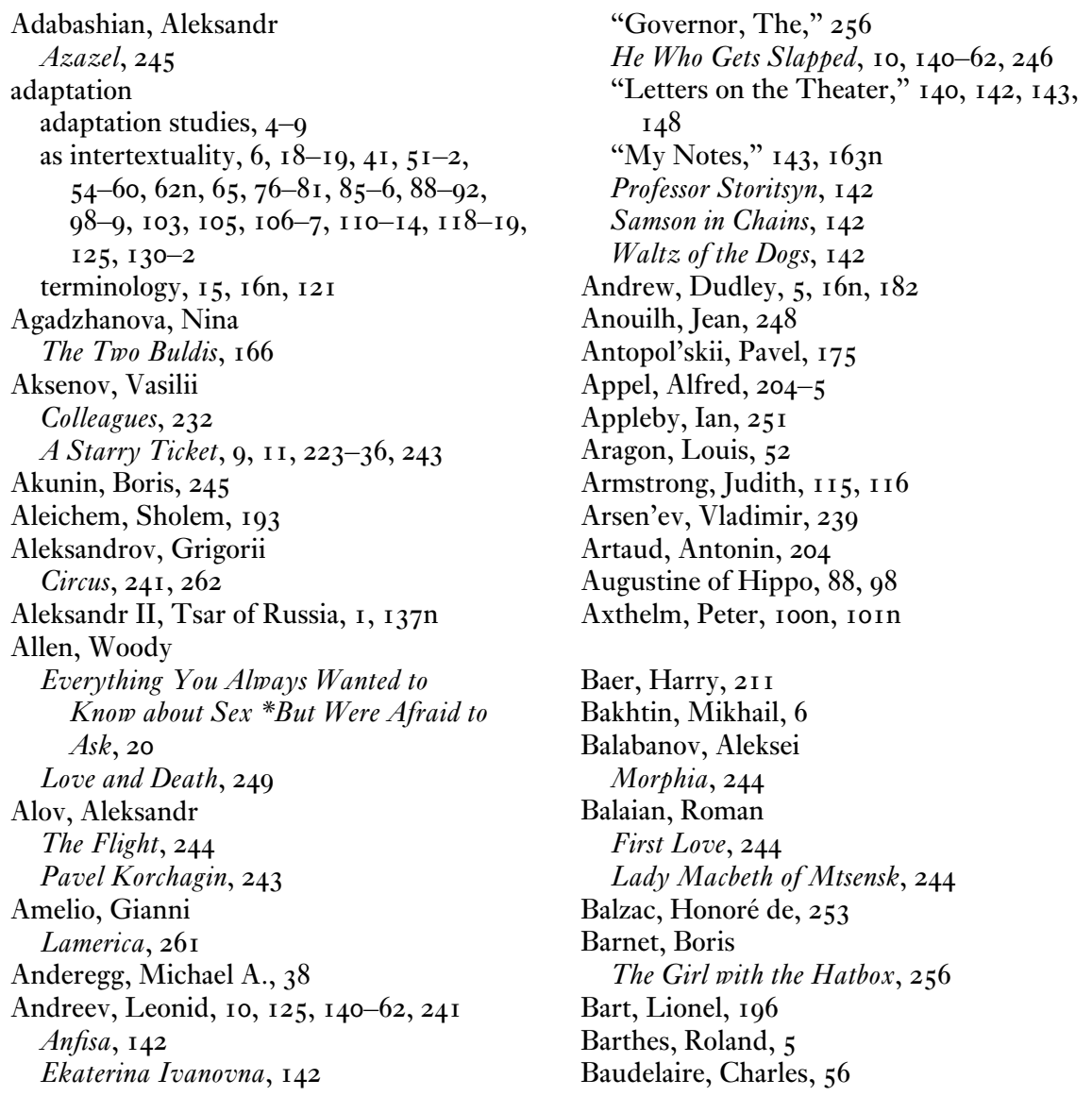


Beatty, Warren

Reds, $198 \mathrm{I}$

Beck, Sandra L., 73

Belinskii, Vissarion, I79

Bellocchino, Marco

The Seagull (Il gabbiano), 26I

Benjamin, Walter, 4I, I I3

Bernanos, George, 66, 86

Bertolucci, Bernardo, 2

The Conformist (Il conformista), 26I

Last Tango in Paris, 26I

Partner, 26I

Beumers, Birgit, 244, 263n

Bhansali, Sanjay Leela My Love (Saamariya), I3, 4I, 53-6, 58, 6o

Biebrach, Rudolf

Die Rollende Kugel, 256

Bill Haley and the Comets, 44, 45-6

Blok, Aleksandr, 2 I 2

Blondie, $5^{8}$

Bluestone, George, 5

Bodrov, Sergei Sr.

Prisoner of the Mountains, 244, 262

Bogomolov, Vladimir, 243

Bolchi, Sandro Anna Karenina, 107

Boleslawski, Richard Rasputin and the Empress, $2 \mathrm{I}$

Bollywood, 4I, 54, 60

Bolt, Robert, 38

Bondarchuk, Fedor, 245

Bondarchuk, Sergei, 2

The Fate of Man, 243

Quiet Flows the Don, 244

War and Peace, 243, 249, 262

Bordwell, David, 57

Bornemann, Fritz

The Lower Depths (Nachtasyl), 257

Borodianskii, Aleksandr, I37n

Bortko, Vladimir

The Idiot, 2, 245

The Master and Margarita, 2, 245

Taras Bulba, 2, 25I

Bosch, Hieronymus, 8, 2 I I-I 2

Bouissac, Paul, I40, I45, I 52, I62

Bourdieu, Pierre, 262-3n

Brecht, Bertold, I6I, 204, 257

Bremer, Harry Mother (Die Mutter), 257

Brenon, Herbert

The Kreutzer Sonata, 246

Bresson, Robert, 2, 4, 239, 253

L'Argent, 86, 255

Au Hasard Balthazar, 254
Diary of a Country Priest (Fournal d'un curé de campagne), 48, 69, 86, 93-4, Io In

Four Nights of a Dreamer (Quatre nuits d'un rêveur), I3, 4I, 47-53, 54, 56, 57, 58, 59, 6o, 6in, 62n, 63n, 67, 254, 259

The Meek One (Une femme douce), 48, 53, 67,254

Pickpocket, 8, Iо, II , I2, 64-82, 83n, 84n, 85-99, Ioon, 253-4, 262

Brezhnev, Leonid, I93

Brik, Osip, I66, I67, I83, I84n

Brook, Peter, I60-I

Brooks, Mel

Blazing Saddles, I 88, 20on, 20In

High Anxiety, I 88, 20 In

Life Stinks, 2oon

The Producers, I88, I9 I, 200n, 20In

Silent Movie, I 88

Tmelve Chairs, The, го, I88-99, 20on, 20In, 250, 252

Young Frankenstein, I 88, 20In

Brooks, Richard

The Brothers Karamazov, 36-7, 39, 249-50, 259

Brown, Clarence

Anna Karenina, I04, I I8, 246, 248

The Eagle, 246, 247, 258

Intruder in the Dust, 246

The Last of the Mohicans, 246

Bulgakov, Mikhail, I, 2, 239, 244, 259, 262

Buñuel, Luis

An Andalusian Dog (Un chien andalou), I I I-I 3 , I 8

Burel, Léonce-Henry, 83n, 85

Burry, Alexander, $4 \mathrm{I}$

Caine, Hall, I49

Camerini, Mario The Captain's Daughter (La figlia del capitano), 258

Cameron, James Titanic, $\mathbf{2 5 2}$

Campiotti, Giacomo Doctor Zhivago, $25^{2}$

Camus, Albert, 8, г2 , 85, 86, 87, 88-92, 99, IOIn, 254

Carlin, George A., I40, I4I, I 55-8, I6 I

Cartier, Rudolph Anna Karenina, I I 3

Cartmell, Deborah, I8

Castellani, Renato A Pistol Shot (Un colpo di pistol), 26I

Cecchi d'Amico, Suso, 43

Cederstrand, Ragnar, I49 
Chagall, Marc, I93

Chardynin, Petr

Dubromsky, der Räuber Ataman, 256

The Kreutzer Sonata, 255

Chekhov, Anton, I, 2, 4, 9, Iо, 239, 24I, 256, 259, 26I , 262, 263n

"The Cricket," 243

"The Duel," I 26

"The Lady with a Little Dog," I23, 243

Sakhalin Island, I23-4, I38n

The Seagull, 252

The Steppe, I23, 259

Three Sisters, 244

Uncle Vania, I23, I38n, 244

"Ward no. 6," I2 I-37, 244-5

Chekhov, Michael, 2

Chernyshevskii, Nikolai, I

Chukhrai, Grigorii

The Forty-First, 243

Clark, Katerina, 227

Coleman, Basil Anna Karenina, I I 8

Cooper, James Fenimore, 246

Copland, Aaron, 24

Curtiz, Michael

Mission to Moscom, 23, 25

Dal', Vladimir, I74, 24I

Dalí, Salvador, I I I

Daneliia, Georgii Walking the Streets of Moscom, 235

Darlow, Michael Crime and Punishment, 249

Daves, Delmer Never Let Me Go, 26

Davidson, Ray, 89-90

Davies, Joseph E., 25

Dawkins, Richard, I5

deconstruction, 4-5

degeneration theory, I22, I25-7, I29, I30-2, I $37,207-8$

Deleuze, Gilles, 5, I 6

Della Coletta, Cristina, 6, 9, I2, I 8-19, 23, 239

Derrida, Jacques, 5,6

Dewey, John, 25

Dickens, Charles, I04

Dieterle, William

Man by the Roadside (Der Mensch am Wege $), 256$

Dobuzhinskii, Mstislav, 6o

Donskoi, Mark

The Childhood of Maksim Gor'kii, 24I

My Apprenticeship, 24I
My Universities, 24I

Dostoevskaia, Anna, 84n

Dostoevskii, Fedor, I, 2, 83-4n, I97, 2 I 2, 2I3, 2I 5, 216, 222n, 24I, 243, 244, 245, 249, 253, 257, 259, 261, 262

The Brothers Karamazov, 4, 9, 36-37, 39, 48,90 , Ioon, I25, I26, I30-2, I 34,243 , 249-50, 256, 259

Crime and Punishment, 8, I2, 48, 49, 64-82, 85-99, Ioon, Io In, 249, 253-4, 256

The Double, 2 I 5-I6

The Gambler, 65, 69, 76, 77-8I, 82

The Idiot, 3, 48, 239, 243, 244, 254, 259

The Insulted and Injured, 239

"The Meek One," 53, 254

Notes from the House of the Dead, I23, I38n, I $85 \mathrm{n}$

Notes from Underground, 4I, 92, Ioon, IoIn

"Petersburg Chronicle," 4I

Poor Folk, 42

The Possessed, 254, 255

"White Nights," I3, 40-6o, 243, 254

A Writer's Diary, I26

Douglas, Gordon

I Was a Communist for the FBI, 27

Dovzhenko, Aleksandr

Earth, I I2

Drankov, Aleksandr

Picturesque Russia, 240

Stenka Razin, 24I

Dréville, Jean

The Kreutzer Sonata, 255

du Maurier, Daphne, 223

Duffie, Bruce, I6I

Duras, Marguerite, 205

Durgnat, Raymond, 87

Durkin, Andrew, I30

Duvivier, Julien

Anna Karenina, 35-6, I I 3, 248

Edwards, J. Gordon Anna Karenina, 246

A Woman's Resurrection, 246

Eikhenbaum, Boris, I66, I67, I68, I75, I 83 , I $84 \mathrm{n}$, I $86 \mathrm{n}$

Eisenstein, Sergei, 2, I04, 249

Ivan the Terrible, 257-8

Ellis, Havelock, 207

Elsaesser, Thomas, 202, 2 I0, 214, 2 I 8-I9

Engels, Erich Der Mörder Dimitri Karamasoff, 256

Englund, George

The Ugly American, 32, 33 
Erofeev, Venedikt, I2 I, I37n

Eshpai, Andrei

Children of the Arbat, 245

expressionism (German), 45, 257-8

Faintsimmer, Aleksandr

Lieutenant Kizhe, Io, I2, I65-83, $24 \mathrm{I}$

Faiziev, Dzhanik

The Turkish Gambit, 245

Farrell, James T., 25

Fassbinder, Rainer Werner

Despair, 8, I2-I3, 202-20, 257

Fox and His Friends, 2 10

In a Year of Thirteen Moons, 222n

Querelle, 208

Faulkner, William, 246

Fedorov, Vasilii

House of the Dead, $185 \mathrm{n}$

Fellini, Federico, 6o

female gaze, $5^{8}$

fidelity criticism, $5,7,9$, I02-3, I 72-3, I 82

Finke, Michael, I26, I30, I38n

Flaubert, Gustave, I, 253

Fleming, Ian, 33

Fleming, Victor

Gone With the Wind, 37, 248, 25I

Formalism, Russian, I65-7, I73, I8 I, I 82-3

Forman, Milos

One Flem Over the Cuckoo's Nest, I39n

Foucault, Michel, I33

Freda, Riccardo

Black Eagle (Aquila Nera), 258

Revenge of the Black Eagle (La vendetta di Aquila Nera), 258

Freud, Sigmund, I I I, I I6

Froehlich, Carl

The Brothers Karamazov (Die Brüder Karamasoff), 256

Fruchtmann, Karl, I37n

Fuller, Sam

Pickup on South Street, 27, 30-2

Furmanov, Dmitrii, 3, 24I

Gadamer, Hans Georg, 6, I8

Gaidai, Leonid, $25^{2}$

The Tmelve Chairs, I90-I, I93, 200n

Gallone, Carmine

Michel Strogoff, 258

Gandhi, Mahatma, 2

Ganier-Raymond, Lucien

Father Sergius, 255

Gardin, Vladimir

Anna Karenina, 105-6, I I9n

The Poet and the Tsar, 168
Garnett, Constance, 7

Garshin, Vsevolod, I25-6

Gazarov, Sergei

The Inspector General, 244

gender and film, I3, I I 5

Gendries, Klaus

Die Letzten, 257

Genet, Jean, 22 In

Genette, Gérard, 5, 7, I5

Gerasimov, Sergei

Quiet Floms the Don, 243

Gershwin, Ira, 24

Ghai, Subhash

Karz, 55

Gide, André, 73, 89

Givens, John, 3

Godard, Jean-Luc, $5^{\mathrm{I}}$

La Chinoise, 254

Goethe, Johann Wolfgang von, 59

Gogol, Nikolai, I, 35, 42, I69, I 70, I7 I, I 72-3, I79, I $85 \mathrm{n}, 2$ I 3,2 I 5,2 I $6,24 \mathrm{I}$, $244,245,25$ I, 259, 262

Göhler, Fritz

Kinder der Sonne, 257

Die Kleinbürger, 257

Golan, Menahem

Crime and Punishment, 249

Goldschmidt, John

Maschenka, 257

Golstein, Vladimir, I3 I

Goncharov, Ivan, 3, 244

Goncourt Brothers, I

Gorenshtein, Fridrikh, 224

Gor'kii, Maksim, 239, 24I , 244, 253, 257

Goscilo, Helena, I I 9n, I $38-9$ n

Goulding, Edmund Love, I04, I I9n, 246

Govorukhin, Stanislav

The Russia That We Lost, 237n

Graffy, Julian, 230, 232

Gray, James Two Lovers, 4I, 6o, 62n

Green, Alfred E. Invasion USA, 27, 28-9, 3I , 39

Griffin, Jonathan, 65

Griffith, D. W. Resurrection, 104, 246

Griffith, James, I02-3

Grishakova, Marina, 2 I 5

Grossman, Vasilii, 3

Gruber, Krzysztof, I37n

Guerín, José Luis, I3, 4I, 54, 56-6o In the City of Sylvia (En la ciudad de Sylvia), I3, 4I, 54, 56-6o, 6In 
Gupta, Charu, $5^{8}$

Guttiérez Alea, Tomás

The Topelve Chairs, 252

Hafiz, 2 I I

Hamilton, Guy

Goldfinger, 33

Hanlon, Lindley, 8I

Hansen, Rolf

Resurrection (Auferstehung), 257

Harlan, Veit

The Kreutzer Sonata (Die Kreutzersonate), 256

Harris, James B., 250

Hashamova, Yana, I38-9n

Healy, Dan, 207

Hegel, Georg Wilhelm Friedrich, 95

Heinz, Wolfgang

Die Letzten, 257

Mother (Die Mutter), 257

Hercher, Karin

Die Letzten, 257

Hetterle, Albert

The Lower Depths (Nachtasyl), 257

Hill, George W.

The Cossacks, 246

Hitchcock, Alfred, 6o, I88, 223

The Birds, 223

North by Northwest, 27

Strangers on a Train, 27

Vertigo, 6o

Hitler, Adolf, 25, I 88, 204

Hoffmann, E. T. A., 42, I79, I 85 n, 2 I 5

Hollywood, 9-I0, I7-39, I04, I49-50, I99, 20 In, $246,250,25$ I, 255

homosexuality, I2-I3, 200, 204, 205-I3, 2I7-I 8, 257

horizon of expectations, I8

House Un-American Affairs Committee (HUAC), 25, 26, 28

Hugo, Victor, 253

Humfress, Paul

Sebastiane, 209-Io

Humphrey, William

Atonement, 246

Hurst, Fannie, 2oon

Hutcheon, Linda, 6, I 5, I8, 60, I6 г, 226, $236 n$

Hutchings, Stephen, 3

Hyvönen, Mauno

Vassa Zheleznova, 244

Iampol'skii, Mikhail, I7 I, I 84n, I85n Iankovskii, Filipp
The State Counsellor, 245

Ibsen, Henrik, I49

Ignatov, Il'ia, I05

Il'f, Il'ia

The Golden Calf, 195, 244, 245

The Tmelve Chairs, Iо, I88-99, 200n, 24I, 245,252

Under the Big Top, 24I

Ilichev, Leonid, 233, 234

Iutkevich, Sergei, 67, 83n, I74, I77

Ivanov, Aleksandr

Soldiers, 243

Jakobson, Roman, I82, I87n, 22 In

James, Henry, 30, 37

Jansenism, 87

Jarman, Derek

Sebastiane, 209-Io

Jarmusch, Jim

Down By Lam, I69

Jarrott, Charles

Mary, Queen of Scots, 252

Jewish themes, I0, I2-I3, I89, I93, I98, 204, 205-I3, 2I 4, 2I 7-I 8, 257

Jewison, Norman

Fiddler on the Roof, 193

The Russians Are Coming The Russians Are Coming, 32-3, 20In

Jose, Edward

Resurrection, 246

Joyce, James, 2 I 6

Kachanov, Roman

Down House, 244

Kael, Pauline, 38, 20 In

Kallash, Maria, i I 9 n

Kapoor, Raj

Shree 420, 55, 56

Kassagi, Henri, 72, 83n, 96

Kassil', Lev, 233, 234

Kataev, Valentin, I90, 226

Keil, Gerd Somow und andere, 257

Kennan, George, 26

Kheifits, Iosif

The Lady with a Lapdog, 243

Khomeini, Ayatollah Ruhollah, I9

Khrushchev, Nikita, 34, 230, 235, 236, 238n, $25^{8}$

Khutsiev, Marlen I Am Twenty, 228

King Jr., Martin Luther, 2

Kinik, Anthony, 204

Kirby, Lynne, I Io-I I 
Kiukhel'beker, Vil'gel'm, I 68

Klein, Michael, 5

Kline, T. Jefferson, 72-3, 83n, 84n, 85

Knapp, Liza, I38n

Kolodin, Irving, I6o

Kolotozov, Mikhail

The Cranes Are Flying, 223-4, 243, 262

Konchalovskii, Andrei

Asia's Happiness, 243-4

A Nest of Gentlefolk, 244

Uncle Vania, 244

Korda, Alexander, 248

Koster, Henry

The Inspector General, 35, 39

Kozintsev, Grigorii

The Overcoat, I67, I68, I72-4, I85n, $24 \mathrm{I}$

S.V.D. (The Club of the Great Deed), I67, I68, I 75

Krafft-Ebing, Richard von, 207

Kranz, David, 6

Kubrick, Stanley, 20In, 250, 262

Dr. Strangelove, 32, 33, 20 In

Lolita, 20, 250, 262

Kuleshov, Lev

The Two Buldis, I66

Kupke, Peter

The Lower Depths (Nachtasyl), 257

Kurosawa, Akira, 2, 239

Dersu Uzala, 239

The Idiot, 239

The Lower Depths, 239

Red Beard (Akahige), 239

Throne of Blood, $\mathrm{I} 7 \mathrm{I}$

Kuznetsov, Anatolii, 227

Kvinikhidze, Leonid, 6In

Lacan, Jacques, I I 5

Lagerlöf, Selma, I 49

Lampin, Georges

Crime and Punishment (Crime et châtiment), 69

Lang, Walter

The King and I, $25 \mathrm{I}$

Langton, Simon Anna Karenina, I07, 248

Lanzoni, Rémi Fournier, 253

Latil le Dantec, Mireille, 67

Lattuada, Alberto

Heart of a Dog (Cuore di cane), 259

The Overcoat (Il cappotto), 259

The Steppe (La steppa), 259

The Tempest (La tempesta), 258-9, 260

Lavrenev, Boris, 24I, 243
Lean, David

Doctor Zhivago, 37-9, 20 In, 25 I-2, 262

Lady Gray, 252

Lamrence of Arabia, 25 I

Leitch, Thomas, 6, 239

Lem, Stanisław, 244

Lenin, Vladimir, I94, 200n, 254-5

Lermontov, Mikhail, I, I97, 24I

Leskov, Nikolai, 244

Levakovskaia, Evgeniia, 229

Leving, Yuri, 205

L'Herbier, Marcel

Feu Mathias Pascal, 255

The Living Corpse, 255

Resurrection, 255

Lipovetsky, Mark, I97

Litvak, Anatole

Tovarich, 2 I

Lombroso, Cesare, I26

Lönnqvist, Barbara, I I 5

López, Ignacio, I I I

Loteanu, Emil

My Tender and Affectionate Beast, 244

Queen of the Gypsies, 244

Lubitsch, Ernst

Ninotchka, 2 I-3, 24, 26, 33, 34, 35

Ludwig, Edward

Big Fim McLain, 27, 28, 29

Luhrmann, Baz, 62n

Lumet, Sidney, $25^{2}$

Fail-Safe, 32

Long Day's Fourney into the Night, 252

The Seagull, 252

Twelve Angry Men, 252

Lumière, Auguste and Louis

The Arrival of a Train, Io6, I I8, I I9n

Lungin, Pavel

Dead Souls, 245

Lyne, Adriane

Lolita, 250-I

MacCabe, Colin, i6n

McCarey, Leo

My Son Fohn, 27, 29-30, 3 I

McCarthy, John, I25

McCarthy, Joseph, 27

Macdonald, Dwight, 25

McFarlane, Brian, 5

McGill, Lawrence B. Crime and Punishment, 249

Mack, Max

Die Erkenntnis, 256

Maître, Maurice

Anna Karenina, I05 
Makoveeva, Irina, I09-Io, I I4

male gaze, I3, I I 5-I6

Malle, Louis, 2, 65, 72, 74, I37n

Mamoulian, Rouben, 257

Silk Stockings, 33-5

We Live Again, 248, 257

Mandelker, Amy, I04, I I 7

Manet, Edouard, 58

Marx, Karl, I I3

Marx Brothers, The, I69, I92

Maupassant, Guy de, 253

Maiakovskii, Vladimir, I66, I84n

Mazierska, Ewa, 202, 2 I 2

Meerzon, Yana, I24-5

Meierkhol'd, Vsevolod, 2, I42

Migala, 59

Mikhailov, Mikhail, I

Mikhalkov, Nikita, 2, 259

Dark Eyes (Oci ciornie), 259

A Fem Days from the Life of I. I. Oblomov, 244, 262

An Unfinished Piece for a Mechanical Piano, 244

Milestone, Lewis

The North Star, 23, 24

Milius, John

Red Damn, 24

Millar, Daniel, 82

Miller, Arthur, I6o

Miller, Frank, 25 I

Miller, Robin Feuer, 98

Mishra, Vijay, $5^{6}$

Morel, Benedict, I 26

Morgan, Guy, 248

Moroz, Iurii

Pelagiia and the White Bulldog, 245

Moscow Art Theater, 2, I05, I42

Mulvey, Laura, I3, I I 5, I I6

Nabokov, Vladimir, I, 8, I Iо, I I8, 220n, $22 \mathrm{In}, 222 \mathrm{n}, 25 \mathrm{I}, 257,262$

Despair, I2, 202-20, 222n

Lolita, 203, 206, 213, 250

Pale Fire, 220

Nair, Shivam

Slowly, Slowly (Ahista Ahista), 40

Narbut, Vladimir, I9o

Naumov, Vladimir

The Flight, 244

Pavel Korchagin, 243

Nazi Germany, 3, 8, 202, 204, 206, 207-I0, 2I 8,2 I $9,220,257$

Nekraskov, Viktor, 243

Nemirovich-Danchenko, Vladimir, I 42 neo-realism (Italian), 43-4, 45, 46, 47, 53, 60,250

Neuß, Alwin

Lebendig tot, 256

New Economic Policy (NEP), Io, I90, I95, 252

New Wave (French), 40-I , 48, 5I-2, 53, 55, $60,205,250,253$

Niccol, Andrew

SImone, I78

Nikolai II, Tsar of Russia, I37n

Nikolic, Djordje, I93

Nixon, Richard, 194

Nobel Prize (literature), I9, 26

Nordau, Max, I 26

Nowell-Smith, Geoffrey, 6In

Odesskaya, Margarita, I38n

Oksman, Iulian, I 68

O'Neil, Barry

The Weakness of Man, 246

Oosterhuis, Harry, 206

Ostrovskii, Aleksandr, 24I, 244

Ostrovskii, Nikolai, 243

Oswald, Richard

Der lebende Leichnam, 256

Otsep, Fedor

The Living Corpse, 256

Der Mörder Dimitri Karamasoff, 256

Panfilov, Gleb

In the First Circle, 245

Papernik, Maksim

The Tolve Chairs, I9I

Paperno, Irina, I03

Parker, Gillian, 5

Parts, Lyudmila, I37n

Pasternak, Boris, I, I9, 20, 23, 26, 3-38, 245, $25 \mathrm{I}-2,262$

Pelevin, Viktor, I

Peterson, Rolf

The Kreutzer Sonata (Die Kreutzersonate), 256

Petrarch, 59

Petrov, Evgenii

The Little Golden Calf, 195, 244, 245

The Twelve Chairs, I0, I88-99, 200n, 24I, 245,252

Under the Big Top, 24I

Peucker, Brigitte, 2 I 9

Pichul, Vasilii

Idiot's Dreams, 244

Pipolo, Tony, 69-70, 73, 83n

Platonov, Andrei, 26r 
Porter, Cole, 33

Pravov, Ivan

Quiet Flows the Don, 243

Prédal, René, 87

Preobrazhenskaia, Olga

Quiet Flows the Don, 243

Prokhorov, Aleksandr, 227

Proshkin, Aleksandr

Doctor Zhivago, 245

Expiation, 224

Protazanov, Iakov, 24I , 242, 243, 255, 256

Aelita, 24I

Father Sergius, 24I

The Forty-First, 24I, 242

The Keys to Happiness, 24I

The Man from the Restaurant, 24I

The Possessed, 255

The Queen of Spades, 24I, 255

Ranks and People, 24I

War and Peace, 24I

White Eagle, 24I, 256

Without Dowry, 24I

Pudovkin, Vsevolod, 256

Storm Over Asia, I66, I84n

Pushkin, Aleksandr, I, 42, 43, 60, I68, 2 I3, 2I 5, 239, 24I , 244, 246, 247, 255, 256, $25^{8-9}, 261,262$

Putin, Vladimir, 2, 8, I0, I29, 244

Pyr'ev, Ivan, 6in, 243

The Brothers Karamazov, 243

The Idiot, 243

White Nights, 6In, 243

Quandt, James, 68

Rajagopalan, Sudha, 235

Ramachandran, Naman, 55

Ratoff, Gregory

Song of Russia, 23, 24-5

Razumnyi, Aleksandr

The Queen of Spades (Pique Dame), 256

Superfluous People (Überflüssige

Menschen), 256

Reader, Keith, 62n, 85

Reed, Carol

The Third Man, 27, I77-8

Renoir, Jean

La Bête Humaine, 253

A Day in the Country (Une partie de campagne), 253

The Lower Depths, 253

Madame Bovary, 253

Ricoeur, Paul, 2 I 9
Robbe-Grillet, Alain, 205

Rohmer, Eric

The Kreutzer Sonata, 255

Room, Abram

The Bay of Death, 167

Roosevelt, Franklin Delano, 25

Rose, Bernard Anna Karenina, I3, I07, I Iо, 248

Rosenbaum, Jonathan, 87

Rosi, Francesco

Three Brothers (Tre fratelli), 26I

Rossini, Gioachino, 42, 43, 60

Rota, Nino, 46

Roth-Ey, Kristin, 232

Rousseau, Jean-Jacques, 98

Rozanov, Vasilii, 209, 22 In

Rozov, Viktor, 224, 225, 243

Rushdie, Salman, I9, 20

Russian Revolutions, 2, I9, 20, 2 I, 37-8, I I 4, I 57, I 89, 243, 25 I , 254-5

Riazanov, Eldar

Without a Dowry, 244

Rybakov, Anatolii, 245

Salinger, J. D., 229

Saltykov-Shchedrin, Mikhail, 24I

Samsonov, Samson The Cricket, 243

Sanders, Denis Crime and Punishment U.S.A., 249

Sanders, Julie, I 7

Sandomirskaia, Irina, 27

Sargeant, Winthrop, I6o

Sartre, Jean-Paul, 89

Savchenkova, Nina, 202

Schrader, Paul, 66

Schultze, Sydney, i Io

Scott, Sir Walter, 42, 43, 6o

Sedgwick, Eve Kosofsky, 2 I 8

Selznick, David O., 248

Sepman, I., I 75

Serebrennikov, Kirill, I37n

Shaffner, Franklin J.

Nicholas and Alexandra, 25I

Shakhnazarov, Karen

Assassin of the Tsar, $\mathrm{I} 37 \mathrm{n}$

Ward no. 6, I0-I I, I2 I-37, I38n, I39n, $244-5,262 \mathrm{n}$

Shilkina, Uliana

The Golden Calf, I9I, 245

Shitova, Vera, 232

Shklovskii, Viktor, 97, I66-7, I75, I83, I84n, I $85 \mathrm{n}, \mathrm{I} 87 \mathrm{n}$

Shmelev, Ivan, 24I 
Shmulin, Herman

Watch on the Rhine, 24

Sholokhov, Mikhail, 239, 243, 244

Shubin, V., I75

Shveitser, Mikhail

The Little Tragedies, 244

Shvyrev, Iurii

The Ballad of Bering and His Friends, $\mathrm{I} 67$

Sidney, George

The Red Danube, 27

Siegel, Don

Invasion of the Body Snatchers, 27

Sigurjonsson, Johan, I49

Sjöström, Victor

He Who Gets Slapped, Iо, I40, I4I, I $48-55$, I 56, I 57, I 59, I6I, I62, 246

Ingeborg Holm, I 49

A Man There Was (Terje Vigen), I49

Name the Man, I49

The Outlaw and His Wife, I49

The Phantom Chariot (aka Thy Soul Shall Bear Witness), I 49

Skolimowski, Jerzy

King, Queen, Knave, 257

Smith, Alexandra, I9o

Social Darwinism, 126

Sokolov, Vadim, 232

Sokurov, Aleksandr

Russian Ark, I7 I

Solov'ev, Sergei Anna Karenina, I3, I05, I07, I I8, 248

The Station Master, 244

Solzhenitsyn, Aleksandr, 245

Sontag, Susan, 85, 94

Sorokin, Vladimir, 244

Spaak, Charles, 253

Springsteen, R. G.

The Red Menace, 27-8, 29, 30, 39

Stadler, Eva Maria, 62n

Stalin, Joseph, 3, 22, 25, 28, 34, 20on, 225, 227, 24I

Stam, Robert, 5, 6, 7, I 5, I 7, I8, 62n, I9 I

Stambler, Bernard, I40, I4I, I 58-60, I6 I-2

Stanislavskii, Konstantin, 2, I05, I42, 252, $263 \mathrm{n}$

Stasov, Vladimir, i i 9 n

Stellovskii, Fedor, 83-4n

Stenbock-Fermor, Elisabeth, I $20 n$

Stendhal, 253

Stepanov, Nikolai, I75

Sternberg, Josef von

Blonde Venus, 26

Crime and Punishment, 249

Fet Pilot, 26
Morocco, 26

The Scarlet Empress, 2 I, 26

Shanghai Express, 26

Stevenson, Robert

I Married a Communist (aka The Woman on Pier I3), 27

Stone, Rob, 58, 62-3n

Stoppard, Tom, 7-8, 202, 203, 209, 22on, 248

Strayer, Frank R.

The Sickle or the Cross, 27

Strugatskii, Arkadii and Boris, 223, 244

Studlar, Gayle, I3, I 6

Sturges, John

The Magnificent Seven, $25 \mathrm{I}$

Sue, Eugène, 253

Sukhikh, Igor, I39n

Surrealism, I I I-I 2

Suvorin, Aleksei, I38n

Syberberg, Hans-Jürgen

Scarabea - wieviel Erde braucht der Mensch, $257,25^{8}$

Talankin, Igor

Father Sergius, 244

Tarantino, Quentin, I07

Tarich, Iurii

The Wings of a Serf, 167

Tarkovskii, Andrei, 69, 244, 255

Ivan's Childhood, 243

Nostalghia, 255

Solaris, 244

Stalker, 233, 244, 262

Tarsis, Valerii, I2 I, I37n

Taviani, Paolo and Vittorio, 259, 26I

Night Sun (Il sole anche di notte), 259

Resurrection, 26I

San Michele aveva un gallo, 259

Taylor, John Russell, 83n

Tchaikovsky, Petr, 24

Testa, Carlo, 258, 259, 26I

Thalberg, Irving, I 50

Theimann, Paul, 24I

Thiher, Allen, 64

Thomas, Annelies

Barbaron, 257

Thompson, J. Lee

Taras Bulba, 25I

Thompson, Nathaniel, $25 \mathrm{I}$

Tieck, Ludwig, 2 I 5

Timoshenko, Semen, I 85

Toddes, Evgenii, I86n

Todorovskii, Valerii

Evenings in Moscom Suburbs, 244 
Tolstoi, Aleksei Konstantinovich, 2 I 5

Tolstoi, Aleksei Nikolaevich, 24I

Tolstoi, Andrei, $25^{\circ}$

Tolstoi, Lev, I, 2, 9, 20on, 239, 24I, 243 , 244, 246, 248, 255, 256, 257, 259, 262

Anna Karenina, 9, I3, 20, I02-I9, I20n, 226, 24I , 243, 246, 248, 256, 262

The Cossacks, 246

Father Sergius, 24I, 244, 246

"The Forged Coupon," 86, 255

Hadji-Murat, 256

Kreutzer Sonata, 246, 255, 256

"The Living Corpse," 246, 255, 256

"Prisoner of the Caucasus," 244

Resurrection, 243, 246, 248, 255, 257

War and Peace, 4, 35, I02, 24I, 243, 249

Tolstoyanism, 2

Trauberg, Leonid

The Overcoat, I67, I68, I 72-4, 24I

S.V.D. (The Club of the Great Deed), 167 , I 68, I 75

The Travelers (Peredvizhniki), $187 \mathrm{n}$

Trollope, Anthony, I04

Trotsky, Leon, I9o, 2oon

Truffaut, François

Stolen Kisses (Baisers volés), 52

Tsivian, Yuri, I05, 106, I07, I84n

Turgenev, Ivan, I, I I 4, 244

Tvardovskii, Aleksandr, 226

Tynianov, Iurii

"The Archaists and Pushkin," I68

"Brooks's Parrot," I68

The Death of Vazir-Mukhtar, I68, I75, I $84 \mathrm{n}$

"Film-Word-Music," I $87 n$

"The Fundamentals of Cinema," I67, I8 I

Kiukhlia, $\mathbf{1} 68$

Lieutenant Kizhe, 9, I2, I65-83, I86n, 24I

"On Literary Evolution," I 83

"On siuzhet and fabula in the Cinema," I 67, I 68

"On the Screenplay," I67, I68, I73, I8 г

The Overcoat, I67, I68, I 72-4, I85n, 24I

S.V.D. (The Club of the Great Deed), I67, I 75

Ursuliak, Sergei

Summer Folks, 244

van Gogh, Vincent, 204

Vasil'ev, Georgii and Sergei

Chapaev, 24I, 262

Venuti, Lawrence, 40

Verbitskaia, Anastasiia, 24I
Vernitski, Anat, 3

Vertov, Dziga

Man with a Movie Camera, I3, I Io-I4, I I 8,248

Vidor, King

War and Peace, 249

Vigo, Jean

L'Atalante, $5^{2}$

Visconti, Luchino, 2, I3, 48, 60

Rocco and His Brothers (Rocco e i suoi fratelli), 259

White Nights (Le notti bianche), I3, I4, 40, 4I, 43-7, 49, 53, 54-5, 56, 58, 254, 259

Volkov, Aleksandr

The White Devil (Der Weiße Teufel), 256

voyeurism, I3, I I 5-I 7

Wagner, Geoffrey, 5

Walkow, Gary

Notes from Underground, $62 \mathrm{n}$

Walther-Fein, Rudolf

Bigamie, 256

Ward, Robert, I40, I4I, I 58-60, I6I-2

Wasiolek, Edward, Io8, I I 4, I I 6

Waxman, Franz, 25I

Wekwerth, Manfred

Fegor Bulytschom und die Andere, 257

Mother (Die Mutter), 257

Welles, Orson, ${ }_{7} 78$

Wellman, William

The Iron Curtain, 27

Whelehan, Imelda, 18

White, Frederick H., I25-6

Wiene, Conrad

Die Macht der Finsternis, 256

Wiene, Robert, 256

Wilde, Oscar, 248

Wilkinson, Amber, $\mathrm{I}_{3} 8 \mathrm{n}$

Wilson, Carey, I 49, I 50

Wilson, Edmund, 25

Winfrey, Oprah, 20

World War II, 3, 20, 22, 23, 243, 257, 26I

Worsley, Wallace

The Hunchback of Notre Dame, I 50

Wright, Joe

Anna Karenina, 8, I3, I7, I07, I Iо, I I2, II, I I 6, I I 7 , 248

Wyllie, Barbara, 204-5

Yeltsin, Boris, 244

Young, Terence

From Russia with Love, 27, 32, 33

Youngblood, Denise, 243 
Zaitsev, Iakov, I84n

Zakharov, Mark

The Topelve Chairs, I9I

Zamiatin, Evgenii, I66, 253

Zarkhi, Aleksandr

Anna Karenina, ${ }_{105}$

My Younger Brother, Iо, I I, 223-36, 243

Zeldovich, Aleksandr

Moscom, 244
Zelnik, Frederic

Anna Karenina, 256

Zhigalov, Dmitrii, I38n

Zilboorg, Gregory, I48

Zola, Emile, 253

Zorkaya, Neya, I02

Zoshchenko, Mikhail, I 66

Zürn, Unica, 204 